
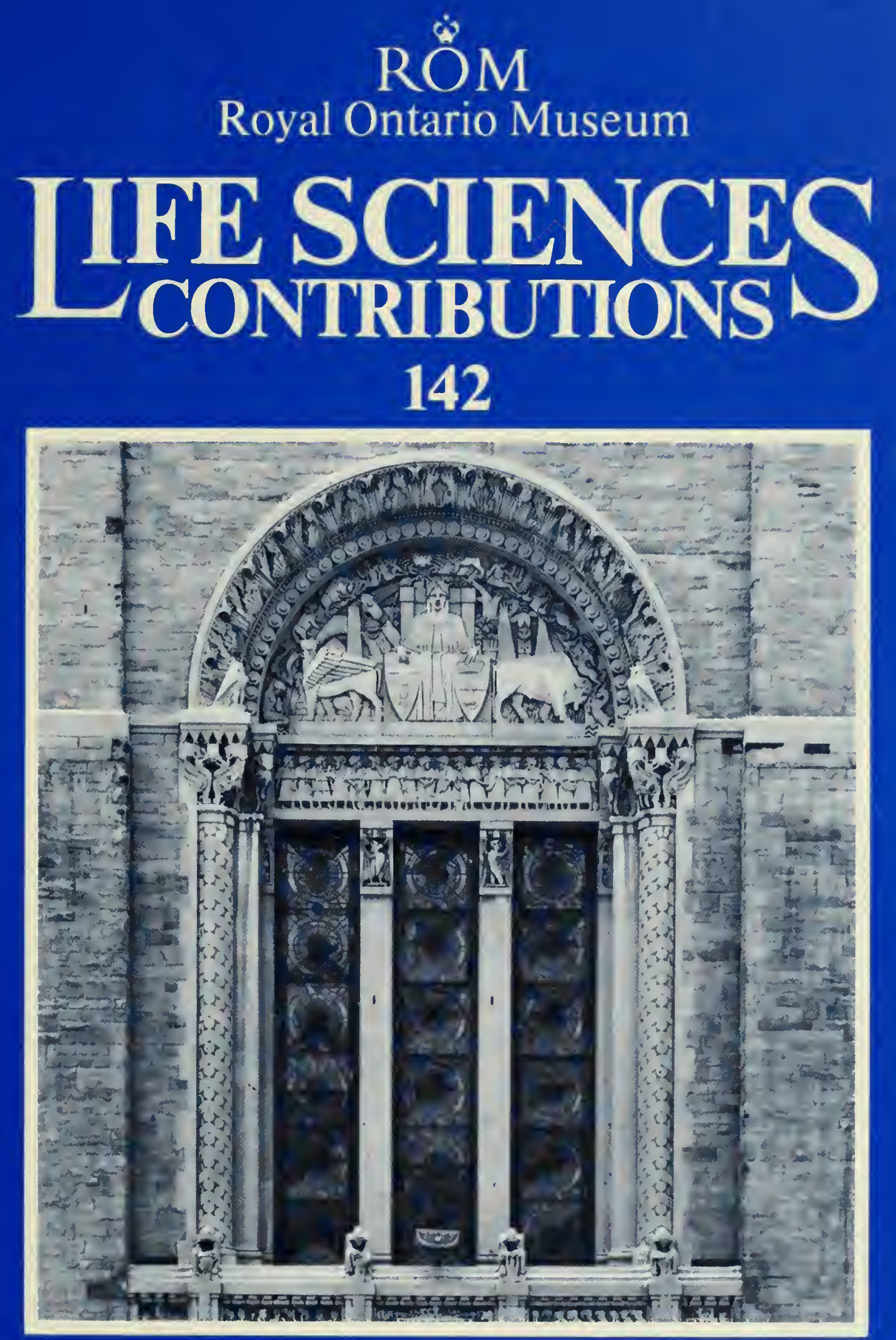

Review of the Gobioid Fishes of the Chagos Archipelago, Central Indian Ocean

\author{
Richard Winterbottom \\ and \\ Alan R. Emery
}




\section{ROYAL ONTARIO MUSEUM LIFE SCIENCES PUBLICATIONS INSTRUCTIONS TO AUTHORS}

A uthors should prepare their manuscripts carefully according to the following instructions; failure to do so will result in the manuscript's being returned to the author for revision. All manuscripts are considered on the understanding that they are not currently offered for publication elsewhere.

1. General Papers for publication are accepted from ROM staff members and research associates, and from researchers reporting on work done with ROM collections. Monographs on the flora and/or fauna of Ontario may be considered for publication by authors not affiliated with the ROM. Financial contributions towards publication will be welcome. Authors are expected to write clearly and concisely and to omit any material not essential for an understanding of the main theme of the paper.

2. Format Manuscripts (including captions, synonymies, literature cited, and tables) should be typed with double space on 11 " $\times 8 \frac{1}{2}$ " paper with a $1 \frac{1 / 2}{2}$ " margin on all sides. Three xerox copies should be submitted to the Senior Editor of the Editorial Board; the original should be retained by the author(s). The submission should include a separate sheet giving the author(s) names and affiliations, the title of the publication, the series for which it is submitted, the number of typed pages, the number of tables, and the number of plates or figures. Manuscripts should normally be organized in the following order: Contents, Abstract, Introduction, Materials and Methods, Results, Discussion, Conclusions, Summary (if manuscript is long), Acknowledgements, Appendices, and Literature Cited. Authors are encouraged to include foreign-language translations of the Summary, if appropriate. Main headings should be centred; subheadings should be left-justified to the text margin. The first line of the first paragraph in each new section should not be indented. Literature citations in the text should be in the form "Jones (1972)" or "(Jones, 1972)" or "(Smith, 1960:71-79, fig. 17)".

3. Standard Sources The primary authority on questions of format and style is Guide to Authors, available from ROM Publication Services. For matters not covered in the Guide, consult CBE Style Manual (Fifth Edition). Other standard sources are as follows: for
English spelling, The Concise Oxford Dictionary; for Canadian place names and coordinates, Canada Gazetteer Atlas; for the spelling of geographic names, The Times Atlas.

4. Abstract All papers must be preceded by a short, factual abstract, about one per cent of the text in length. The abstract may be followed by four to six key words in parentheses.

5. Taxonomy The name of a taxon should be given in full in headings, at the beginnings of paragraphs, and at its first occurrence in the text. Give the authority and date, if appropriate, with the first mention of each taxon, but not thereafter. Taxonomic papers, particularly synonymies, should follow the layout in Life Sciences Contributions beginning with No. 136. International Codes of Biological Nomenclature must be followed.

6. Literature Cited A complete list of references, in alphabetical order of authors, must be given at the end of the paper. When two or more works of one author are cited, they should be listed chronologically. The names of journals should not be abbreviated. For correct bibliographic form, see Life Sciences Contributions beginning with No. 136.

7. Tables All tables should be typed on separate sheets and numbered consecutively in arabic numerals in the order of their first mention in the text. Mark the location of each table in the margin of the text.

8. Plates, Figures, and Text-figures Illustrations may be designated according to the conventions of the author's discipline; in some disciplines grouped photographs of scientific subject matter are commonly termed Plates, while line drawings and locality and other illustrations that occupy a full page or less are Text-figures. Usage must be consistent throughout the paper. A full-page illustration for a Contribution, with its caption, should be sized to fit an area of $17.3 \times$ $22.75 \mathrm{~cm}$; for Occasional Papers, the area is $14.1 \times$ $21.2 \mathrm{~cm}$. If captions are lengthy, they may be placed on the facing page. A scale or magnification factor should be included. Authors are reminded that when illustrations are reduced magnification factors will change, and that they are responsible for the conversion. For details, see Guide to Authors. 
Review of the Gobioid Fishes of the

Chagos Archipelago, Central Indian Ocean 
Digitized by the Internet Archive in 2011 with funding from University of Toronto 


\title{
Review of the Gobioid Fishes of the Chagos Archipelago, Central Indian Ocean
}

\author{
Richard Winterbottom
}

and

Alan R. Emery

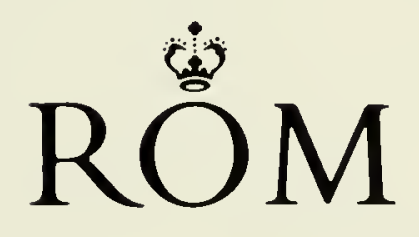

ROYAL ONTARIO MUSEUM 


\section{ROYAL ONTARIO MUSEUM}

\section{PUBLICATIONS IN LIFE SCIENCES}

The Royal Ontario Museum publishes three series in the Life Sciences: Contributions: a numbered series of original scientific publications.

Occasional Papers: a numbered series of original scientific publications, primarily short and of taxomonic significance.

Miscellaneous Publications: an unnumbered series on a variety of subjects.

All manuscripts considered for publication are subject to the scrutiny and editorial policies of the Life Sciences Editorial Board, and to independent refereeing by two or more persons, other than Museum staff, who are authorities in the particular field involved.

\section{LIFE SCIENCES EDITORIAL BOARD}

Senior editor: J. C. Barlow

Editor: E. J. Crossman

Editor: J. L. Eger

External editor: C. S. Churcher

Manuscript editor: D. R. Calder

Richard Winterbottom is Curator, Department of Ichthyology and Herpetology, Royal Ontario Museum, Toronto.

Alan R. Emery is Director, National Museum of Natural Sciences, Ottawa.

\section{Canadian Cataloguing in Publication Data}

Winterbottom, Richard, 1944-

Review of the gobioid fishes of the Chagos Archipelago,

Central Indian Ocean

(Life sciences contributions, ISSN 0384-8159; no. 142)

Bibliography: $p$.

ISBN 0-88854-320-4

1. Gobiidae. 2. Fishes - Chagos Islands.

I. Emery, Alan, 1939- II. Royal Ontario Museum.

II. Title. IV. Series.

QL638.G7W56 $1985 \quad 597^{\prime} .58 \quad$ C85-099857-3

Publication date: 15 March 1986

ISBN 0-88854-320-4

ISSN 0384-8159

(C) Royal Ontario Museum, 1986

100 Queen's Park, Toronto, Canada, M5S 2S6

PRINTED AND BOUND IN CANADA AT THE ALGER PRESS 


\section{Contents}

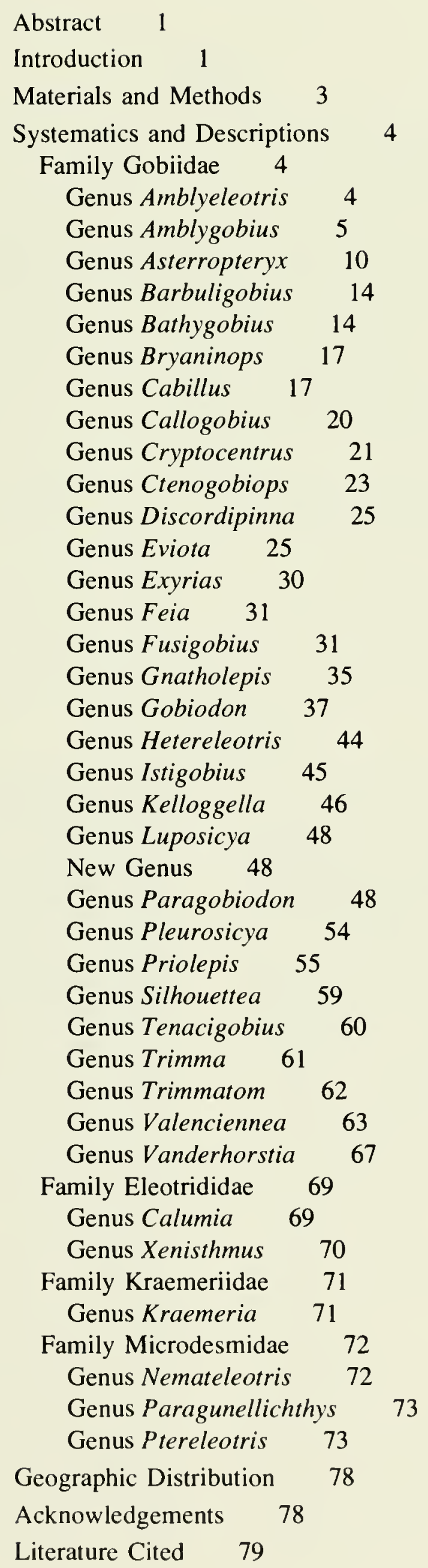





\title{
Review of the Gobioid Fishes of the Chagos Archipelago, Central Indian Ocean
}

\begin{abstract}
A two-and-a-half month fish-collecting expedition to the Chagos Archipelago yielded specimens of 98 species (in 36 genera) of gobioid fishes. Ninety species belong to the Gobiidae, three to the Eleotrididae, one to the Kraemeriidae, and four to the Microdesmidae. Additional species, not collected by us, are Paragunnellichthys fehlmani (Microdesmidae), described from five specimens collected at Diego Garcia, and Paragobiodon echinocephalus, represented by material in the British Museum (Natural History) collected by the Gardiner Expedition. Thus, the total known gobioid fauna of the archipelago is 100 species in 37 genera. Detailed descriptions and figures are given for 52 species, and short descriptions for 4 species. Forty-four species either are under active review by our colleagues or are represented in quite adequate existing descriptions and figures, and we simply list our material (with a figure of a freshly dead specimen where available).

For those species with relatively well known geographic ranges $(n=43), 51 \%$ had an Indo-Pacific distribution and 30\% were restricted to the Indo-west Pacific (west of the Andesite line).
\end{abstract}

\section{Introduction}

The Chagos Archipelago is a fragmented southerly extension of the Maldive/Laccadive ridge, and consists of a complex system of low atolls and submerged banks bounded by $4^{\circ} 40^{\prime}-7^{\circ} 30^{\prime} \mathrm{S}$ and $71^{\circ}-72^{\circ} 45^{\prime} \mathrm{E}$ (Fig. 1). To the east lies the 5-km-deep Chagos Trench; to the west is the mid-Indian Ocean ridge, the sea-floor spreading centre separating the African and Indo-Australian plates. In some cases, very deep water separates the atolls and banks; in other cases, they are separated by water less than $500 \mathrm{~m}$ deep. All the reef structures have steep outer drop-offs. There are five atolls-Diego Garcia, Egmont, the Great Chagos Bank (a few islands, such as Eagle and Three Brothers, remaining on the western side and one on the northern side), Peros Banhos, and Salomon. The approximate distances to the nearest land are: $500 \mathrm{~km}$ to the north (Addu Atoll, Maldives); $1800 \mathrm{~km}$ to the west (Seychelles); and $3500 \mathrm{~km}$ to the east (Sumatra). The islands are bathed by the northern limits of the South Equatorial Current (westward flowing) during July, and by the Easterly Counter Current during January. Thus, recruitment of pelagic larvae could come from the western Indian Ocean or from the western Pacific, although the large distances involved could be expected to filter out a fair proportion of those reef fishes with short pelagic stages.
In 1967, Adair Fehlmann spent six weeks on Diego Garcia, and made 27 collections of fishes and other organisms to a maximum depth of about $3 \mathrm{~m}$. These collections have been sorted and shelved at the Smithsonian Institution, and it is at present impossible to determine what species were taken without searching the major portion of the fish collection. Sorne records of Chagos fishes are available as a result of specialized studies (e.g., Lachner and Karnella, 1980; Dawson, 1969). A fisheries feasibility study was conducted in the Indian Ocean (including Chagos) by the Japanese from 1971 to 1975. The published results (Kyushin et al., 1977) list 78 species from the Chagos Archipelago (mainly lethrinids, lutjanids, and serranids), and none of them are gobioids. Regan (1908), reporting on the fishes of the Gardiner Expedition, recorded 32 shore fishes from Chagos, five of them gobiids. Of the five, three were described as new species, and two of these are currently recognized as valid-Gobiomorphus cinctus (now placed in Priolepis) and Gobiopterus modestus (now placed in Gobiodon). Cryptocentrus octofasciatus, described on the basis of a specimen from Diego Garcia, is here regarded as a junior synonym of $C$. cryptocentrus. Of the two other species recorded by Regan, the specimens of Eleotris lantzii were examined and proved to be Valenciennea 


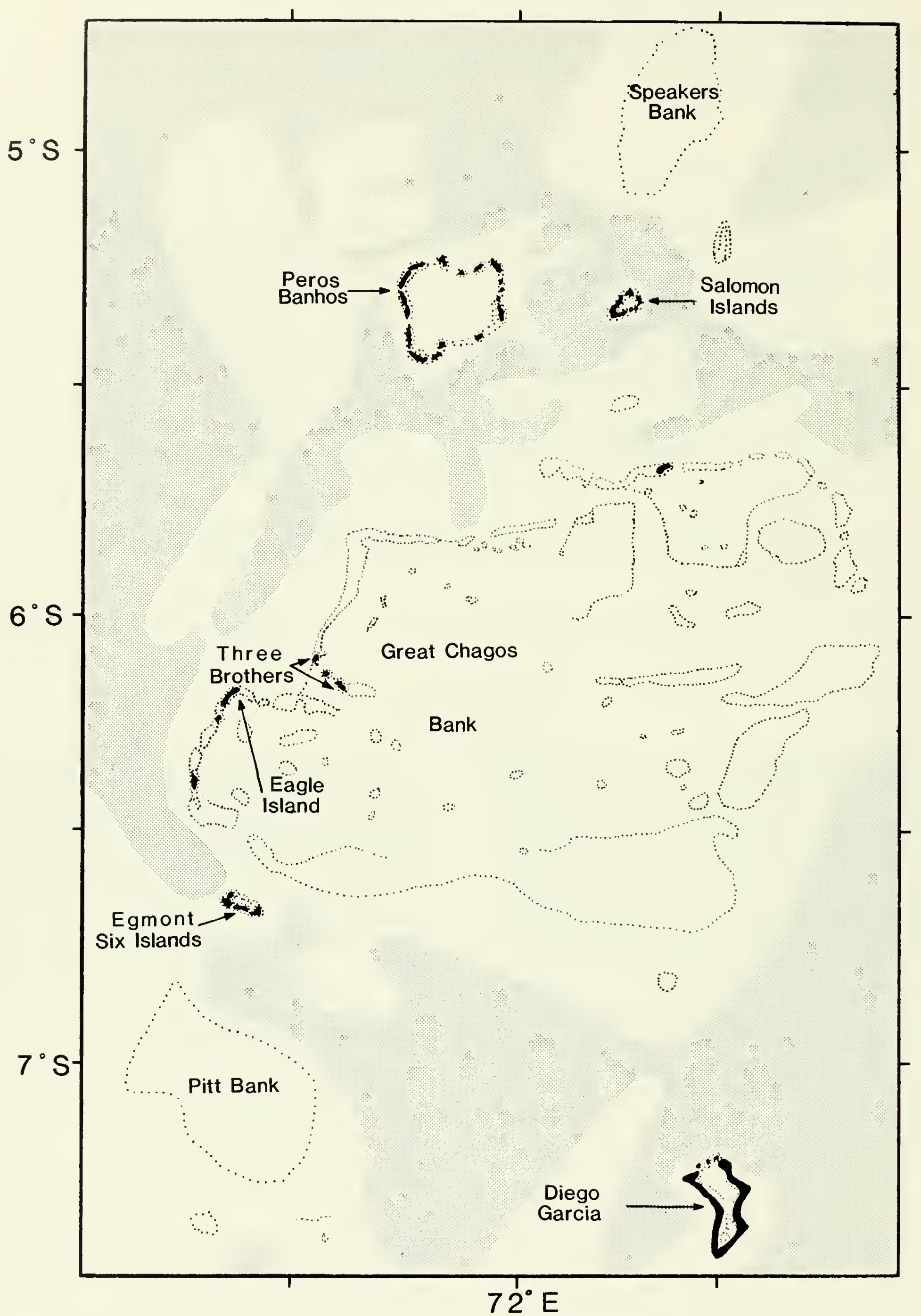

Fig. 1. Map of the Chagos Archipelago. Land black, reef margins with dotted outlines, areas below $500 \mathrm{~m}$ stippled. 
sexguttata; those recorded as Gobius nebulopunctatus were at Cambridge but became dehydrated and were destroyed (Wheeler, pers. comm.). Other specimens from the Seychelles that were identified as this species by Regan proved to be a species of Bathygobius, which may or may not have been the same as that collected by the Gardiner Expedition at Chagos.

This paper treats the Chagos gobioids in some detail since descriptions of these fishes currently available are seldom diagnostic. Exceptions have been made where we felt that adequate descriptions and figures were readily obtainable, or where other workers are actively revising genera. In these cases, we either give a brief description, or simply list our material. Wherever possible, we have included photographs of freshly dead specimens, notes on preferred habitat and on gut contents, and some anatomi- cal notes from cleared and stained material.

The family-group taxonomy of gobioid fishes is very unsatisfactory at present, as has been pointed out by several authors. In this paper, we follow Douglass Hoese's (pers. comm.) system while acknowledging that the Eleotrididae is almost definitely not monophyletic. In addition, it is highly probable that the sister groups of the Microdesmidae and Kraemeriidae lie among the fishes grouped into the Gobiidae, indicating that the latter taxon is polyphyletic. However, we feel it more practical, given the purely descriptive nature of this paper, to retain the older, probably incorrect classification rather than restrict the Gobioidei to two monophyletic families (Rhyacichthyidae and Gobiidae), as, for example, Springer (1983) has done. We do this in spite of the fact that we agree with the approach and the logic used by Springer.

\section{Materials and Methods}

During 1978/1979, the Joint Services Trust of the British Armed Forces supported a nine-month scientific and training expedition to the Chagos Archipelago. We joined the expedition for two and a half months to survey the ichthyofauna, from intertidal to a maximum of $48 \mathrm{~m}$. Seventy-one rotenone stations were made, at Eagle Island and Three Brothers (both on the western margin of the Great Chagos Bank), and at Peros Banhos and Salomon atolls. One small collection was made at Diego Garcia, and this was supplemented by seven rotenone collections made there by J. Ryther in May 1980.

Counts and measurements are as in Winterbottom (1984) and usually consist of the range followed by the mean in parentheses. Differences in scale counts from other published accounts may well reflect different methods of counting scales. Head papillae patterns reflect what was seen in the material. They may be incomplete because of specimen condition and the difficulties sometimes encountered in distinguishing papillae from the surrounding areas (see Hoese, 1983, for a review of the variables affecting the condition of the papillae). Although gill-raker counts in the literature often include a single raker at the angle between the first epi- and ceratobranchials (giving a formula of $x+1+y$ ), this raker can be seen in cleared and stained material to represent the dorsalmost of the ceratobranchial gill rakers and is counted as such here (giving a formula of $x+y$ ). The dorsal pterygiophore formula is presented as suggested by Birdsong (1975).

The conventional view that perciforms possess a total of five hypurals in the caudal skeleton is followed here. However, the presence of six hypurals in generalized lampridiforms (see, for example, Rosen, 1973:485, fig. 111) may indicate that hypurals 4 and 5 have fused together in perciforms. If so, then the small dorsalmost hypural corresponds to hypural 6 and should be so named. Otherwise, one must assume that the sixth hypural has been lost and that its anatomical position has been taken over by hypural 5 . 


\section{Systematics and Descriptions}

\section{Family Gobiidae}

\section{Genus Amblyeleotris}

\section{Amblyeleotris steinitzi (Klausewitz)}

Figs. 2, 3

Cryptocentrus steinitzi Klausewitz, 1974:70 (Gulf of Aquaba, also Palau and Eniwetak).

\section{MATERIAL}

Three lots, 3 specimens, $15.3-34.5 \mathrm{~mm} \mathrm{SL}$. Depth range 7-13 $\mathrm{m}$, lagoons only, at Peros Banhos and Three Brothers.

\section{DESCRIPTION}

The genus is currently being revised by Hoese and Randall, to whom we have sent our material. The following brief description is given pending their review. D VI + I 12-13; A I 12; P 19; V I 5, no fraenum, short basal membrane. Lateral scales 69 . Gill opening to below posterior margin of eye. Teeth in both jaws in several series, outer row enlarged. Tongue truncate with a slight

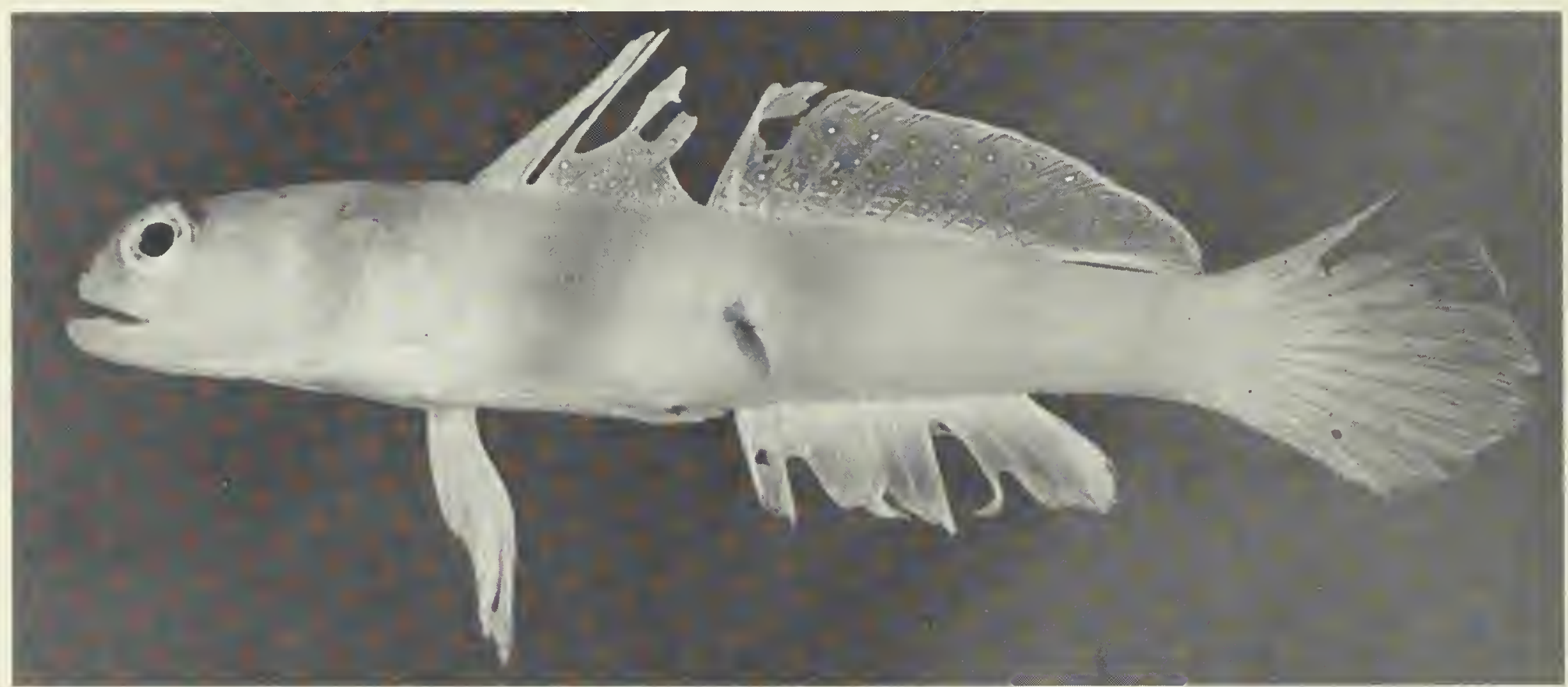

Fig. 2. Left lateral view of Amblyeleotris steinitzi, $34.5 \mathrm{~mm}$ SL. Specimen speared (mark between origins of anal and second dorsal fins).
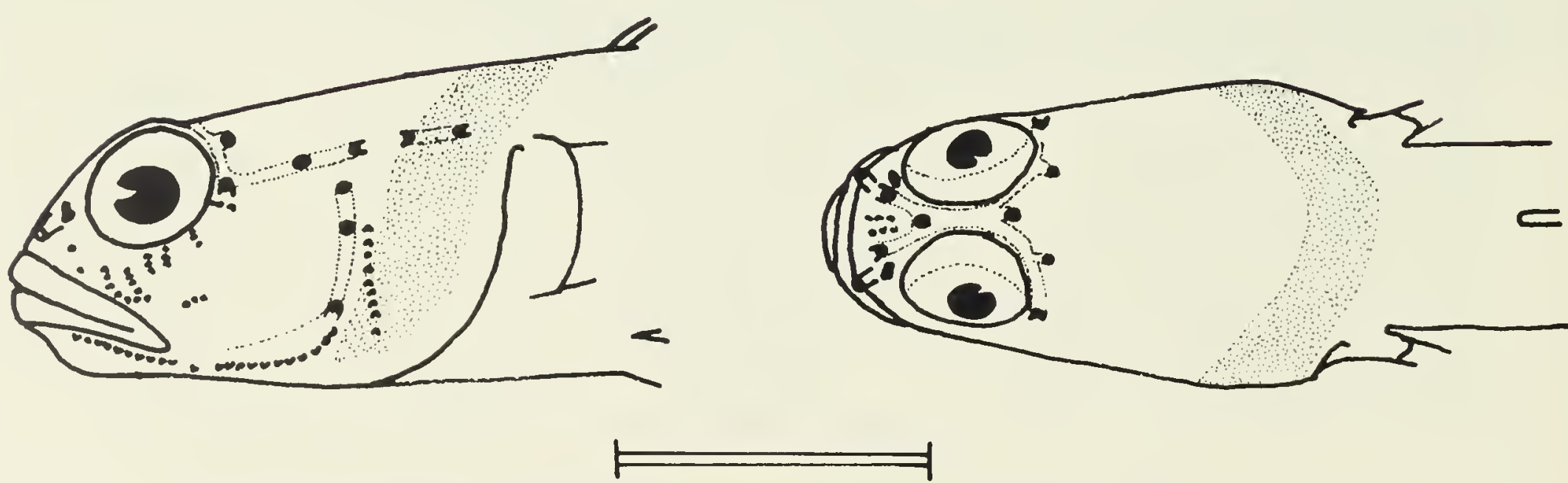

Fig. 3. Left lateral (left) and dorsal (right) views of the head of Amblyeleotris steinitzi, $34.5 \mathrm{~mm}$ SL, to show head pores, papillae, and position of first body bar. Scale equals $1 \mathrm{~cm}$. 
notch. First gill slit open; gill rakers on first arch $0-2+9$. Head pores and papillae as in Fig. 3.

Colour pattern (freshly dead, $34.5 \mathrm{~mm}$ SL specimen): background white; five brown, eye-diameter-width bars across body, the first two sloping anteroventrally-first bar over posterior portion of opercle, second centred on fifth dorsal spine, third centred on fourth ray, fourth on last ray, and fifth on peduncle-bars becoming fainter posteriorly. First dorsal fin and distal two-thirds of second dorsal fin with small yellow spots and scattered yellow streaks on a background of iridocytes, proximal one-third of second dorsal fin with two lines made up of short yellow dashes; caudal, anal, and pelvic fins white; pectoral fin hyaline. A few blue spots on the cheek and opercle. Preserved: off-white with brown bars still evident, but other details of colour pattern faded.

\section{Genus Amblygobius}

Amblygobius hectori (Smith)

Figs. 4, 5

Seychellea hectori Smith, 1956a:726 (Mahé, Seychelles); Goren, 1979:51 (Red Sea).

Amhlygobius hectori-Masuda et al., 1980:274 (Japan).

\section{MATERIAL}

Seven lots, 15 specimens, 19.7-47.0 mm SL. Depth range $3-36 \mathrm{~m}$, primarily in lagoons (a single specimen from the drop-off), at Peros Banhos, Salomon, and Three Brothers.

\section{DESCRIPTION}

Based on 10 specimens from lots WE 79-43, 79-69, and 79-82 (19.7-47.0 mm SL), plus 2 cleared and stained

Fig. 4. Left lateral view of Amblygobius hectori, $37.3 \mathrm{~mm} \mathrm{SL.}$
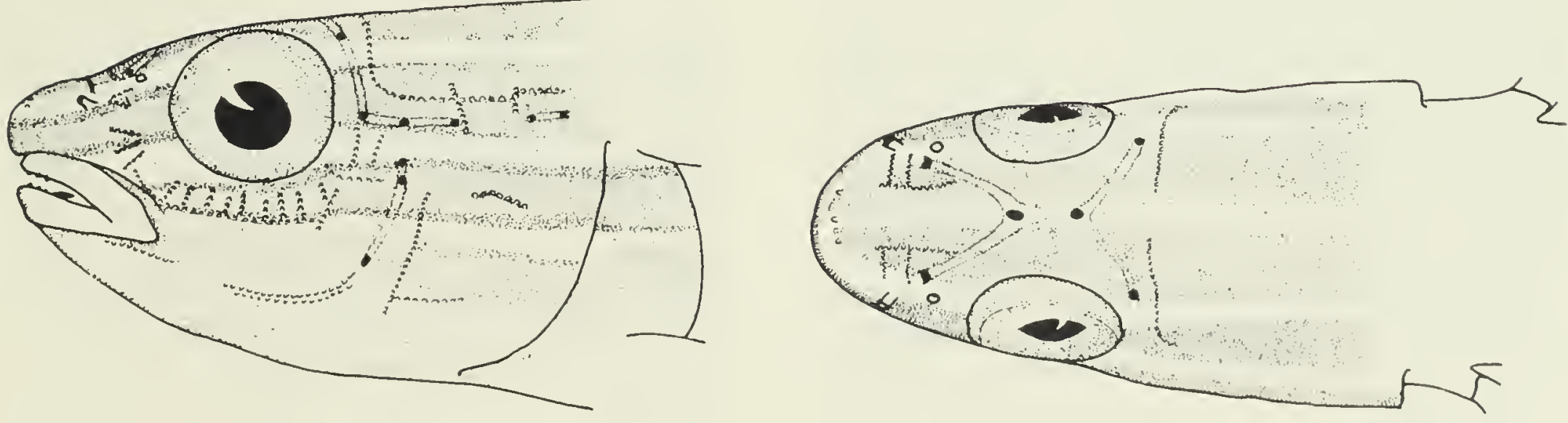

Fig. 5. Left lateral (left) and dorsal (right) views of the head of Amblygobius hectori, 25.9 $\mathrm{mm} \mathrm{SL}$, to show head pores, papillae, and colour pattern. Scale equals $5 \mathrm{~mm}$ 
specimens from WE 79-48 (24.3-24.8 mm SL). D VI + I 15 (once I 14, once I 16), first and second spines longest, reaching to bases of the first to sixth rays of second dorsal fin; A I 15 (once I 14, once I 16); P 15-17 (16.4), reaching to a vertical with anal-fin origin; V I 5 , complete basal membrane, no evidence of a fraenum, reaching posteriorly from between anal-fin origin to a point just anterior to anus. Lateral scales 48-54 (52.0); transverse 17-19 (17.7); predorsal 16-21 (18.3). Prepelvic and pectoral base scaled; seven of ten specimens with a single row of three to five scales along upper edge of opercle (naked in the other three specimens). Scales on nape, pectoral base, prepelvic area, opercle, and just behind pectoral-fin base cycloid; scales on rest of body weakly ctenoid. Gill opening partly restricted, reaching a point ventrally between pectoral base and vertical limb of preopercle. Mouth terminal, inclined slightly dorsally; upper jaw with four to six spaced, curved, enlarged conical teeth in an outer row and one to two irregular inner rows of small conical teeth. Lower jaw as for upper jaw, but lateral to outermost enlarged teeth are one or two very much enlarged, curved, laterally flaring canines. Anterior nostril tubular, posterior porelike. Tongue truncate. First gill slit open; gill rakers fleshy, $0+7$; first epibranchial with a fleshy lobe bearing two to three fleshy processes; pseudobranch with five lobes. Five branchiostegal rays. Dorsal pterygiophore formula $3(2,2,1,1,0)$; vertebrae 10 $+15+$ ural centrum $=26$. Seven dorsal and 6 ventral branched caudal-fin rays, with 11 dorsal and 10 to 11 ventral unbranched caudal-fin rays. As percentage standard length: head length 26-30 (28.7); origin of first dorsal fin 36-44 (39.0); origin of second dorsal fin 55-60 (57.6); origin of anal fin 59-63 (60.8); caudal-peduncle length 15-19 (17.0). As percentage head length: eye diameter 22-29 (25.4); snout length 24-32 (28.8); upper-jaw length 30-35 (32.2). Caudal-peduncle depth as percentage caudal-peduncle length 63-75 (70.2). Head pores and papillae as in Fig. 5. Caudal skeleton with haemal spine of preural centrum $2(=$ pu 2$)$ broad and fused to centrum; parahypural small, well removed from ural centrum proximally; hypurals 1 and 2 fused together and articulating with ural centrum; hypurals 3 and 4 fused together and to urostyle; small, autogenous fifth hypural; single, broad epural with what appears to be a fusion line along the middle of its length; neural spine of pu 2 triangular, with a large foramen in its base.

Intestine long and coiled, peritoneum black. Gut of $42.2 \mathrm{~mm} \mathrm{SL}$ female contained fine, unbranched filamentous algae with some harpacticoids, ostracods, amphipods, and nematodes.

Colour pattern (freshly dead): background brown; three thin, longitudinal stripes along head and body. Dorsalmost stripe green-yellow, from tip of snout, across top of eye adjacent to bases of dorsal fins, to top of caudal peduncle.
Middle stripe from tip of upper jaw to caudal peduncle, passing just dorsal to pectoral base. Third stripe from corner of mouth, across pectoral base to caudal peduncle. Second and third stripes connected at base of caudal fin by a black-edged, red stripe in form of a " $U$ " on its side, with open end of $U$ facing anteriorly. On head, a short stripe along preopercle-interopercle region. All stripes with darkened edges. All but dorsalmost stripe pale blue to blue-green, except for that part of second stripe on head, which is brown in centre, flanked by pale yellow. Dorsal fins with a broad, basal, brown stripe, margined distally with a thin, diffuse, darker stripe, and above this a thin yellow stripe. A jet black, eye-sized spot ringed with chrome yellow above yellow stripe in first dorsal fin, lying between spines one to four. A black-edged, bright red, comet-tailed spot above eye-sized spot, the "comet tail" passing along first and second spines to their tips. Distal end of second dorsal with a black-edged, orange stripe. A jet black, eye-sized spot ocellated by chrome yellow lying between the bases of rays 7-12. An elongate, oblique, black spot, rimmed with yellow anteroventrally, on dorsal margin of caudal peduncle. It and the red, U-shaped stripe margined distally by a thin white stripe. Remainder of caudal fin, as well as pectoral and pelvic fins, hyaline; anal fin dusky. Preserved: similar, but reds, oranges, yellows, and blues appear as pale areas.

\section{DISCUSSION}

Although the Chagos specimens agree well with descriptions of $A$. hectori, there are a few minor exceptions. For example, both Smith (1956a) and Goren (1979) stated that the head was naked in their specimens, and yet there is a single row of scales on the opercle in seven of the ten Chagos specimens examined. In addition, Smith (1956a) stated that his specimens possessed a fraenum (absent in Chagos specimens) and had four to five lower gill rakers (vs seven to eight in Red Sea specimens [Goren, 1979] and seven in Chagos examples).

\section{Amblygobius semicinctus (Bennett)}

Figs. 6, 7

Gobius semicinctus Bennett, 1833:32 (Mauritius).

Amblygobius semicinctus-Lachner and Gomon, 1974:18 (tropical Indian Ocean).

\section{MATERIAL}

Thirteen lots, 57 specimens, 16.5-76.1 mm SL. Depth range 0.1-22 $\mathrm{m}$, lagoons only, at Diego Garcia, Peros Banhos, Salomon, and Three Brothers.

\section{DESCRIPTION}

Based primarily on 10 specimens from WE 79-44 (46.5-75.3 mm SL) (Peros Banhos), but colour variation based on most of the specimens. D VI + I 13-15 (14.7), 


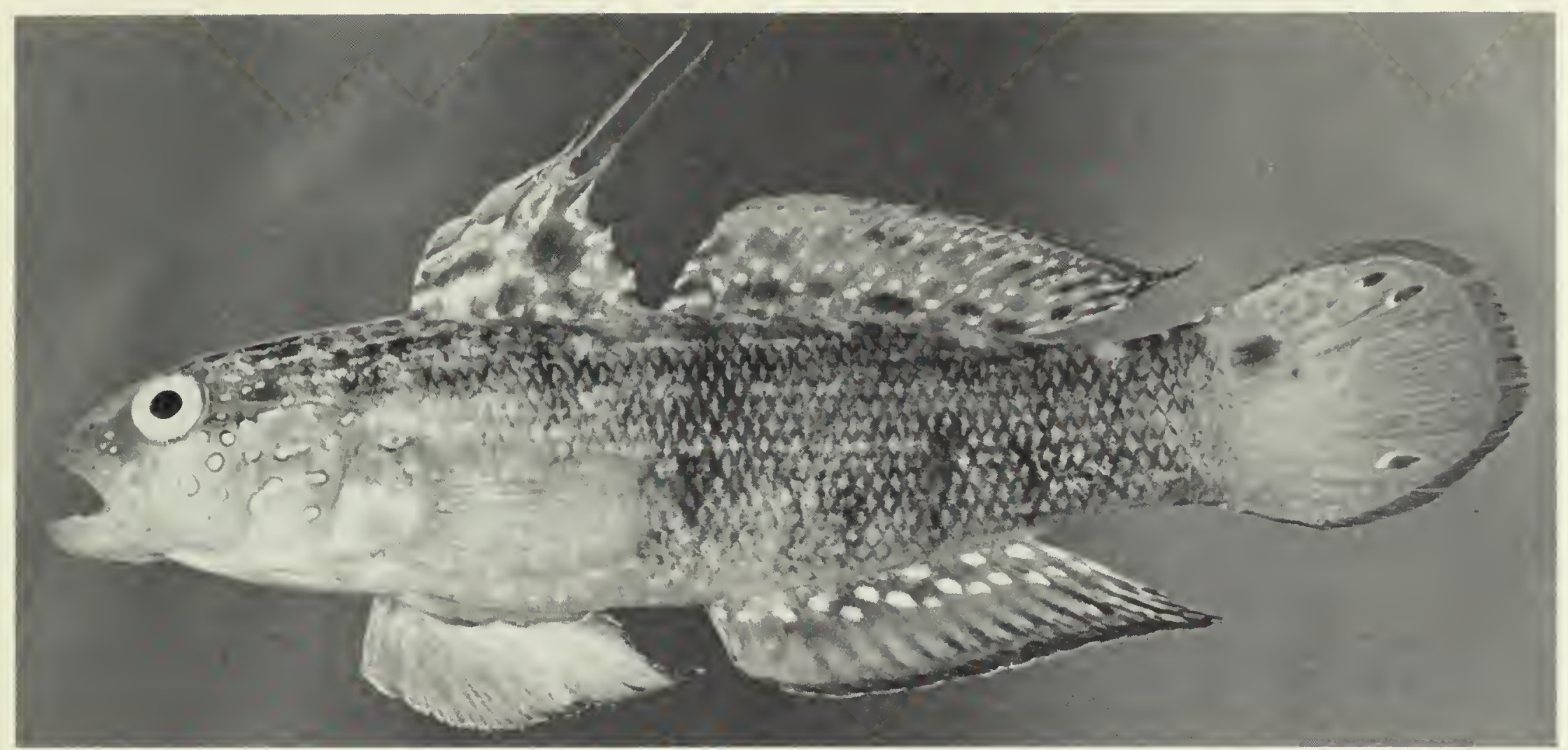

Fig. 6. Left lateral view of Amblygobius semicinctus, $76.1 \mathrm{~mm}$ SL.

second, third, fourth, and occasionally fifth spines elongate, reaching to bases of first to fifth rays of second dorsal fin; A I 14-15; P 19-21 (21 once; 19.8), reaching almost to, or just beyond origin of anal fin; V I 5, pelvic spine with distinct pad near tip and completely covered with thickened skin, basal membrane and fraenum complete, fin extends almost to, or beyond anal-fin origin. Lateral scales 52-55 (54.3); transverse scales 18-20 (18 once; 19.6). Nape and head scaled; head scales extend almost to eyes. Prepelvic and pectoral bases scaled. Head scales cycloid; body scales distinctly ctenoid. Gill opening partly restricted, reaching ventrally just anterior to a vertical line from posterior limb of preopercle. Mouth terminal, inclined dorsally; upper jaw with multiple rows of conical teeth, two enlarged canines at margin, approximately one-third of distance towards posterior of jaw. Lower jaw as for upper jaw. Anterior nostril tubular and marked with dark pigment, posterior nostril porelike. Tongue spatulate with rounded edges. First gill slit open; gill rakers elongate but fleshy, $0+6-7$ (6.9); first epibranchial with large, fleshy, pouchlike structure surrounded at its opening by six to eight fingerlike projections; pseudobranch with four heavy lobes; five branchiostegal rays. Dorsal pterygiophore formula $3(2,2,1,1,0)$; vertebrae $10+15+$ ural centrum $=26$. One anomalous specimen with $3(2,2,1,1,1)$, the extra pterygiophore not bearing a spine, and 11 abdominal vertebrae. As percentage standard length: head length 28-32 (29.3); origin of first dorsal fin 32-36 (34.1); origin of second dorsal fin 54-58 (55.1); origin of anal fin 56-61 (58.0); caudal-peduncle length 14-17 (16.1). As

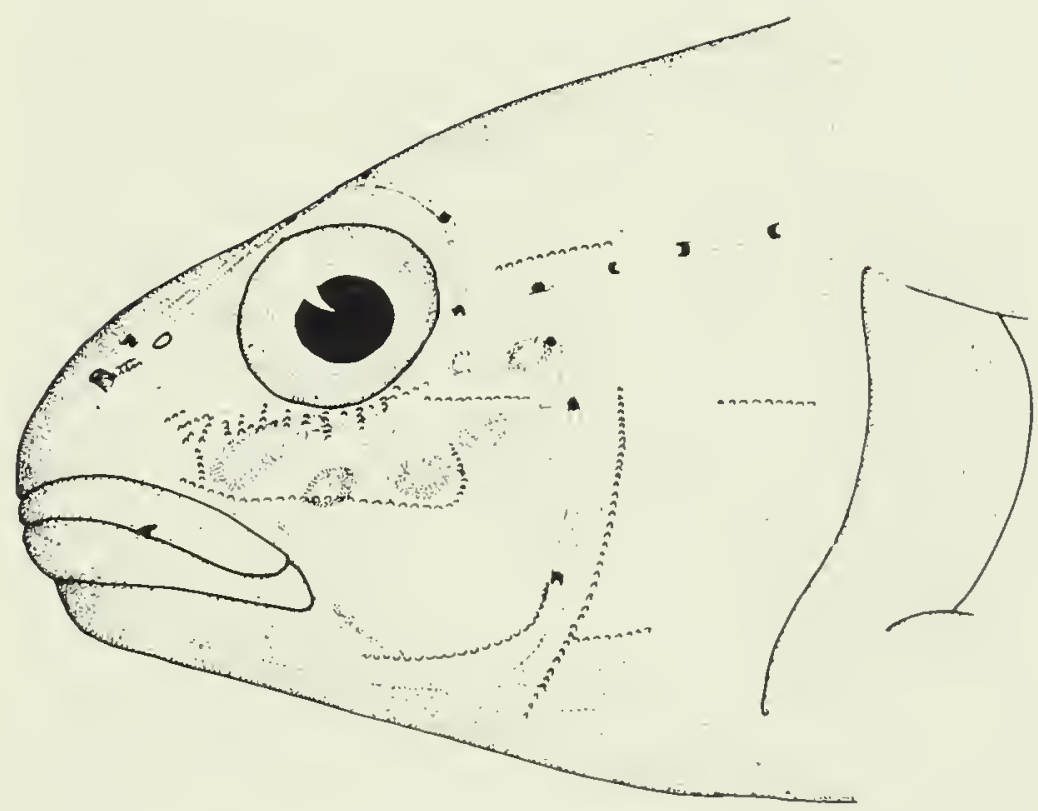

Fig. 7. Left lateral view of the head of Amblygobius semicinctus, $69.1 \mathrm{~mm} \mathrm{SL}$, to show head pores, papillae, and disposition of blue spots beneath eye. Scale equals $1 \mathrm{~cm}$.

percentage head length: eye diameter 22-27 (24.2); snout length 19-32 (27.6); upper-jaw length 32-4l (35.7). Caudal-peduncle depth as percentage of caudal-peduncle length 80-101 (91.7). Head pores and papillae as shown in Fig. 7. Caudal skeleton as for $A$. hectori.

Intestine long, pale, and coiled; peritoneum dark to dusky. Gut of $65.1 \mathrm{~mm}$ female dominated by fine, unbranched filamentous algae. Most abundant animals were approximately 20 species of harpacticoid copepods. 
Next in abundance were nematodes (possibly parasitic), tanaids, polychaetes, decapod shrimps, amphipods, and a few sand grains.

Colour patterns sexually dichromatic, and in addition, highly variable. Background colour for females mottled pale to dark brown dorsally, grading to yellow-brown ventrally. Snout greenish brown with several blue spots. Iris is yellow dorsally, grading to greenish brown ventrally. Nape and occiput reddish brown with three or four narrow lines of blue breaking up into small blue spots at level of first dorsal fin. Cheek and opercles yellowbrown, dotted with large blue spots. Lower jaw and throat pale yellow or cream. Pectoral base and chest cream, coloured with small yellow-brown speckles. Lateral aspect of background coloration of body broken by narrow, white or silvery bars beginning about one-third of way down body and continuing right around belly to other side. Five or six recognizable bars beginning just behind pectoral-fin base. Each white bar about $20 \%$ width of intervening dark body colour. Posterior to sixth bar, a white-and-brown mottled pattern. All specimens showing at least an indication of five or six dusky, but diffuse-edged vertical bars, distinguishable by their black, rather than brown, pigment even on dark fish. First bar originating immediately behind operculum; second under middle of first dorsal fin; third, fourth, and fifth under origin, middle, and posterior end of second dorsal fin, respectively; and sixth, when visible, on caudal peduncle. First dorsal fin with yellow-brown tips to elongate spines, pale or white at margins, crossed from anterior to posterior with alternating white and brown bars, becoming less distinct beyond third spine. Large, round black spot covering fourth and fifth spines, spot approximately same size as pupil of eye. Second dorsal fin edged with pale blue. Fin yellow-brown with faint blue bar at $20 \%$ distance from margin to base, rest of fin marked with blue spots approximately one-third of diameter of pupil. Anal fin similarly marked, but with blue spots aligned in three rows, outermost row almost completely coalesced to form a bar. Caudal fin pale brown, rays tinged with mauve-pink, a stronger flash of pink dorsally and speckled lightly with white. Two or three large dusky ocellated spots in caudal fin, largest located dorsally at edge of scales between third to sixth dorsal principal caudal rays. Smaller dorsal and ventral dusky ocellated spots (about a third of size of large dorsal spot) located three-quarters posteriad on fifth and twelfth principal caudal rays, respectively. Pelvic and pectoral fins translucent and colourless. Colour of males similar to that of females except in following: no silver or white bars continuing from lateral aspect of body around thoracic or belly region ventrally. In addition, approximately twothirds of specimens with silver or white spots on anal fin-these lacking in all females. On males lacking spots, anal fins extremely pale, with white spots no longer visible on white background. Preserved: similar, but pink, blue, and white areas visible only as pale areas.

\section{DISCUSSION}

Species of the $A$. albimaculatus group, to which $A$. semicinctus belongs, have long been a source of confusion to systematists, both because of the sexual dichromatism and because of the subtle colour differences between species. We here follow Lachner and Gomon (1974) in identifying our specimens as $A$. semicinctus, based on the position of the black spot overlying the upper hypu$\mathrm{ral} /$ caudal-fin ray region and on other details of colour pattern.

Amblygobius tekomaji (Smith)

Figs. 8,9

Seychellea tekomaji Smith, 1959:204 (Tekomaji Island, Mozambique).

\section{MATERIAL}

Six lots, 29 specimens, $11.8-32.2 \mathrm{~mm} \mathrm{SL}$. Depth range 3-22 m, lagoons only, at Diego Garcia, Salomon, and Three Brothers.

\section{DESCRIPTION}

Based on 10 specimens from lots WE 79-43, 79-69, and 79-82 (22.2-30.1 mm SL), plus 3 cleared and stained specimens from lot WE 79-82 (23.3-32.2 mm SL). D VI + I 13 (twice I 14), second to fifth spines longest, and may just reach origin of second dorsal fin when depressed; A I 13 (twice I 14); P 18-20 (18.7) reaching to a vertical line with anus, usually dorsalmost and ventralmost two rays unbranched; V I 5 , complete basal membrane and fraenum, not reaching anus. Lateral scales 62-65 (63.3); transverse 19-23 (21.3); no predorsal scales in midline; head scales extending anteriorly on either side of midline and above opercle, half-way to eye. Prepelvic scales to gill opening; two specimens ( 25.5 and $30.1 \mathrm{~mm} \mathrm{SL}$ ) with a few scales on pectoral base, which is naked in others. All scales cycloid, increasing in size from anterior to posterior. Gill opening partly restricted, reaching a point ventrally between pectoral base and vertical limb of preopercle. Mouth terminal, inclined slightly dorsally. In upper jaw, outer row of teeth with three to six enlarged, curved conical teeth, and one to two irregular inner rows of small conical teeth. In lower jaw, outer row of four to six enlarged, curved conical teeth-next to lateralmost of these on each side, one (sometimes two) greatly enlarged, curved, laterally flaring canine-and one or two irregular inner rows of small conical teeth. Anterior nostril tubular, posterior porelike. Tongue truncate with rounded margins. First gill slit open; gill rakers fleshy, unossified, $0+6$; first epibranchial with a large, fleshy pad, bearing four fleshy processes; pseudobranch with five lobes. Five 


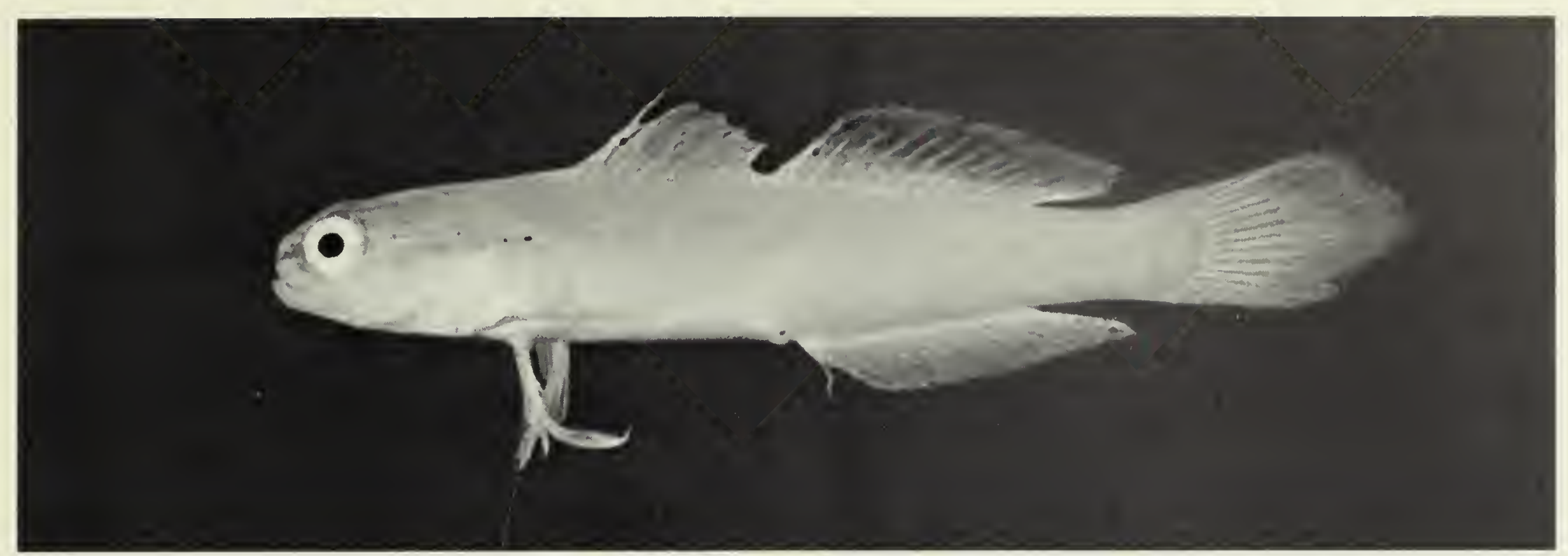

Fig. 8. Left lateral view of Amblygobius tekomaji, $29.4 \mathrm{~mm}$ SL.

branchiostegal rays. Dorsal pterygiophore formula $3(2,2,1,1,0)$; vertebrae $10+15+$ ural centrum $=26$. Seven dorsal and 6 ventral branched caudal-fin rays with 10 to 11 dorsal and 9 to 10 ventral unbranched caudal-fin rays. As percentage standard length: head length $27-29$ (28.2); origin of first dorsal fin 34-38 (36.1); origin of second dorsal fin 54-58 (55.8); origin of anal fin 56-62 (59.6); caudal-peduncle length 14-19 (16.0). As percentage head length: eye diameter 22-27 (25.3); snout length 16-24 (20.3); upper-jaw length 32-39 (36.0). Caudalpeduncle depth as percentage caudal-peduncle length 59-77 (69.7). Head pores and papillae as in Fig. 9. Caudal skeleton as in $A$. hectori, but neural spine of pu 2 not as broad.

Intestine long, coiled, filled with fine sand. Peritoneum black. Gut of one specimen (27.1 mm SL) contained primarily flocculent material interspersed with ostracods, foraminifera, and diatoms.

Colour pattern (freshly dead): cream above, becoming white ventrally. An orange stripe continuous around snout, including anterior nostril, passing through iris, across upper cheek, and fading out below first dorsal fin. A second orange stripe beginning behind posterodorsal margin of orbit, fading out on nape. A faint, light orange, oblique bar across subopercle. First dorsal fin with a single, faint, horizontal, creamy yellow stripe, second dorsal fin with two such stripes, other fins hyaline. Preserved: creamy yellow with the two orange stripes dusky, bar on opercle and stripes in dorsal fins not evident.

\section{DISCUSSION}

The Chagos specimens agree well with Smith's (1959:204) description of Seychellea tekomaji. Prepectoral scales are present only in two of the larger Chagos specimens, but presence of these scales seems dependent
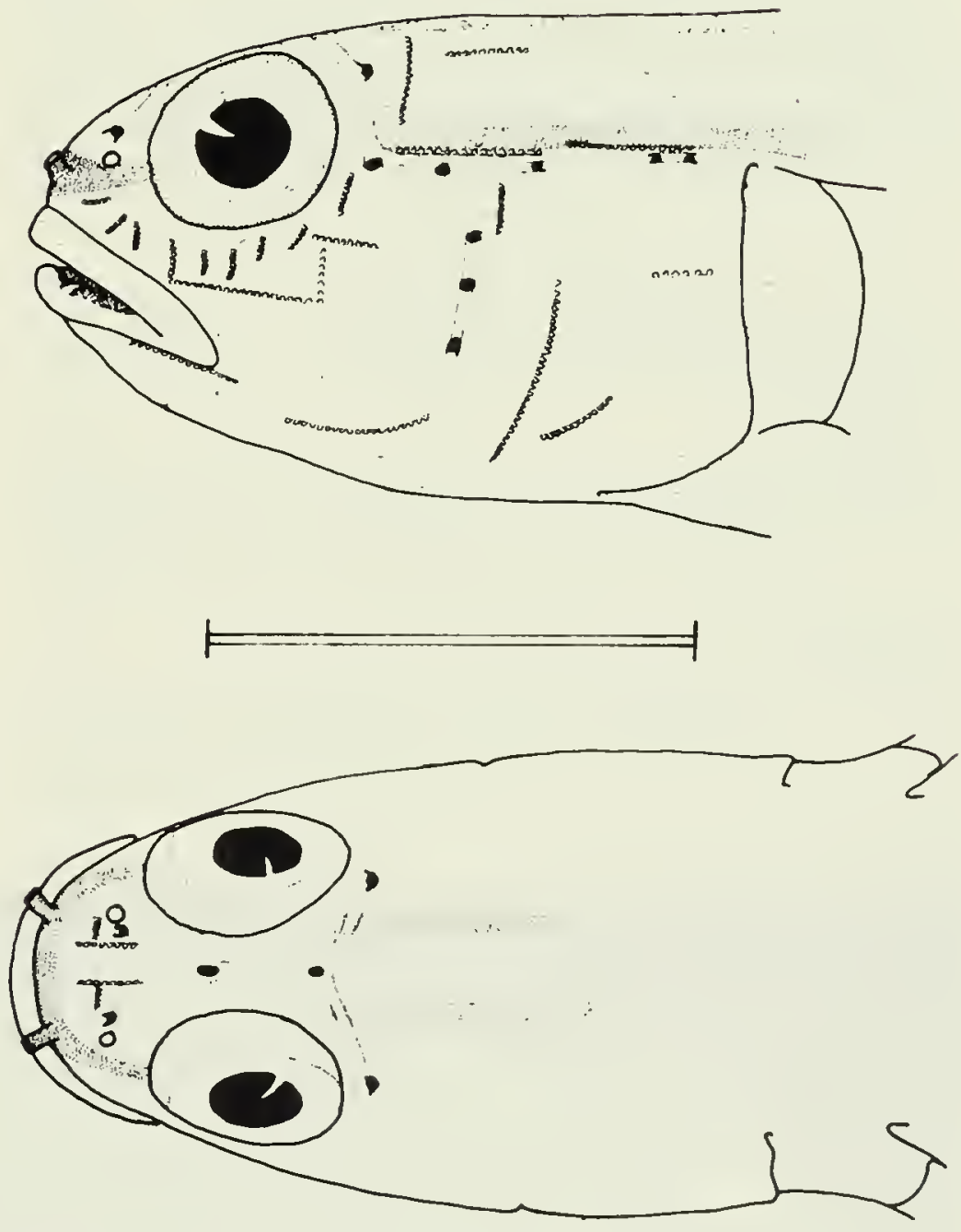

Fig. 9. Left lateral (above) and dorsal (below) views of the head of Amblygobius tekomaji, $26.9 \mathrm{~mm} \mathrm{SL}$, to show head pores, papillae, and position of orange stripes (stippled). Scale equals $5 \mathrm{~mm}$.

on size, with prepectoral scales being developed only at about $30 \mathrm{~mm}$ SL (Smith's specimens were $46-52 \mathrm{~mm}$, apparently total length because one of his paratypes, RUSI 732 , is $37.1 \mathrm{~mm} \mathrm{SL}$ and $46 \mathrm{~mm} \mathrm{TL}$ ). The pectoral-fin count given by Smith (1959) appears not to have included 
all specimens, for RUSI 732 has 19 rays on both sides.

Four paratypes of Yabotichthys nocturnus Herre, 1945 from Busuanga, Philippines were examined (SU 36829) at the suggestion of Dr D. F. Hoese. The species is very close to $A$. tekomaji, sharing cycloid scales and a similar colour pattern. However, $A$. nocturnus has a dark horizontal bar on the cheek below the eye and a teardrop-shaped dusky mark (both markings apparently violet in life) on the opercle, with the "tail" of the "tear" pointing posteriorly-both are absent in $A$. tekomaji. $A$ nocturnus also has a somewhat longer head (30.4-33.8, $\bar{x}$ $=31.5 \%$ standard length, $n=4$ ) than does $A$. tekomaji $(27.5-29.0, \bar{x}=28.2)$. It is possible that the colour differences are due to different times of capture (night for $A$. nocturnus, daylight for $A$. tekomaji) or may represent, as may the difference in head length, geographical variation. Until a more detailed analysis of additional material is undertaken, we retain them as separate species.

Amblygobius myersi Herre, 1935 from the Solomon Islands differs most obviously from $A$. nocturnus and $A$. tekomaji in the possession of a scaled nape and ctenoid scales posteriorly on the body.

\section{Genus Asterropteryx}

\section{Asterropteryx species (= DFH sp. 7)}

Figs. 10, 11

\section{MATERIAL}

Six lots, 24 specimens, 13.5-31.9 mm SL. Depth range 4-32 m, lagoons only, at Peros Banhos and Salomon.

\section{DESCRIPTION}

Based on 10 specimens from WE 79-69 (25.6-31.5 mm SL), and 1 cleared and stained specimen from WE 79-64 (29.3 mm SL). D VI + 110, fourth spine longest reaching to base of first or second ray of second dorsal fin, all rays branched; A I 9, all rays branched; P 18-20 (18.9), uppermost and lowermost one or two rays unbranched, reaching end of anal-fin base when depressed; V I 5, basal membrane present, no fraenum, all rays branched, reaching second ray of anal fin when depressed. Lateral scales 23-25 (23.6); transverse 10; predorsal 4-5 (4.6). Scales mostly ctenoid, except cycloid on head, and prepectoral and prepelvic bases. Gill opening reaching to below vertical limb of preopercle. Mouth terminal; teeth in upper jaw in several rows, outer enlarged and spaced out; those of lower jaw similar but with inner row also enlarged and spaced. Anterior nostril a thin tube, posterior nostril porelike. Tongue rounded with a central notch. Preopercle armed with four to seven spines, with relationship to the three preopercle canal pores (pop) as follows: one to three, usually two, spines between pop 1 and 2 ; one spine at pop 2; and two spines between pop 2 and 3, the upper of which is largest spine present. First gill slit closed for about one-fifth of its normal extent ventrally by membrane; gill rakers $2-3+10-12$ (including rudiments). Cleared and stained specimen with $0+8$ ossified gill rakers. Pseudobranch with six lobes. Five branchiostegal rays. Dorsal pterygiophore formula $3(2,2,1,1,0)$; vertebrae 10 $+15+$ ural centrum $=26$. Seven dorsal and six ventral branched caudal-fin rays, with eight dorsal and seven ventral unbranched caudal-fin rays. Head pores and papillae as in Fig. 11. Caudal skeleton as in $A$. hectori, except that in the single cleared and stained specimen, neural spine of pu 2 double, two parts together forming a flat triangle.

Peritoneum scattered with melanophores. Gut of $28.7 \mathrm{~mm}$ SL female contained mainly siliceous sponges with a few harpacticoid copepods and a juvenile gastropod.

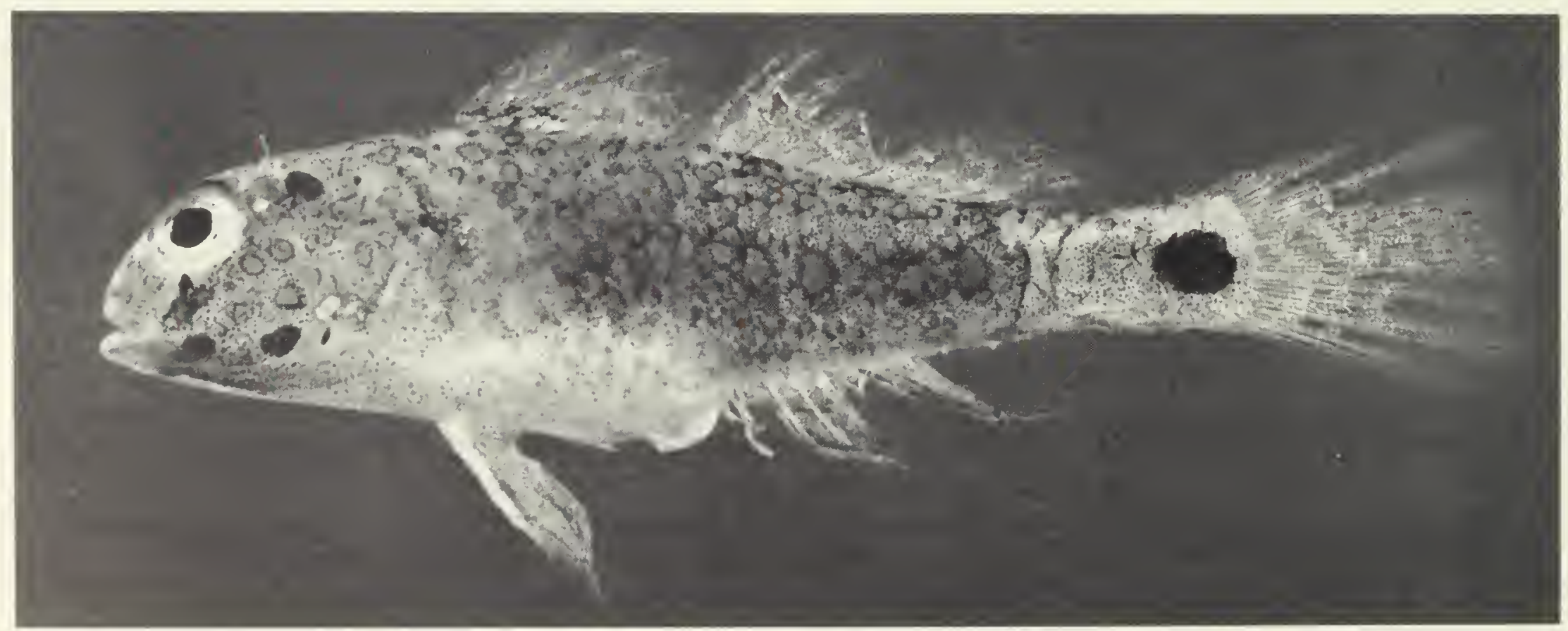

Fig. 10. Left lateral view of Asterropteryx sp., $23.7 \mathrm{~mm} \mathrm{SL}$. 

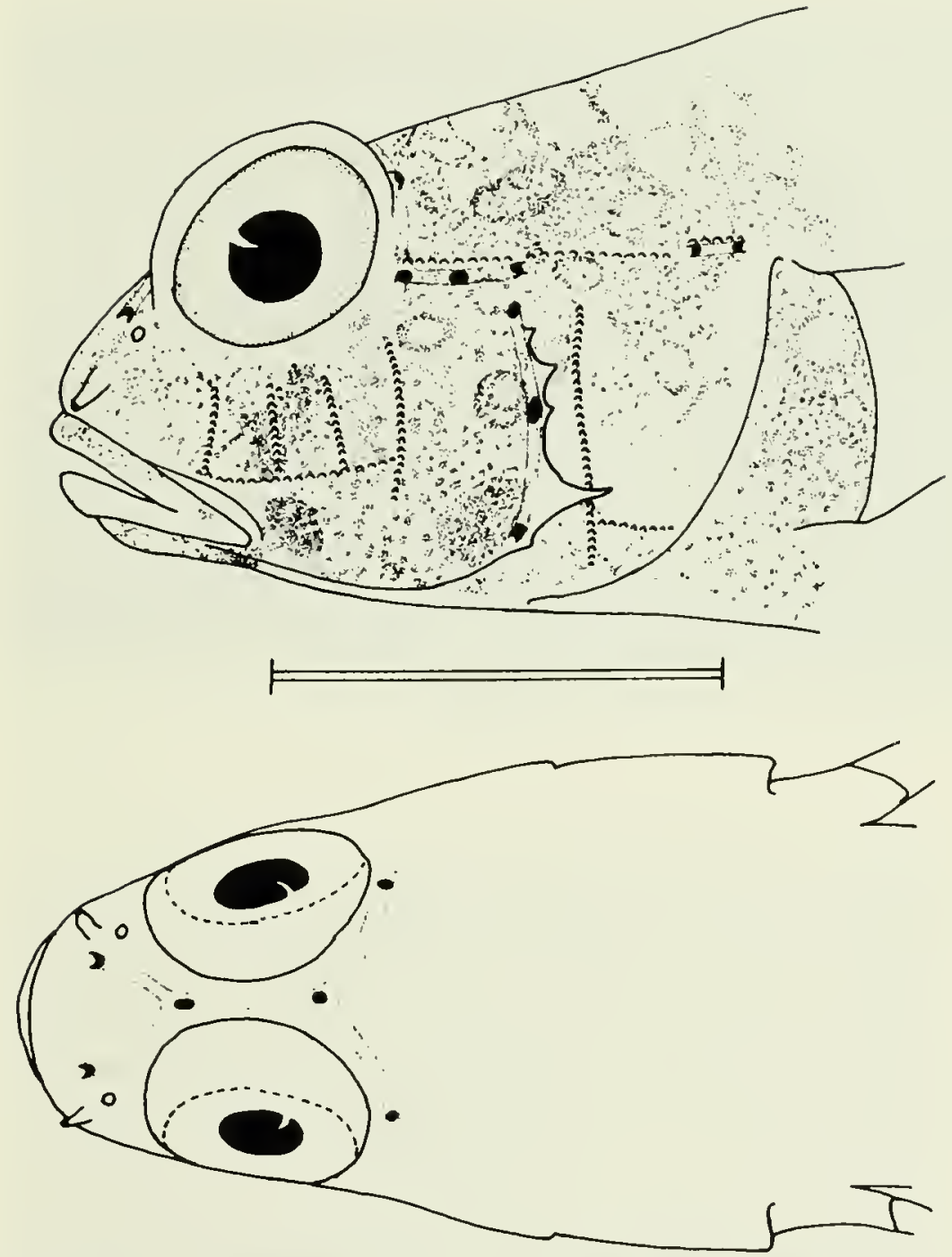

Fig. 11. Left lateral (above) and dorsal (below) views of the head of Asterropteryx sp., $26.3 \mathrm{~mm} \mathrm{SL}$, to show head pores, papillae, and pigmentation pattern. Scale equals $5 \mathrm{~mm}$.

Colour pattern (freshly dead): background light, speckled with small black melanophores. Body and head covered with half-pupil-diameter spots ranging from yellow to orange, often in contact with each other on body. Larger spots typically orange and faintly ringed with melanophores. Head with two dusky smudges under eye, coalescing to form vertical stripe in some specimens; another smudge in angle of preopercle. Dusky markings usually absent at sizes below $25 \mathrm{~mm} \mathrm{SL}$. Large black spot on caudal peduncle about two-thirds of eye diameter. Dorsal and caudal fins with three to five horizontal rows of orange spots and a background of small leucocytes (= "salt"), proximal row in first dorsal fin separated by black pigment; anal fin with indistinct yellow spots on a "salt and pepper" background. Preserved: similar to above, except that all yellow-to-orange areas without pigment.

\section{DISCUSSION}

This species is apparently undescribed, and will be treated in a revision of Asterropteryx by Dr D. F. Hoese, who has specimens from Samoa and the Carolines.
Asterropteryx ensiferus (Bleeker)

Figs. 12, 13

Brachyeleotris ensiferus Bleeker, 1874a:375 (Buru, East Indies).

Asterropteryx monacanthus Regan, 1908:240 (Amirante, Seychelles).

\section{MATERIAL}

Two lots, 10 specimens, 8.6-24.7 mm SL. Depth range 10-22 m, lagoon only, at Salomon.

\section{DESCRIPTION}

Based on six specimens from lots WE 79-69 and 79-72 (15.3-24.7 mm SL). No specimens cleared and stained. D VI + I 10, third spine longest, reaching from base of first ray of second dorsal fin $(15.3 \mathrm{~mm} \mathrm{SL})$ to tip of last ray $(24.7 \mathrm{~mm} \mathrm{SL})$; A I 9; P 17-19 (17.5), reaching a vertical with midregion of anal-fin base; V I 5 , no fraenum, vestigial basal membrane, longest ray reaching midregion of anal-fin base. Lateral scales 24-25 (24.5); transverse 8 (once 7); predorsal 7 (once 8); cheek, opercle, pectoral-fin base, breast, and isthmus scaled; scales mostly ctenoid except usually cyćloid anterior to paired fin bases and on cheek. Gill opening partly restricted, reaching ventrally to a point between vertical limb of preopercle and pectoral-fin base. Mouth terminal, slightly upturned; teeth in upper jaw in several rows, outer row enlarged, spaced, and curved. Lower jaw teeth similar, but with inner row slightly enlarged. Anterior nostril tubular, posterior porelike. Tongue roundly truncate, a slight median notch sometimes present. Preopercle with single, strong, posteriorly directed spine at angle, between preopercular pores 2 and 3. First gill slit closed ventrally for one-fifth of its normal extent; gill rakers 4-5 + 7-8. As percentage standard length: head length 33-35 (34.1); origin of first dorsal fin 40-43 (41.0); origin of second dorsal fin 60-63 (61.5); origin of anal fin 60-63 (61.8); caudal-peduncle length 24-26 (25.0). As percentage head length: eye diameter 26-30 (28.0); snout length 19-23 (20.9); upper-jaw length 29-30 (29.4). Sexual dimorphism in ratio of caudal-peduncle depth to caudalpeduncle length may occur, females with a narrower peduncle than males-50-51 (50.8) in femaies, 61-64 (62.1) in males. However, of six specimens which were $14.9 \mathrm{~mm} \mathrm{SL}$ or longer, the three females measured $14.9-15.8 \mathrm{~mm} \mathrm{SL}$ and the three males, $22.6-24.7 \mathrm{~mm}$ SL. Thus, small sample size and disparate size of specimens do not rule out the possibility of allometric growth. Head pores and papillae as in Fig. 13.

Intestine relatively long, peritoneum sprinkled with brown melanophores. Gut of $22.6 \mathrm{~mm} \mathrm{SL}$ male contained copepods and polychacte setac.

Colour pattern when freshly dead: not recorded. Preserved: dark brown above, paler below. A dusky bar from eye to rictus, continuing ventrally across chin. A 


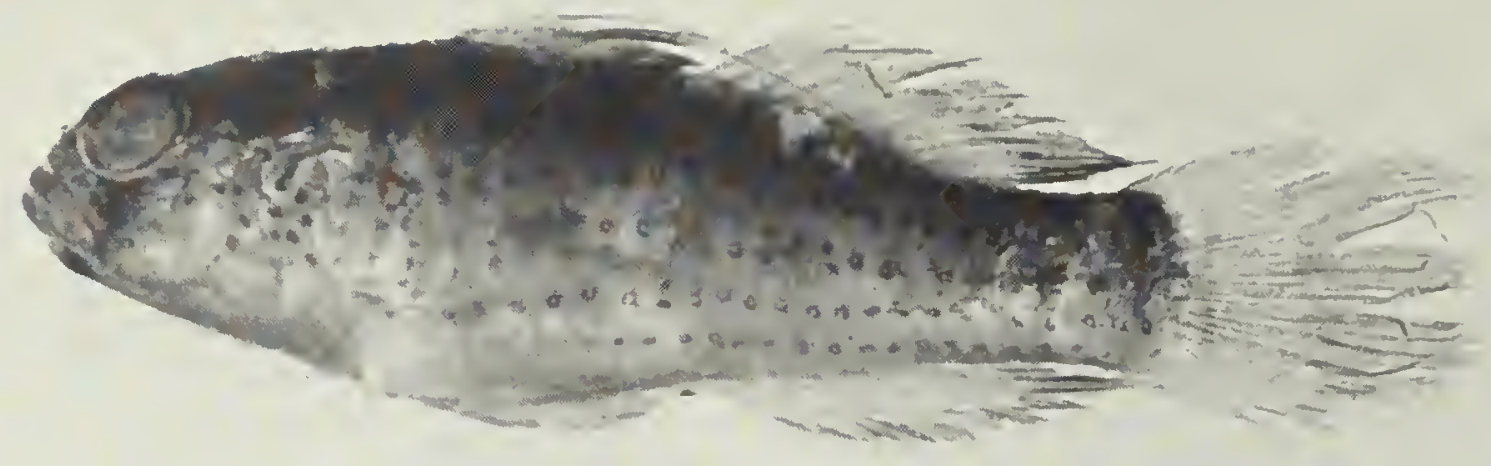

Fig. 12. Left lateral view of Asterropteryx ensiferus, $24.7 \mathrm{~mm} \mathrm{SL}$ (preserved).
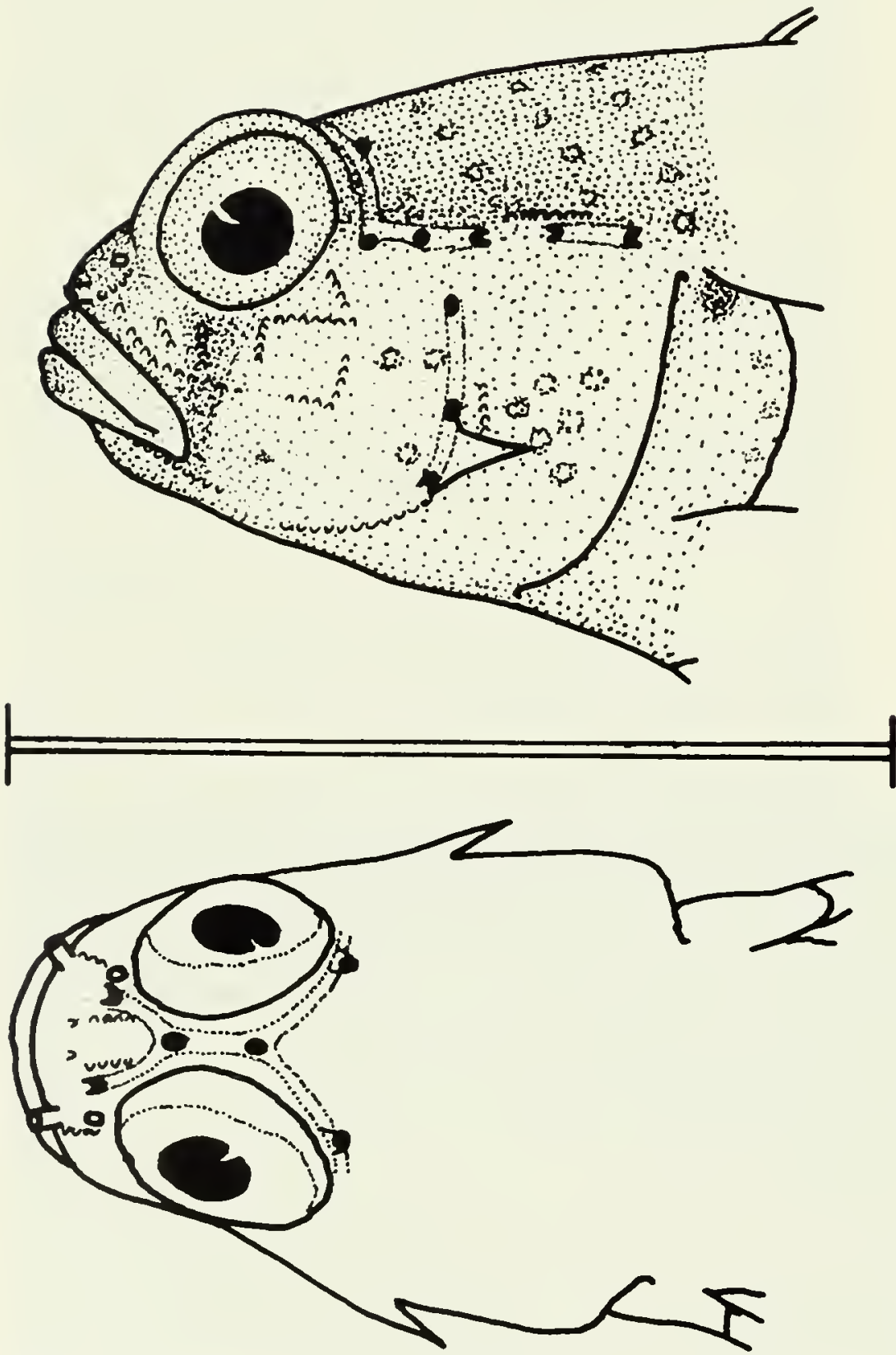

Fig. 13. Left lateral (above) and dorsal (below) views of the head of Asterropteryx ensiferus, $22.3 \mathrm{~mm} \mathrm{SL}$, to show head pores, papillae, and head pigmentation pattern. Scale equals $1 \mathrm{~cm}$ dusky spot on upper pectoral base, caudal peduncle with a diffuse, dusky, vertical stripe. Faint dusky blotches along midlateral region of body in one specimen. Two largest specimens (23.6-24.7 $\mathrm{mm}$ SL males) with a pale, ocellated spot in the centre of each scale (except those on nape). Median fins with dusky edges, paired fins hyaline.

Asterropteryx semipunctatus Rüppell Figs. 14, 15 Asterropteryx semipunctatus Rüppell, 1830:138 (Massawa, Red Sea); Smith 1958:143 (widespread tropical Indo-Pacific).

\section{MATERIAL}

Three lots, 26 specimens, 12.5-29.0 mm SL. Depth range $7-15 \mathrm{~m}$, lagoons only, at Salomon and Three Brothers.

\section{DESCRIPTION}

Based on 10 specimens from lots WE 79-43, 79-66, and 79-82 (19.5-28.7 $\mathrm{mm} \mathrm{SL})$, and 4 cleared and stained specimens from lot WE 79-82 (17.8-25.2 mm SL). D VI + I 10 (once I 9), third spine longest, reaching posteriorly to between first dorsal ray base (small specimens) to tip of last dorsal-fin ray (large specimens); A I 9; P 15-18 (16.8), reaching posteriorly to a vertical with midregion of anal-fin base, two to four upper rays unbranched; V I 5, no fraenum, basal membrane vestigial, fin reaching posteriorly to anterior base of anal fin. Lateral scales 23-24 (23.9); transverse 8; predorsal 6-7 (6.5); pectoral base, breast, isthmus, cheek, and opercle scaled; scales strongly ctenoid; some on head, nape, and paired fin bases cycloid. Gill opening partly restricted, reaching ventrally to a point between pectoral base and vertical limb of preopercle. Mouth terminal, inclined obliquely upwards. Teeth in upper jaw in several rows; outer row spaced, curved, and somewhat enlarged. Lower jaw teeth similar, but outer- 


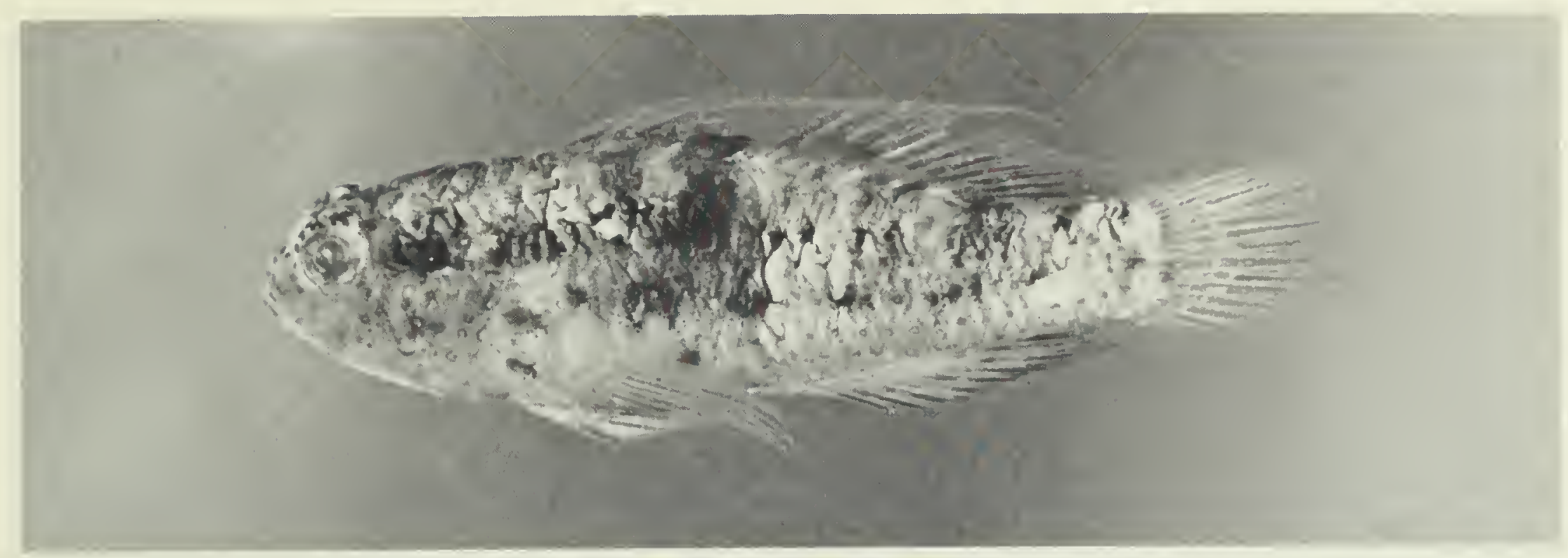

Fig. 14. Left lateral view of Asterropteryx semipunctatus, $29.0 \mathrm{~mm} \mathrm{SL}$.

row teeth increasing in size laterally (lateralmost tooth largest), innermost row slightly enlarged. Anterior nostril tubular, posterior porelike. Tongue sharply rounded. Preopercle with three to four spines at angle, between pores 2 and 3. First gill slit closed ventrally for one-fifth of its normal extent; gill rakers 4-5 +9-10; ossified rakers in cleared and stained specimens $2+7(17.8 \mathrm{~mm} \mathrm{SL})$ to 4 +10 (25.2 $\mathrm{mm} \mathrm{SL})$; pseudobranch with six to eight lobes; five branchiostegal rays. Dorsal pterygiophore formula $3(2,2,1,1,0)$; vertebrae $10+15+$ ural centrum $=26$. Six dorsal and 6 ventral branched caudal-fin rays, with 9 to 10 dorsal and 7 to 9 ventral unbranched rays. As percentage standard length: head length 30-33 (30.6); origin of first dorsal fin 36-41 (37.8); origin of second dorsal fin 57-62 (58.9); origin of anal fin 59-65 (61.8); caudal-peduncle length 24-26 (24.7). As percentage head length: eye diameter 28-32 (29.4); snout length 18-24 (21.0); upper-jaw length 29-34 (31.9). Caudal-peduncle depth as percentage caudal-peduncle length 50-64 (56.5). Head pores and papillae as in Fig. 15. Caudal skeleton as for Amblygobius hectori, except that neural spine of pu 2 is acutely triangular.

Intestine very long and coiled, peritoneum black. Gut of $28.7 \mathrm{~mm} \mathrm{SL}$ male of flocculent material contained foraminifera and some filamentous algae and sand.

Colour pattern (freshly dead): body pale yellow, with two dusky stripes, one from eye to upper part of peduncle, the other from upper pectoral-fin base to lower peduncle. In some specimens, stripes indistinct, whole upper surface of the body is dusky; in others, stripes broken up into a series of dark blotches. Most scales on head and body with central, small, light blue spot, ocellated with black. Iridescent blotch on upper pectoral-fin base, similar blotch occasionally present on lower base. Median fins dusky, paired fins hyaline. Base of first dorsal fin black. Three rows of light blue spots in second dorsal and anal fins,

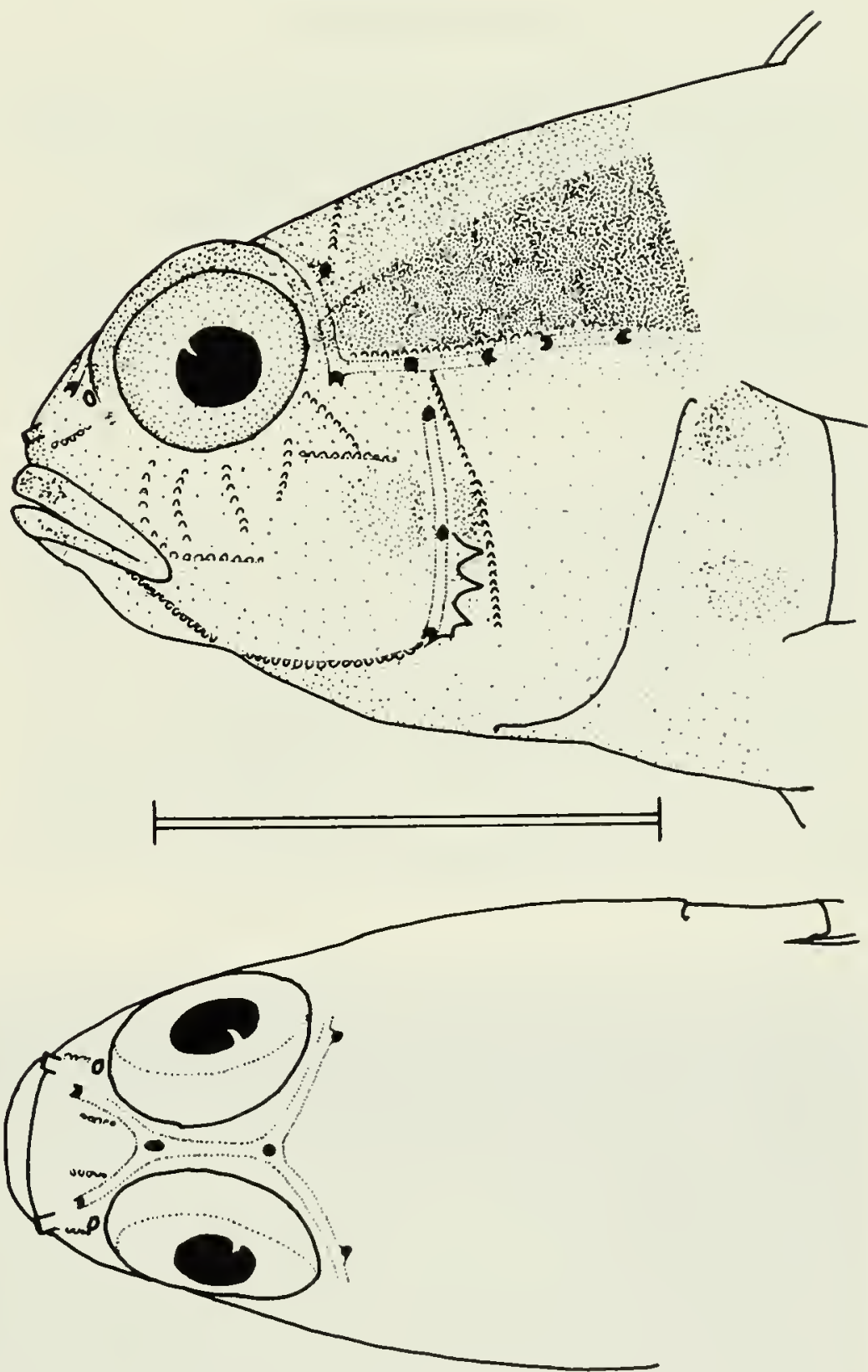

Fig. 15. Left lateral (above) and dorsal (below) views of the head of Asterropteryx semipunctatus, $22.1 \mathrm{~mm} \mathrm{SL}$, to show head pores, papillac, and pigmentation pattern on head. Scale equals $5 \mathrm{~mm}$. 
caudal fin with scattered blue spots. A faint dusky bar or two to three dusky spots aligned vertically across hypural region of caudal peduncle. Preserved: similar to above, but blue spots same colour as pale yellow background, and blotch(es) on pectoral-fin base no longer iridescent.

\section{DISCUSSION}

Asterropteryx semipunctatus may be distinguished from all other species in the genus in the following: in possessing two to four preopercular spines, all of which lie below the middle preopercular pore with the ventralmost spine being equal to or smaller than the spine above; and in having the third dorsal spine longest in both sexes (Hoese, ms. key). Smith's description (1958:143) may involve more than one species; he states there may be up to nine spines on the preopercle.

\section{Genus Barbuligobius}

Barbuligobius boehlkei Lachner and McKinney Fig. 16 Barbuligobius boehlkei Lachner and McKinney, 1974:871 (Taiwan, also western Indian Ocean).

\section{MATERIAL}

One lot, 1 specimen, $15.4 \mathrm{~mm} \mathrm{SL}$. Depth $7 \mathrm{~m}$, lagoon at Peros Banhos.

\section{DESCRIPTION}

The description of this genus and species is detailed, well illustrated, and recent, and only a brief description of the Chagos specimen is offered here. Head pore and papillae patterns as illustrated by Lachner and McKinney (1974, figs. 2-3). Genus monotypic, distinguished from other gobioids by lack of an anterior interorbital pore, presence of barbels and fleshy flaps along sides and underside of head, six dorsal spines, scaled body lacking predorsal scales, and five branchiostegal rays. D VI + I 9; A I 9; P
20; V I 5 (weak fraenum, basal membrane present). Lateral scales 24; transverse 8; scales ctenoid. Gill opening reaching a point between pectoral base and vertical limb of the preopercle anteroventrally. Mouth terminal; teeth of uniform size in several rows in each jaw; tongue roundly truncate. First gill slit open; gill rakers $0+$ 1 (the single raker is small). Our specimen falls within the ranges for morphometrics given by Lachner and McKinney $(1974$, table 1) except for snout length $(6.6 \%$ SL vs 7.3-8.4\% SL).

Colour pattern (freshly dead): as in Lachner and McKinney (1974, fig. 1), but with a brownish tinge to the dorsal saddles; colour faded on preservation.

\section{Genus Bathygobius}

Bathygobius albopunctatus (Valenciennes) Figs. 17, 18 Gobius albopunctatus Valenciennes in Cuvier and Valenciennes, 1837:57 (Mauritius).

\section{MATERIAL}

Two lots, 6 specimens, 42.1-59.1 mm SL. Depth range 0-0.5 m, intertidal reef-flats at Diego Garcia and Peros Banhos.

\section{DESCRIPTION}

Based on all specimens (WE 79-15 and Stn B), two cleared and stained. D VI + I 9, fourth spine longest and reaching spine of second dorsal fin when depressed, last ray reaching unbranched caudal-fin rays posteriorly; A I 8, last ray not quite reaching unbranched caudal-fin rays; $P$ 18-20 (19.0), reaching posteriorly to a vertical with anus, first four rays with free (silklike) tips; V I 5, full basal membrane, fraenum well developed with a smooth, concave margin, longest ray reaching posteriorly almost to anus. Lateral scales 35-37 (36.3); transverse 15; predorsal 18-22 (20.5) reaching anteriorly to just behind eyes;

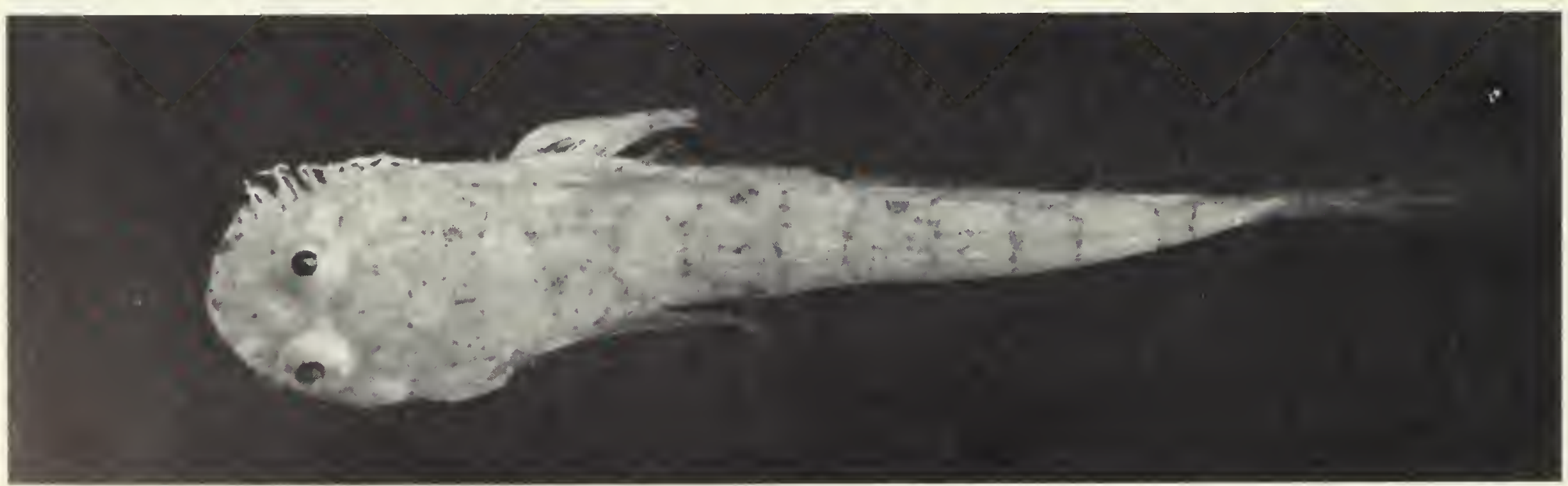

Fig. 16. Dorsal view of Barbuligobius boehlkei, 15.4 mm SL. 


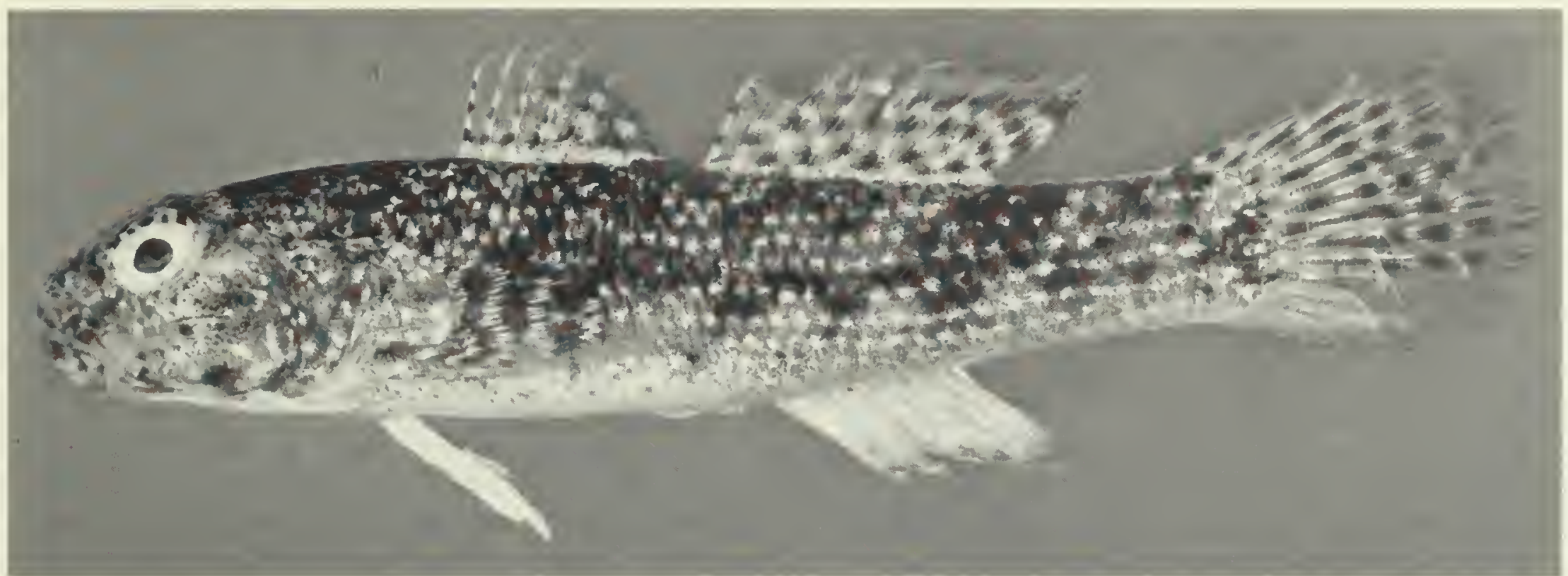

Fig. 17. Left lateral view of Bathygobius albopunctatus, $57.4 \mathrm{~mm} \mathrm{SL}$.

scales on nape, pectoral base, breast, and midline of belly cycloid; other scales ctenoid. Gill opening partly restricted ventrally to below vertical margin of preopercle. Mouth terminal, slightly inclined upwards. Upper jaw with an outer row of curved, spaced, enlarged canines and several irregular inner rows of short conical teeth. Lower jaw with an outer row of curved, spaced, enlarged canines near symphysis, canines becoming smaller and less curved posteriorly; three irregular inner rows of small conical teeth near symphysis giving way to single row of enlarged, curved teeth from bend of dentary to half its length, posterior to which only single outer row remaining. Anterior nostril a short tube with a flared rim, posterior porelike. Tongue rounded with a prominent median notch. Mental fraenum with straight posterior margin, edge attached to underlying tissue. First gill slit open to first hypobranchial ventrally; gill rakers $1+8$. Five branchiostegal rays, dorsal pterygiophore formula $3(2,2,1,1,0)$, vertebrae $10+16+$ ural centrum $=27$. Seven or 8 dorsal and 7 ventral branched caudal-fin rays, with 10 dorsal and 8 ventral unbranched caudal-fin rays. As percentage standard length: head length 31-32 (31.3); origin of first dorsal fin 38-39 (38.5); origin of second dorsal fin 54-59 (56.8); origin of anal fin 59-62 (60.5); caudal-peduncle length 24-25 (24.7). As percentage head length: eye diameter 23-27 (24.0); snout length 26-27 (26.4); upper-jaw length $40-43$ (41.5). Caudal-peduncle depth as percentage caudal-peduncle length 53-58 (54.5). Head pores and papillae as in Fig. 18. Caudal skeleton as for $A$. hectori, except that anterior margin of ventral hypural plate with proximal hooklike process.

One cleared and stained specimen with fish vertebrae in gut.

Colour pattern (freshly dead, $57.4 \mathrm{~mm}$ SL female): body brown, mottled with black forming vague blotches
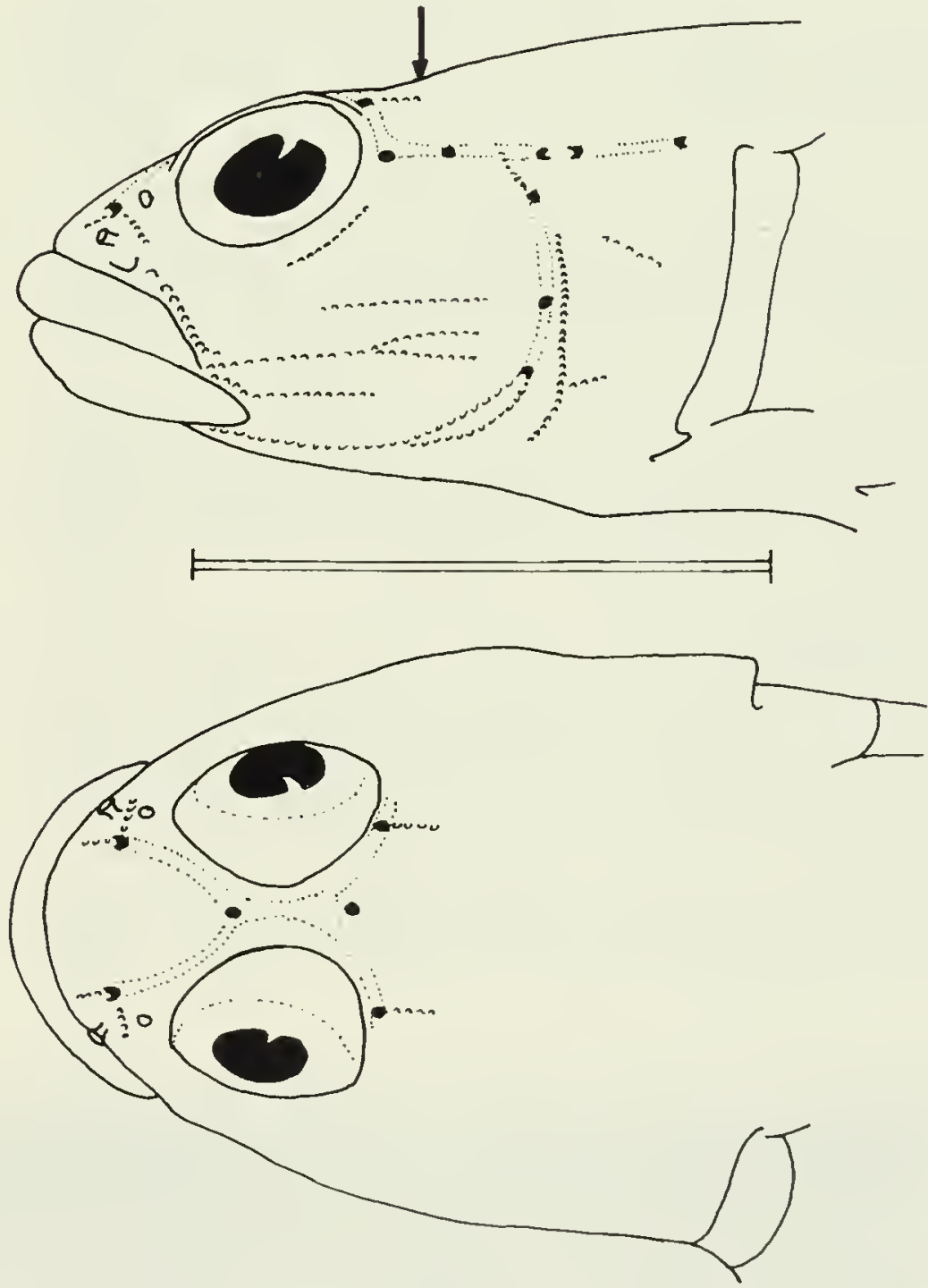

Fig. 18. Left lateral (above) and dorsal (below) views of the head of Bathygobius albopunctatus, $42.1 \mathrm{~mm} \mathrm{SL}$, to show head pores and papillae (arrow indicates anterior extent of predorsal scales). Scalc equals $1 \mathrm{~cm}$. 
along midlateral septum, a white spot in centre of each of most scales, the rows of spots forming intermittent, thin longitudinal stripes. Belly pale. Head mottled with white, black, and brown. First dorsal fin with pale, narrow basal band, fin spines with four rows of discrete black spots, the interspinous membrane dusky with half-pupil-diameter light spots. Elements of the second dorsal fin with three rows of pupil-diameter black spots, membrane pale. Caudal rays with four irregular rows of similar black spots but margined with white, membrane hyaline. Anal fin hyaline with a dusky margin, pelvic fins hyaline, pectoral fin with alternating white (four) and dark (three) bands of pigment. Iris straw-coloured. A $51.8 \mathrm{~mm} \mathrm{SL}$ male similarly coloured, but much lighter (with less black pigment on dorsum). Preserved: very similar to above description of fresh specimens.

\section{DISCUSSION}

Bathygobius albopunctatus is at present only recorded from the Indian Ocean. However, B. padangensis (Bleeker) from the west-central Pacific is very similar and possibly identical.

\section{Bathygobius cocosensis (Bleeker)}

Figs. 19, 20

Gobius cocosensis Bleeker, 1854:47 (Cocos-Keeling).

\section{MATERIAL}

Eight lots, 396 specimens, 7.2-37.4 mm SL. Depth range 0-0.75 m, reef-flats and lagoons at Diego Garcia, Peros Banhos, and Salomon.

\section{DESCRIPTION}

Based on 5 males and 5 females from lot WE 79-15, and 18 cleared and stained specimens (ROM 517CS). D VI + I 9-10 (9.1), fourth spine longest, reaching base of second dorsal-fin spine, last ray reaching to, or to within two scales of, unbranched caudal-fin rays; A 18 , last ray to within one to three scales of unbranched caudal-fin rays; $\mathrm{P}$ 18-19 (18.7), reaching posteriorly to a vertical between urogenital papilla and anal-fin origin; V 15 , fraenum with smooth, concave posterior margin; full basal membrane, all rays branched, reaching posteriorly to anus. Lateral scales 36-37 (36.6); transverse scales 11-13 (12.4); predorsal scales 6-11 (7.4), reaching anteriorly to region above pectoral-fin base. Cycloid scales on nape, pectoral-fin base, breast, and midline of belly, other scales ctenoid. Gill opening restricted to region between pectoral base and vertical limb of preopercle. Mouth terminal, inclined very slightly upwards. Teeth as for $B$ a albopunctatus, except that inner row of enlarged teeth in lower jaw represented by one to two strongly hooked canines at bend of dentary, canines poorly developed or absent in females. Anterior nostril a short tube, posterior porelike. Tongue broadly rounded, with a prominent median notch. Mental fraenum with concave posterior margin and well-developed, free lateral edges. First gill slit open to hypobranchial ventrally; $1+7$ gill rakers. Dorsal pterygiophore formula $3(2,2,1,1,0)$; vertebrae 10 $+16+$ ural centrum $=27$. As percentage standard length: head length 28-32 (30.2); origin of first dorsal fin $37-41$ (38.2); origin of second dorsal fin 56-59 (58.0); origin of anal fin 57-62 (59.5); caudal-peduncle length 23-26 (24.2). As percentage head length: eye diameter 26-32 (29.9); snout length 21-26 (24.3); upper-jaw length 27-43 (38.2). Caudal-peduncle depth as percentage caudal-peduncle length 45-56 (49.5). Head pores and papillae as in Fig. 20. Caudal skeleton as for $B$. albopunctatus.

Gut contained polychaetes, isopods, amphipods (including caprellids), and brachyurans.

Colour pattern (freshly dead, $32.6 \mathrm{~mm}$ SL male): background sandy (light yellow-brown), with numerous diffuse white spots sometimes aligned into longitudinal stripes on body. Spots intermittent along midlateral scale row, resulting in a series of brown blotches. First dorsal fin with pale bands proximally and distally, separated by a dusky band of melanophores. Second dorsal fin similar, but with one or two rows of white spots on shafts of fin rays in dusky band. Caudal fin with four very irregular

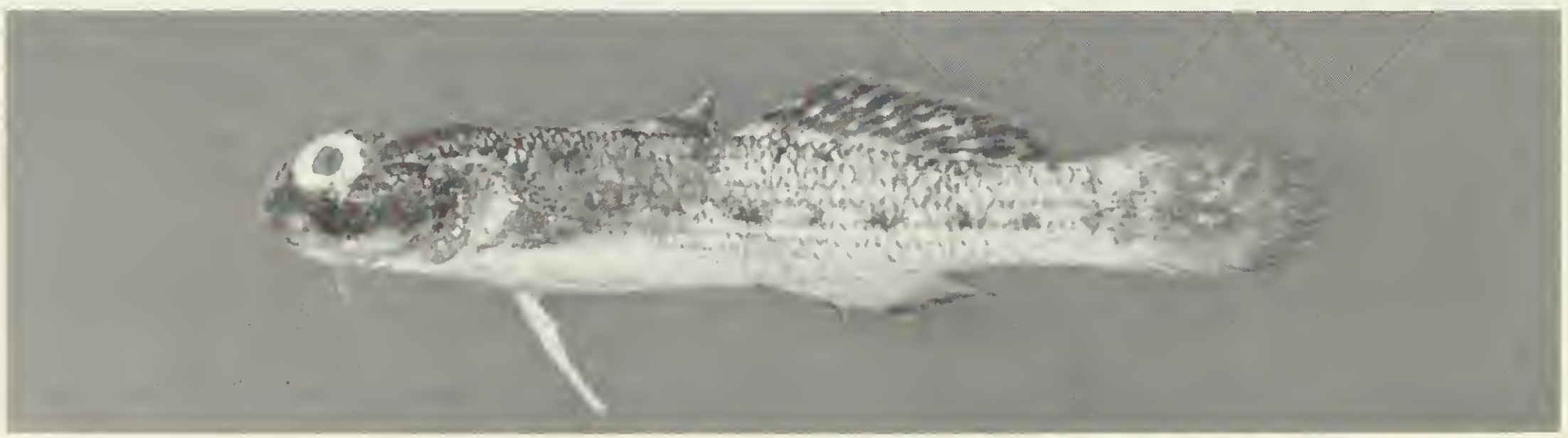

Fig. 19. Left lateral view of Bathygobius cocosensis, $26.3 \mathrm{~mm} \mathrm{SL}$ 

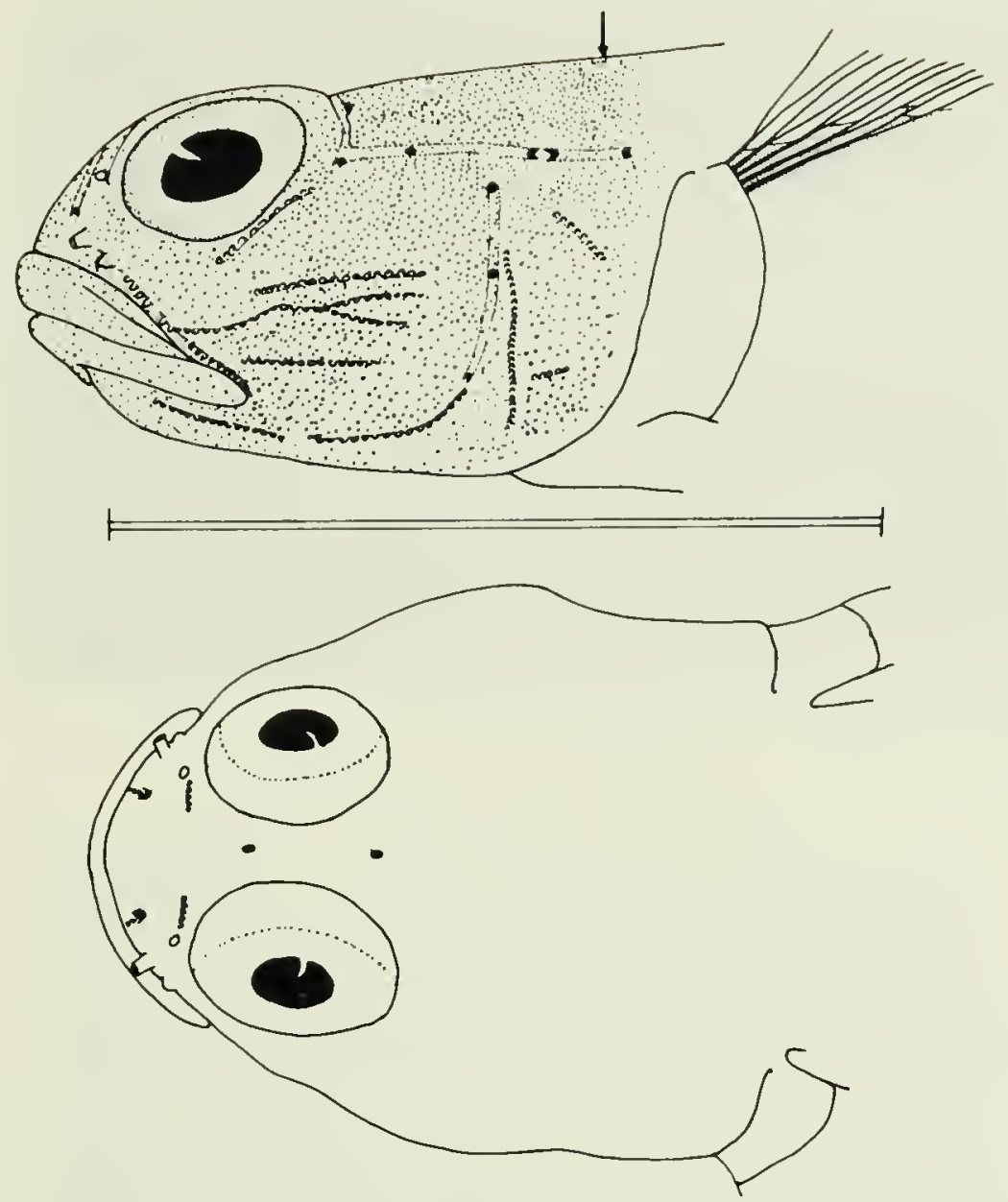

Fig. 20. Left lateral (above) and dorsal (below) views of the head of Bathygobius cocosensis, $30.4 \mathrm{~mm} \mathrm{SL}$, to show head pores, papillae, and pigmentation on head (each stipple point in upper figure represents one melanophore of approximately the same diameter; arrow indicates anterior extent of predorsal scales). Scale equals $1 \mathrm{~cm}$.

stripes of white spots on rays. Anal fin hyaline with dusky margin, pelvic and pectoral fins hyaline. Chin dusky. A $26.3 \mathrm{~mm}$ SL male similar in overall coloration, but very much darker, with head being almost black and scale pockets strongly outlined with a mixture of melanophores and brown chromatophores. Preserved: basically similar to above description.

\section{DISCUSSION}

Bathygobius cocosensis is widely distributed in the Indo-Pacific, from East Africa to at least Hawaii.

\section{Genus Bryaninops}

\section{Bryaninops ridens Smith}

Bryaninops ridens Smith, 1959:216 (Pinda, Mozambique).

\section{MATERIAL}

Two lots, 2 specimens, $10-12 \mathrm{~mm}$ SL. Depth range 0-10 $\mathrm{m}$, lagoon and reef-top at Eagle Island. Our specimens were identified for us by $\mathrm{H}$. K. Larson.

\section{Genus Cabillus}

Cabillus lacertops Smith

Figs. 21, 22

Cabillus lacertops Smith, 1959:207 (Pinda, Mozambique).

\section{MATERIAL}

One lot, 3 specimens, 25.1-30.3 mm SL. Depth range 12-15 m, lagoon at Peros Banhos.

\section{DESCRIPTION}

Based on the three specimens. D VI + I 9, third dorsal spine longest, but not extending beyond base of first dorsal fin; A I 8; P 17-18, longest rays not quite reaching to anus; V I 5, all rays branched, complete basal membrane, fraenum present, longest rays reaching posteriorly to origin of anal fin. Lateral scales 27 (one specimen damaged) extending just forward of pectoral-fin origin; transverse 9; no predorsal scales in midline but one specimen with scales present laterally anterior to dorsal-fin origin. Scales completely covering prepelvic area, but pectoral base and head naked. Scales on body all strongly ctenoid except slightly smaller and cycloid scales in small patch below anterior half of base of first dorsal fin, and of normal size and cycloid on belly and prepelvic regions. Gill opening restricted, lower edge of opercular fold at level of pectoral base. Mouth terminal or slightly underslung and oblique; upper and lower jaws with double inner row of conical teeth and shorter outer row of about seven enlarged, recurved canine teeth on each side of symphysis. Anterior nostril a truncate tube, posterior nostril porelike. Tongue truncate, enlarged at tip (appearing to be rolled over). First gill slit open; gill rakers $2+$ 7-8, on epibranchial short and somewhat fleshy, on ceratobranchial longer and not fleshy; pseudobranch with six lobes. Seven dorsal and 6 ventral unbranched caudal rays, with 14 branched caudal rays. As percentage standard length: head length 30-32 (30.9); origin of first dorsal fin 35-38 (36.3); origin of second dorsal fin 52-58 (56.0); origin of anal fin 61-64 (62.0); caudal-peduncle length 21-22 (21.1). As percentage head length: eye diameter 34-37 (34.8); snout length 18-22 (20.8); upper-jaw length 29-34 (31.6). Caudal-peduncle depth as percentage caudal-peduncle length 42-46 (44.4). Head pores and papillae as in Fig. 22.

Stomach short, heavy walled; intestine short, almost straight. Gut contents of $30.3 \mathrm{~mm}$ female with crustacean remains exclusively: amphipod legs in lower intestine, one calanoid copepod and two unidentified crustaceans (possibly cumaceans).

Colour pattern (freshly dead): background pale to tan, with darker small brown spots scattered over body, and a series of larger pearly white spots on head and body. Single, anteriorly directed, elongate dark spot below each 


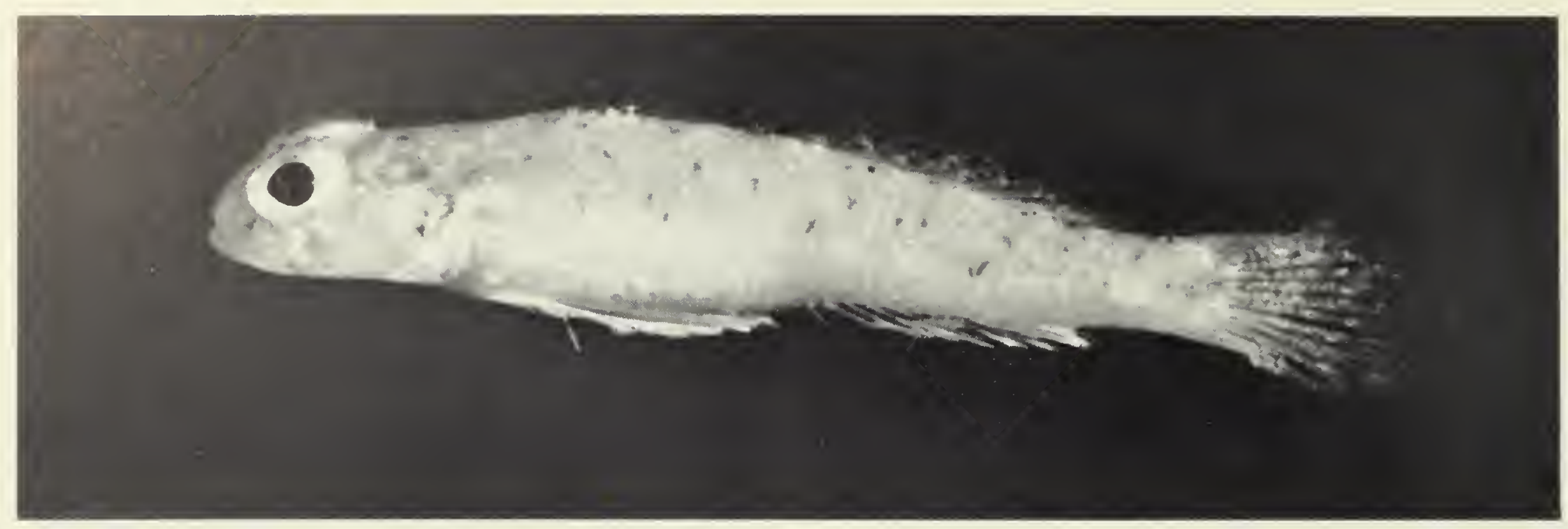

Fig. 21. Left lateral view of Cabillus lacertops, $31.1 \mathrm{~mm} \mathrm{SL}$.
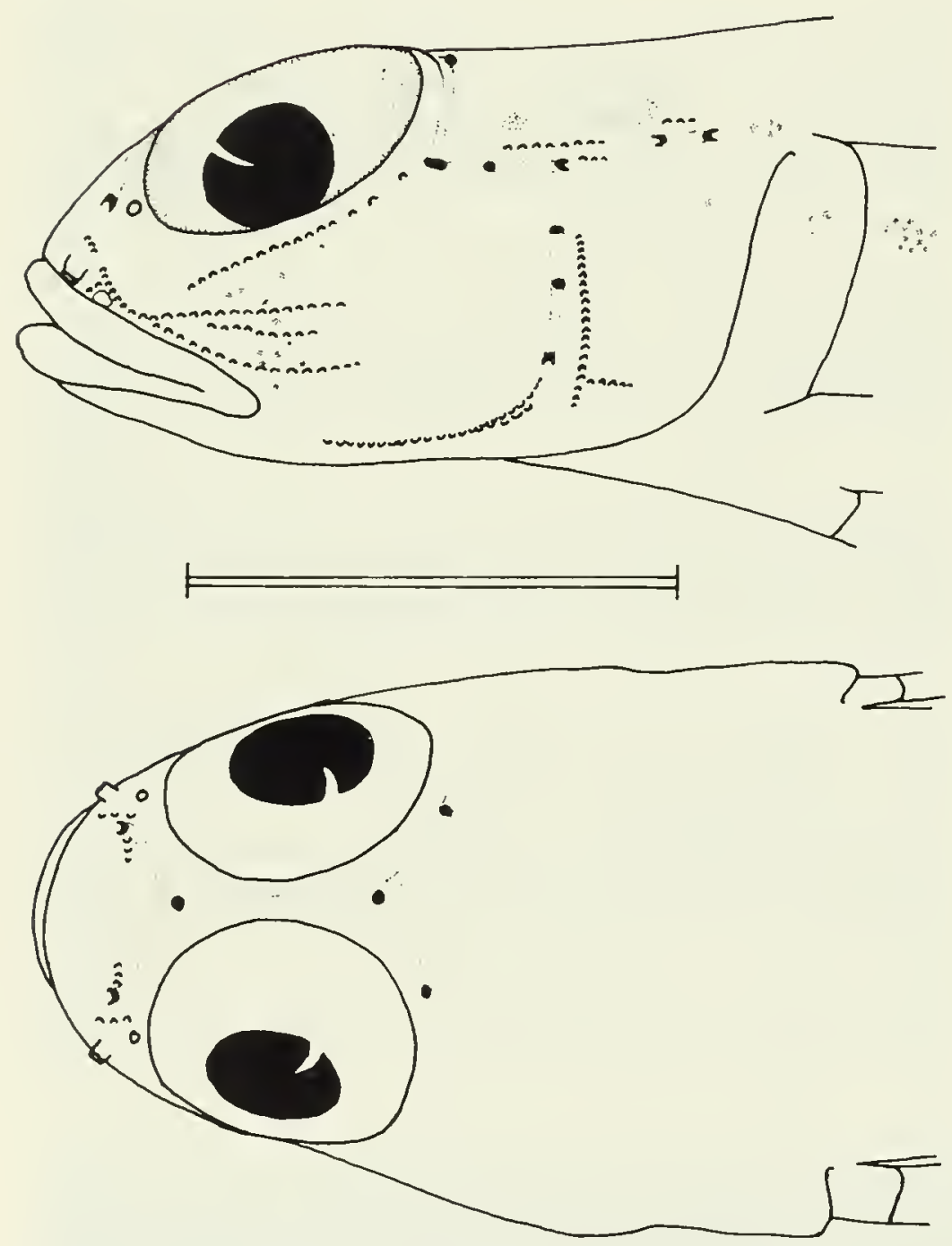

Fig. 22. Left lateral (above) and dorsal (below) views of the head of Cabillus lacertops, $30.3 \mathrm{~mm} \mathrm{SL}$, to show head pores, papillae, and head pigmentation. Scale equals $5 \mathrm{~mm}$. eye. Several brown spots on top of eye, on upper edge of operculum, and laterally on nape. Pectoral base essentially brown, with large pearl white band through middle of base. Diffuse brown spot at origin of first dorsal fin. Both white and brown spots scattered randomly on rest of body. Large prominent patches of pearly white colour below eye and cheek and also on operculum. A white followed by a diffuse brown spot near end of caudal in midlateral line. Fins transparent with a few scattered dots of brown or white present on membranes, except slightly more opaque and whitish on pelvic fin.

\section{DISCUSSION}

Chagos specimens of $C$. lacertops are similar to the original description in sufficient degree to be considered conspecific, although there are several significant differences. Smith (1959:207) described the tongue as bilobed (vs truncate); he found no pelvic fraenum, whereas all our specimens have a well-developed fraenum. He described the colour as yellow, whereas ours were whitish with no obvious yellow present. He figured a large prominent elongate spot on the lateral midline of the caudal peduncle; in ours the spot was present, but diffuse at best. There were also minor differences in the scale counts: Smith-28 lateral, 8 transverse; Chagos-27 lateral, 9 transverse. The species extends from the Indian Ocean east to the Great Barrier Reef (Hoese, pers. comm.).

Cabillus tongarevae (Fowler)

Figs. 23, 24

Glossogobius tongarevae Fowler, 1927:27 (Tongareva Island); Gosline, 1971:284 (Line Islands and Hawaii).

\section{MATERIAL}

Five lots, 39 specimens, $11.5-29.7 \mathrm{~mm} \mathrm{SL}$. Depth range 0-1.0 m, lagoons only, at Eagle Island and Peros Banhos. 


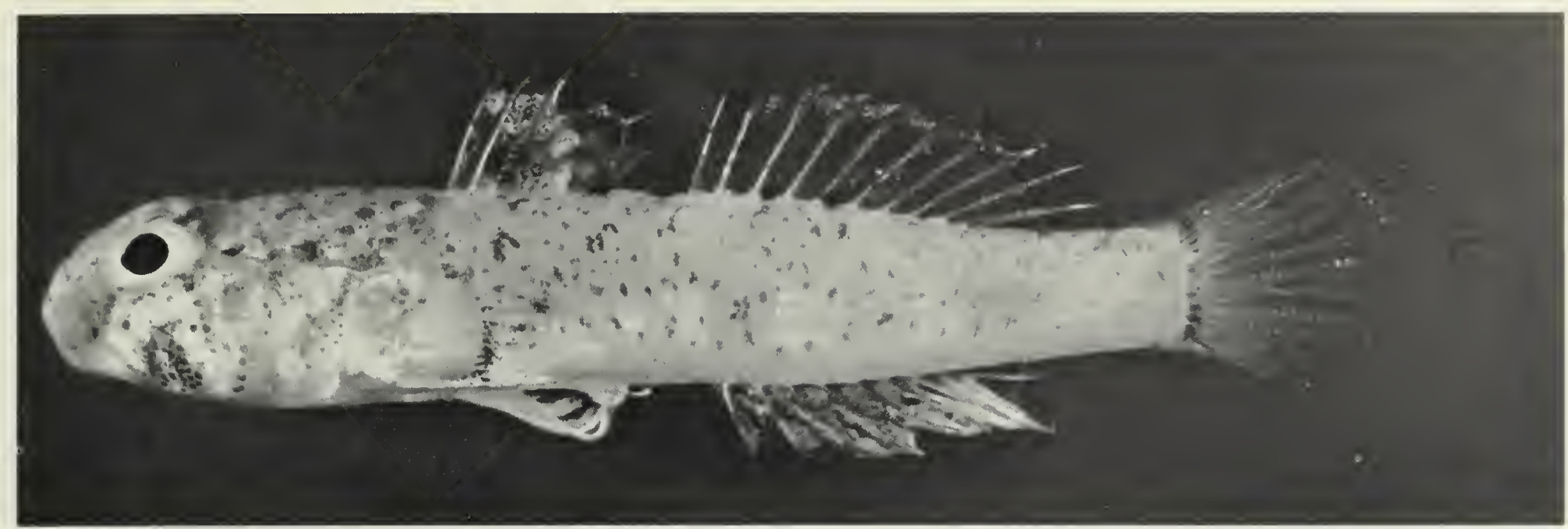

Fig. 23. Left lateral view of Cabillus tongarevae, $27.9 \mathrm{~mm} \mathrm{SL}$

\section{DESCRIPTION}

Based on 10 specimens from lots WE 79-37, WE 79-40, and WE $79-45(20.2-30.1 \mathrm{~mm} \mathrm{SL})$, plus 3 cleared and stained specimens from WE 79-41 (16-34 mm TL). D VI + I 9-10 (9.4), second and third spines longest, but not elongate; A 1 8-9 (8.3); P 16-18 (17.4; 16 only once), reaching to or beyond anus; V I 5, basal membrane complete to about 25-35\% length of the fin, fraenum present and strong on males and absent or weakly developed on females, fin reaching to or nearly to anus. Lateral scales 23-25, usually 23; transverse scales 9-10, rarely 10. Predorsal area and pectoral-fin base naked, prepelvic area with single cycloid scale. Scales on rest of body strongly ctenoid. Gill opening partly restricted, reaching to ventral edge of pectoral-fin base. Mouth terminal, inclined somewhat dorsally; upper jaw with 2 or 3 curved, enlarged canines anteriorly in outer row, followed by 12 to 14 smaller conical teeth, and 2 or 3 inner rows of small conical teeth. Lower jaw with four or five curved, enlarged conical teeth in anterior part of outer row, not followed by smaller teeth, but with one or two irregular inner rows of smaller conical teeth. Anterior nostril tubular, posterior porelike. Tongue bilobed, rounded. First gill slit closed by membrane anteriorly for approximately one-quarter to one-half of its length; gill rakers short fleshy knobs $0-1+5-6$ (5.9); pseudobranch with four or five lobes. Five branchiostegal rays. Dorsal pterygiophore formula $3(2,2,1,1,0)$; vertebrae $10+15+$ ural centrum $=26$. Seven dorsal and seven ventral branched caudal-fin rays, with six dorsal and five ventral unbranched caudal-fin rays. As percentage standard length: head length 29-33 (31.6); origin of first dorsal fin $30-40$ (36.7); origin of second dorsal fin 55-60 (57.2); origin of anal fin 61-65 (62.4); caudal-peduncle length 13-21 (17.4). As percentage head length: eye diameter 29-38 (33.2); snout length 17-23 (20.4); upper-jaw length 33-46 (38.3). Caudal-peduncle depth as percentage
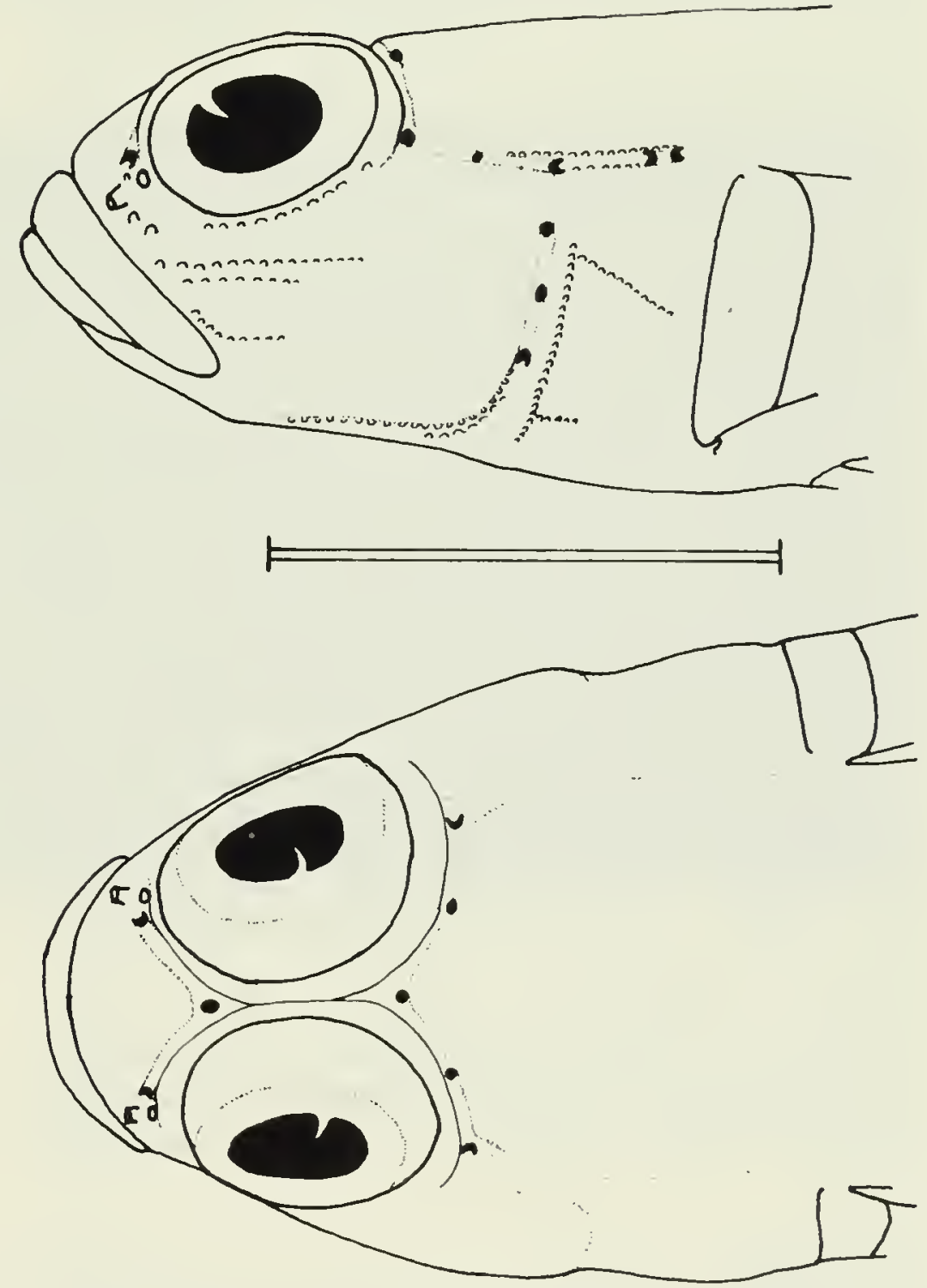

Fig. 24. Left lateral (above) and dorsal (below) views of the head of Cabillus tongarevae, $24.0 \mathrm{~mm} \mathrm{SL}$, to show head pores and papillae. Scale equals $5 \mathrm{~mm}$. 
caudal-peduncle length 44-84 (59.8). Head pores and papillae as in Fig. 24. Caudal skeleton as for A. hectori.

Intestine short with one large, simple loop, peritoneum colourless. Gut of $27.8 \mathrm{~mm}$ SL male included remains of mantid shrimps; gut of $23.9 \mathrm{~mm} \mathrm{SL}$ female included one juvenile specimen of Cabillus tongarevae, indicating possible cannibalistic habit.

Colour pattern (freshly dead): background pale with brown, black, and white spots or blotches. Most prominent markings on body are randomly spaced brown blotches, each about size of scale. In addition, three or four large blotches (one-third of body depth in diameter) just below lateral line in a row beginning posterior to pectoral base. A large, inverted, U-shaped saddle of white under eye enclosing a patch of dark ground colour. Two other large white patches present, one on opercle and one on pectoral-fin base. All patches containing a series of bright blue dots, each dot individually surrounded by a black ring; dots densely concentrated in the patch of dark ground colour below the eye. First dorsal fin transparent but marked conspicuously with black dots on outer margin, in large patch near its base extending from second to fifth spine and in two smaller patches of black, one at base of sixth spine and one at confluence of fin membrane and dorsal surface of body. In addition, wide band of white dots curving from mid-fin height at first spine to fin base posterior to fifth spine. Second dorsal fin similarly edged with black dots, but with band of white dots immediately below dark margin extending length of fin. A brown-black spot below each of second and fourth dorsal rays. Anal fin smudged with white marks, otherwise transparent. Pelvic fin of females unmarked; of males darkly pigmented with black on at least some rays. Pectoral fin marked at about one-quarter of its length with crescent-shaped black bar that is approximately one-half of fin width. Beyond this bar, fin smudged with white, otherwise transparent. Upper half of caudal fin with wide black margin, lower margin transparent. Brown band of about one scale width extending from upper to lower margin of caudal-fin base. Otherwise, fin transparent except for a few flecks of brown colour scattered on rays. Preserved: black and brown pigments remaining apparent, but white and blue disappearing to resemble pale ground colour.

\section{DISCUSSION}

Cabillus tongarevae was originally described in the genus Glossogobius, and has been referred to in the literature by the same name (Gosline, 1971). We use the genus Cabillus (described by Smith, 1959) on the advice of $\mathrm{Dr}$ D. F. Hoese. Aside from this species and C. lacertops, the type species, he includes only C. macropthalmus (Weber) (Hoese, ms.). Fowler's (1927) description of C. tongarevae agrees in many aspects with our specimens, but differs in the number of dorsal-fin rays. Fowler stated that there are five dorsal-fin rays, but he figures seven; our specimens all have eight or nine. He also showed scales in advance of the dorsal fin, although his text indicated there were none, and thus his text gave 23 as the number of scales in lateral series (agreeing with our number), but there were 26 or 27 on his drawing. Our reexamination of the holotype indicates there are nine dorsal rays and no scales in advance of the dorsal fin. Thus, we conclude that our specimens are $C$. tongarevae.

\section{Genus Callogobius}

This genus is currently under study by Lachner and McKinney, to whom we have sent our material; no descriptions are offered here. However, we provide figures of freshly dead specimens where available. The following identifications were provided.

\section{Callogobius sp. 3}

\section{MATERIAL}

Three lots, 4 specimens, 13.4-24.7 mm SL. Depth range 0.5-32 m, lagoon and drop-off at Peros Banhos and Salomon.

\section{Callogobius centrolepis Weber}

Callogobius centrolepis Weber, 1909:157 (Bawean).

\section{MATERIAL}

Four lots, 23 specimens, 11.2-40.0 mm SL. Depth range 5-25 m, lagoon and drop-off at Salomon.

Callogobius flavobrunneus (Smith)

Fig. 25

Mucogobius flavobrunneus Smith, 1958:145 (Pinda, Mozambique; also East African coast from Bazaruto to Pemba, and Seychelles).

\section{MATERIAL}

Three lots, 20 specimens, 16.6-29.4 mm SL. Depth range $0-10 \mathrm{~m}$, lagoons only, at Peros Banhos and Salomon.

Callogobius maculipinnis (Fowler) Fig. 26 Drombus maculipinnis Fowler, 1918:69 (Philippines).

\section{MATERIAL}

Three lots, 6 specimens, 22.2-35.7 mm SL. Depth range 0-7 m, lagoons only, at Peros Banhos, Salomon, and Three Brothers. 


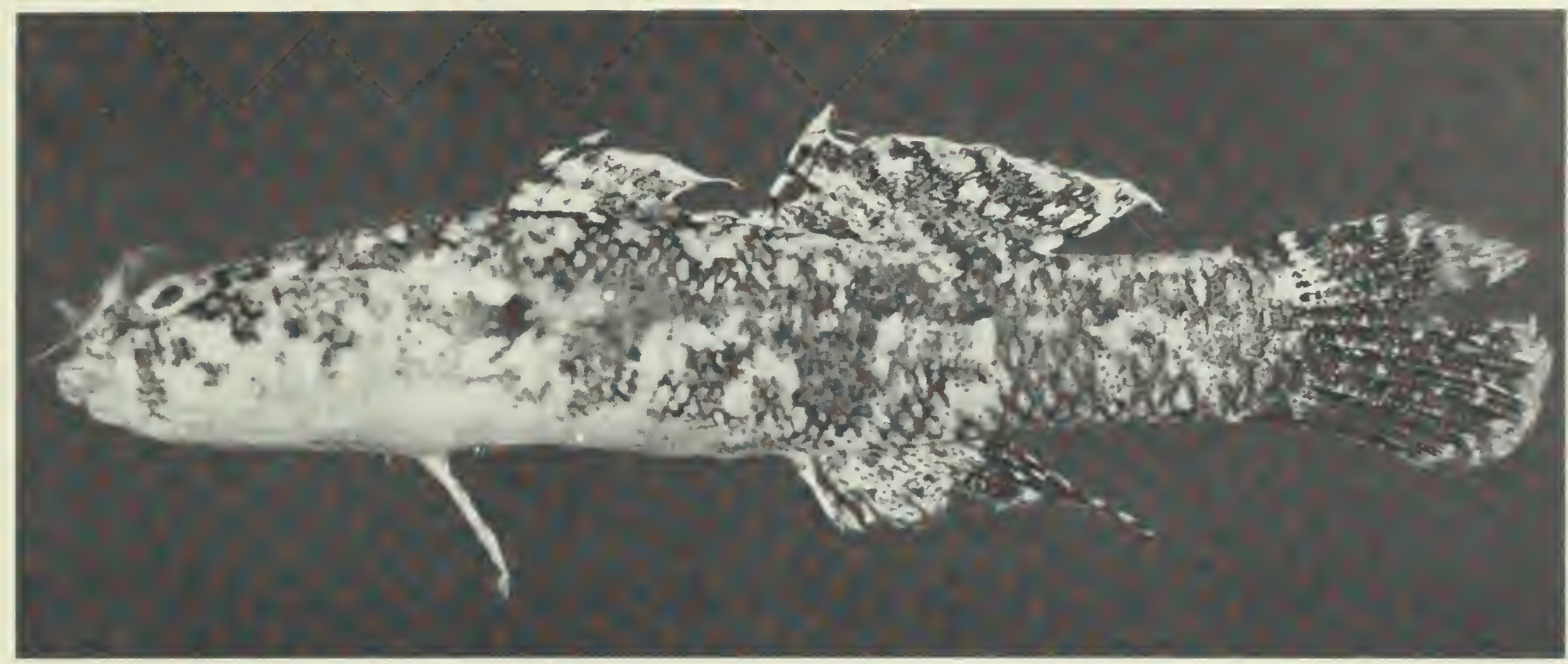

Fig. 25. Left lateral view of Callogobius flavobrunneus, $23.0 \mathrm{~mm} \mathrm{SL}$.

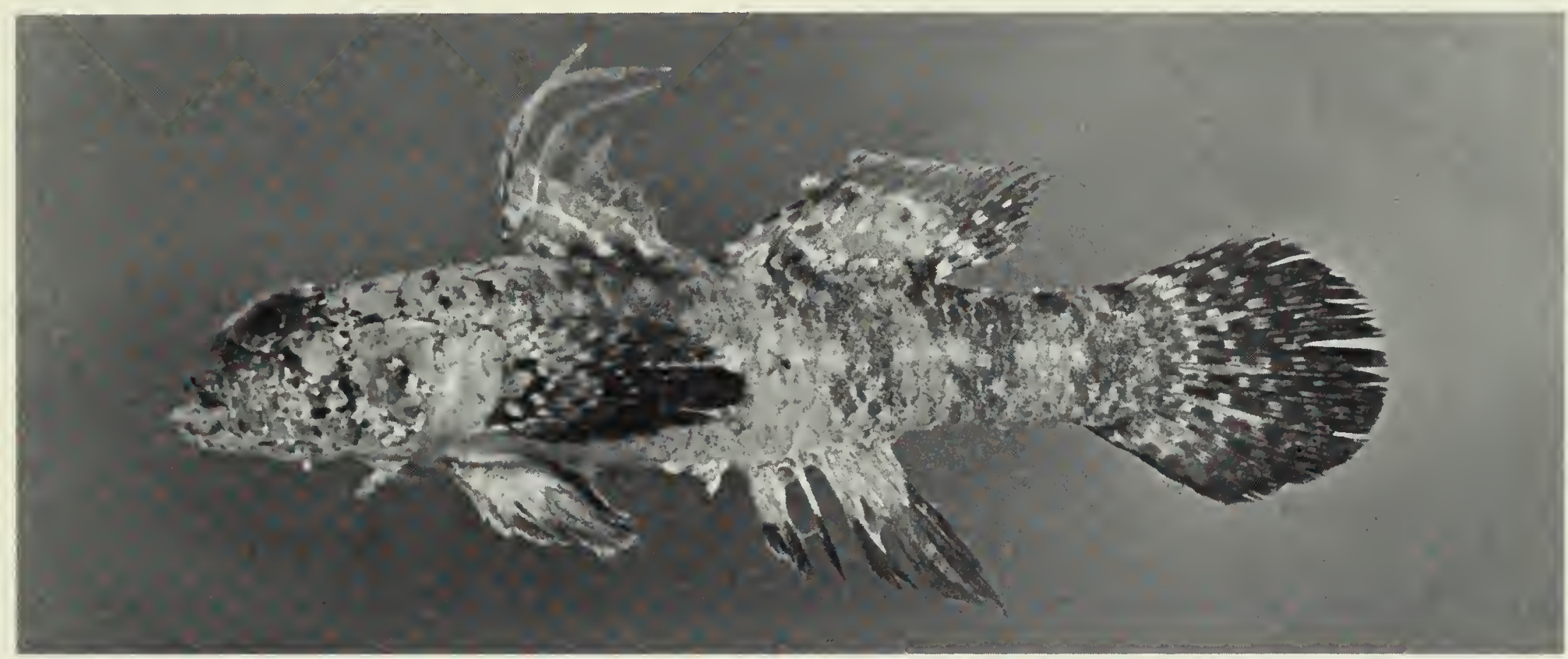

Fig. 26. Left lateral view of Callogobius maculipinnis, $33.7 \mathrm{~mm} \mathrm{SL}$.

\section{Callogobius sclateri (Steindachner)}

Fig. 27

Eleotris sclateri Steindachner, 1880:157 (Society Islands).

\section{MATERIAL}

Five lots, 11 specimens, 9.7-27.2 mm SL. Depth range 0-36 m, intertidal, reef-top, and drop-off at Eagle Island, Peros Banhos, and Salomon.

\section{Genus Cryptocentrus}

Cryptocentrus cryptocentrus (Valenciennes) Figs. 28, 29 Gobius cryptocentrus Valenciennes in Cuvier and Valen- ciennes, 1837:111 (Massawa, Red Sea).

Cryptocentrus octofasciatus Regan, 1908:241 (Diego Garcia).

\section{MATERIAL}

Four lots, 4 specimens, 26.1-73.4 mm SL. Depth range 0-2 m, lagoons only, at Diego Garcia and Salomon.

\section{DESCRIPTION}

Based on all specimens. D VI +110 , third and fourth spines longest, reaching to bases of first to third rays of second dorsal fin; A 1 9; P $16-17$ (16.7), reaching posteriorly to a vertical with end of first dorsal-fin base; $\mathrm{V}$ I 5, fraenum and basal membrane complete, reaching 


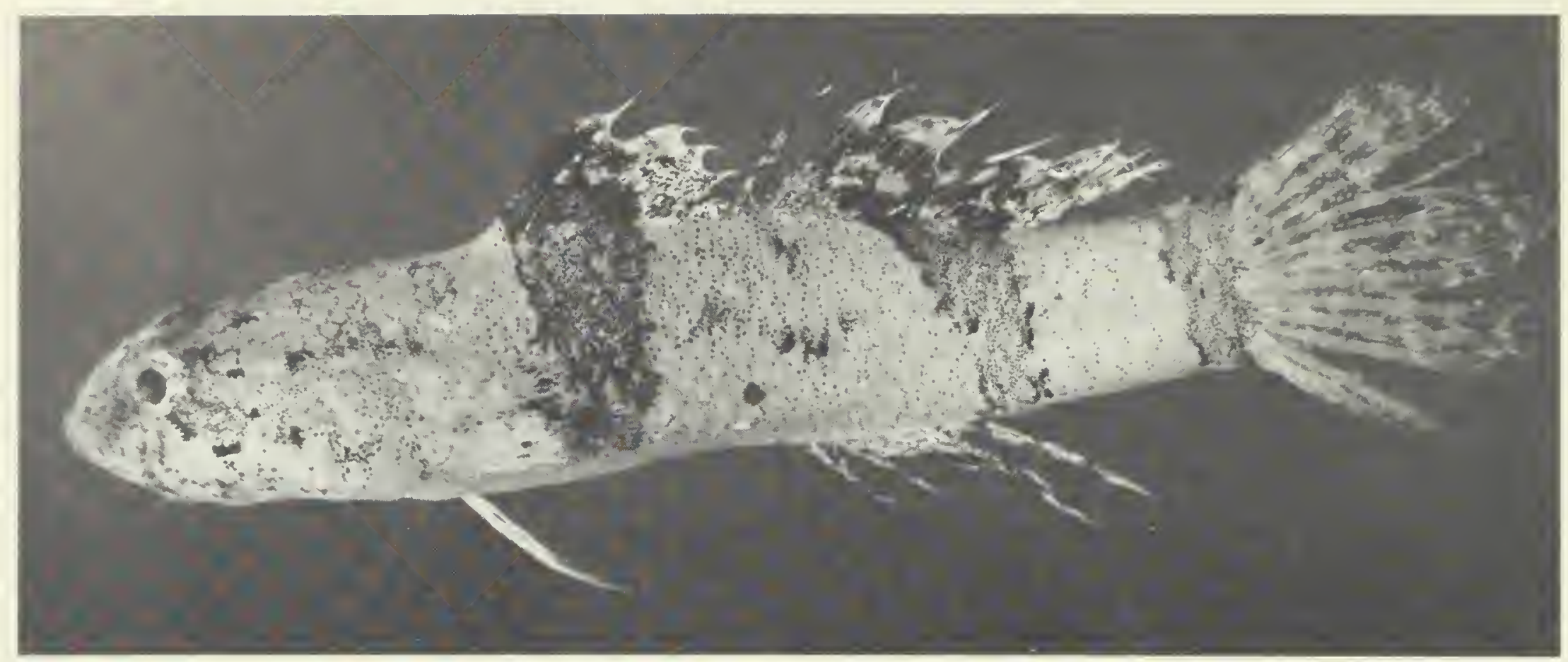

Fig. 27. Left lateral view of Callogobius sclateri, $23.1 \mathrm{~mm} \mathrm{SL}$.

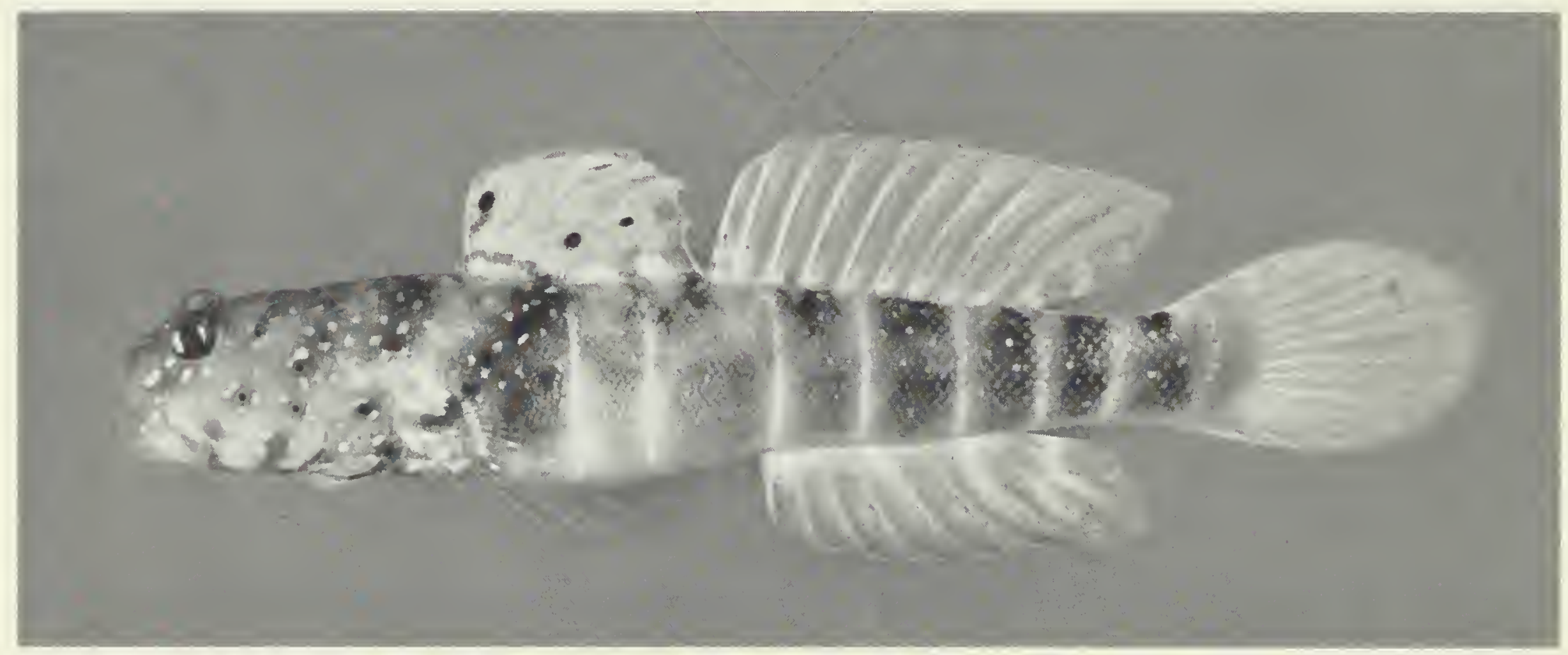

Fig. 28. Left lateral view of Cryptocentrus cryptocentrus, $58.8 \mathrm{~mm} \mathrm{SL}$.

posteriorly three-quarters of distance to anus. Lateral scales about 75; transverse about 35; predorsal 0-3. Head, prepelvic area, and pectoral-fin base naked; scales cycloid. Gill opening partly restricted, reaching a point ventrally between pectoral base and vertical limb of preopercle. Mouth terminal, slightly inclined dorsally; outer teeth in both jaws enlarged and curved; several inner rows of small conical teeth. Anterior nostril tubular, posterior porelike. Tongue truncately rounded. Anteroventral margin of subopercle with a forwardly directed spine. First gill slit open; $2-4+11$ gill rakers; pseudobranch with seven to nine lobes. Five branchiostegal rays. As percentage standard length: head length 28-31 (29.2); origin of first dorsal fin 35-37 (35.7); origin of second dorsal fin 56-58 (56.4); origin of anal fin 62-64 (63.3); caudal-peduncle length 19-20 (19.1). As percentage head length: eye diameter 18-23 (19.9); snout length 24-27 (24.8); upper-jaw length 40-47 (44.0). Caudal-peduncle depth as percentage caudal-peduncle length 55-59 (56.9). Head pores and papillae as in Fig. 29.

Peritoneum black. Gut of $72.5 \mathrm{~mm}$ SL female contained remains of a bivalve mollusc, amphipods, isopods, copepods, ostracods, bits of vascular plants, and detritus.

Colour pattern (freshly dead): background grey-brown, darker above, with seven vertical, narrow white bands across body beginning at base of the fourth spine of first dorsal fin and ending on caudal peduncle. Anterior and 

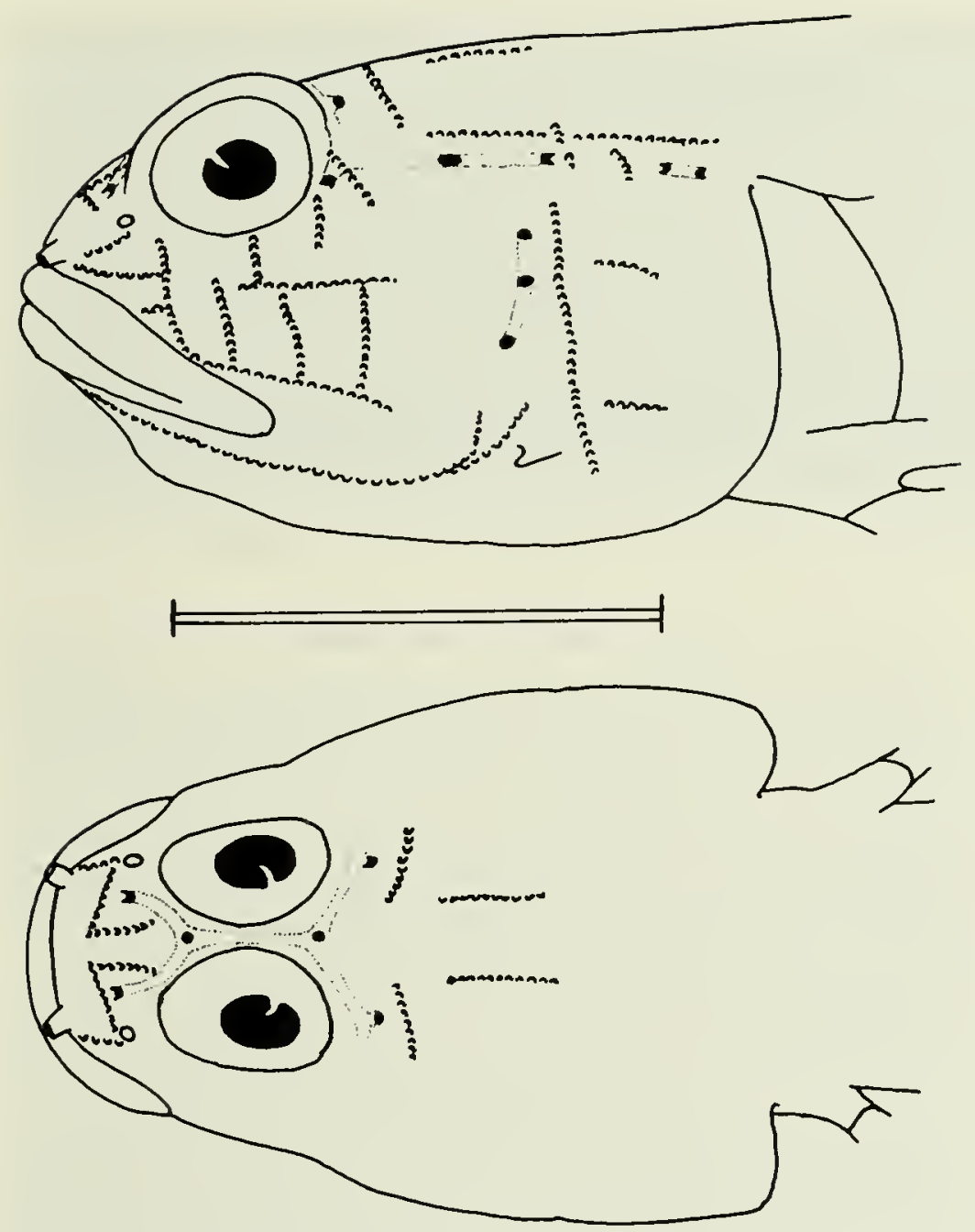

Fig. 29. Left lateral (above) and dorsal (below) views of the head of Cryptocentrus cryptocentrus, $26.1 \mathrm{~mm} \mathrm{SL}$, to show head pores and papillae. Scale equals $5 \mathrm{~mm}$.

posterior one-third of body (including head) covered with bright sky blue spots, about pupil size, lighter in centres than at edges. A few similar spots adjacent to dorsal fins in middle one-third of body. Head and nape with sprinkling of rusty coloured spots and blotches, some having small jet black spots at centres. White spots and blotches on pectoral fin and fin base. First dorsal fin with or without a scattering of black spots. Dorsal, anal, and caudal fins with a varied pattern of light salmon pink suffusions, pelvics dusky, pectoral hyaline. Preserved: similar to above, but blue spots very light, rusty spots no longer visible, and median fins dusky.

\section{DISCUSSION}

There are certain differences between Red Sea specimens and those from the Indian Ocean. Smith (1959) recorded C. octofasciatus from Natal and East Africa to Seychelles, and stated that it had about 90 lateral scales and $2+10$ gill rakers. His figure (pl. 10D) showed seven vertical white bands. He also recorded Cryptocentroides cryptocentrus (Val) from the Red Sea, and reproduced Ehrenberg's figure (as pl. 13L). Goren (1979) reported on nine Red Sea specimens, recording 70-90 scales, $2+13$ gill rakers, a bilobed tongue, and eight to nine vertical bands . Specimens from the Seychelles had 80-108 lateral scales, $?+12$ gill rakers, and seven to eight vertical white bands (Polunin and Lubbock, 1977). Chagos specimens had about 75 lateral scales, $2-4+11$ gill rakers, a truncately rounded tongue, and seven vertical white bands. Our specimens appear conspecific with Smith's (1959) and the different count of lateral scales could be due to different methods of counting. We believe that the Red Sea population is at most a geographical variant (and hence use C. cryptocentrus). If two species are involved, Regan's $C$. octofasciatus is an available name for the Indian Ocean form.

\section{Genus Ctenogobiops}

Ctenogobiops crocineus Smith

Figs. $30-32$

Ctenogobiops crocineus Smith, 1959:191 (Mahé, Seychelles); Lubbock and Polunin, 1977:505 (Red Sea; Seychelles; Great Barrier Reef).

\section{MATERIAL}

Four lots, 5 specimens, 20.7-45.0 mm SL. Depth range 3-13 m, lagoons only, at Peros Banhos and Salomon.

\section{DESCRIPTION}

Based on all specimens (only fin and gill-raker counts taken from cleared and stained specimen-30.6 mm SL). D VI + I 11, second spine longest, reaching to between origin of second dorsal fin and base of second ray of that fin; A 1 10-11 (10.6); P 19, reaching to a vertical in line with base of third anal-fin ray; V I 5 , complete fraenum and basal membrane, reaching to anal-fin origin. Lateral scales 49-53; transverse 16-18; nape, head, and pectoral and prepelvic bases naked. Scales mostly ctenoid, becoming cycloid anteriorly and adjacent to dorsal and ventral midlines. Gill opening extending anteriorly to a point in vertical line with hind margin of eye. Mouth terminal, inclined obliquely upwards. Both jaws with outer row of enlarged, spaced, curved teeth followed by irregular rows of small conical teeth. Innermost row of teeth in upper jaw enlarged (subequal to outer row); innermost row of lower jaw teeth of one to three strong, curved canines at bend of dentary. Anterior nostril a very short conical tube, posterior porelike. Tongue roundly truncate with a deep median notch. First gill slit closed by membrane to posterior end of hypobranchial one; gill rakers $0-3+10(1+8$ ossified in cleared and stained specimen); pseudobranch with eight to nine lobes. Five branchiostegal rays. Dorsal pterygiophore formula $3(2,2,1,1,0)$; vertebrae $10+15+$ ural centrum $=26$. Seven dorsal and 7 ventral branched caudal-fin rays, with 12 dorsal and 10 ventral unbranched caudal-fin rays. As 


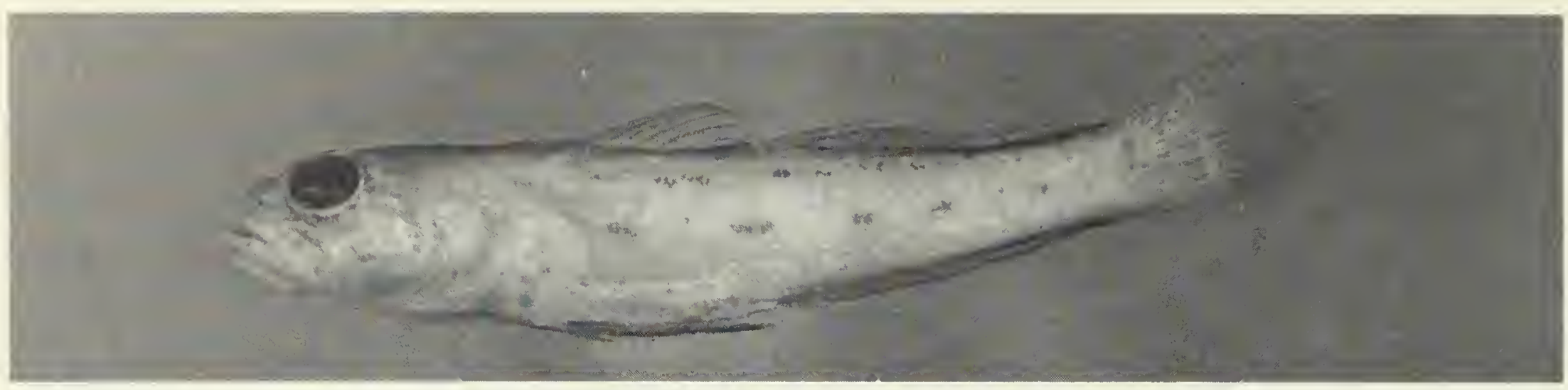

Fig. 30. Left lateral view of Ctenogobiops crocineus, $32.4 \mathrm{~mm} \mathrm{SL} \mathrm{(preserved).}$

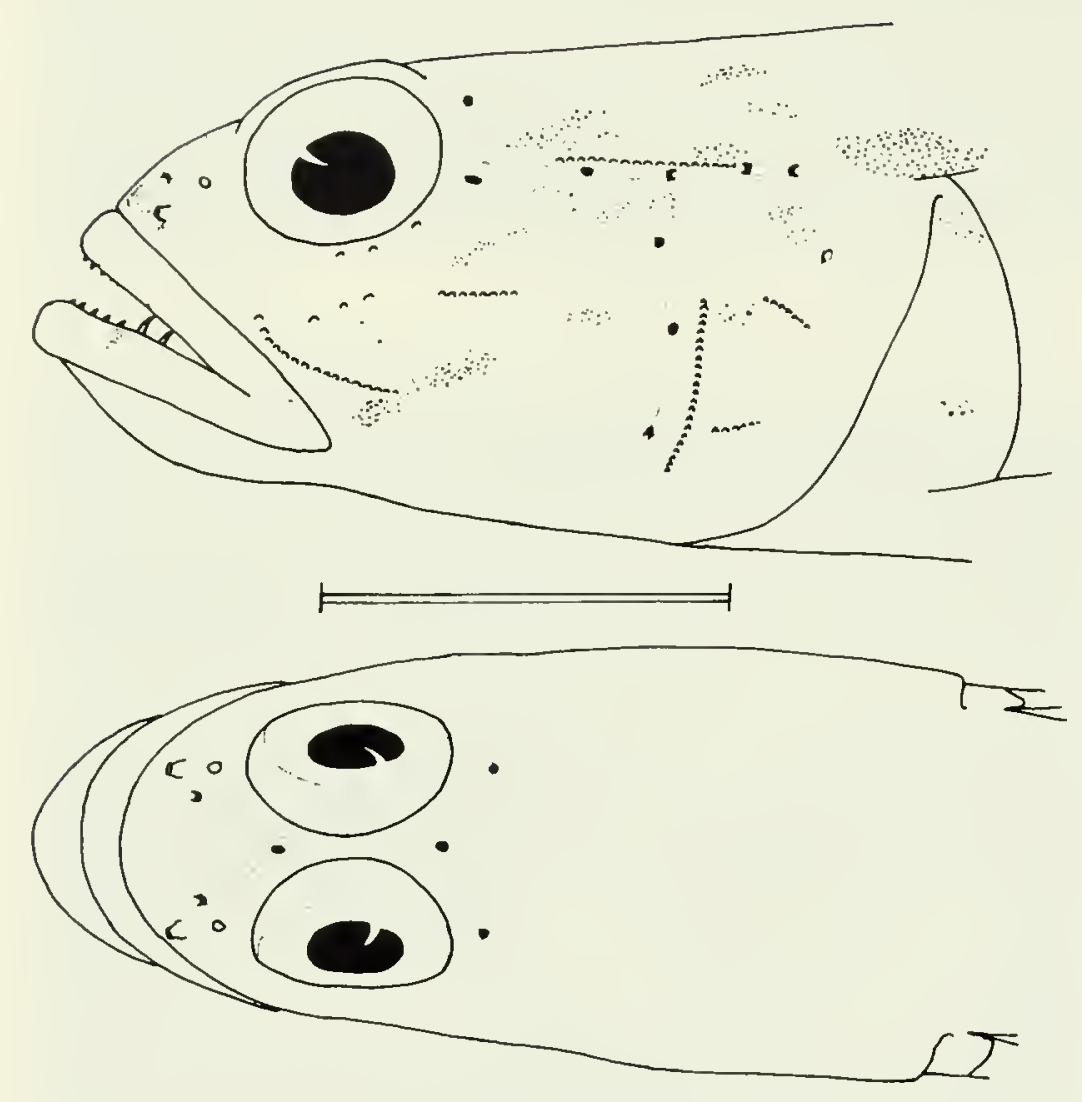

Fig. 31. Left lateral (above) and dorsal (below) views of the head of Ctenogobiops crocineus, $32.4 \mathrm{~mm} \mathrm{SL}$, to show head pores, papillae, and pigmentation (each stipple point represents one melanophore). Scale equals $5 \mathrm{~mm}$.

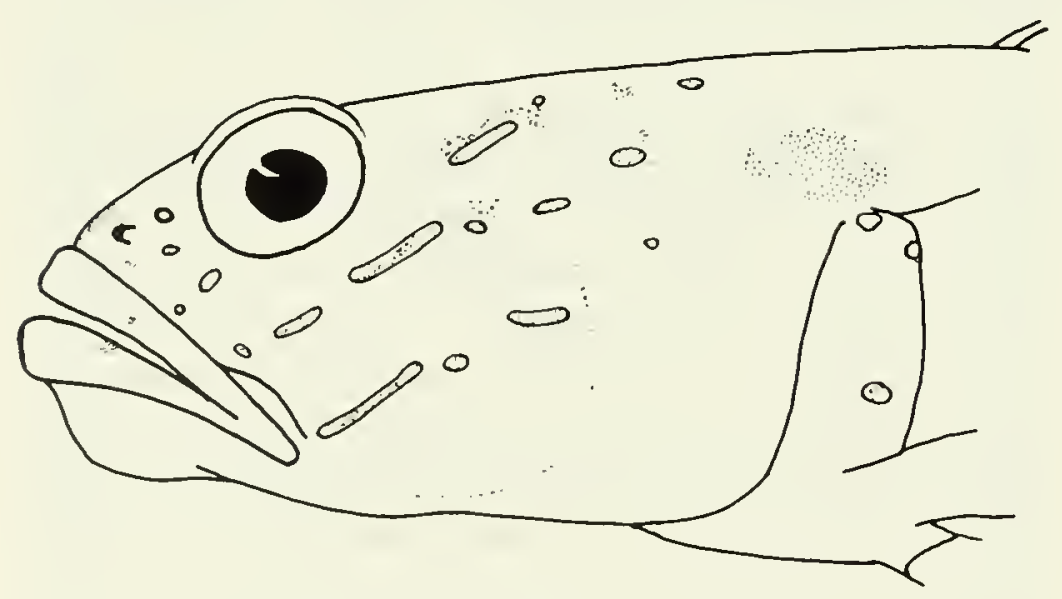

Fig. 32. Left lateral view of the head of Ctenogobiops crocineus, $45.0 \mathrm{~mm} \mathrm{SL}$, to show head pigmentation (light stripes and spots of iridocytes indicated by solid outline, melanophores stippled). Scale equals $5 \mathrm{~mm}$. percentage standard length: head length 33-36 (34.3); origin of first dorsal fin 38-42 (39.4); origin of second dorsal fin 57-59 (58.2); origin of anal fin 59-61 (59.9); caudal-peduncle length 21 (21.0). As percentage head length: eye diameter 20-24 (22.1); snout length 19-22 (20.5); upper-jaw length 38-42 (39.6). Caudal-peduncle depth as percentage caudal-peduncle length 47-53 (50.4). Head pores and papillae as in Fig. 31. Caudal skeleton as for $A$. hectori.

Intestine short, few coils; gut of cleared and stained specimen contained harpacticoids, caridean shrimps, and vertebrae of a small fish.

Colour pattern (freshly dead): not recorded. Preserved: two smaller specimens (20.7-27.7 mm SL) light tan without markings. Two larger specimens $(32.4-45.0 \mathrm{~mm}$ $\mathrm{SL}$ ) of light tan background with oblique stripes or rows of spots on head as in Fig. 32, and two rows of elongated brown spots or blotches on body. The upper elongated row passes from shoulder to dorsal surface of caudal peduncle; the lower is centred along midlateral scale row. A few other irregularly placed brown blotches. Tip of anal fin and midregion of pelvic fins dusky, otherwise fins hyaline.

\section{DISCUSSION}

Of the six species of Ctenogobiops recognized by Lubbock and Polunin (1977), Chagos specimens best fit the figure of $C$. crocineus. Only $C$. crocineus and $C$. tangaroai have the gill opening extending forward to a vertical in line with the hind margin of the eye, and the head stripes of the latter are horizontal rather than vertical. These head stripes in our largest specimen are primarily light (iridocytes) in colour and thus fit the colour pattern of $C$. maculosus. Indeed, the photograph published by Goren (1979, fig. 18) looks very much like our largest specimen. However, our specimen has the more anterior position of the gill opening, an inner row of enlarged teeth in the upper jaw, and the pattern of oblique head stripes and spots, although light, is that of $C$. crocineus rather than $C$. maculosus. The difference in number of gill rakers on the lower limb of the first arch used by Goren (1979:33) in his key appears less significant when the Chagos material is considered ( 8 for 
his C. maculosus; 11 for his $C$. crocineus-Smith, 1959:191 records 10-11; and there are 9 in the Chagos material).

\section{Genus Discordipinna}

\section{Discordipinna griessingeri Hoese and Fourmanoir}

Discordipinna griessingeri Hoese and Fourmanoir, 1978:21 (Gulf of Aqaba, Red Sea; also western Indian Ocean to Tahiti).

\section{MATERIAL}

One lot, I specimen, $12.7 \mathrm{~mm} \mathrm{SL}$. Depth range $18-25 \mathrm{~m}$, drop-off at Salomon.

\section{DESCRIPTION}

The original description of this genus and species is detailed, well illustrated, and recent, and only a brief description of the Chagos specimen is offered here. Head pore and papillae patterns as illustrated by Hoese and Fourmanoir (1978, fig. 1). Discordipinna is monotypic and may be distinguished from other gobioid genera by the following: five-spined first dorsal fin originating over opercular opening, second spine elongate, complete fraenum and basal membrane, wide gill opening, depressed head, posterior nostril with raised rim, and no preopercular head pores. $\mathrm{D} V+I 8$, second spine reaching to end of second dorsal-fin base, posterior rays of second dorsal fin elongate; A I 8, posterior rays elongate; $\mathrm{P} 18$, reaching to a vertical with end of anal-fin base; V 1 5. Gill opening to a point almost reaching a vertical with vertical limb of preopercle. Outer row of teeth in both jaws somewhat enlarged, followed by two inner rows. Lateral scales 24; gill rakers $2+7$, short knobs.

Colour pattern: as described by Hoese and Fourmanoir (1978). Chagos specimen resembling specimens from Red Sea and western Indian Ocean in colour pattern details, rather than those from the eastern Indian Ocean and Pacific.

\section{Genus Eviota}

This genus is currently under study by E. A. Lachner and S. L. Jewett (previously Karnella) at the Smithsonian Institution, to whom we sent all our material. The following identifications were kindly supplied by Jewett. No descriptions are provided here, but we include figures of freshly dead specimens where available.

\section{Eviota species A}

Fig. 33

\section{MATERIAL}

Eighteen lots, 134 specimens, 9.2-17.2 mm SL. Depth range $0.1-43 \mathrm{~m}$, lagoons and (primarily) drop-offs at Peros Banhos and Salomon. A new species, which will be described by Jewett and Lachner.

Eviota species B

Fig. 34

\section{MATERIAL}

One lot, 3 specimens, 11.5-12.6 mm SL. Depth $7 \mathrm{~m}$, lagoon at Three Brothers. A new species, which will be described by Jewett and Lachner.

Eviota species C

Fig. 35

\section{MATERIAL}

Six lots, 18 specimens, 10.8-15.8 mm SL. Depth range 0.1-7 m, lagoons only, at Eagle Island, Peros Banhos, and Salomon. A new species, to be described by Jewett and Lachner.

Eviota albolineata Jewett and Lachner

Fig. 36 Eviota albolineata Jewett and Lachner, 1983:783 (Tahiti; range East Africa to Tuamotus).

\section{MATERIAL}

Thirty-four lots, 183 specimens, 7.7-19.6 mm SL. Depth range 0-33 m, lagoons, intertidal reef-flats, reef-tops, and drop-offs at Eagle Island, Peros Banhos, Salomon, and Three Brothers.

Eviota distigma Jordan and Seale

Fig. 37

Eviota distigma Jordan and Seale, 1906:389 (American Samoa); Lachner and Karnella, 1978:7 (Indo-Pacific).

\section{MATERIAL}

Nine lots, 73 specimens, 5.9-16.0 mm SL. Depth range 0-22 m, lagoons only, at Eagle Island, Peros Banhos, and Salomon.

\section{Eviota infulata (Smith)}

Fig. 38

Eviotops infulata Smith 1956b:826 (Mahé, Seychelles; also Aldabra).

Eviota infulata-Lachner and Karnella, 1980:99 (widespread in tropical Indo-Pacific).

\section{MATERIAL}

Seven lots, 216 specimens, 5.3-13.0 mm SL. Depth range $0-32 \mathrm{~m}$, primarily lagoons (one specimen from edge of drop-off), at Peros Banhos and Salomon. 


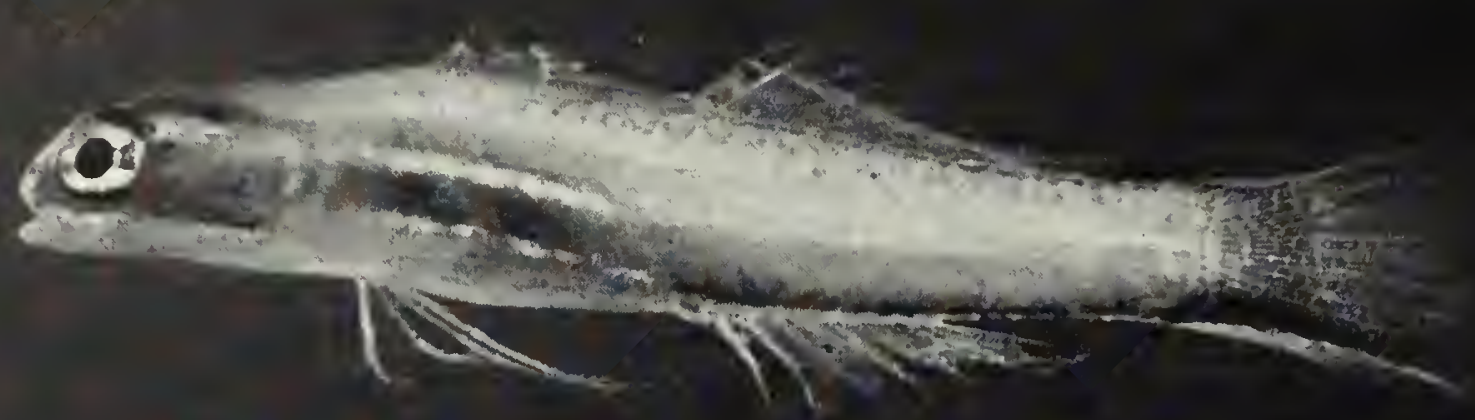

Fig. 33. Left lateral view of Eviota sp. A, $15.3 \mathrm{~mm} \mathrm{SL}$.

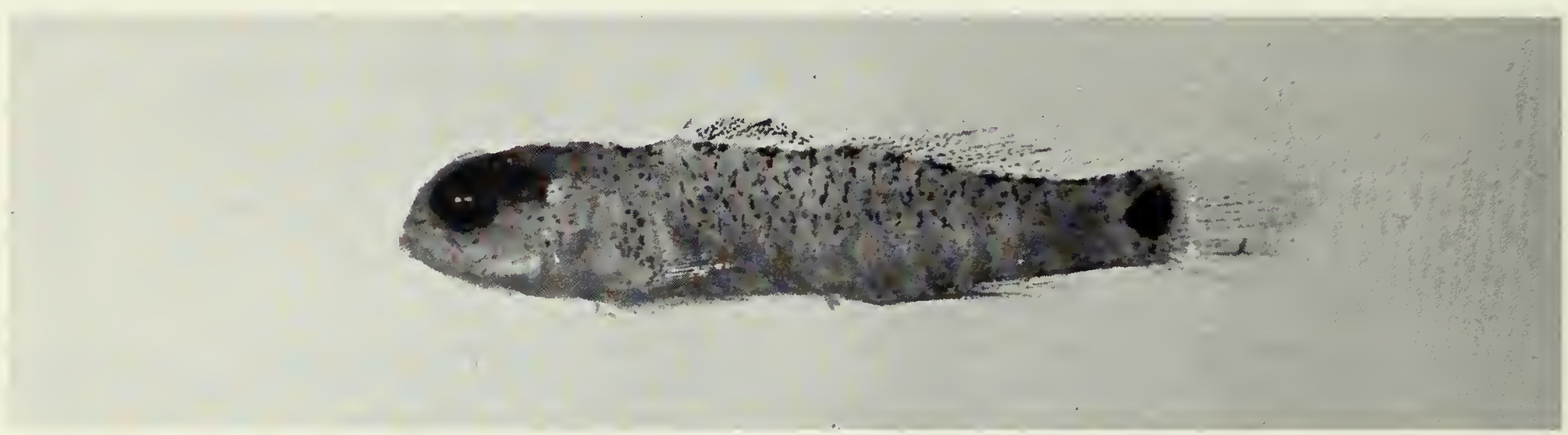

Fig. 34. Left lateral view of Eviota sp. B, $12.6 \mathrm{~mm} \mathrm{SL} \mathrm{(preserved).}$

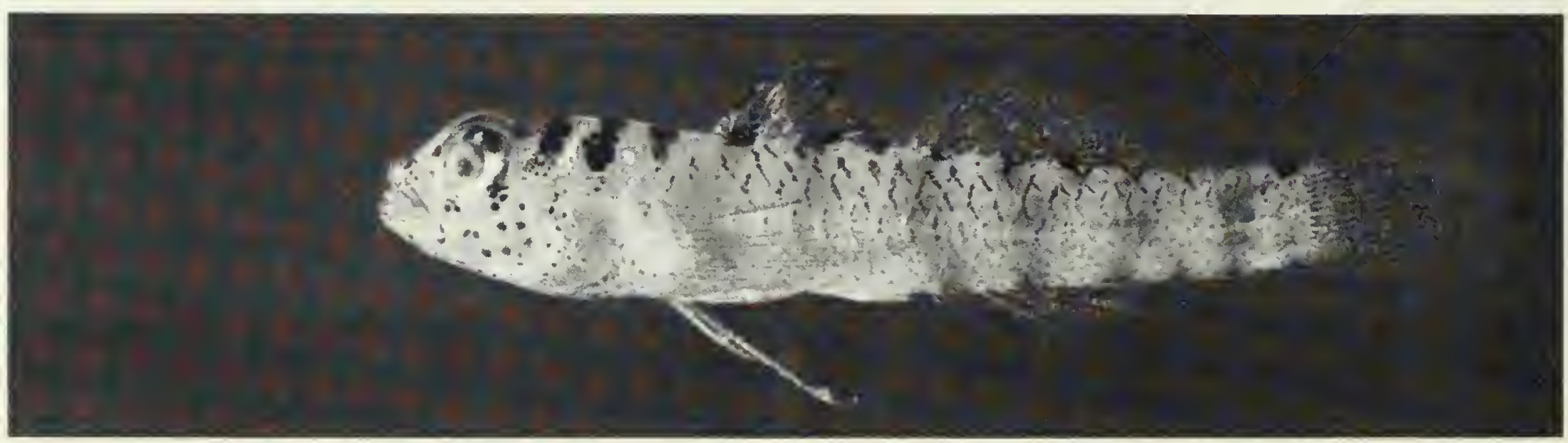

Fig. 35. Left lateral view of Eviota sp. C, $14.7 \mathrm{~mm} \mathrm{SL}$.

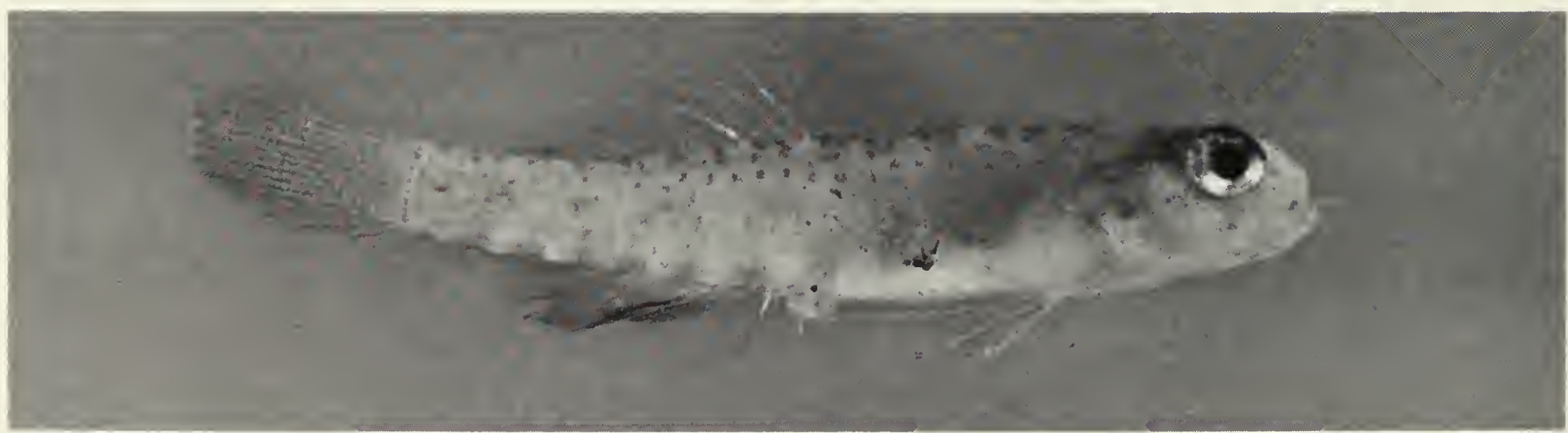

Fig. 36. Right lateral view of Eviota albolineata, $14.3 \mathrm{~mm} \mathrm{SL}$. 


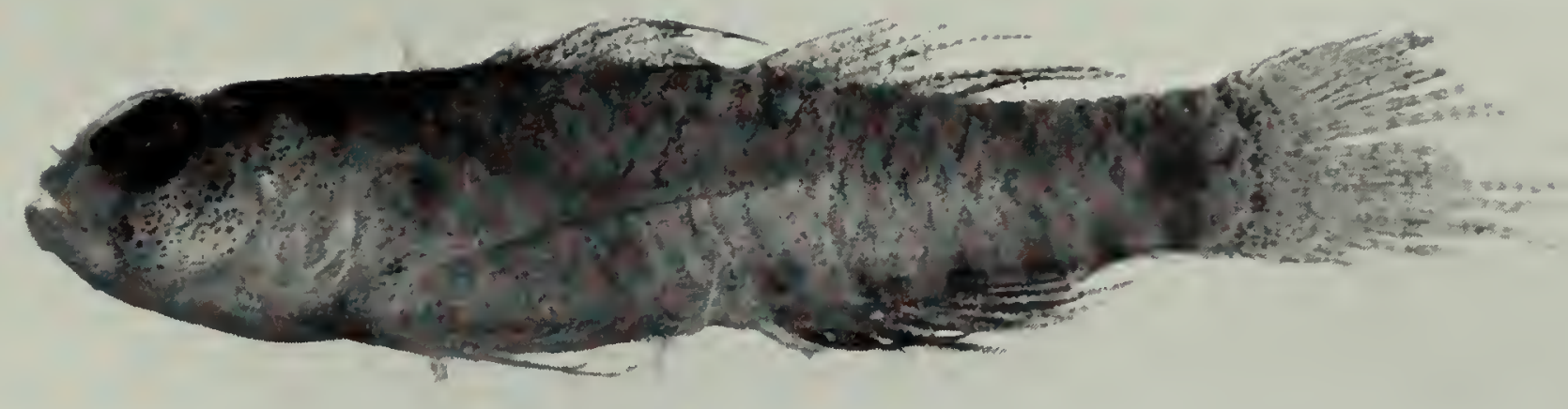

Fig. 37. Left lateral view of Eviota distigma, $15.6 \mathrm{~mm} \mathrm{SL}$ (preserved).

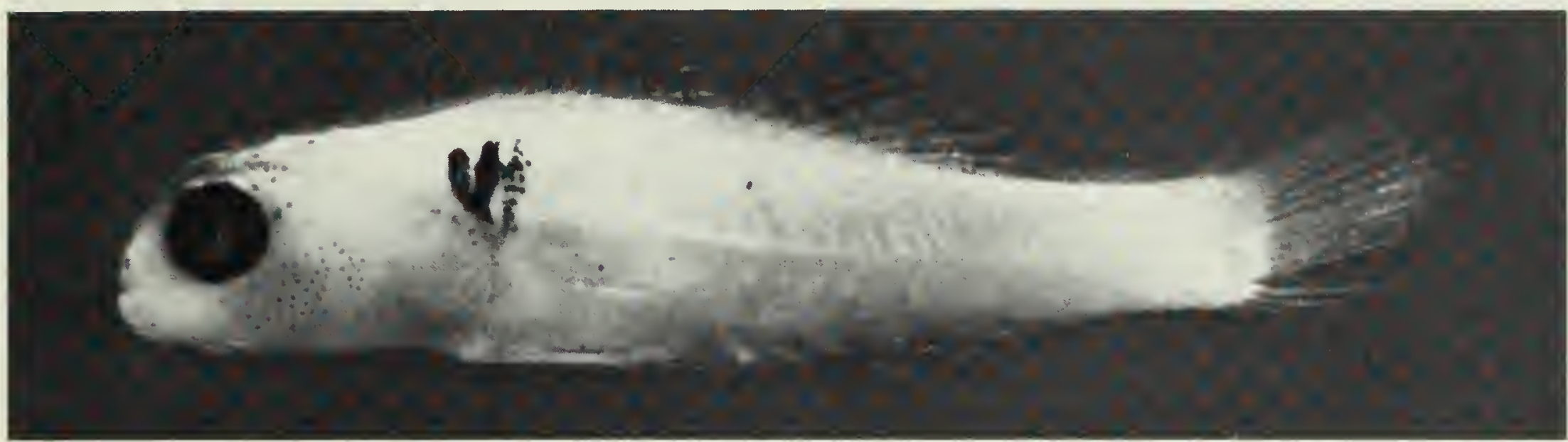

Fig. 38. Left lateral view of Eviota infulata, $11.6 \mathrm{~mm} \mathrm{SL} \mathrm{(preserved).}$

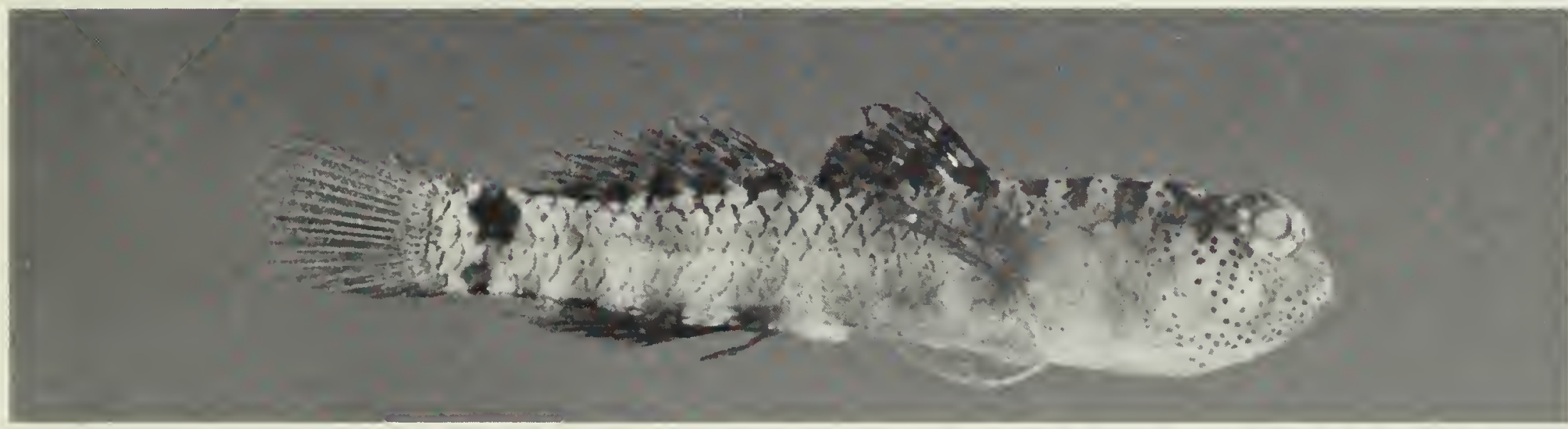

Fig. 39. Right lateral view of Eviota nebulosa, 13.3 mm SL.

Eviota nebulosa Smith

Eviota nebulosa Smith, 1958:141 (Pinda, Mozambique); Lachner and Karnella, 1980:34 (Indo-Pacific).

\section{MATERIAL}

Six lots, 31 specimens, 8.4-14.5 $\mathrm{mm}$ SL. Depth range 3-15 m, lagoon and reef-top at Peros Banhos and Salomon.

Fig. 39
Eviota nigripinna Lachner and Karnella

Fig. 40 Eviota nigripinna Lachner and Karnella, 1980:37 (Agalega Island; also western Indian Ocean, including Chagos).

\section{MATERIAL}

Nine lots, 41 specimens, 7.2-13.2 mm SL. Depth range 0-15 m, lagoon, reef-flat, and reef-top at Eagle Island, Peros Banhos, and Salomon. 


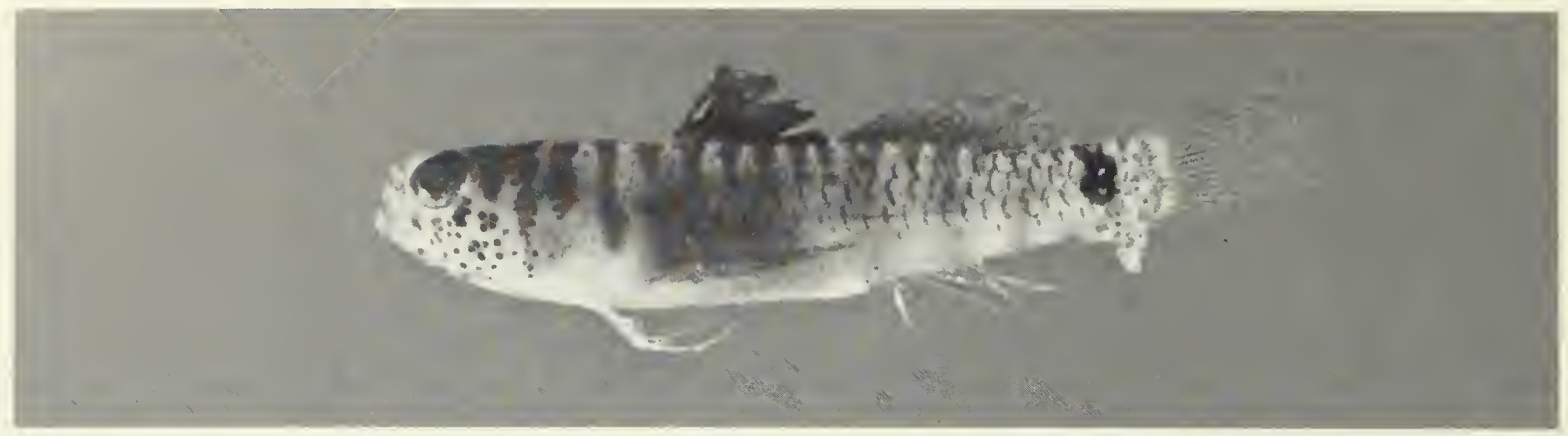

Fig. 40. Left lateral view of Eviota nigripinna, $11.4 \mathrm{~mm}$ SL.

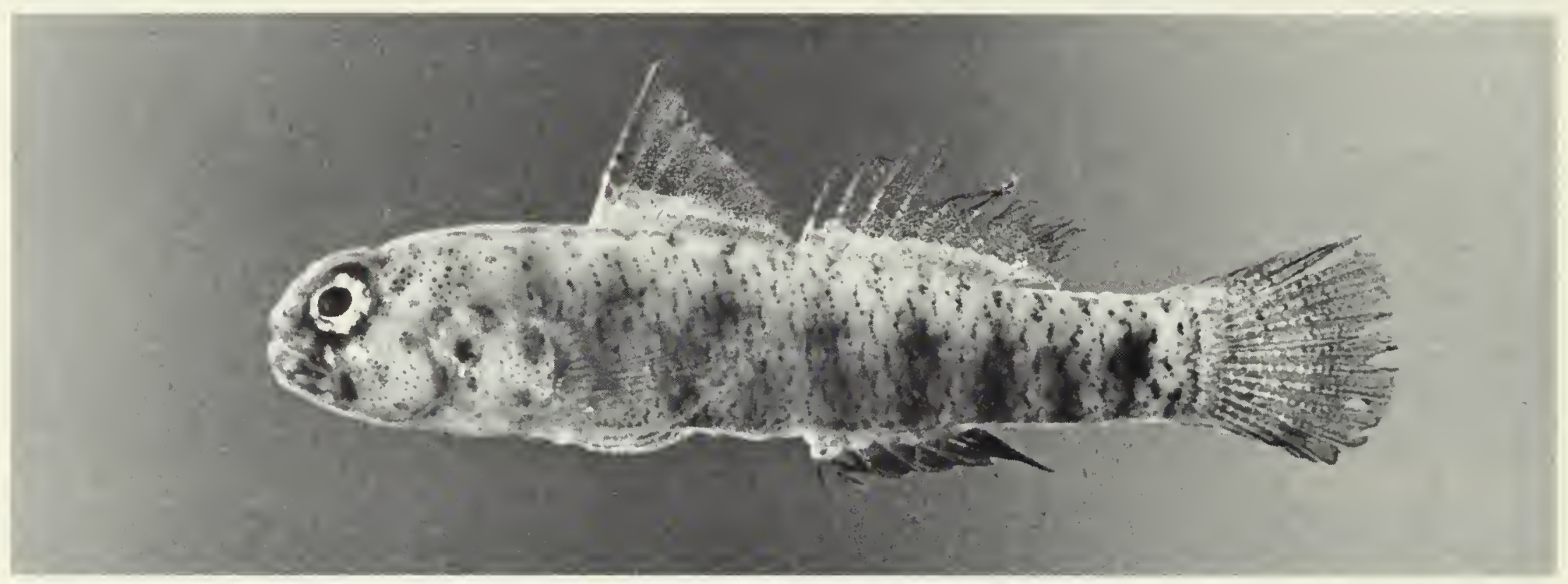

Fig. 41. Left lateral view of Eviota prasina, $15.9 \mathrm{~mm} \mathrm{SL}$.

\section{Eviota prasina (Klunzinger)}

Fig. 41

Eleotris prasinus Klunzinger, 1871:481 (Koseir, Red Sea).

Eviota prasina-Lachner and Karnella, 1978:13 (Red Sea to Oceania).

\section{MATERIAL}

Twelve lots, 548 specimens, 7.2-18.0 mm SL. Depth range $0-3 \mathrm{~m}$, intertidal in lagoons and on reef-flat at Diego Garcia, Eagle Island, Peros Banhos, and Salomon.

\section{Eviota sebreei Jordan and Seale}

Fig. 42

Eviota sebreei Jordan and Seale, 1906:390 (Apia, Western Samoa); Lachner and Karnella, 1980:101 (IndoPacific).

\section{MATERIAL}

Eighteen lots, 45 specimens, 8.3-18.2 mm SL. Depth range $0-33 \mathrm{~m}$, lagoons $(n=36)$ and drop-offs $(n=9)$ at Eagle Island, Peros Banhos, Salomon, and Three Brothers.
Eviota sigillata Jewett and Lachner

Fig. 43

Eviota sigillata Jewett and Lachner, 1983:799 (St Brandons Shoal; range Indian Ocean to Oceania).

\section{MATERIAL}

Three lots, 5 specimens, 12.2-15.2 mm SL. Depth range 10-40 m, lagoons only, at Peros Banhos and Salomon.

Eviota zebrina Lachner and Karnella

Fig. 44

Eviota zebrina Lachner and Karnella, 1978:15 (Curieuse Islands, Seychelles; also Red Sea to east coast of Australia).

\section{MATERIAL}

Eleven lots, 111 specimens, 7.8-14.9 mm SL. Depth range $0-40 \mathrm{~m}$, lagoons only, at Peros Banhos and Salomon. Primarily collected between $10 \mathrm{~m}$ and $20 \mathrm{~m}(n$ =99). 


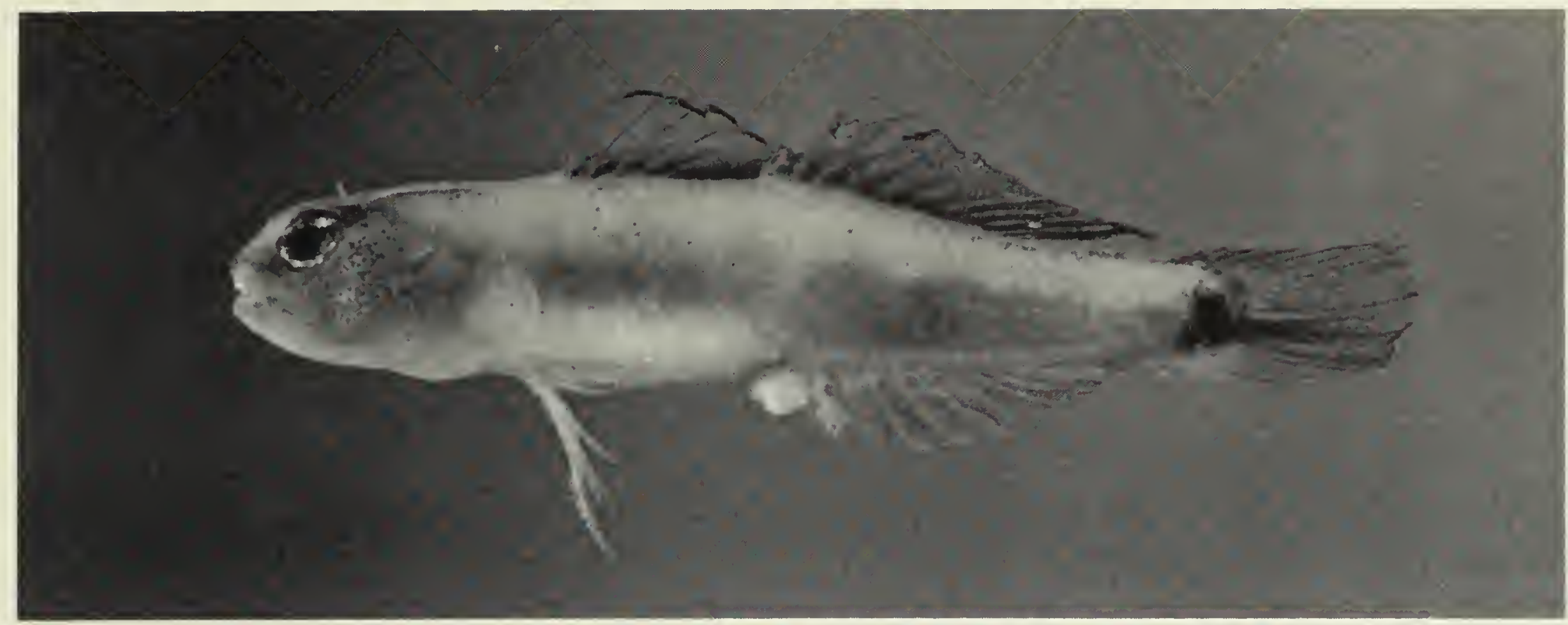

Fig. 42. Left lateral view of Eviota sebreei, $18.2 \mathrm{~mm} \mathrm{SL}$.

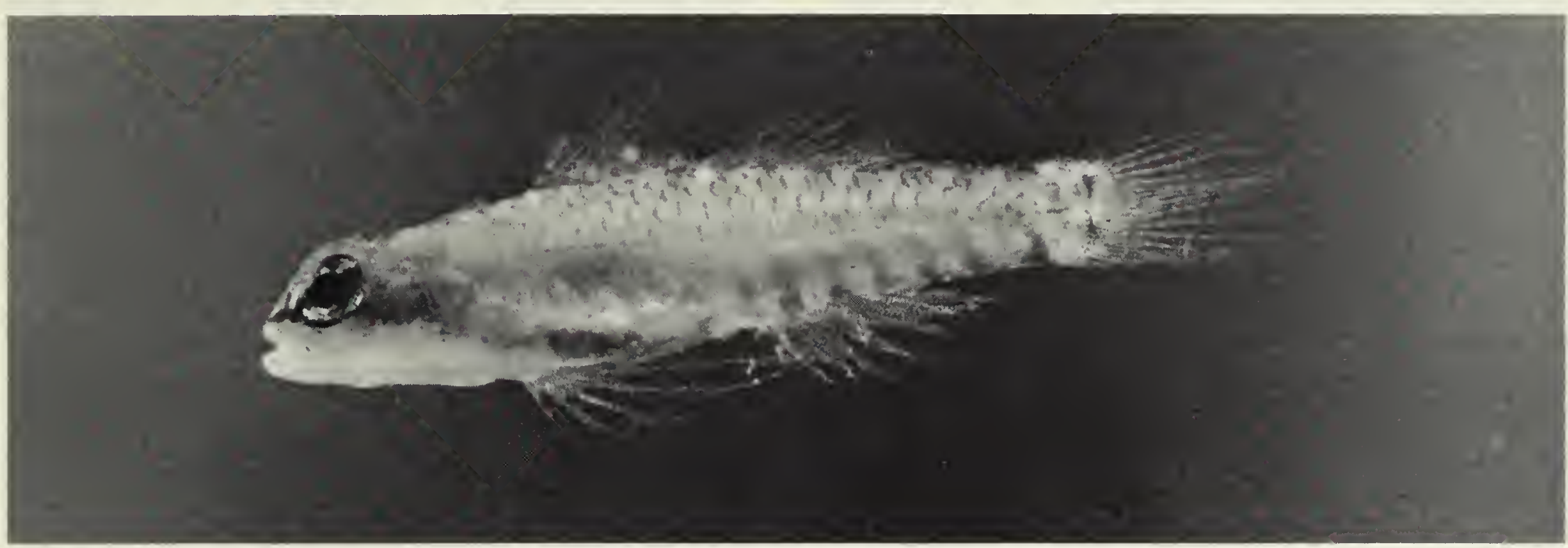

Fig. 43. Left lateral view of Eviota sigillata, $14.4 \mathrm{~mm}$ SL.

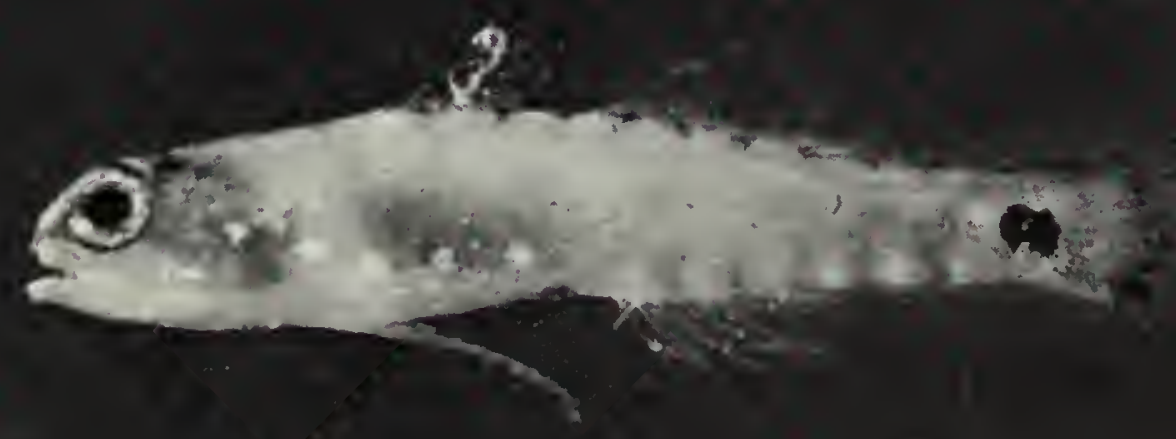

Fig. 44. Left lateral view of Eviota zebrina, $14.8 \mathrm{~mm}$ SL. 


\section{Genus Exyrias}

Exyrias belissimus (Smith)

Figs. 45,46 Acentrogobius belissimus Smith, 1959:202 (Pinda, Mozambique; also Zanzibar).

\section{MATERIAL}

Two lots, 8 specimens, 70.3-85.1 mm SL. Depth range 9-15 m, lagoon only, at Salomon.

\section{DESCRIPTION}

Based on all specimens, including one cleared and stained. D VI + I 10 , first to fourth spines longest, reaching to middle of second dorsal-fin base; A I 9; P 16-18 (17.5), reaching to a vertical with anal-fin origin; V I 5, complete basal membrane and fraenum, reaching posteriorly to anus. Lateral scales 29-30 (29.2); transverse 9; predorsal 6-8 (7.5). Whole body scaled; cheek with four rows of ctenoid scales, uppermost and lowermost rows separated from middle two rows by horizontal lines of sensory papillae; scales on midline of belly and prepelvic area (and sometimes pectoral base) cycloid, others ctenoid. Gill opening restricted, extending ventrally for distance of one-quarter of pectoral-base width below lower margin of pectoral base. Mouth terminal, subinferior; teeth in both jaws in several rows, outer row of upper jaw enlarged and spaced, outer row of lower jaw a little enlarged. Anterior nostril tubular, posterior porelike. Tongue roundly truncate. First gill slit open to posterior margin of first hypobranchial; gill rakers $0+5$, ossified gill rakers $0+6$ with anteroventralmost raker buried in connective tissue; pseudobranch with six to eight lobes. Five branchiostegal rays. Dorsal pterygiophore formula $3(2,2,1,1,0)$; vertebrae $10+15+$ ural centrum $=26$. Seven dorsal and seven ventral branched caudal-fin rays, with seven dorsal and six ventral unbranched rays; central rays of caudal fin sometimes elongate. As percentage standard length: head length 29-31 (30.0); origin of first dorsal fin 33-35 (33.8); origin of second dorsal fin 53-56 (54.6); origin of anal fin 57-62 (58.9); caudal-peduncle length 24-27 (25.6). As percentage head length: eye diameter 23-26 (24.8); snout length 42-45 (43.3); upper-jaw length 38-42 (39.5). Caudal-peduncle depth as percentage caudal-peduncle length 54-61 (57.6). Head pores and papillae as in Fig. 46. Caudal skeleton with hypurals 1 and 2 fused together and to ural centrum, plus hypurals 3 and 4 proximally, with an anteroventral process; neural spine of pu 2 with a sickle-shaped posterodorsal process; otherwise as for $A$. hectori.

Intestine with a few coils, peritoneum light. Gut of $80.5 \mathrm{~mm}$ SL male contained mostly flocculent material, with small gastropods, foraminifera, ostracods, sponge spicules, and some nematodes.

Colour pattern (freshly dead): background light greenblue, centres of most body scales lighter, body with irregular diffuse dark blotches and scattered yellow pigment. Head, pectoral and pelvic bases light, with irregular red spots and lines, a dark spot on posteroventral margin of maxilla. Dorsal fins with thin dark intermittent streaks, becoming rounded posteriorly; caudal fin with elongate rusty spots and a dusky ventral margin; anal fin with dusky margin, strong dusky streaks on cream background with irregular ochre-to-red spots proximally and posteriorly. Proximal portion of pectoral fin barred

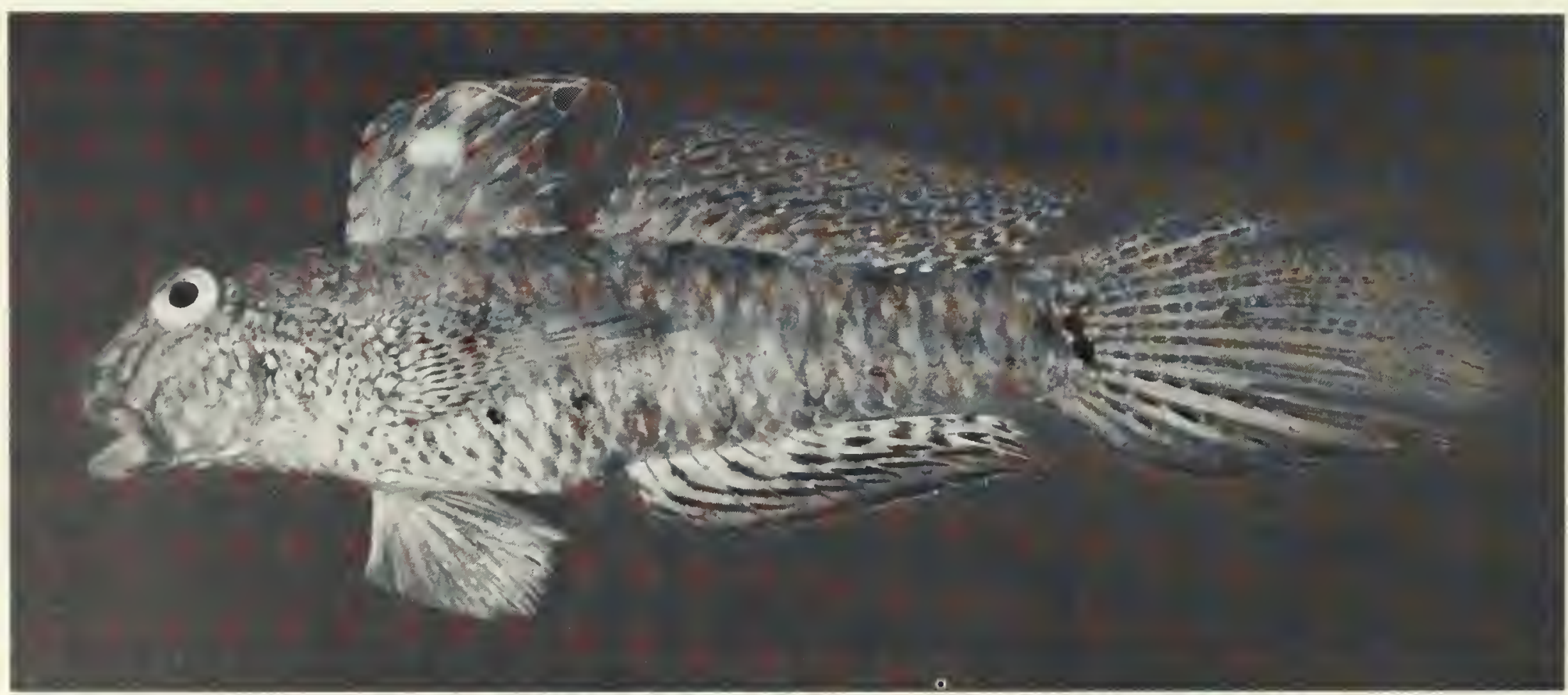

Fig. 45. Left lateral view of Exyrias belissimus, $77.4 \mathrm{~mm} \mathrm{SL}$. 

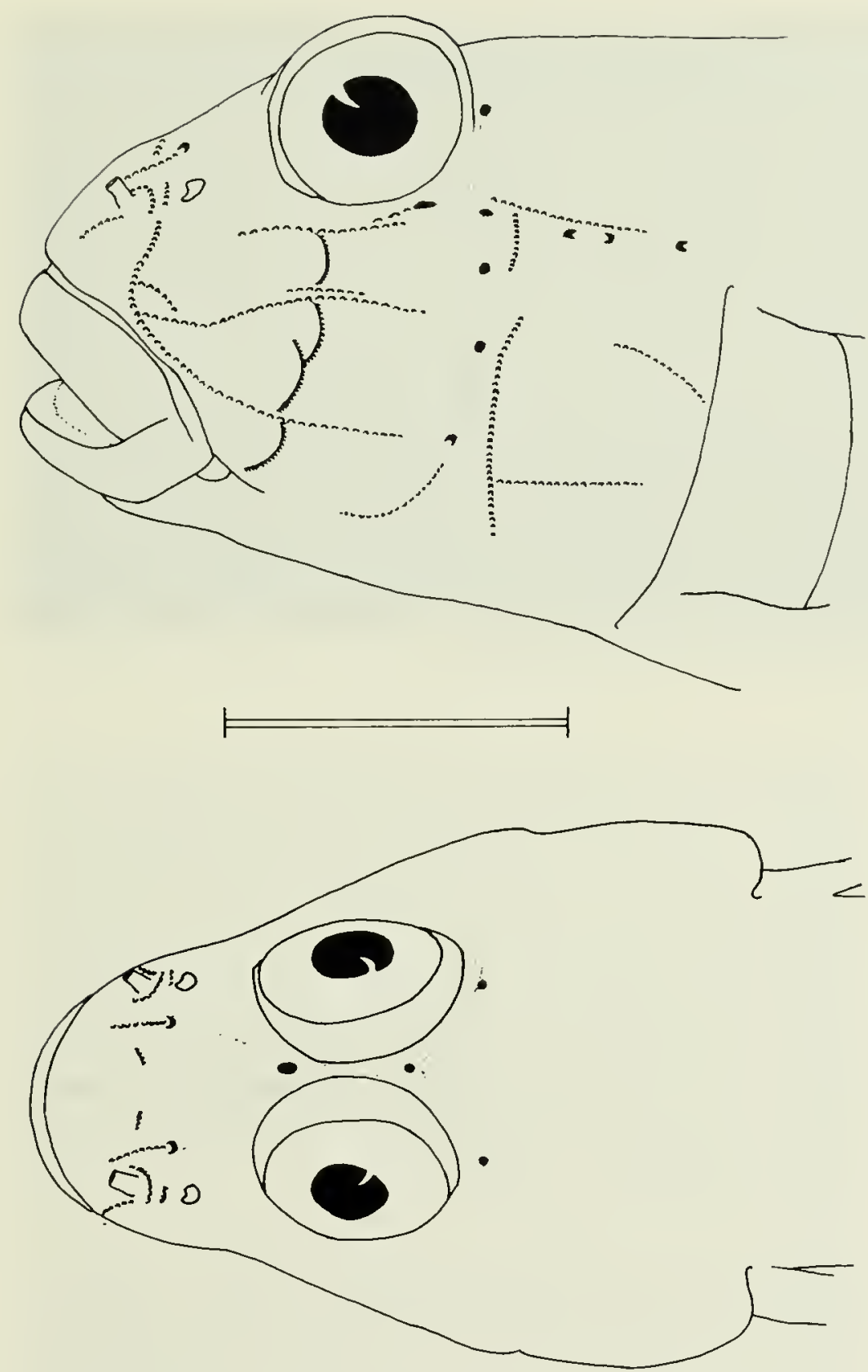

Fig. 46. Left lateral (above) and dorsal (below) views of the head of Exyrias belissimus, $71.5 \mathrm{~mm} \mathrm{SL}$, to show head pores and papillae (with a single vertical row of cheek scales shown). Scale equals $1 \mathrm{~cm}$.

with red and white spots, hyaline distally, pelvic fin hyaline. Preserved: similar to above, with prime colours lost.

\section{DISCUSSION}

The specimens were identified for us by Dr E. O. Murdy.

\section{Genus Feia}

\section{Feia nympha Smith}

Feia nympha Smith, 1959:206 (Pinda, Mozambique).

\section{MATERIAL}

Two lots, 3 specimens, 12.2-12.5 mm SL. Depth range 9-15 m, lagoon at Salomon. Our specimens have been sent to Lachner and McKinney for further study, and will not be described here.

\section{Genus Fusigobius}

Fusigobius species A

Figs. 47,48

\section{MATERIAL}

Ten lots, 21 specimens, 9.5-30.4 mm SL. Depth range 3-26 m, primarily on reef-tops and drop-offs at Peros Banhos, Salomon, and Three Brothers.

\section{DESCRIPTION}

Based on 10 specimens from lots WE 79-87, 79-89, 79-94, and 79-106 (20.2-30.3 mm SL), plus 2 cleared and stained specimens from lot WE 79-76 (24.8-26.6 mm SL). D VI + I 9 (once I 8), first three spines longest, reaching to dorsal interspace or origin of second dorsal fin; A I 8 (once I 9); P 18-20 (18.9), reaching posteriorly to a vertical with first few fin-ray bases of anal fin; V I 5 , fraenum absent or vestigial, basal membrane varying between one-third and completely present, fin rays reaching anal-fin origin, fifth fin ray branching twice. Lateral scales 24-25; transverse 7; no scales on predorsal, head, or pectoral base (may be due to specimen condition); scales of prepelvic area and midline of belly cycloid, otherwise ctenoid. Gill opening partially, restricted, reaching a point ventrally between pectoral base and vertical limb of preopercle. Mouth terminal; outer and inner rows of teeth in both jaws spaced and enlarged, with several irregular rows of smaller teeth in between. Anterior nostril tubular, posterior porelike. Tongue truncate with rounded margins, usually with a broad shallow notch. First gill slit with ventral half closed by membrane; gill rakers $1+5$, cleared and stained specimens with an additional ossified lower gill raker embedded in connective tissue anterior to the open portion of the gill slit $(=1+6)$; pseudobranch with six to seven lobes. Five branchiostegal rays. Dorsal pterygiophore formula $3(2,2,1,1,0)$; vertebrae $10+15+$ ural centrum $=26$. Six dorsal and 6 ventral branched caudal-fin rays, with 11 dorsal and 8 or 9 ventral unbranched caudal-fin rays. As percentage standard length: head length 32-33 (32.9); origin of first dorsal fin 36-40 (37.5); origin of second dorsal fin 55-59 (57.0); origin of anal fin 56-58 (57.0); caudal-peduncle length 28-30 (28.9). As percentage head length: eye diameter 26-30 (27.7); snout length 26-30 (27.9); upper-jaw length 33-36 (34.4). Caudalpeduncle depth as percentage caudal-peduncle length $33-36$ (34.8) in males $(n=4), 30-36(32.5)$ in females $(n$ $=6), 30-36$ (33.4) combined. Head pores and papillae as in Fig. 48. Caudal skeleton as for $A$. hectori.

Intestine with a single flexure, peritoneum unpigmented; gut of one specimen ( $30.3 \mathrm{~mm}$ SL male) contained a single, small brachyuran.

Colour pattern (freshly dead): background translucent white, with scattered orange spots on head and body. A 


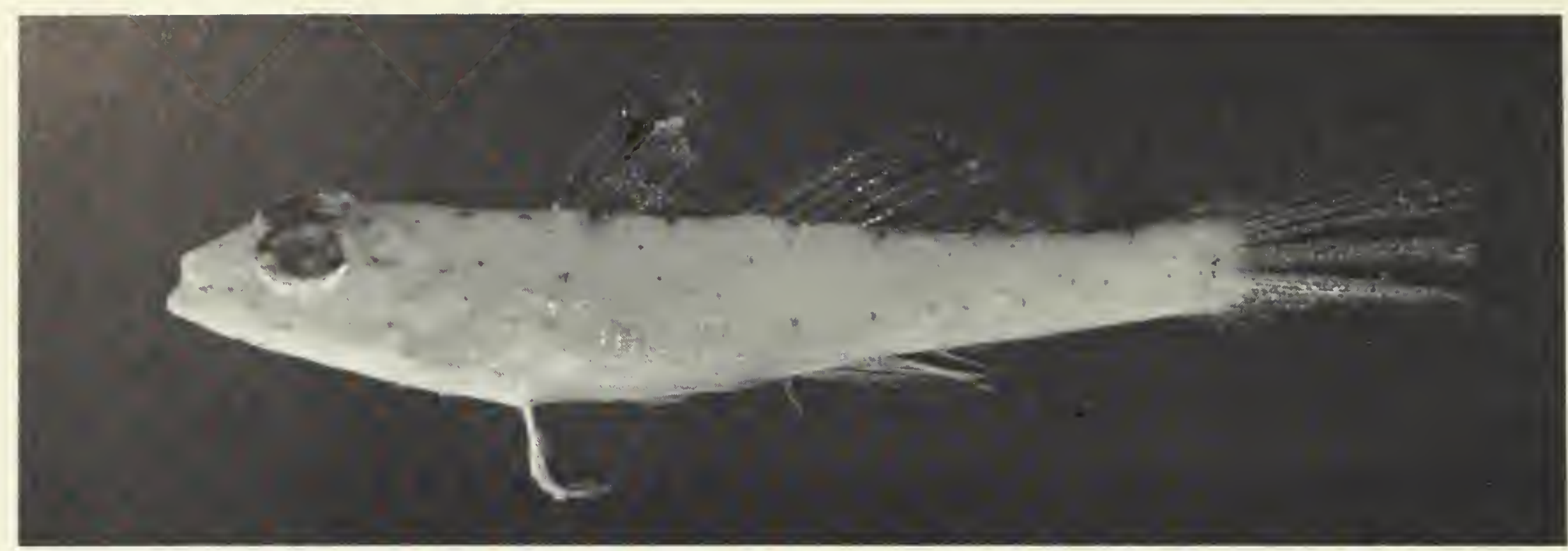

Fig. 47. Left lateral view of Fusigobius sp. A, $18.8 \mathrm{~mm}$ SL.
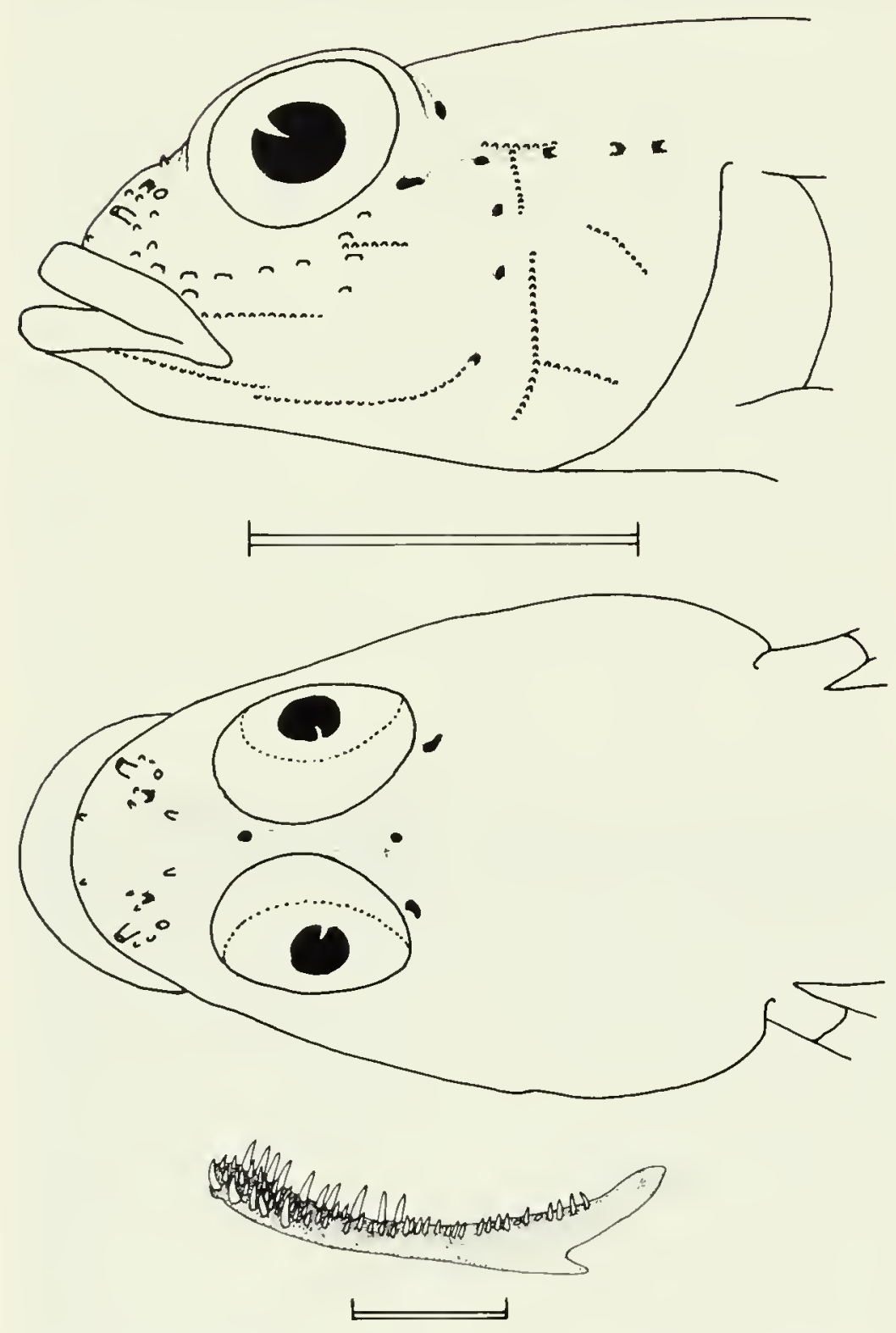

Fig. 48. Left lateral (above) and dorsal (middle) views of the head of Fusigobius sp. A, $27.0 \mathrm{~mm} \mathrm{SL}$, to show head pores and papillae; scale equals $5 \mathrm{~mm}$. Below: dorsolateral view of the dentary of a cleared and stained Fusigobius sp. A, $26.6 \mathrm{~mm} \mathrm{SL}$, to show enlarged inner and outer rows of teeth; scale equals $1 \mathrm{~mm}$. few black melanophores on dorsal part of orbit, and a group of melanophores forming a spot one-quarter of pupil diameter over end of hypural plate on midline. A pupil-sized spot on shoulder. First dorsal fin with membrane between distal tips of first to third and fifth to sixth spines black. A scattering of tiny black spots in second dorsal fin, and median fins with scattered iridocytes. Pectoral and pelvic fins hyaline. Preserved: similar to above, but orange spots on body and iridocytes in fins not evident.

\section{DISCUSSION}

Fusigobius is being revised by Dr D. F. Hoese. Compared against his unpublished key to the species, the Chagos specimens are close to his species 7. Our specimens appear to differ from his in having the inner row of teeth in both jaws enlarged (vs not distinctly enlarged); in having the snout length equal to the eye diameter (vs greater than eye diameter); and in lacking a bar under the eye (vs bar present).

\section{Fusigobius species B}

Figs. 49,50

\section{MATERIAL}

Six lots, 9 specimens, 11.7-29.9 mm SL. Depth range 0.5-32 m, lagoon only, at Peros Banhos, Salomon, and Three Brothers.

\section{DESCRIPTION}

Based on seven specimens from lots WE 79-06, 79-33, $79-43,79-53+57$, and 79-66 (17.3-29.9 mm SL), plus one cleared and stained specimen from WE 79-53 + 57 (21.2 mm SL). D VI + I 9, second to third spines longest, reaching to or slightly beyond origin of second dorsal fin; A I 8; P 18-19 (18.1), reaching to a vertical with bases of first few anal-fin rays; V I 5, fifth ray branched twice, 


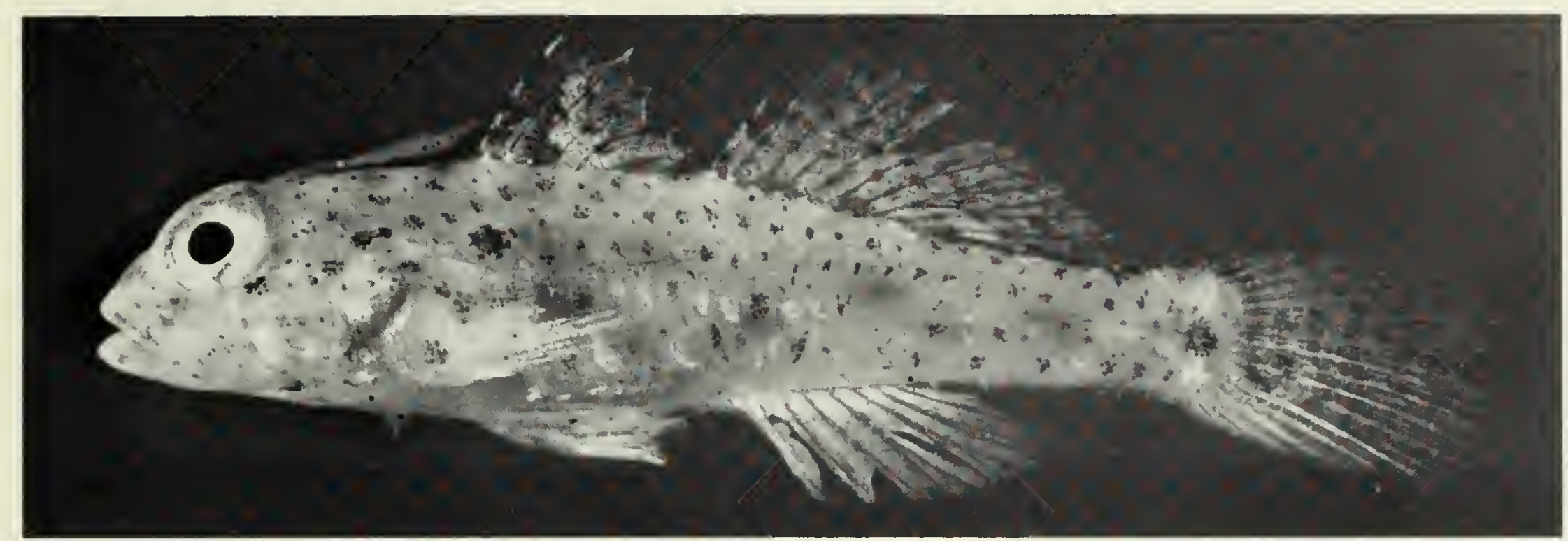

Fig. 49. Left lateral view of Fusigobius sp. B, $24.8 \mathrm{~mm} \mathrm{SL}$.

reaching posteriorly to anal-fin origin or slightly beyond, weak fraenum present or absent, basal membrane present between proximal one-quarter to one-third of pelvic fins. Lateral scales 24; transverse 7. Head and nape naked; pectoral base with large cycloid scales; prepelvic and belly scales cycloid; rest of body covered with ctenoid scales. Gill opening partly restricted, reaching ventrally to a point between pectoral base and vertical limb of preopercle. Mouth terminal; both jaws with several irregular rows of teeth, outer and inner rows enlarged. Anterior nostril a short tube, posterior porelike. Tongue truncately rounded. Ventral one-third of first gill slit closed by membrane, gill rakers $1+6(0+5$ in cleared and stained specimen $)$; pseudobranch with seven to eight lobes. Five branchiostegal rays. Dorsal pterygiophore formula $3(2,2,1,1,0)$; vertebrae $10+15+$ ural centrum $=26$. Six dorsal and six ventral branched caudal-fin rays, with nine dorsal and seven ventral unbranched caudal-fin rays. As percentage standard length: head length 29-34 (32.0); origin of first dorsal fin 35-40 (37.3); origin of second dorsal fin 53-59 (56.7); origin of anal fin 55-59 (57.6); caudal-peduncle length 29-31 (29.6). As percentage head length: eye diameter 28-31 (29.1); snout length 25-27 (25.9); upper-jaw length 34-36 (35.2). Caudal-peduncle depth as percentage caudal-peduncle length 35-41 (37.7). Head pores and papillae as in Fig. 50. Caudal skeleton as for $A$. hectori.

Dorsal half of peritoneum sprinkled with melanophores, gut S-shaped. Gut of $29.9 \mathrm{~mm}$ SL male contained copepods, amphipods, isopods, and polychaete remains.

Colour pattern (freshly dead): background light tan. Head and body with numerous orange spots about one-quarter of pupil diameter in size, spots containing a peppering of black melanophores, arranged in two longitudinal rows along back, somewhat irregular elsewhere. Two larger (three-quarters of pupil diameter), similar spots one above other on pectoral base. An
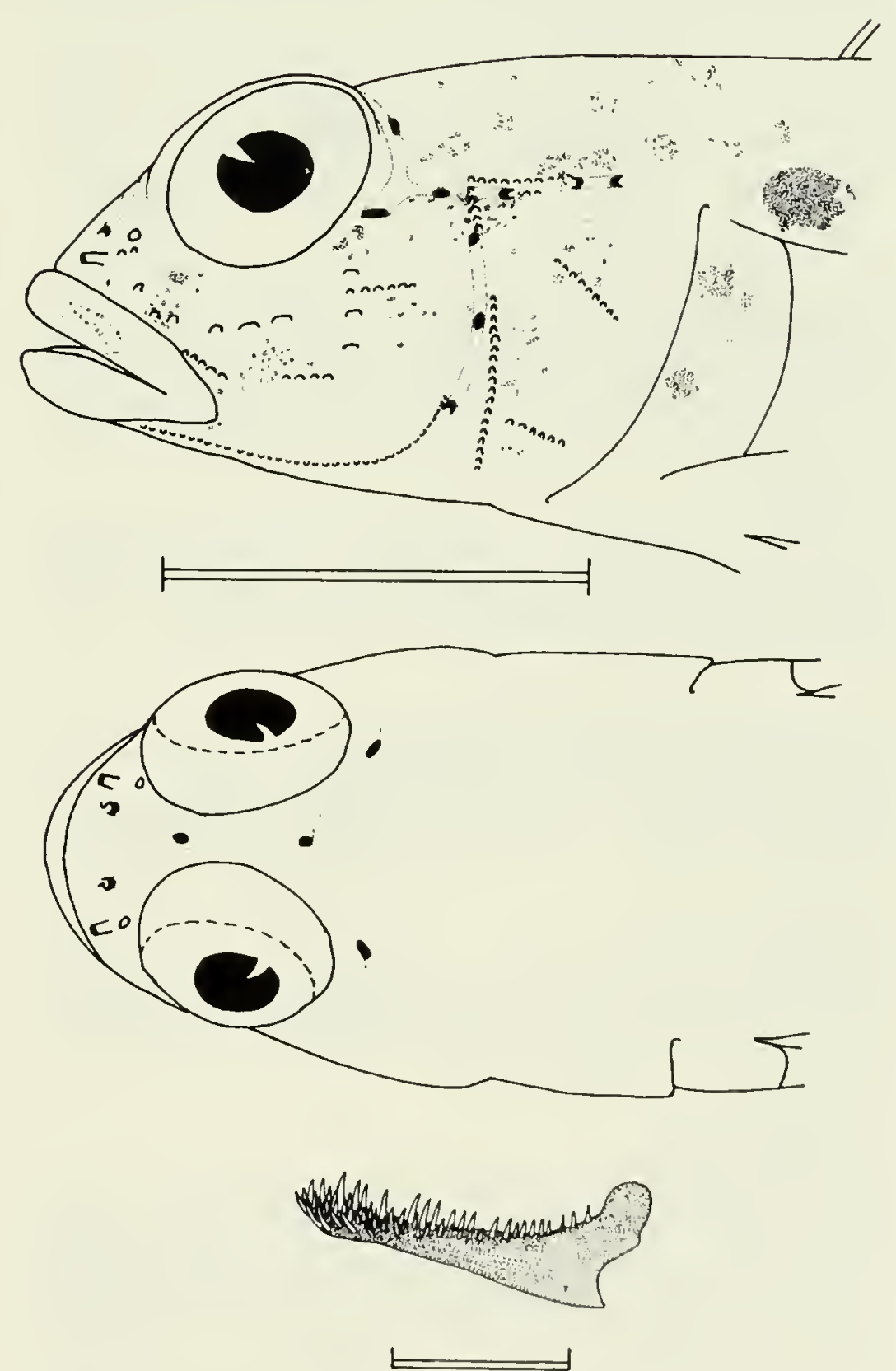

Fig. 50. Left lateral (above) and dorsal (middle) views of the head of Fusigobius sp. B, $24.4 \mathrm{~mm} \mathrm{SL}$, to show head pores. papillae, and pigmentation pattern; scale equals $5 \mathrm{~mm}$. Below: dorsolateral view of dentary of a cleared and stained Fusigobius sp. B, $21.7 \mathrm{~mm} \mathrm{SL}$, to show enlarged inner and outer rows of teeth; scale equals $1 \mathrm{~mm}$. 
intermittent orange stripe from eye to middle of upper jaw A prominent, black, pupil-sized spot on shoulder below first dorsal spine and another, slightly smaller, black spot centred over end of hypural plate. Fins white (iridocytes) with up to four irregular longitudinal rows of orange spots in second dorsal fin. Membrane between first three dorsal spines of first dorsal fin a mixture of melanophores and iridocytes margined posteriorly by a band of iridocytes. An orange spot proximally between bases of third and fourth spines and small scattered orange spots elsewhere in fin membrane. Caudal fin with three to four vertical bars made up of orange spots, pelvic and anal fins with iridocytes, pectorals hyaline except with patch of iridocytes anteroventrally. Preserved: background light tan with only melanophores visible.

\section{DISCUSSION}

The Chagos specimens accord well with species 8 in Hoese's manuscript key. The only difference we could find was the enlarged nature of the inner row of teeth in both jaws in the Chagos specimens (see Fig. 50) as opposed to these teeth being "not distinctly enlarged".

\section{Fusigobius duospilus Hoese and Reader}

Fusigobius duospilus Hoese and Reader, 1985:2 (Great Barrier Reef; range Indo-Pacific east to Society Islands).

\section{MATERIAL}

Two lots, 7 specimens (paratypes), 19.4-31.3 mm SL. Depth range $0.5-43 \mathrm{~m}$, lagoon (near pass) and drop-off at Peros Banhos and Salomon.

\section{Fusigobius neophytus (Günther) \\ Figs. 51, 52 \\ Gobius neophytus Günther, 1877:174 (Ponape, Apia, Huahine, Tahiti).}

\section{MATERIAL}

Nine lots, 16 specimens, $10.1-43.5 \mathrm{~mm} \mathrm{SL}$. Depth range 0-15 m, lagoons only, at Eagle Island, Peros Banhos, Salomon, and Three Brothers.

\section{DESCRIPTION}

Based on 10 specimens from lots WE 79-40, 79-43, 79-53 $+57,79-57,79-66,79-69$, and 79-82 (24.7-43.5 mm SL), plus 2 cleared and stained specimens from WE 79-82 (30.4-35.8 mm SL). D VI + I 9 (once I 8), second and third spines longest, reaching to origin of second dorsal fin or just anterior to this; A I 8; P 17-19 (17 once, 19 twice, 18.1), reaching to a vertical with base of third ray of anal fin; V I 5, a fraenum present or absent, basal membrane ranging from fully developed to one-fifth of length of fifth ray (variation in this and in fraenum may be due to specimen condition), reaching to anal origin. Lateral scales 24-25; transverse 7-9; no scales in predorsal midline but scales extending forward on side of head to behind eye; these scales and those on pectoral base, prepelvic area, and midline of belly cycloid; elsewhere ctenoid. Gill opening restricted, reaching ventrally to a point between pectoral base and vertical limb of preopercle. Mouth terminal; both jaws with several rows of teeth; outer row and, to a lesser extent, inner row enlarged conical teeth, with irregular rows of small conical teeth in between. Larger individuals ( $>40 \mathrm{~mm} \mathrm{SL}$ ) with a pair of canines in outer row of each half of lower jaw. Anterior nostril tubular, posterior porelike. Tongue truncately rounded. Ventral one-quarter of first gill slit closed by membrane, $1-2+6-7$ gill rakers; $0+6$ ossified gill rakers; pseudobranch with 9 to 10 lobes. Five branchiostegal rays. Dorsal pterygiophore formula $3(2,2,1,1,0)$; vertebrae $10+15+$ ural centrum $=26$. Six dorsal and seven ventral branched caudal-fin rays, with eight to nine dorsal and seven ventral unbranched caudal-fin rays. As percentage standard length: head length 32-33 (32.0); origin of first dorsal fin 36-39 (36.7); origin of second dorsal fin 55-59 (56.8); origin of anal fin 55-59 (56.8); caudal-peduncle length 28-31 (29.6). As percentage head length: eye diameter 27-31 (29.1); snout length 31-35 (32.0); upper-jaw length $31-35$ (32.8). Caudal-peduncle depth as percentage caudal-peduncle length 37-47 (40.2), possibly sexually dimorphic, males $38-47(41.6, n=4)$, females $37-43(39.2, n=6)$. Head pores and papillae as in Fig. 52. Two intertemporal pores. Caudal skeleton as for $A$. hectori.

Gut of $40.2 \mathrm{~mm} \mathrm{SL}$ male contained harpacticoids, amphipods, and a polychaete worm.

Colour pattern (freshly dead): background white, covered with spots consisting mostly of a combination of black and orange melanophores, and forming longitudinal rows on body. Those along midline of dorsum and on scale row below midlateral row largest, about pupil-sized. Spot midway between end of anal-fin base and hypural plate in latter series vertically elongated in most specimens. Two prominent spots on pectoral base, a pupil-sized black spot on midlateral region of peduncle. A bar from eye to middle of lower jaw on each side, and a prominent $U$-shaped bar centred on midline of snout. Arms of " $U$ " run parallel to lateral margins of premaxillary pedicles, the "foot" crosses midline just behind upper lip. Median fins heavily sprinkled with iridocytes, containing scattered orange or orange-and-black spots. A prominent black spot in membrane between first and second dorsal-fin spines about midway along length. Preserved: only black melanophores remain visible.

\section{DISCUSSION}

Smith (1959:208) described a new subspecies, Fusigobius 


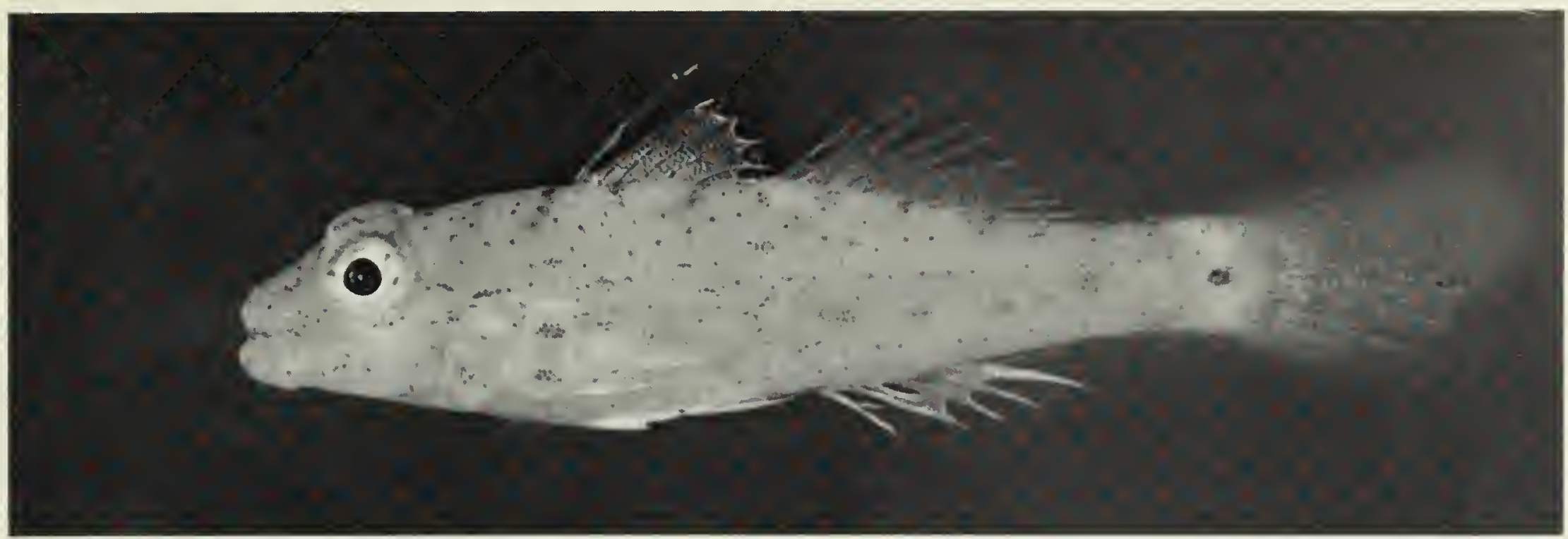

Fig. 51. Left lateral view of Fusigobius neophytus, $37.0 \mathrm{~mm} \mathrm{SL}$

neophytus africanus, diagnosed as having a longer last ray in the dorsal and anal fins, as having canines in the lower jaw of adults, and as usually possessing a scale in the upper corner of the opercle. Chagos specimens show variation in length of the last dorsal- and anal-fin rays which, in the larger specimens, almost reach to the end of the caudal peduncle. Larger $(>40 \mathrm{~mm} \mathrm{SL})$ specimens also have one or two teeth on each side of the lower jaw enlarged and caniform. No specimens possessed a scale on the opercle, but this could be due to loss as a result of net abrasion. Both Smith (1959) and Goren (1979) record three upper gill rakers, while our specimens have one or two (unossified) rakers. We suspect that $F$. n. africanus will be relegated to the synonymy of $F$. neophytus, at least partly from the dubious nature of the usefulness of the subspecific concept in Indo-Pacific fishes at this time, as much as from the apparent lack of characters to differentiate the two populations (western Indian Ocean/Red Sea vs Pacific).

\section{Genus Gnatholepis}

\section{Gnatholepis cauerensis (Bleeker)}

Gobius cauerensis Bleeker, 1853:269 (Cauer = Kauer, Sumatra).

\section{MATE RIAL}

Twelve lots, 25 specimens 10.8-52.7 mm SL. Depth range $0-25 \mathrm{~m}$, primarily in lagoons and on reef-tops (one specimen each from drop-off and reef-flat), at Diego Garcia, Eagle Island, Peros Banhos, and Salomon.

\section{DESCRIPTION}

Based on 10 specimens from lots WE 79-33, 79-41, 79-44, and 79-108 (17.1-52.7 mm SL), plus 1 cleared and stained specimen from WE $79-82$ (26.9 mm SL). D

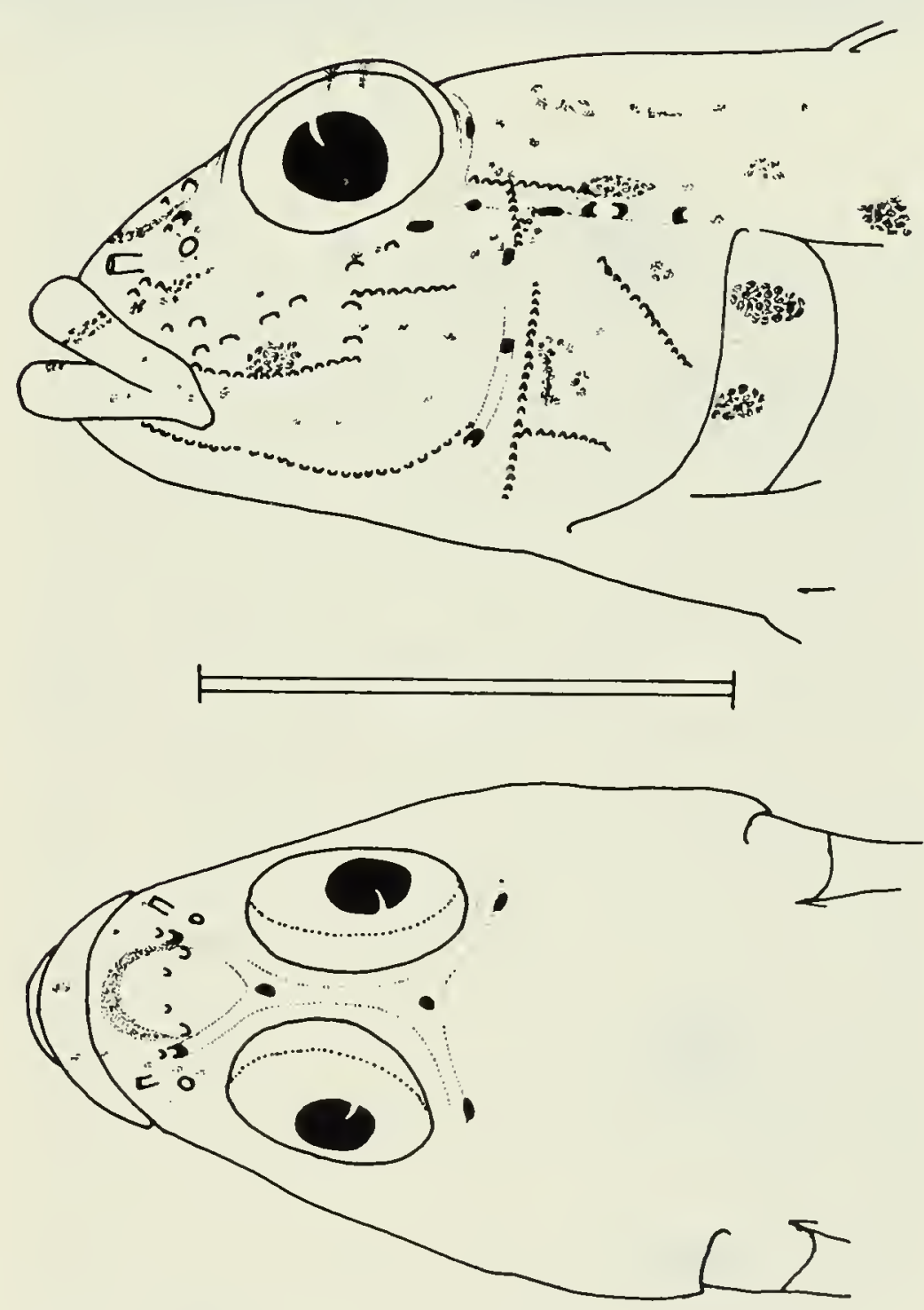

Fig. 52. Left lateral (above) and dorsal (below) views of the head of Fusigobius neophytus, $43.5 \mathrm{~mm} \mathrm{SL}$, to show head pores, papillae, and pigmentation. Scale equals $1 \mathrm{~cm}$. 


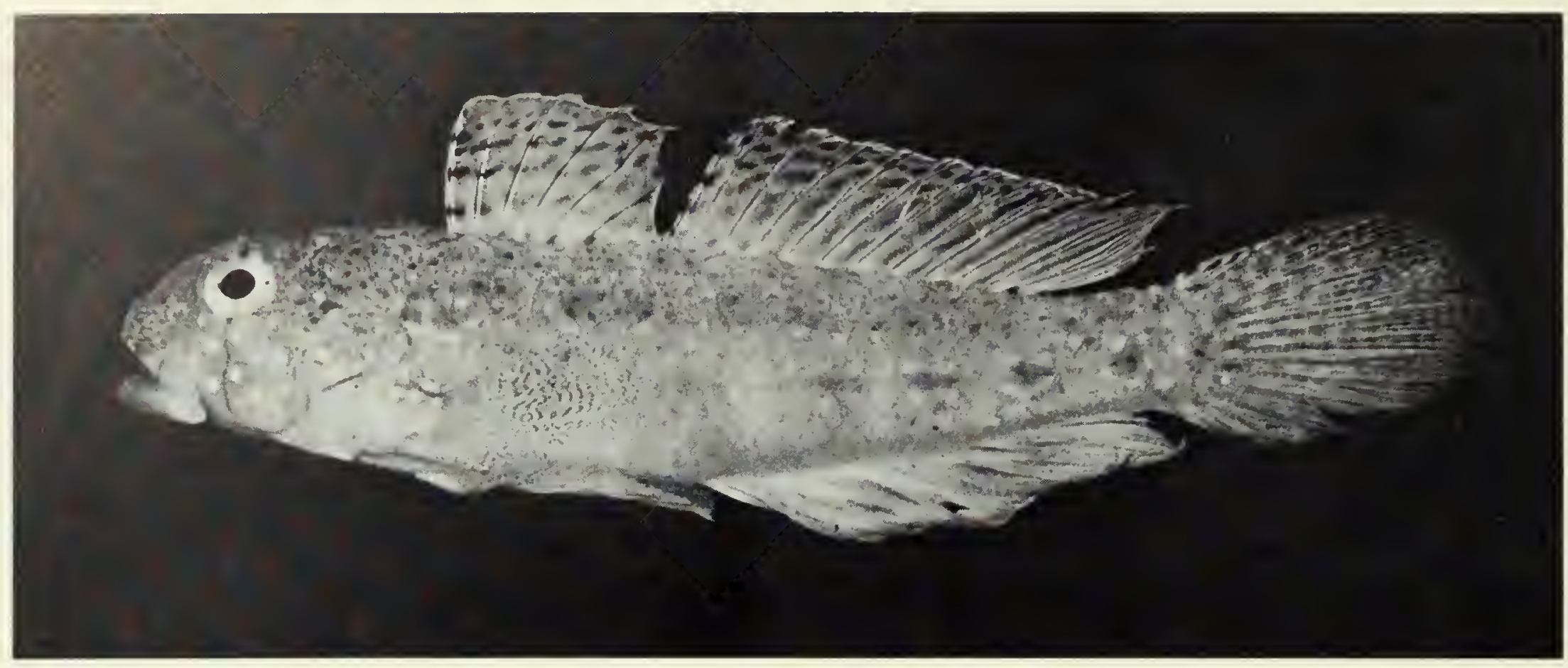

Fig. 53. Left lateral view of Gnatholepis cauerensis, $45.5 \mathrm{~mm} \mathrm{SL}$.
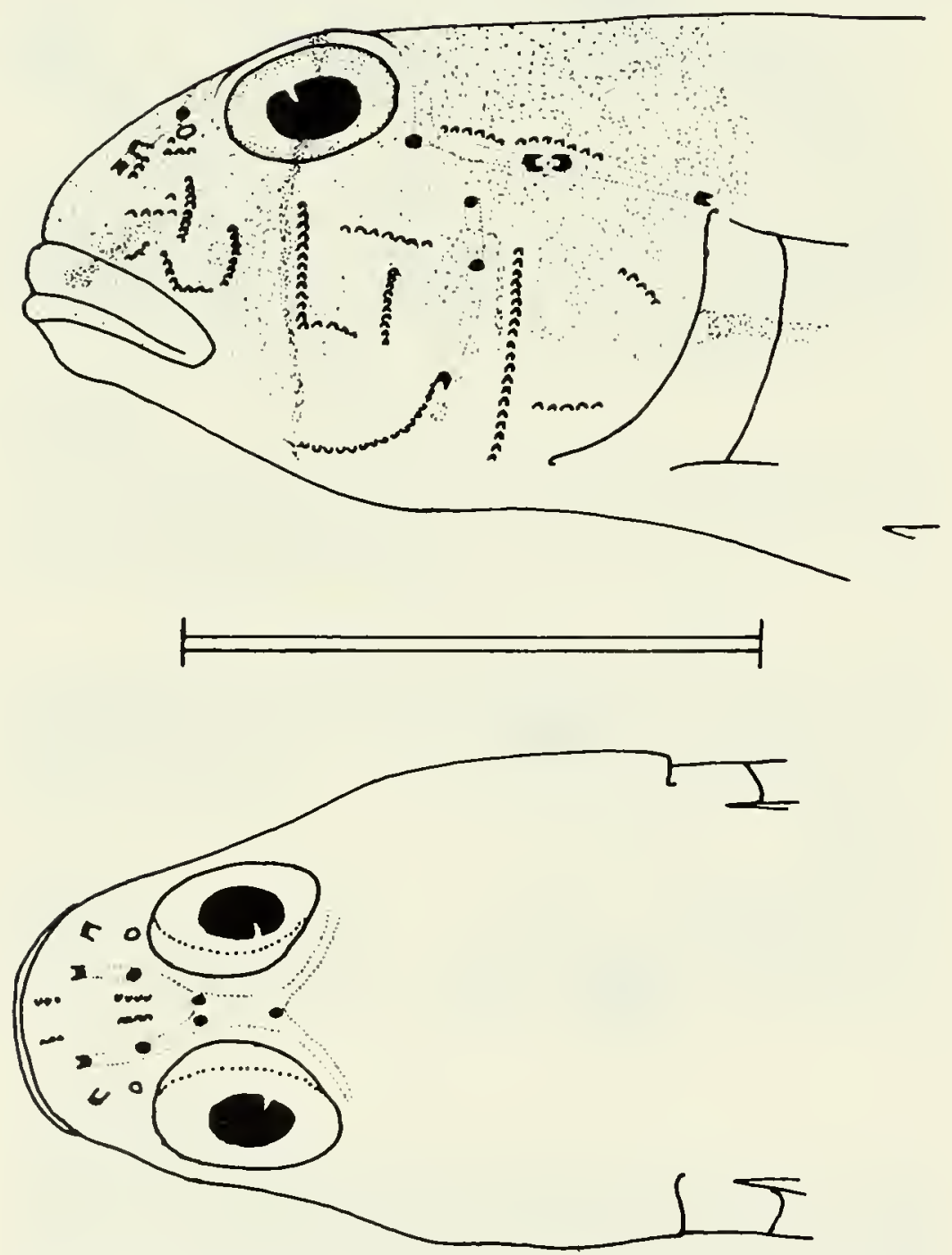

Fig. 54. Left lateral (above) and dorsal (below) views of the head of Gnatholepis cauerensis, $40.0 \mathrm{~mm} \mathrm{SL}$, to show head pores, papillae, and pigmentation. Scale equals $1 \mathrm{~cm}$.
$\mathrm{VI}+\mathrm{I} 11$, fourth and fifth spines longest, reaching between origin of second dorsal fin and base of third ray; A I 11; P 15-17 (16.6), reaching to a vertical with anal-fin origin; V I 5, complete basal membrane and fraenum, reaching to anal-fin origin. Lateral scales 30-32 (30.6); transverse 10; predorsal 9-10 (9.3). Head, pectoral base, and prepelvic area scaled. Anterior predorsal, head, belly, and prepelvic scales cycloid; others ctenoid. Gill opening partly restricted, reaching ventrally to a point between vertical margin of preopercle and base of pectoral fin. Mouth terminal, but situated on ventral region of head. Upper-jaw teeth in irregular rows, outer row enlarged, with a pair of canines near symphysis in each half of jaw. In lower jaw, outer row enlarged, lateralmost teeth largest; a curved, laterally flaring canine at bend of dentary; inner row smaller, somewhat irregular. Anterior nostril a very short tube, posterior porelike. Tongue strongly bilobed. First gill slit closed for one-fifth of its normal extent ventrally by membrane; gill rakers $2+3-4,0+2$ ossified gill rakers; pseudobranch with seven to eight lobes. Five branchiostegal rays. Dorsal pterygiophore formula $3(1,2,2,1,0)$, vertebrae $10+15+$ ural centrum $=26$. Seven dorsal and six ventral branched caudal-fin rays, with eight dorsal and eight ventral unbranched caudal-fin rays. As percentage standard length: head length 28-32 (30.1); origin of first dorsal fin 33-40 (35.9); origin of second dorsal fin 51-57 (54.0); origin of anal fin 54-59 (56.6); caudal-peduncle length 15-19 (17.5). As percentage head length: eye diameter 23-30 (25.6); snout length 23-35 (31.2); upper-jaw length 30-40 (34.6). Caudal-peduncle depth as percentage caudal-peduncle length $62-76(66.8)$; possibly sexually dimorphic: females 62-68 $(64.2, n=4)$, males 63-76 $(68.5, n=6)$. Head pores and papillae as in Fig. 54. 
Anterior interorbital pore double (i.e., bilaterally symmetrical), an extra pore between it and the nasal pore on each side. Supraotic and posterior otic pores absent, and canal between anterior and posterior temporal pores three times as long as usual in gobiids. Caudal skeleton as for $A$. hectori, except two epurals, both flattened plates of bone, posteriormost epural with a thickened posterior margin.

Intestine long and coiled, peritoneum black. Gut of $52.7 \mathrm{~mm}$ SL male of flocculent material containing primarily harpacticoid copepods, with occasional amphipods and foraminifera.

Colour pattern (freshly dead): ground colour pale tan, with irregular black and pale red spots. Dusky transverse stripe over top of orbit, continued ventrally below orbit to margin of interopercle as thin red line; a short, oblique, thin red stripe on ventral margin of opercle; a short, horizontal red stripe on base of pectoral fin. Cheek, opercle, and pectoral base with pale blue spots. Pale red spots on body most prominent in scale row below midlateral scale row, where each spot flanked by four blue spots, as in a five of a deck of cards. An elongate pale red blotch on shoulder above pectoral-fin base. Three to four irregular rows of black spots in dorsal fins and upper half of caudal fin, latter with pale red spots. Anal fin with irregular suffusions of pale red and yellow; pelvic and pectoral fins peppered with small black melanophores. Preserved: black and red areas represented by small black melanophores, no trace of blue spots remaining.

\section{DISCUSSION}

The genus Gnatholepis was erected by Bleeker (1874b) with Gobius anjerensis Bleeker, 1850 as the type species. The species was based on an unpublished figure by Kühl and van Hasselt and the specimen, if it was retained, is now missing (Boeseman, pers. comm.). The figure, and Bleeker's description taken from the figure, are not sufficiently diagnostic to allow positive identification (although our specimens could be conspecific). We do not wish to formally state our opinion that $G$. anjerensis is a nomen dubium since it is the type species of the genus. Rather, we feel this is a matter for a future revisor of the genus and we will ignore the problem in further discussion. We suggest that our specimens are conspecific with Bleeker's (1853) Gobius cauerensis from Sumatra (the holotype of which we have examined).

Although the genus Gnatholepis seems quite distinct morphologically, especially in head pore and papillae patterns, problems are acute at the species level (Redigobius shares with Gnatholepis the double anterior interorbital pores but has longitudinal rows of papillae and no transverse rows). Our Gnatholepis specimens appear to be conspecific with Smith's (1959) Acentrogobius cauerensis as figured in his plate $1 \mathrm{IC}$, but we suspect that his plate $11 \mathrm{D}$, labelled as "var." is a different species from ours, and we have further reservations about the conspecificity of Goren's (1979) A. cauerensis with our material. However, we have experienced difficulty in separating the Caribbean $G$. thompsoni from our material, and can only suggest the consistently more intense and slightly different coloration of $G$. thompsoni as a means of separating this species from the Chagos material.

\section{Genus Gobiodon}

Gobiodon fulvus Herre

Figs. 55-57

Gobiodon fulvus Herre, 1927:292 (Calapan, Mindoro). Gobiodon albolineatus Smith, 1959:219 (Assumption Island; also La Digue).

\section{MATERIAL}

Seven lots, 16 specimens, 5.5-30.0 mm SL. Depth range 5-10 m, reef-top at Salomon (one specimen from lagoon, near pass, at Peros Banhos).

\section{DESCRIPTION}

Based on nine specimens from lots WE 79-67, 79-70, 79-73, and 79-90 (13.6-30.0 mm SL) and one cleared and stained specimen from WE 79-95 (14.2 mm SL). D VI + I 10 (once I 9), fifth spine longest, reaching to base of spine of second dorsal fin when depressed, membrane between dorsal fins reaching one-half to two-thirds of way up spine of second dorsal fin with virtually no notch between fins (Fig. 56); A I 8-9 (8.7); P 18-20 (19.1), reaching posteriorly to a vertical in line with anus; V I 5 , fraenum and basal membrane complete, fin length about equal to width of gill opening, reaching one-half to two-thirds of distance between its origin and anus. No scales. Gill opening restricted, ending ventrally opposite bases of 13 th to 15 th pectoral-fin rays. Mouth small, terminal. In upper jaw, four to six enlarged, spaced outer teeth and two to three inner rows of small conical teeth (Fig. 56). Teeth in lower jaw similar, but outer row only slightly enlarged, and one to two large curved inner canines near symphysis. Nostrils tubular, tongue rounded. A groove between interopercle and isthmus. First gill slit open; gill rakers short, unossified, $2-3+3-4$; pseudobranch with six to eight lobes. Five branchiostegal rays. Dorsal pterygiophore formula $3(2,2,1,1,0)$; vertebrae 10 $+15+$ ural centrum $=26$. Eight dorsal and seven ventral branched caudal-fin rays, with six dorsal and six ventral unbranched caudal-fin rays. As percentage standard length: head length 29-32 (31.1); origin of first dorsal fin $37-40$ (38.4); origin of second dorsal fin 57-60 (58.8); origin of anal fin 60-65 (62.1); caudal-peduncle length 20-23 (21.2); head depth at vertical limb of preopercle 27-32 (28.9); depth at pelvic-fin origin 33-37 (34.7); body depth at anal-fin origin 25-31 (27.9). As percentage 


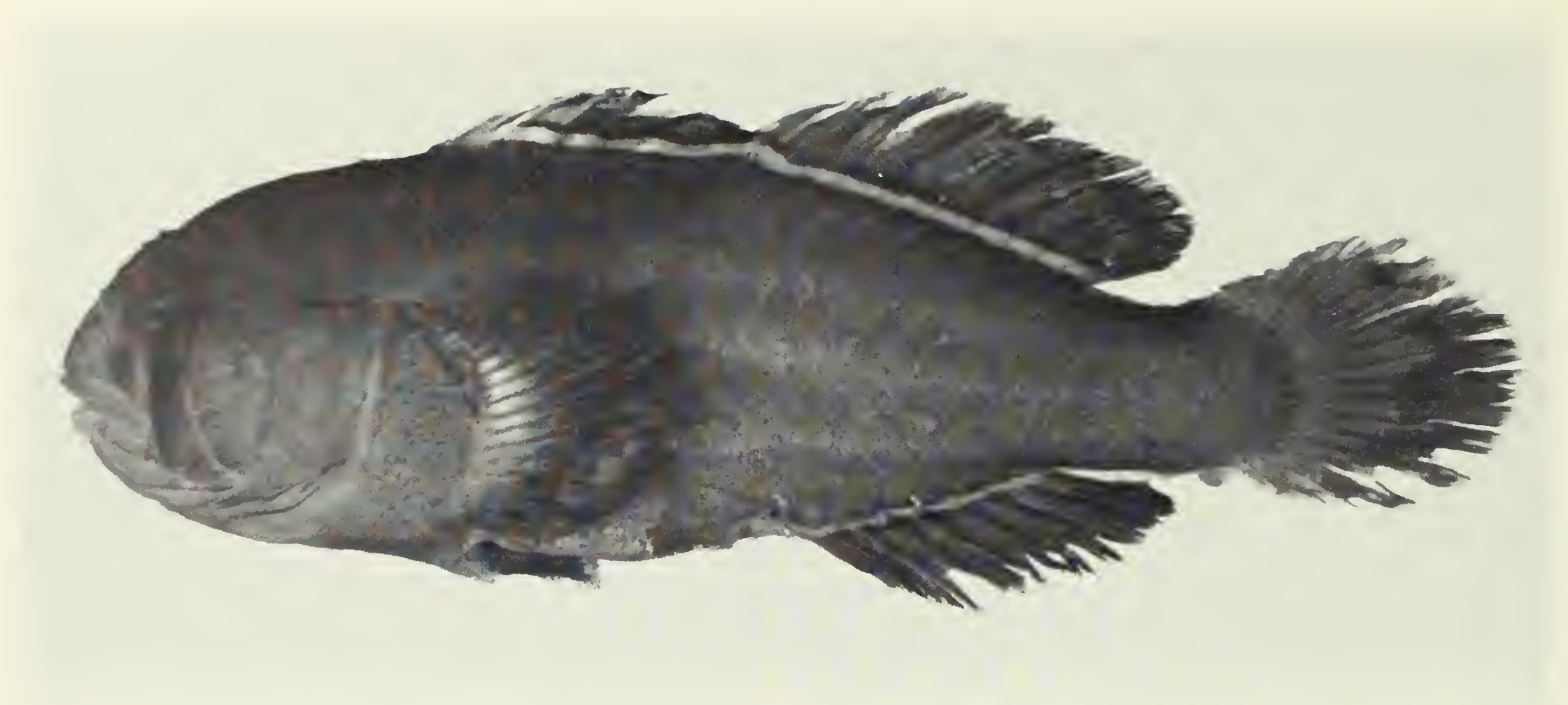

Fig. 55. Left lateral view of Gobiodon fulvus, $25.7 \mathrm{~mm} \mathrm{SL}$ (preserved).
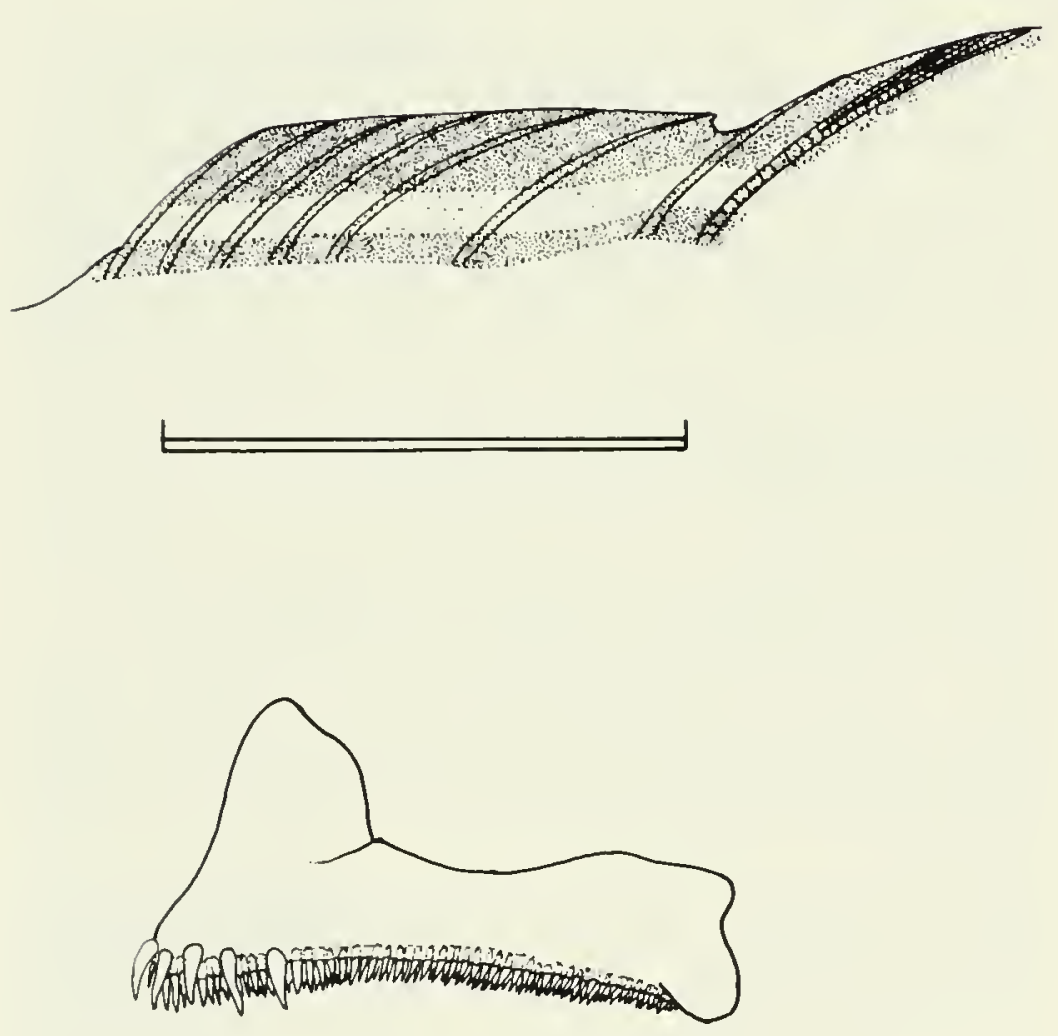

Fig. 56. Above: left lateral view of anterior portion of dorsal fins of Gobiodon fulvus, $21.6 \mathrm{~mm} \mathrm{SL}$, to show colour pattern and shape; scale equals $5 \mathrm{~mm}$. Below: left lateral view of the premaxilla of a cleared and stained Gobiodon fulvus, $14.2 \mathrm{~mm}$ $\mathrm{SL}$, to show teeth; scale equals $1 \mathrm{~mm}$. head length: eye diameter 19-25 (21.2); snout length 30-33 (31.5); upper-jaw length 33-37 (34.9). Caudalpeduncle depth as percentage caudal-peduncle length 62-75 (67.9). Head pores and papillae as in Fig. 57. Caudal skeleton as for $A$. hectori.

Colour pattern (freshly dead): not recorded. Preserved (Fig. 55): body and fins brown with up to four light vertical bands on head. First band passes from anterior part of eye to rictus of jaw; second from posterior region of eye across cheek (area between these two bands being more intensely pigmented than rest of head); third (if present) across rear margin of opercle; and fourth (if present) across pectoral-fin base. An intense dark spot at dorsal margin of the opercular membrane. Bases of dorsal and anal fins with a broad white longitudinal stripe.

\section{DISCUSSION}

Chagos specimens described here are tentatively assigned to $G$. fulvus. Koumans (1953:8) synonymized this species with $G$. erythrospilus after examining the type specimens of both species. However, we note that Hoese (ms. key) diagnoses $G$. histrio (with two colour morphs, an "erythrospilus" form and a "histrio" form) by its possession of spots or stripes on the body, and an inflected groove between the interopercle and isthmus. The groove is straight in the Chagos specimens, and the body uniform in colour. Further, $G$. histrio is not represented as having the longitudinal light stripes in the dorsal- and anal-fins bases and as only "sometimes" possessing an opercular spot. Sawada and Arai (1973) synonymize G. fulvus with $G$. micropus, but their specimens would appear to be neither of these two nominal species, for they lack the 


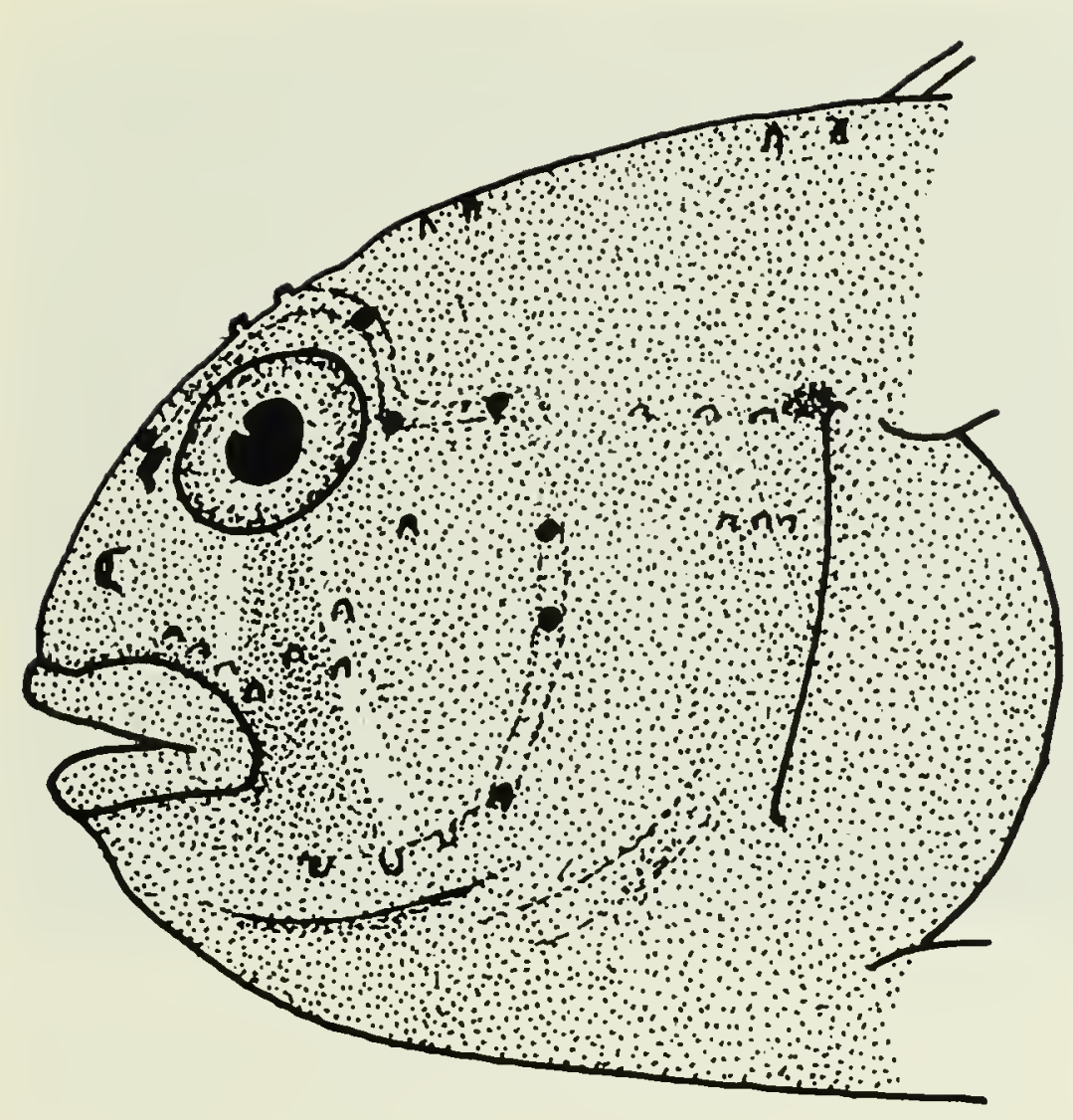

$\vDash$

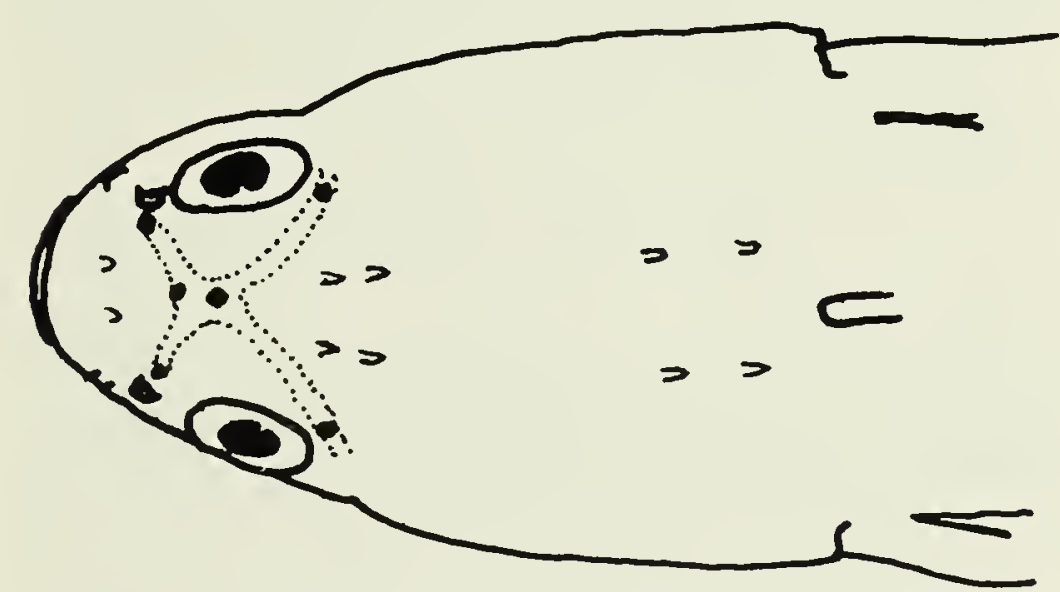

Fig. 57. Left lateral (above) and dorsal (below) views of the head of Gobiodon fulvus, $25.5 \mathrm{~mm} \mathrm{SL}$, to show head pores, papillae, and pigmentation. Scale equals $1 \mathrm{~cm}$.

groove between the isthmus and interopercle that is present in the above two species. Our misgivings in applying the name $G$. fulvus to our species are based on Herre's (1927) statement that $G$. fulvus has 11 soft dorsal-fin rays (vs 9-10) and on his failure to mention the light bars on the head. The latter omission is the only part of the description of $G$. albolineatus by Smith (1959) that differs from the Chagos specimens. We therefore suspect that the additional soft dorsal-fin ray of $G$. fulvus is due to variation or a different method of counting fin rays, that $G$. albolineatus is a junior synonym, and that the Chagos specimens are assignable to this species. We have not examined all the types of nominal species of Gobiodon, and conclude that there may well be an earlier name available for this species.

Gobiodon micropus Günther

Figs. 58, 59

Gobiodon micropus Günther, 1861:89 (China Seas).

\section{MATERIAL}

Six lots, 8 specimens, 10.9-28.0 mm SL. Depth range 0-22 m, lagoons only, at Peros Banhos and Salomon.

\section{DESCRIPTION}

Based on all specimens, none cleared and stained. D VI + I 12, sixth spine longest, complete membrane between it and first spine of second dorsal fin; A I 11; P 19-20 (19.1), reaching posteriorly to a vertical with base of fourth anal-fin ray; V I 5, complete basal membrane and fraenum, reaching (juveniles) or not quite reaching (adults) anus. No scales. Gill opening restricted, equals pectoral base in width. Mouth small, terminal. Teeth in both jaws in several rows, outer row enlarged. One or two inner canines in lower jaw. Anterior nostril tubular, posterior nostril with a raised rim. A straight groove in between isthmus and interopercle (best developed in juveniles). A fleshy, median crest from eye to origin of first dorsal fin (best developed in adults). First gill slit open; gill rakers small, $1-2+4$; pseudobranch with six to seven lobes. Five branchiostegal rays. As percentage standard length: head length 27-35 (31.8); origin of first dorsal fin 34-41 (36.9); origin of second dorsal fin 53-60 (56.8); origin of anal fin 58-63 (59.4); caudal-peduncle length 18-20 (19.2); head depth at preopercle 27-34 (30.5); depth at pelvic-fin origin 30-39 (35.6); depth at anal-fin origin 25-34 (29.5). As percentage head length: eye diameter 21-26 (24.4); snout length 24-32 (27.7); upper-jaw length 28-34 (32.1). Caudal-peduncle depth as percentage caudal-peduncle length 70-86 (76.2). Head pores and papillae as in Fig. 59.

Colour pattern (freshly dead): ground colour orange, two broad diffuse red stripes from eye towards first dorsal fin. Dorsal fins orange proximally, with a clear longitudinal basal stripe. Fins become hyaline, margined with orange. Caudal and anal fins hyaline with dusky margins. Pelvic fin orange to white, pectoral fin hyaline. Preserved: body straw-coloured, fins dusky (particularly distally), no trace of red stripes above eye.

\section{DISCUSSION}

As far as we are aware, $G$. micropus has not been reported since the original description (although it is possible that 


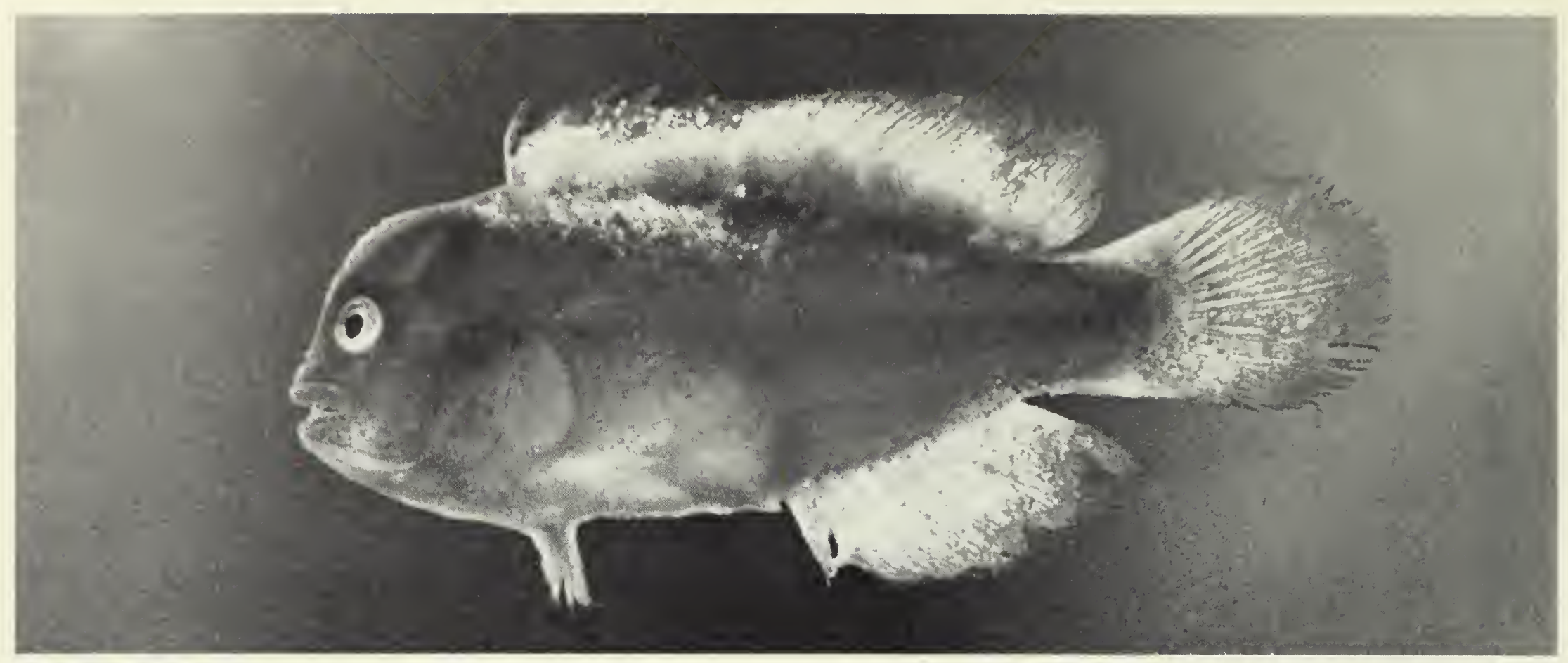

Fig. 58. Left lateral view of Gobiodon micropus, $28.0 \mathrm{~mm} \mathrm{SL}$.

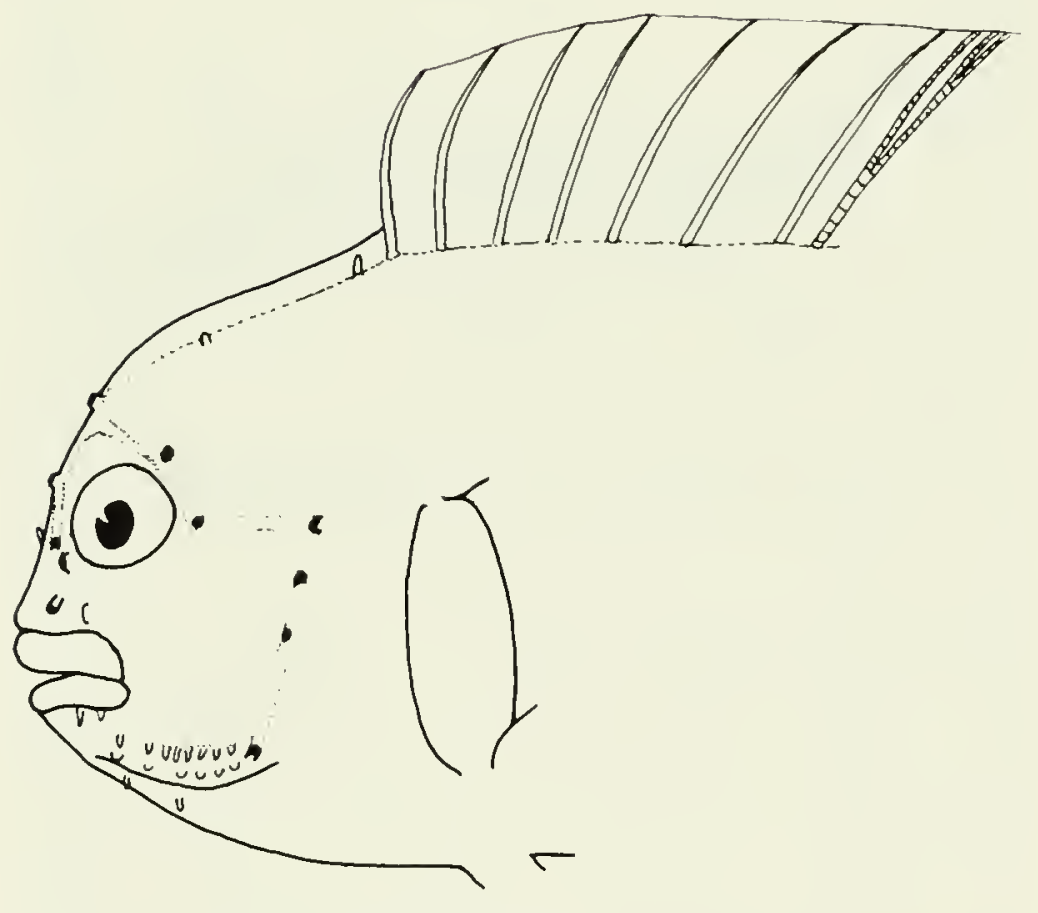

Fig. 59. Left lateral view of the head and anterior body of Gobiodon micropus, $28.0 \mathrm{~mm} \mathrm{SL}$, to show head pores, papillae, and form of dorsal fins. Scale equals $1 \mathrm{~cm}$.

the two orange specimens identified by Herre (1927) as $G$. fulvus from Batangas are this species). This new record for the Indian Ocean may simply reflect the difficulties inherent in identifying members of this genus rather than the implied localized distribution of the species. The record of G. micropus by Sawada and Arai (1973) from the Ryukyu lslands off Japan is apparently not that species (Hoese, pers. comm., who also identified our specimens).
Gobiodon rivulatus (Rüppell)

Gobius rivulatus Rüppell, 1830:136 (Red Sea).

Gobiodon rivulatus-Smith, 1959:219 (tropical Indo-west Pacific, but see Discussion).

\section{MATERIAL}

Twenty-five lots, 156 specimens, $6.3-27.7 \mathrm{~mm} \mathrm{SL}$. Depth range 3-25 m, lagoons, reef-tops, and drop-offs at Diego Garcia, Eagle Island, Peros Banhos, and Salomon.

\section{DESCRIPTION}

Based on 10 specimens from lots WE 79-06 and 79-21 (19.1-27.0 mm SL), and 10 cleared and stained specimens from WE 79-53 + 57 (16.6-23.1 mm SL). D VI + I 10 , fourth and fifth spines longest, reaching to base of second dorsal-fin spine when depressed, membrane between dorsal fins attaching one-quarter to one-half of way up spine of second dorsal fin (Fig. 61); A I 8; P 18-20 (19.2), reaching a vertical with anal-fin origin; V I 5 , complete basal membrane and fraenum, reaching threequarters of distance from its origin to anus. No scales. Gill opening restricted ventrally, ending opposite bases of 15 th to 18 th pectoral-fin rays. Mouth small, terminal. Teeth in both jaws in several series, outer row enlarged and spaced. More irregular inner rows of teeth in lower jaw than in upper jaw. Usually one to two (once three) large curved canines in lower jaw medial to other jaw teeth. Anterior nostril tubular, posterior with a raised rim. Tongue rounded. No groove between interopercle and isthmus. First gill slit open; gill rakers rudimentary, $2+2-3$, minute nubbins in cleared and stained specimens; pseudobranch with five to nine lobes. Five branchiostegal rays. Dorsal pterygiophore formula $3(2,2,1,1,0)$; verte- 


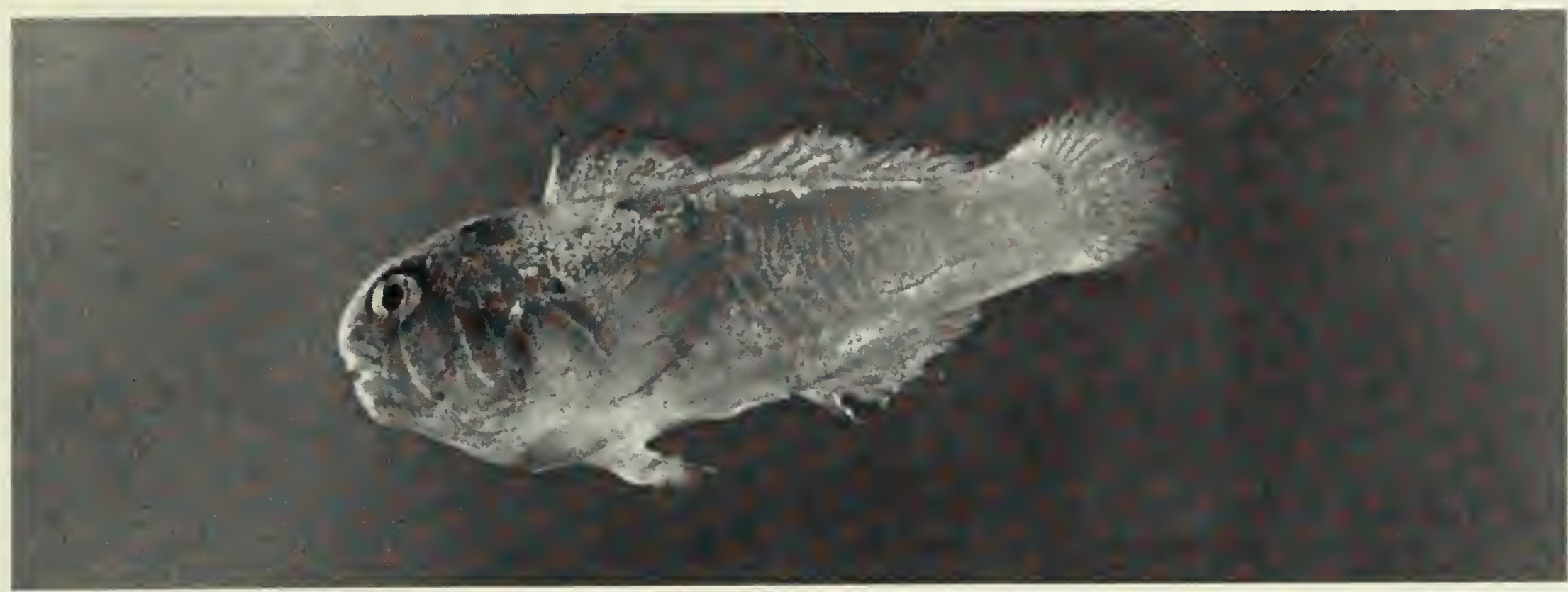

Fig. 60. Left lateral view of Gobiodon rivulatus, $24.7 \mathrm{~mm} \mathrm{SL}$.

brae $10+15+$ ural centrum $=26$. Eight to nine dorsal and seven to eight ventral branched caudal-fin rays, with six to eight dorsal and five to seven ventral unbranched rays. As percentage standard length: head length 30-33 (30.9); origin of first dorsal fin 36-40 (37.5); origin of second dorsal fin 56-59 (57.6); origin of anal fin 58-66 (61.0); caudal-peduncle length 20-26 (24.6); head depth at preopercle margin 29-31 (29.2); depth at pelvic-fin origin 33-36 (34.6); depth at anal-fin origin 27-29 (28.6). As percentage head length: eye diameter 20-24 (22.1); snout length 26-30 (28.1); upper-jaw length 30-35 (32.2). Caudal-peduncle depth as percentage caudalpeduncle length $60-74(65.8)$. Head pores and papillae as in Fig. 61. Caudal skeleton as for $A$. hectori, except fused hypurals 1 and 2 also fused to the centrum.

Gut of $24.6 \mathrm{~mm} \mathrm{SL}$ specimen contained flocculent material.

Colour pattern (freshly dead): ground colour orange, head and anterior two-thirds of body with narrow, wavy, blue-grey vertical lines. Bases of dorsal fins and of anal fin with a narrow blue-grey longitudinal stripe. Preserved: two colour morphs. Photographed specimen strawcoloured, the wavy lines on the head and body appearing as light lines with a darker margin (see Fig. 61); other (usually large) specimens with dark bodies, becoming lighter on head, pattern of wavy lines still apparent.

\section{DISCUSSION}

The name $G$. rivulatus is used here with considerable misgivings, for Rüppell's description is not diagnostic. The next available name for a Gobiodon with wavy vertical lines on the head and body is G. quinquistriatus (Valenciennes, in Cuvier and Valenciennes, 1837). However, in this species the vertical wavy lines on the body are found only in juveniles, and are absent in adults (Hoese, pers. comm.). We thus provisionally hold the

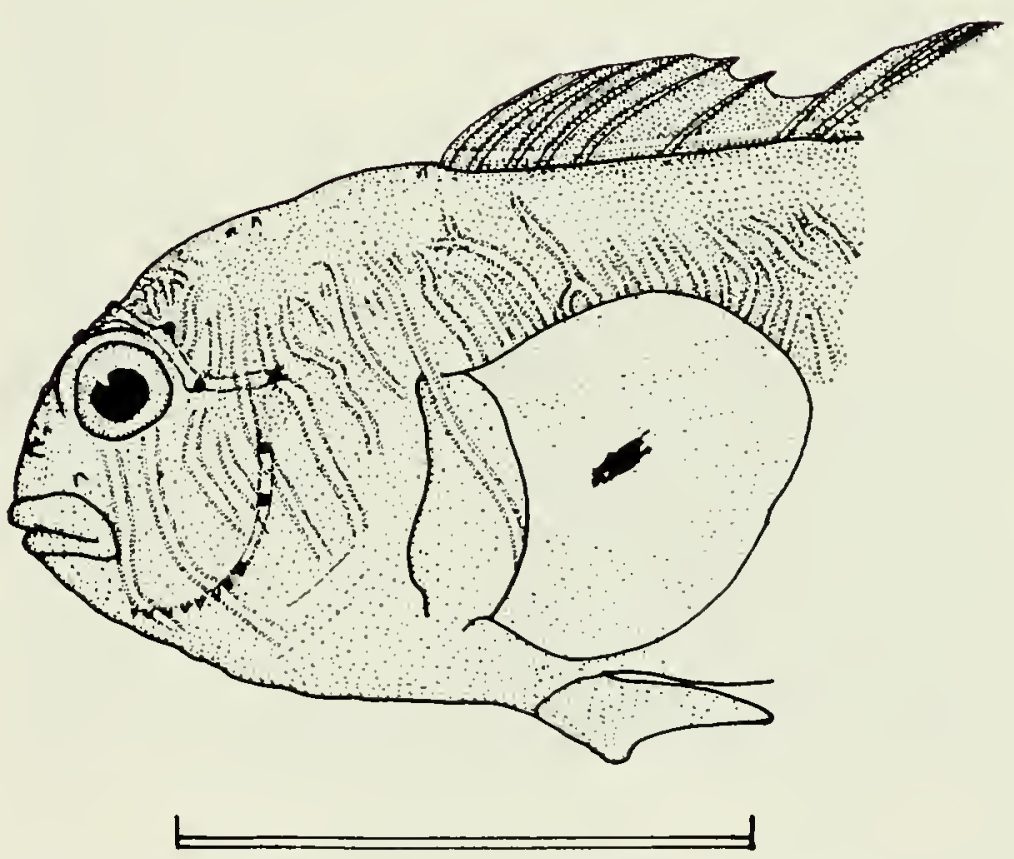

Fig. 61. Left lateral view of the head and anterior body of Gobiodon rivulatus, $26.4 \mathrm{~mm} \mathrm{SL}$, to show head pores, papillae, form of dorsal fins, and pigmentation pattern. Scale equals $1 \mathrm{~cm}$.

Indian Ocean form distinct, and, rather than propose a new name or examine all the types of nominal species of Gobiodon, we use Rüppell's name. Further, the name $G$. rivulatus has commonly been used for this species in the Indian Ocean (e.g., Smith, 1959).

Habitat distribution based on the collection data reveals a somewhat confusing picture. Eighty per cent of our specimens were collected in the lagoons, with a mean of 11.2 specimens per collection; yet $G$. rivulatus appeared in only $30 \%$ of the collections made in the lagoons. The respective values (per cent of total, mean number of specimens per collection, and per cent of collections in that area containing specimens) for reef-top collections were 12, 2.6, and 50; values for the drop-off were 8, 2.0, and 30 . There is thus some evidence to suggest a patchy 
but high-density distribution in the lagoons, but a more even and spread-out distribution on the reef-tops, and probably on the drop-off as well. Because Gobiodon is a dweller in the interstices of living coral, the above pattern may simply reflect distribution of suitable coral species.

\section{Gobiodon unicolor (Castelnau)}

Figs. 62, 63

Ellerya unicolor Castelnau, 1873:95 (Eclipse Island, Cape Sidmouth, Queensland).

\section{MATERIAL}

Three lots, 3 specimens, 15.7-23.5 mm SL. Depth range 3-25 m, lagoon, reef-top, and drop-off at Peros Banhos and Salomon.

\section{DESCRIPTION}

Based on all specimens (see also Discussion). D VI +10 , membrane between first and second dorsal fins attaching three-quarters of way along spine of second dorsal fin (Fig. 63; less than one-third of way up in $15.7 \mathrm{~mm} \mathrm{SL}$ specimen), fifth dorsal spine longest; A 18 (II 8 in $15.7 \mathrm{~mm}$ SL specimen); P 19-20, reaching to a vertical with anal-fin origin (base of first anal ray in $15.7 \mathrm{~mm} \mathrm{SL}$ specimen); V I 5, fraenum and basal membrane complete, reaching posteriorly three-quarters of distance between origin of pelvic spine and anus (94\% of that distance in 15.7 mm SL specimen). No scales. Gill opening equal to full width of pectoral-fin base. Mouth small, terminal. Teeth in both jaws in several rows, outer row enlarged (more so in upper than in lower jaw), lower jaw with one to two large curved inner canines behind the symphysis.
Tongue truncate with rounded margins. Anterior and posterior nostrils short tubes. A well-developed straight groove between isthmus and interopercle. First gill slit open; gill rakers 1-2 + 4-6; pseudobranch with six to seven lobes. As percentage standard length: head length 33-34 (33.1); origin of first dorsal fin 41 (41.0); origin of second dorsal fin 57-61 (59.4); origin of anal fin 61-71 (65.8); caudal-peduncle length 21-23 (22.4); head depth at vertical limb of preopercle 31-33 (31.8); depth at anal-fin origin 26-32 (27.8). As percentage head length: eye diameter 22 (21.7); snout length 27-32 (29.4); upper-jaw length 33-36 (34.7). Caudal-peduncle depth as percentage caudal-peduncle length 68-75 (70.4). Head pores and discernible papillae as in Fig. 63.

Colour pattern (freshly dead): not recorded. Preserved: uniform brown with speckling of larger, dark melanophores on body (lacking in $15.7 \mathrm{~mm}$ SL specimen). No stripes on fins, body, or head in larger two specimens, but an indistinct dark bar below eye in $15.7 \mathrm{~mm}$ SL specimen.

\section{DISCUSSION}

The name used here was suggested by D. F. Hoese (pers. comm.) based on his examination of the type, which has the groove between the interopercle and isthmus. Four other specimens from Chagos-WE 79-10 (2), WE 79-73, and one of the syntypes of Gobiopterus modestus Regan in $\mathrm{BM}(\mathrm{NH})$ 1908.3.23.242-250-are very similar in morphology to $G$. unicolor (we refer to them as $G$. nr unicolor). These differ from $G$. unicolor in lacking the interopercle/isthmus groove; in having the gill opening just less than the pectoral-fin base in width (ending

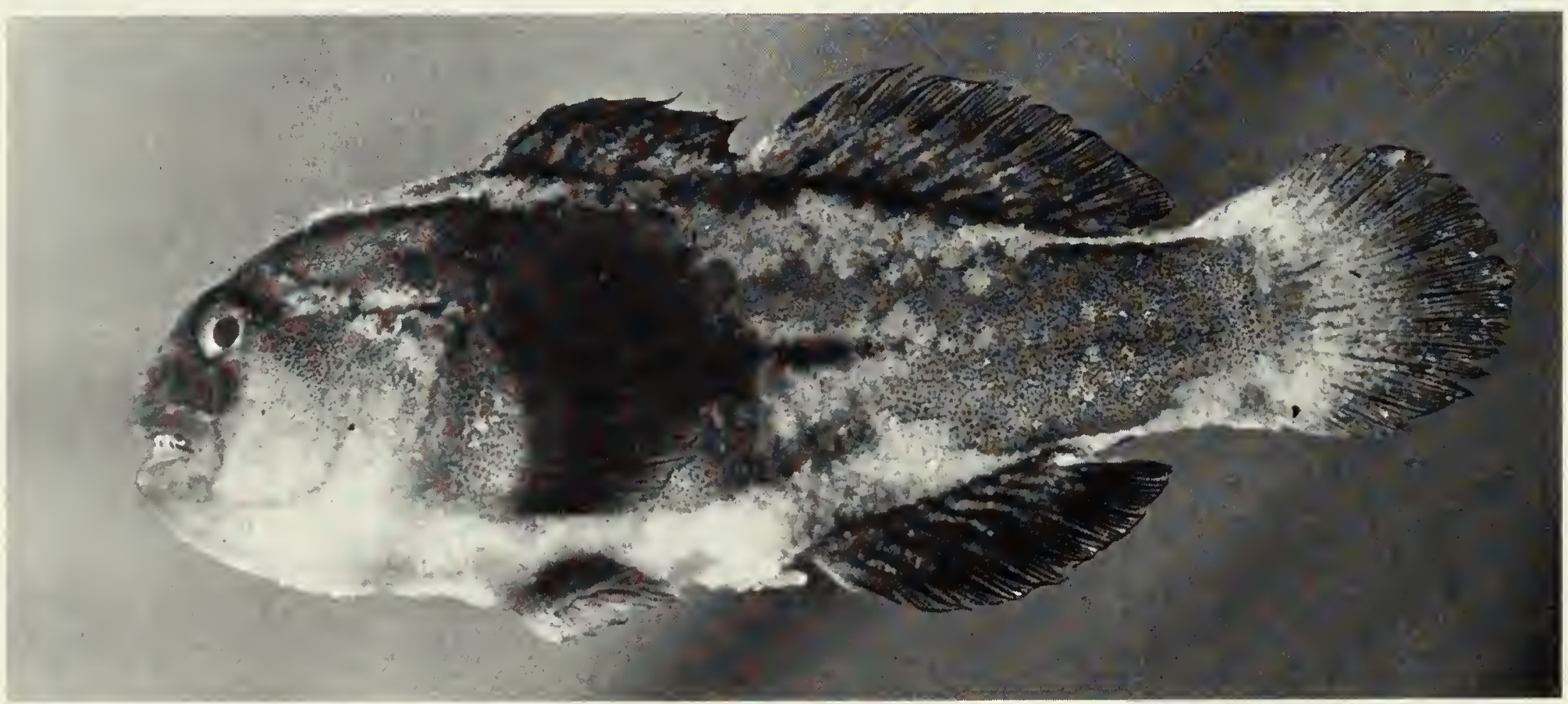

Fig. 62. Left lateral view of Gobiodon $\mathrm{nr}$ unicolor, $32.6 \mathrm{~mm} \mathrm{SL}$. 

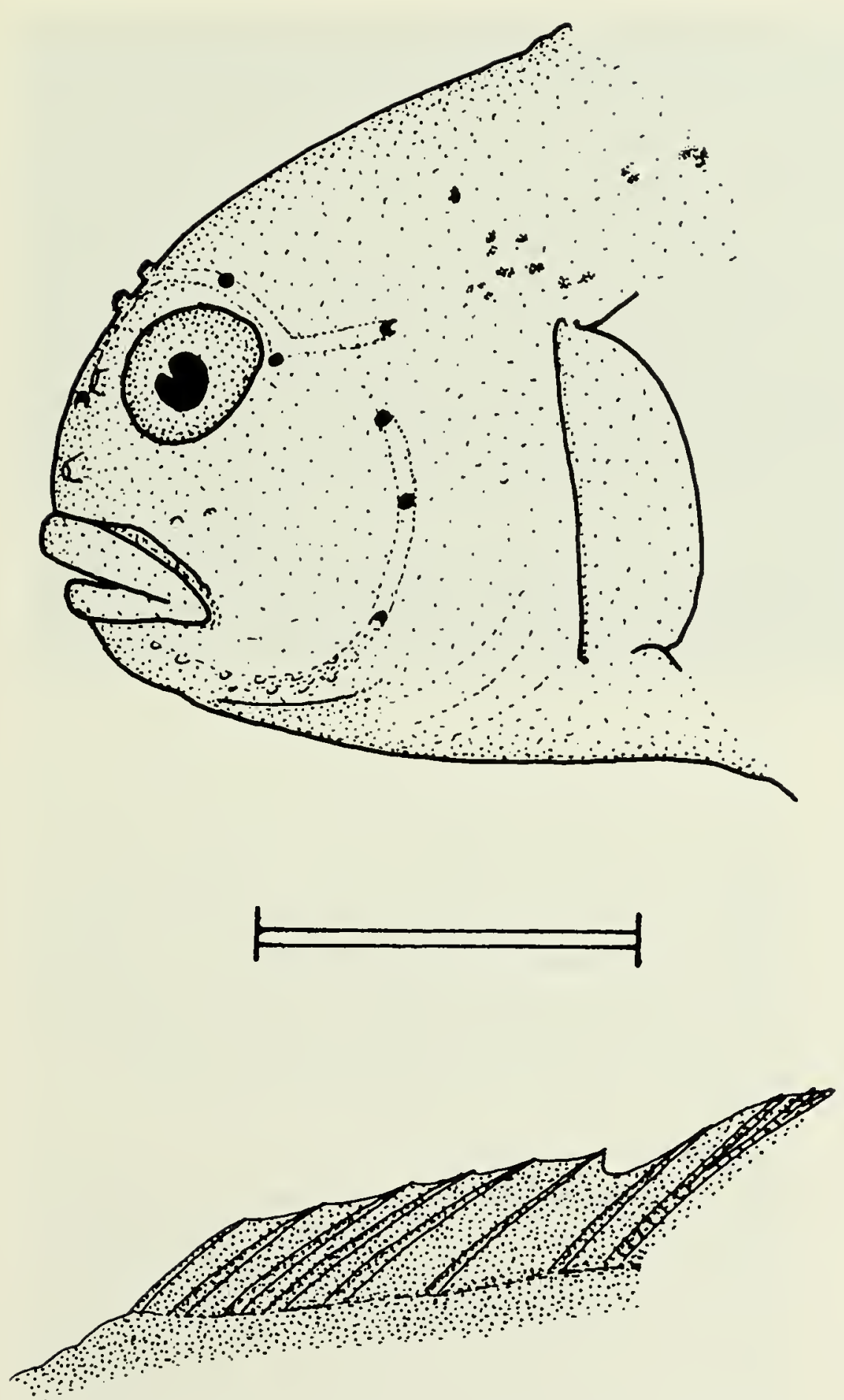

Fig. 63. Gobiodon unicolor, $23.5 \mathrm{~mm} \mathrm{SL}$. Above: left lateral view of head, to show head pores, papillae, and pigmentation. Below: anterior portion of dorsal fins, to show form and pigmentation. Scale equals $5 \mathrm{~mm}$.

ventrally opposite the bases of the 18th to 19th fin rays); in having the 9 anal-fin rays and, in three of the four specimens, 11 dorsal-fin rays; in the membrane joining the two dorsal fins attaching one-fifth to one-quarter of the way up the spine of the second dorsal fin; and in the pelvic fin reaching or almost $(80 \%)$ reaching the anus. All four specimens lack dark melanophores on the body, and the three small specimens have a diffuse light longitudinal line in the bases of the dorsal and anal fins (indistinct or absent in the largest specimen). There are possibly morphometric differences as well, but these cannot be statistically tested on such small sample sizes. For comparison with values given in the description above, they are as follows: head length 29-31 (29.1); upper-jaw length 36-39 (38.2); origin of first dorsal fin 36-38 (36.9); caudal-peduncle length 23-24 (23.1). We have used the interopercle/isthmus groove, gill-opening width, and lack of a light stripe in the dorsal- and anal-fin bases to ascribe the $15.7 \mathrm{~mm} \mathrm{SL}$ specimen to $G$. unicolor. However, we note that it shares with the above four specimens a pelvic fin almost (94\%) reaching the anus, the low attachment of the membrane between the two dorsal fins and the lack of small dark melanophores on the body. Further material would be needed to resolve the nature of this variation. Colour pattern (freshly dead): (one of specimens described as being near $G$. unicolor) uniform brown body and fins, with a light basal stripe in dorsal and anal fins. Preserved: as above.

Gobiodon DFH sp. 3

Figs. 64,65

\section{MATERIAL}

Two lots, 2 specimens, 23.9-24.2 mm SL. Depth range 5-13 m, lagoons only, at Peros Banhos and Salomon.

\section{DESCRIPTION}

Based on both specimens, from lots WE 79-10 and WE 79-66. D VI + I 10, membrane between dorsal fins reaching one-third of way up spine of second dorsal fin, third to fifth spines longest, reaching to base of spine of second dorsal fin when depressed; A I 8; P 19, reaching posteriorly to a vertical in line with base of second anal-fin ray; V I 5, complete basal membrane and fraenum, reaching or nearly reaching anus $(80-100 \%$ of distance between pelvic-fin origin and anus). No scales. Gill opening restricted, reaching a point opposite base of 14th or 15th pectoral-fin ray ventrally. Mouth terminal, inclined obliquely upwards; both jaws with several series of teeth, outer row in both jaws enlarged. A single canine in lower jaw medial to tooth rows and near symphysis. Both nostrils tubular. Tongue rounded. No groove between isthmus and interopercle. First gill slit open; $2+$ 3-4 small gill rakers on first gill arch; pseudobranch with seven to nine lobes. As percentage standard length: head length 31.0 ; origin of first dorsal fin 34.7-37.2; origin of second dorsal fin 56.5-56.6; origin of anal fin 58.6-65.3; caudal-peduncle length $24.4-25.1$; head depth at vertical limb of preopercle 24.3-24.4; depth at origin of pelvic fin 28.0-28.5; depth at anal-fin origin 23.0-23.1. As percentage head length: eye diameter $24.0-25.7$; snout length 21.6-26.7; upper-jaw length 35.1-36.0. Caudalpeduncle depth as percentage caudal-peduncle length 60.0-66.1. Head pores and papillae as in Fig. 65.

Colour pattern (freshly dead): ground colour orangebrown, most intense on head and anterior body, fading somewhat posteriorly. Five vertical, bluish white lines on 


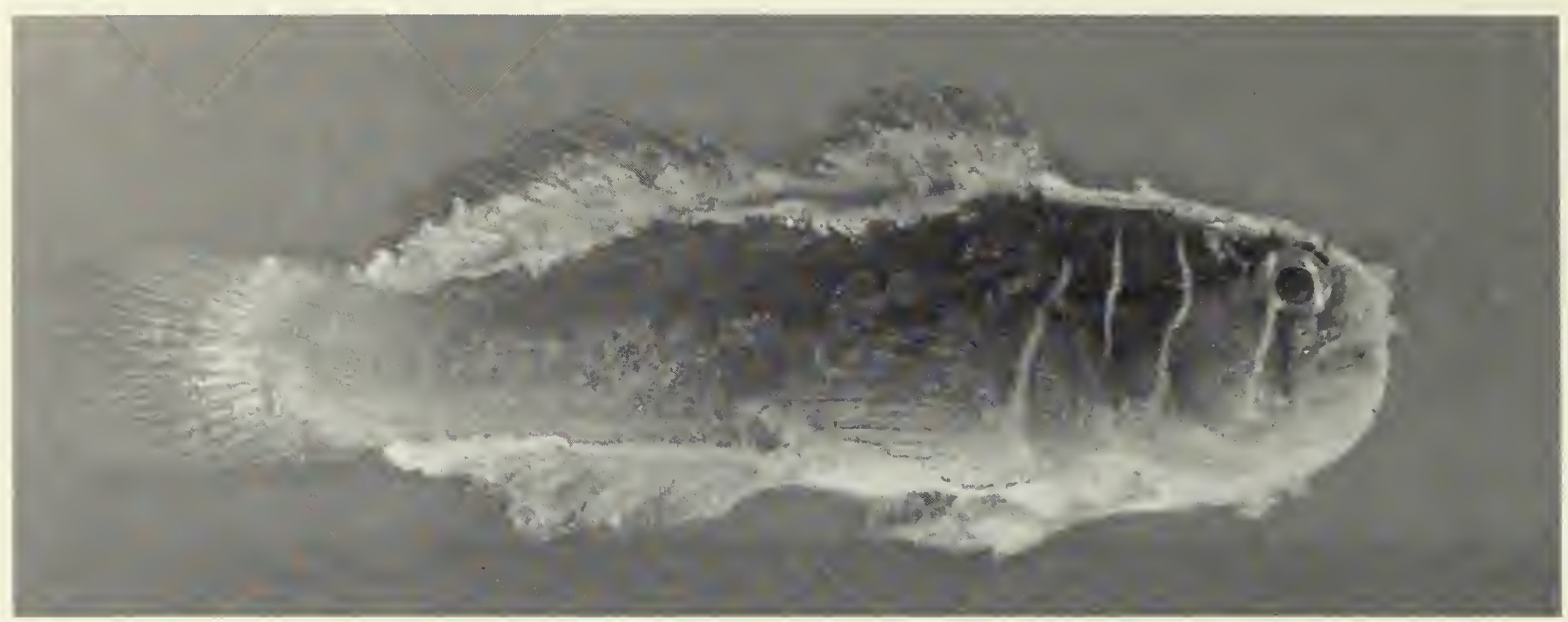

Fig. 64. Right lateral view of Gobiodon DFH sp. 3, $24.2 \mathrm{~mm} \mathrm{SL}$.
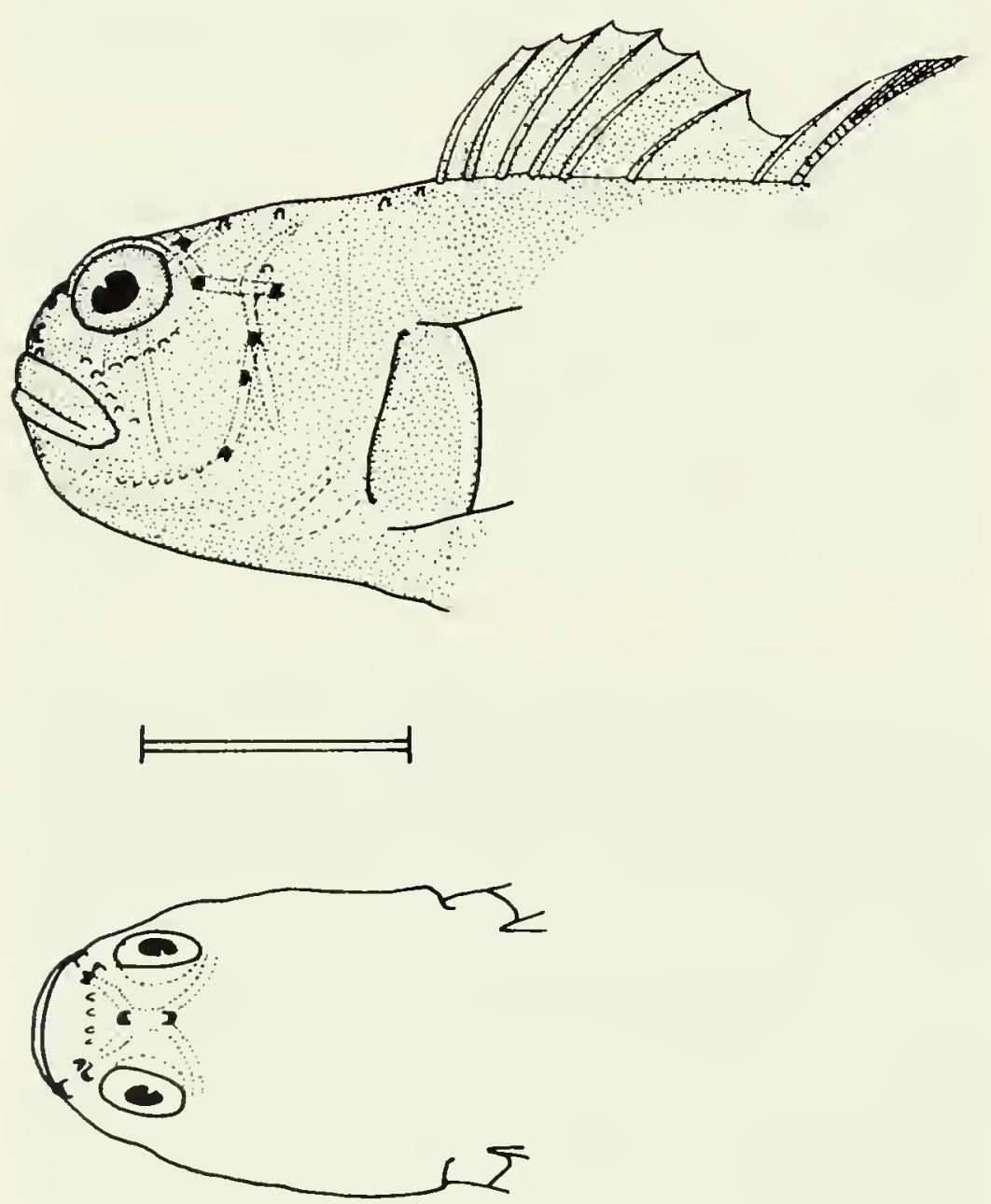

Fig. 65. Left lateral (above) and dorsal (below) views of the head and anterior body of Gobiodon DFH sp. 3, $23.9 \mathrm{~mm} \mathrm{SL}$, to show head pores, papillae, form of dorsal fins, and pigmentation pattern. Scale equals $5 \mathrm{~mm}$. head (Fig. 65); one below anterior of pupil to tip of maxilla; one from nape (in vicinity of supraotic pore) curving through iris and down across cheek; one curving down more or less in line with vertical limb of preopercle; a short line near posterior margin of opercle and a line across base of pectoral fin. Fins dusky. Preserved: similar, but ground colour brown rather than orange-brown.

\section{DISCUSSION}

Hoese, in his manuscript key to Gobiodon of the Great Barrier Reef, records what is apparently this species as "species 3". He reports that there is a white stripe at the bases of the dorsal and anal fins. Unfortunately, the bases of these fins are covered in mucous in our photographed specimen, and the presence or absence of these stripes could not be determined. There is, however, no evidence of them in our preserved material after removal of the mucous from the fin bases.

\section{Genus Hetereleotris}

Hetereleotris aporus (Hoese and Winterbottom) Fig. 66 Lioteres aporus Hoese and Winterbottom, 1979:2 (Sodwana Bay, Kwazulu).

\section{MATERIAL}

One lot, 1 specimen, $12.9 \mathrm{~mm} \mathrm{SL}$. Depth 5-7 m, lagoon at Peros Banhos.

\section{DESCRIPTION}

This species has been recently described and illustrated, and only a brief description of the Chagos specimen is offered here. The species may be recognized by lack of 


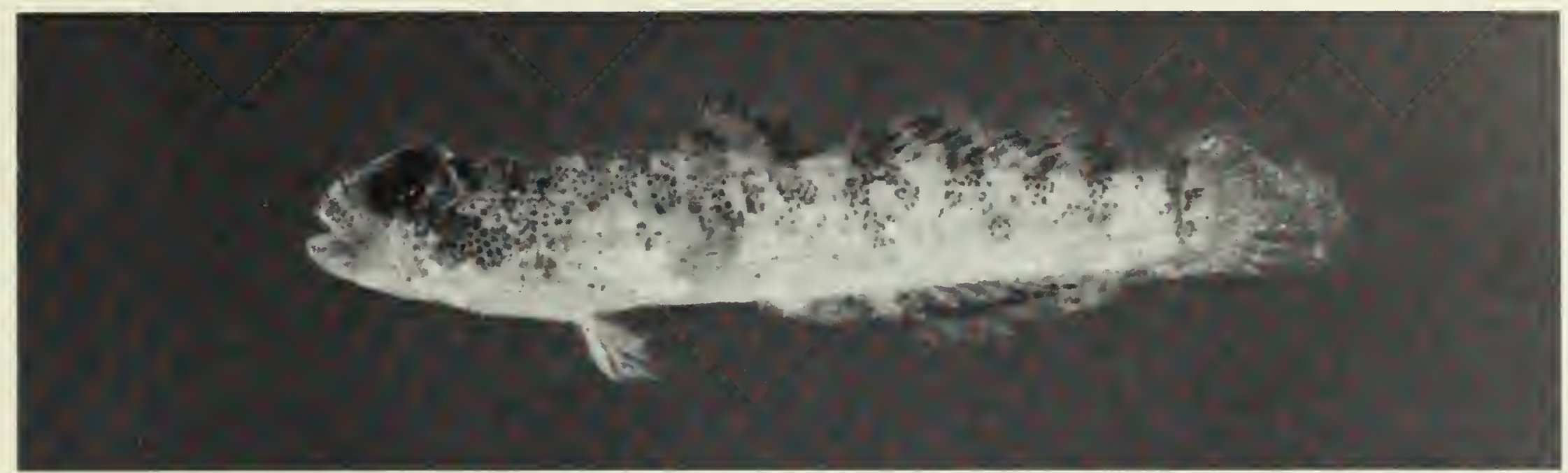

Fig. 66. Left lateral view of Hetereleotris aporus, $12.9 \mathrm{~mm} \mathrm{SL}$.

head pores; opercle with two spines on its posterior margin; tubular anterior and posterior nostrils (see Hoese and Winterbottom, fig. 2); body naked, with a few ctenoid scales on caudal peduncle; restricted gill opening; first gill arch joined to suspensorium by membrane; five branchiostegal rays; four rays in pelvic fin; no fraenum or basal membrane. D VI + I 11; A I 10; P 16; V I 4. General description as given by Hoese and Winterbottom (1979:2-3). Certain proportional differences were noted and may be due to geographic differentiation, small sample size, size of specimens $(12.9 \mathrm{~mm} \mathrm{SL}$ vs 14.3-21.6 mm SL in type series), or some or all of those factors. The value for the Chagos specimen is given first, followed by the range from the four type specimens in parentheses. As percentage head length: eye diameter 29.7 (23-25); upper-jaw length 43.8 (37-41); caudal-peduncle length 53.1 (44-47). The dark bars across the dorsum are narrower than in the type series, and four bars (rather than three) cross the base of the second dorsal fin. The head of the Chagos specimen is more heavily pigmented than in the type specimens. We follow Akihito and Meguro (1981) in assigning Lioteres to the synonymy of Hetereleotris.

\section{Genus Istigobius}

\section{Istigobius decoratus (Herre)}

Figs. 67,68

Rhinogobius decoratus Herre, 1927:181 (Cabalian, Leyte, Philippines).

\section{MATERIAL}

Nine lots, 28 specimens, 14.3-67.1 mm SL. Depth range 0.5-10 m, lagoons only, at Peros Banhos, Three Brothers, and Salomon.

\section{DESCRIPTION}

Based on 10 specimens from lots WE 79-06, 79-43,
79-55, and 1 cleared and stained specimen from WE 79-21 (43.5 mm SL). D VI + I 10 (once I 9), second to fourth spines longest, reaching to spine or first ray of second dorsal fin when depressed; A I 9; P 18-19, reaching to a vertical between anus and anal spine. Lateral scales 26 (once 27); transverse 9; predorsal 8-10. No scales on cheek or branchiostegal membranes. Prepelvic scales to, or a little anterior to, a vertical in line with vertical limb of preopercle; pectoral base with three to four rows of scales. Body scales ctenoid, those on prepelvic area cycloid; scales on pectoral base and midline of nape predominantly cycloid, sometimes a few ctenoid. Gill opening restricted, reaching ventrally to a point between a vertical with vertical margin of preopercle and pectoral base. Mouth subterminal; teeth in both jaws in several series, of which outer a little enlarged; a single laterally flaring canine at bend of dentary on each side. Anterior nostril a short tube, posterior margin raised in a short rounded simple flap; posterior nostril porelike. Tongue truncate, with rounded margins and a shallow indentation in midline. First gill slit open; gill rakers $0+6$, a fleshy pad with short papillae on ventral surface of first epibranchial; pseudobranch with six to nine lobes. Dorsal pterygiophore formula $3(2,2,1,1,0)$; vertebrae $10+15+$ ural centrum $=26$. As percentage standard length: head length 26-30 (27.9); origin of first dorsal fin 34-39 (36.2); origin of second dorsal fin 54-57 (55.3); origin of anal fin 53-57 (55.0); caudal-peduncle length 24-27 (25.4). As percentage head length: eye diameter 22-29 (25.7); snout length 25-33 (29.3); upper-jaw length 32-37 (34.3). Caudal-peduncle depth as percentage of caudal-peduncle length 43-51 (47.2). Head pores and papillae as in Fig. 68. Caudal skeleton as for $A$. hectori, but whole hypural fan more elongate than usual in the family.

Gut of $57 \mathrm{~mm} \mathrm{SL}$ specimen contained remains of decapod crustacea, polychaetes (setae), ostracods, and flocculent material.

Colour pattern (freshly dead): background pale tan. Dorsum and head with irregular dark spots rimmed with 


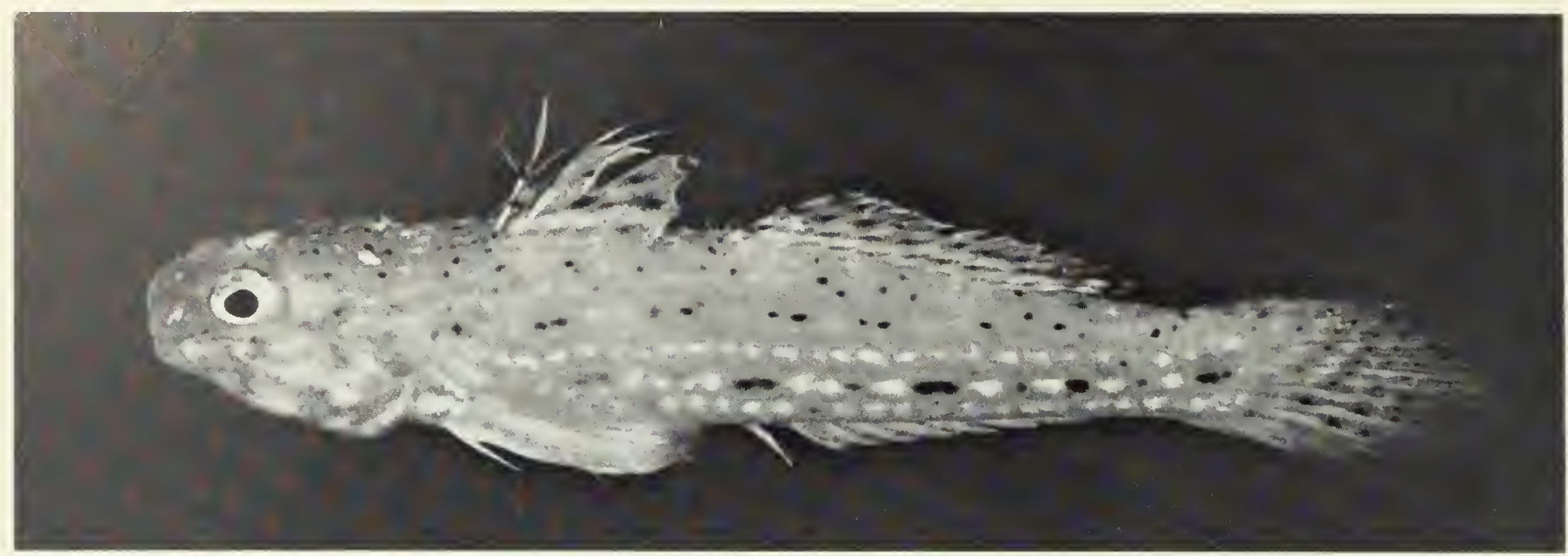

Fig. 67. Left lateral view (with a slight dorsal inclination) of Istigobius decoratus, $50.9 \mathrm{~mm} \mathrm{SL}$.
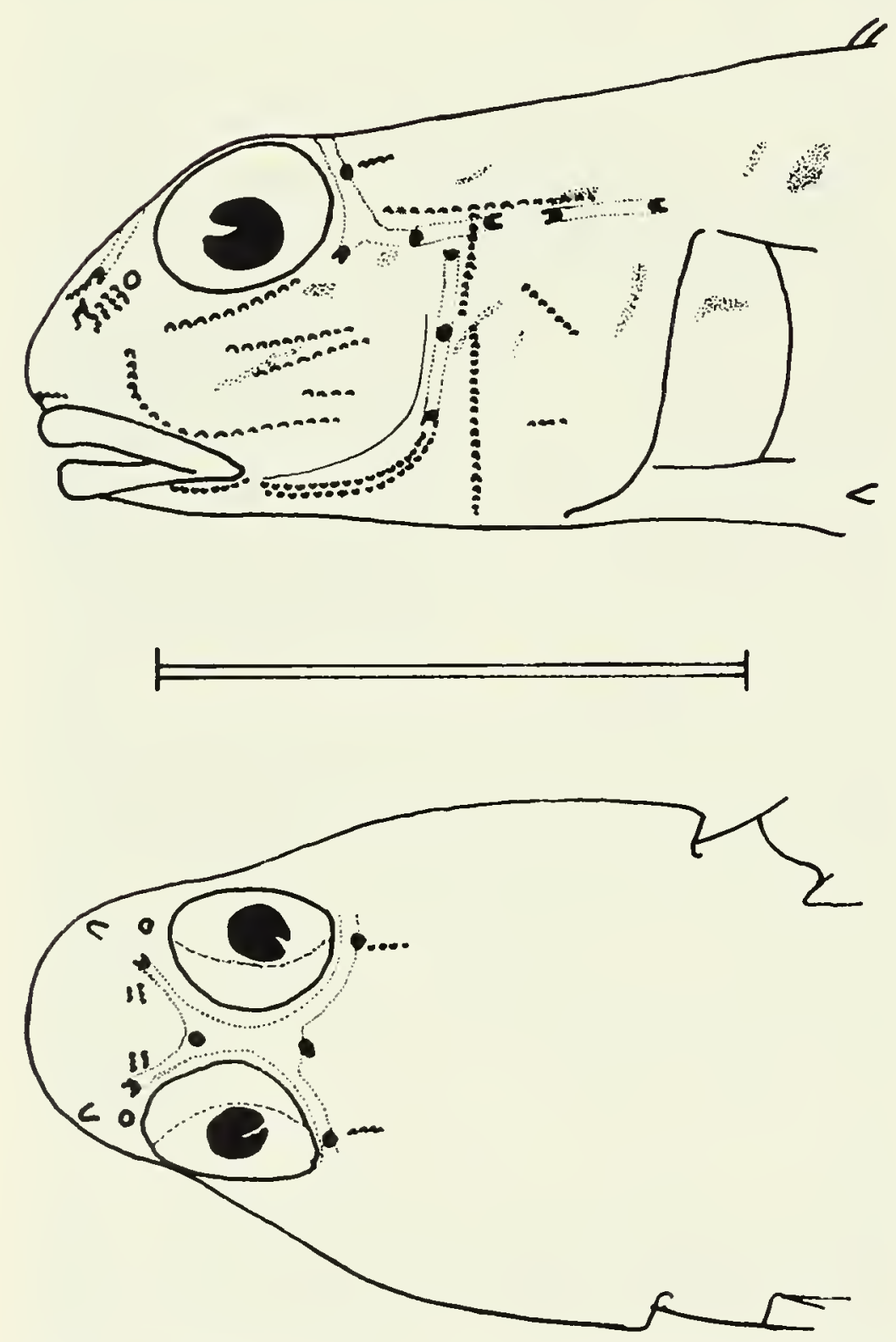

Fig. 68. Left lateral (above) and dorsal (below) views of the head of Istigobius decoratus, $39.7 \mathrm{~mm} \mathrm{SL}$, to show head pores, papillae, and pigmentation. Scale equals $1 \mathrm{~cm}$. ochre, sometimes more or less aligned in longitudinal rows and interspersed with occasional white spots or dashes. Midlateral scale row with line of prominent, irregularly spaced, single or double dark spots edged with ochre, and interspersed with elongate white spots, including prominent one over bases of hypurals. A few scattered dark spots below this with a prominent row of white spots. Preserved: as above, except that ochre edges to spots not visible and white spots/dashes not as prominent. Dorsal and caudal fins with rows of dark spots, other fins hyaline.

\section{DISCUSSION}

Our specimens have been identified by Dr E. O. Murdy, who is revising the genus Istigobius.

\section{Genus Kelloggella}

Kelloggella quindecimfasciata (Fowler) Figs. 69, 70 Agunia quindecimfasciata Fowler, 1946:207 (Ryukyu Islands).

Kelloggella centralis Hoese, 1975:482 (Cook Islands and Eniwetak).

\section{MATERIAL}

One lot, 1 specimen, $15.8 \mathrm{~mm} \mathrm{SL}$. Depth range $0-0.5 \mathrm{~m}$, reef-flat at Peros Banhos.

\section{DESCRIPTION}

D VI + I 10, first spine longest, reaching to dorsal interspace when depressed; A I 7; P 12, reaching to vertical with base of sixth dorsal spine; V I 5 , complete basal membrane and fraenum, reaching half-way to anus. No scales. Gill opening restricted, equal to pectoral base. Mouth terminal, slightly dorsally inclined. Teeth tricus- 


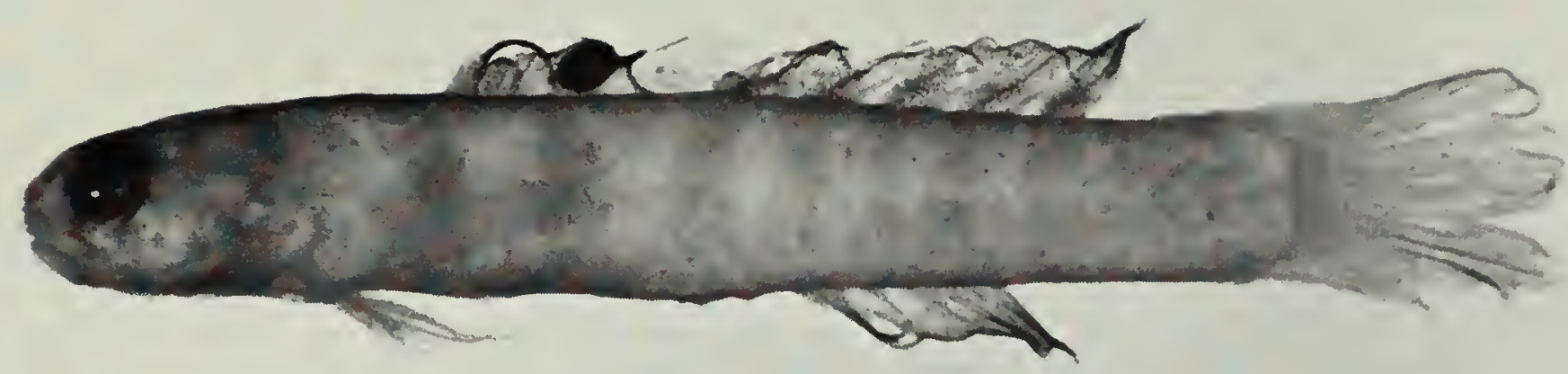

Fig. 69. Left lateral view of Kelloggella quindecimfasciata, $15.8 \mathrm{~mm} \mathrm{SL} \mathrm{(preserved).}$

pid, in several series in each jaw. One or two large inner canines in lower jaw near corner of mouth. Both nostrils tubular, short. Tongue rounded. A groove ventrally on head between interopercle and isthmus. First gill slit open, no gill rakers apparent. Five branchiostegal rays. Five upper and five lower branched caudal-fin rays, with nine upper and seven lower unbranched rays. A total of 16 segmented caudal-fin rays. As percentage standard length: head length 24.1 ; origin of first dorsal fin 35.4 ; origin of second dorsal fin 55.7; origin of anal fin 61.4; caudalpeduncle length 23.4. As percentage head length: eye diameter 23.7; snout length 23.7; upper-jaw length 36.8 . Caudal-peduncle depth as percentage caudal-peduncle length 56.8. No head pores or papillae (Fig. 70).

Colour pattern (freshly dead): slides mislaid, recorded in field notes as "elongate, with orange vertical bands." Preserved: head and body covered with melanophores except 12 light vertical bars across dorsal midline (or alternatively, 13 dark bars). These light bars almost reaching ventral midline anteriorly, but becoming progressively shorter posteriorly, posteriormost only reaching to midlateral septum. Melanophores tending to form pupil-sized spots on head, particularly around eye. First dorsal fin dusky, with proximal hyaline areas between third and fourth spines and behind sixth spine. An intense, black, eye-sized spot in membrane between fifth and sixth spines, not reaching dorsum ventrally, but edging margin of fin membrane dorsally. Second dorsal fin dusky, with vertical hyaline stripes centred on second, fourth, sixth, and eighth fin rays. Caudal and anal fins dusky, pectoral with a few melanophores, pelvic hyaline.

\section{DISCUSSION}

Kelloggella was revised by Hoese (1975). He described a new species, $K$. centralis (from the Cook and Marshall islands), and contrasted it with the closely related $K$.
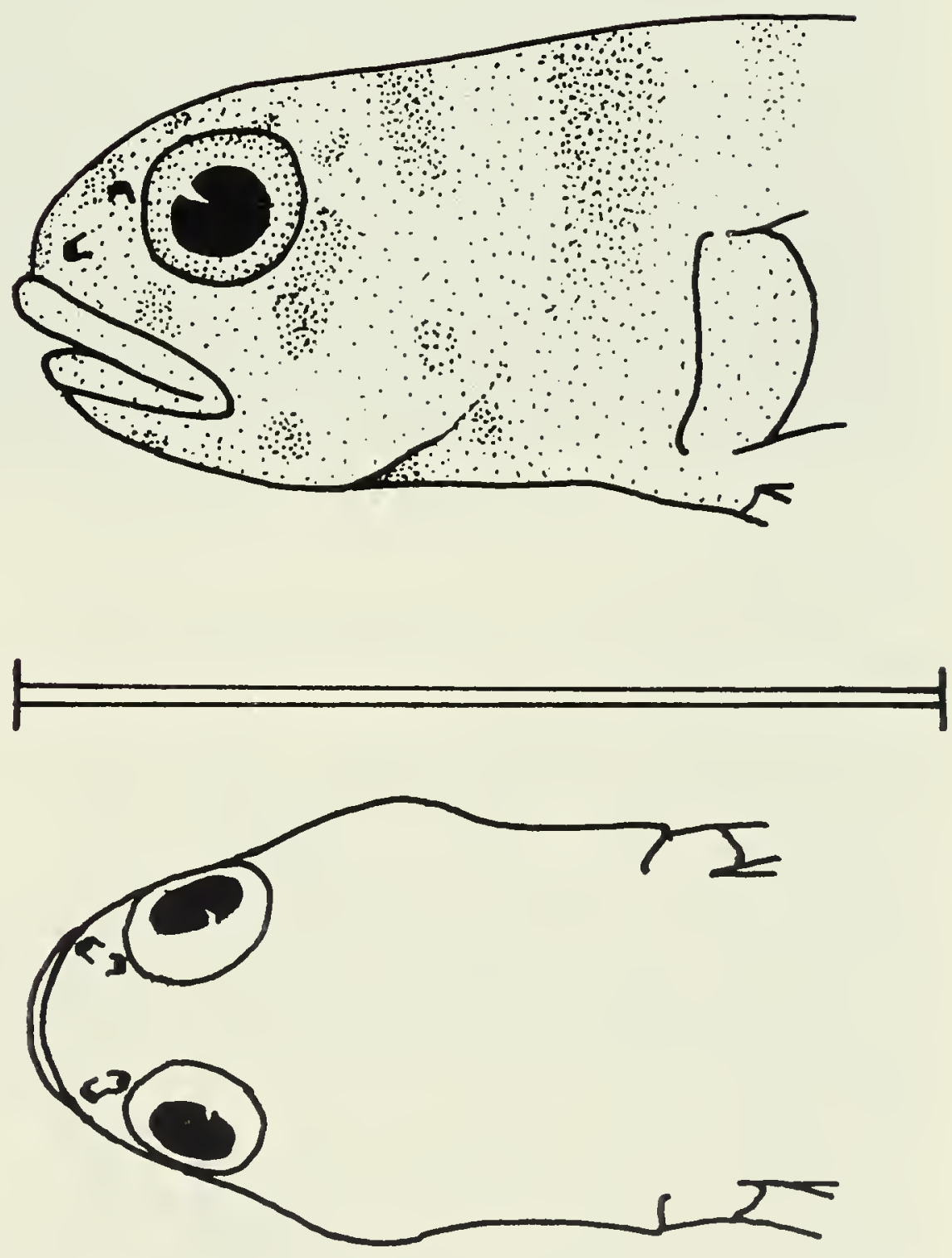

Fig. 70. Left lateral (above) and dorsal (below) views of the head of Kelloggella quindecimfasciata, $15.8 \mathrm{~mm} \mathrm{SL}$, to show outline and pigmentation. Scale equals $5 \mathrm{~mm}$. 
oligolepis (from Hawaii and Easter Island). He regarded Agunia quindecimfasciata Fowler as a synonym of $K$. oligolepis on the basis of dentition, of the number of segmented caudal-fin rays (15-but Smith-Vaniz [pers. comm.] counts 16 segmented caudal-fin rays on Fowler's holotype), and of colour pattern. He pointed out that the pectoral-fin and second dorsal-fin ray counts of the holotype were low for K. oligolepis. Sawada (1977) reported two additional specimens of Kelloggella from the Ryukyu Islands, which he identified as $K$. centralis. In addition to sharing the pectoral-fin and second dorsal-fin ray counts with Fowler's specimen (12 and 10 respectively), they possessed 16 segmented caudal-fin rays (all three values being typical of $K$. centralis). Sawada pointed out that the dentition and colour pattern of $K$. oligolepis is closely similar to that of males of $K$. centralis, but refrained from resurrecting Fowler's name for $K$. centralis. We have taken that step here for the following reasons:

a. two of the three specimens of Kelloggella from the Ryukyu Islands have 16 segmented caudal-fin rays $(93.3 \%$ of $K$. centralis specimens, and only $3.4 \%$ of $K$. oligolepis specimens have been reported with 16 such rays);

$b$. the number of second dorsal-fin and pectoral-fin rays is typical for $K$. centralis (in which $92.6 \%$ have 10 dorsal-fin and $84 \%$ have 12 pectoral-fin rays, as opposed to $85 \%$ of $K$. oligolepis with 11 dorsal-fin and $96.2 \%$ with 13 pectoral-fin rays);

$c$. the Ryukyu Islands are in closer geographical proximity to the Cook and Marshall islands than to Hawaii and Easter Island;

d. Smith-Vaniz counts 16 segmented caudal-fin rays in Fowler's holotype.

We acknowledge that the above is based on the assumption that there is only one species of Kelloggella at the Ryukyu Islands. In summary, the only character exhibited by the holotype of $K$. quindecimfasciata that would place it in $K$. oligolepis rather than $K$. centralis is the contested number of segmented caudal-fin rays (15, but 16 in Smith-Vaniz's count). Fifteen rays are reported in 2 of the 28 specimens of $K$. centralis examined by Hoese (1975).

We could find no differences between our Chagos specimen and $K$. quindecimfasciata, except that the dark spot in the first dorsal fin appears to be higher up in the membrane in the Chagos specimen (touches dorsum in $K$. quindecimfasciata [Hoese, 1975, fig. 3; Sawada, 1977, fig. 3]). This could be due to geographic variation, individual variation, or fading on preservation. The Chagos specimen was recorded by Springer (1982), who quoted a letter from Hoese suggesting it may represent an undescribed species.

\section{Genus Luposicya}

\section{Luposicya lupus Smith}

Luposicya lupus Smith, 1959:217 (Pinda, Mozambique); Russell, 1983:134 (eastern Australia).

\section{MATERIAL}

One lot, 1 specimen, $20.6 \mathrm{~mm} \mathrm{SL}$. Depth range 5-7 m, lagoon at Salomon.

\section{DESCRIPTION}

Our single specimen has been sent to H. K. Larson, who is revising the genus.

\section{New Genus}

The genus contains two species which will be described and illustrated in detail by Winterbottom and Hoese, and will not be described here. Members of the genus are very similar in size and appearance to species of Eviota, but differ in having the fifth pelvic-fin ray branched, and in possessing a basal membrane.

\section{New Species A}

Fig. 71

\section{MATERIAL}

Three lots, 10 specimens, $10.1-13.9 \mathrm{~mm}$ SL. Depth range $18-48 \mathrm{~m}$, drop-off caves at Peros Banhos and Salomon.

\section{New Species B}

Fig. 72

\section{MATERIAL}

Thirty-one lots, 178 specimens, 6.9-18.6 mm SL. Depth range 3-43 $\mathrm{m}$, lagoon, reef-top, and drop-off at Peros Banhos and Salomon.

\section{Genus Paragobiodon}

Paragobiodon echinocephalus (Rüppell)

Fig. 73 Gobius echinocephalus Rüppell, 1830:136 (Red Sea). Gobiopterus modestus Regan, 1908:242 (partimEgmont and Salomon, Chagos).

\section{MATERIAL}

Two lots, 6 specimens, $23.7-30.5 \mathrm{~mm}$ SL. Egmont and Salomon (all specimens part of the syntypic series of $P$. modestus Regan, and deposited in the British Museum [Natural History]). 


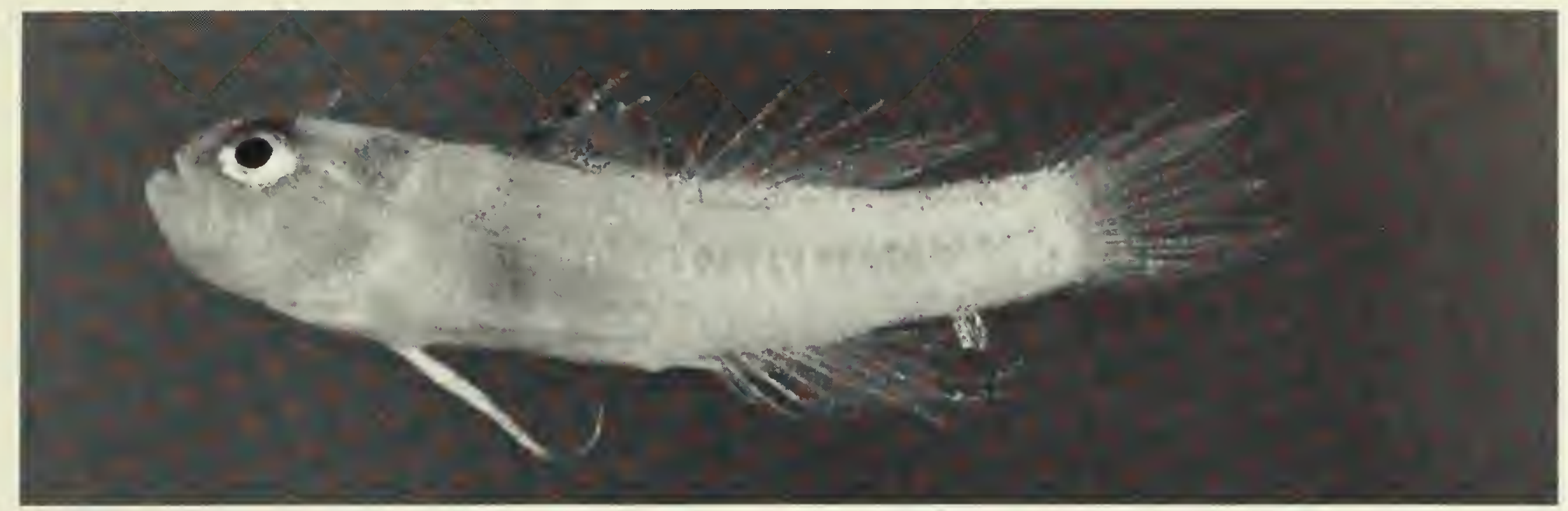

Fig. 71. Left lateral view of the new genus, new species A, $13.9 \mathrm{~mm}$ SL.

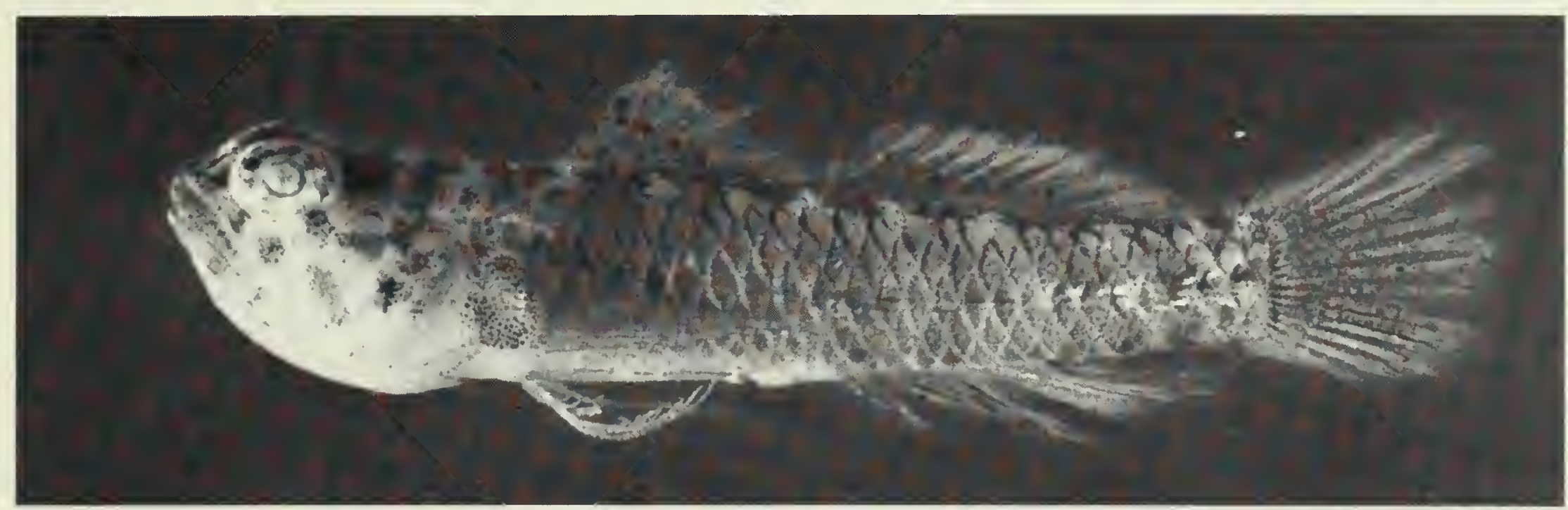

Fig. 72. Left lateral view of the new genus, new species B, $18.6 \mathrm{~mm}$ SL.
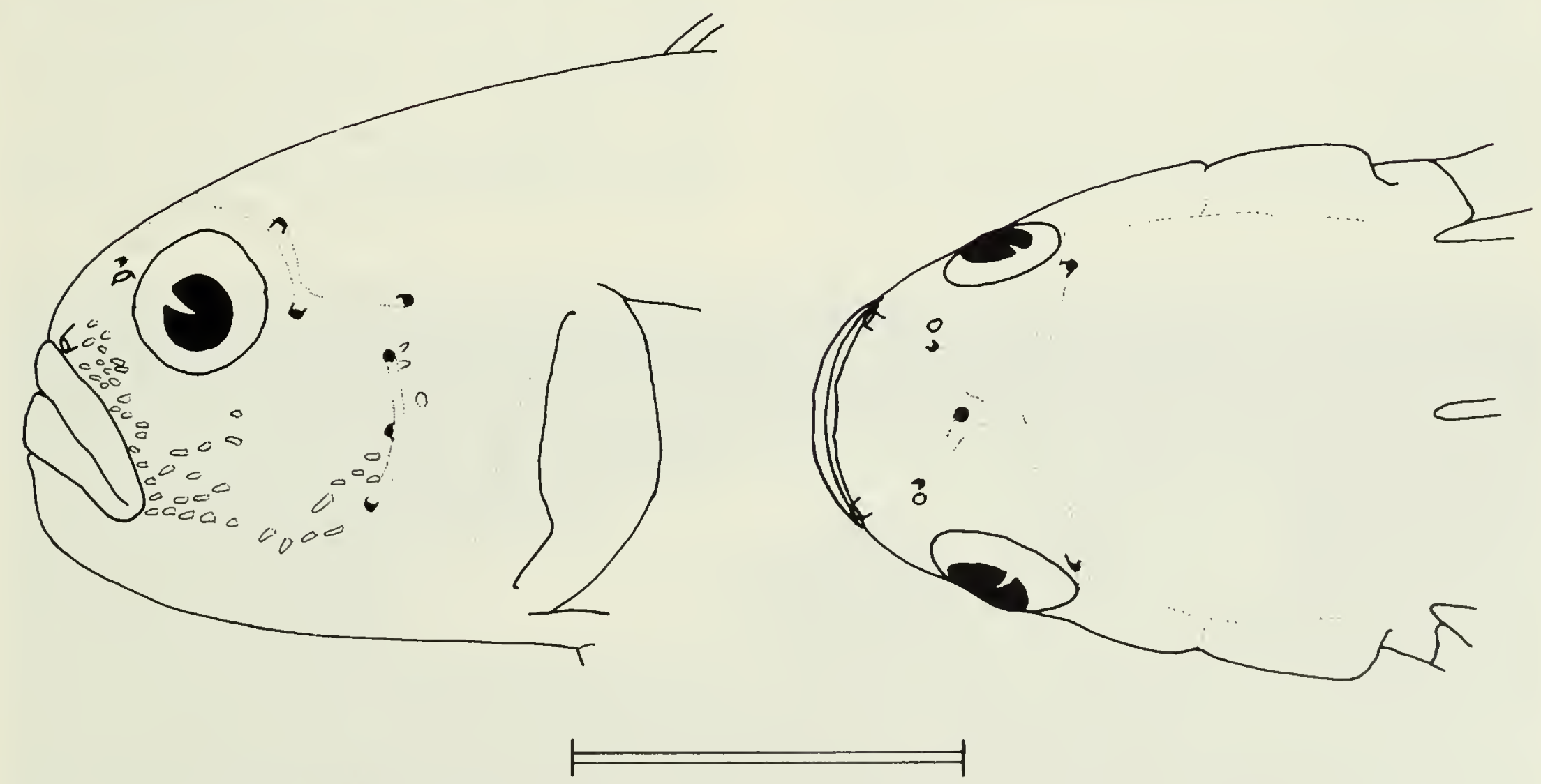

Fig. 73. Left lateral (left) and dorsal (right) views of the head of Paragobiodon echinocephalus, $23.2 \mathrm{~mm} \mathrm{SL}$, to show head pores and papillae (on cheek only). Scale equals $5 \mathrm{~mm}$. 


\section{DESCRIPTION}

Based on all six specimens. D VI + I 9, second to fifth spines longest, membrane from sixth spine attached one-fifth of way up first spine of second dorsal fin; A I 9; P 20-22 (21.1); V I 5, basal membrane and fraenum complete, reaching posteriorly to a point between anus and urogenital papilla. Lateral scales 25-27 (25.8); transverse 9-10 (9.3). No scales on head, nape, pectoral base, or breast. Scales ctenoid except cycloid on belly. Gill opening restricted, reaching ventrally to a point opposite ventralmost pectoral-fin ray. Mouth terminal, inclined obliquely upwards. In upper jaw, outer row of enlarged teeth and several inner rows of smaller teeth. In lower jaw teeth similar, but innermost row enlarged, equal to outermost row. Two large inner canines. Anterior nostril a short tube, posterior porelike, with a raised rim. Tongue rounded. Head and nape covered with numerous papillae, longest on nape and cheeks (almost pupil diameter in length). None immediately ventral to eye, one or two rows between eye and maxilla. Upper lip smooth. First gill slit open; gill rakers $2+2$; pseudobranch with six to eight lobes. Five branchiostegal rays. As percentage standard length: head length 30-31 (30.6); origin of first dorsal fin 33-38 (35.7); origin of second dorsal fin 52-58 (55.2); origin of anal fin 54-57 (55.7); caudal-peduncle length 22-25 (24.0). As percentage head length: eye diameter 24-26 (25.0); snout length 26-30 (28.2); upper-jaw length 38-41 (38.8). Caudal-peduncle depth as percentage caudal-peduncle length 66-76 (66.2). Head pores and cheek papillae as in Fig. 73.

Colour pattern (preserved): body and fins black, head somewhat lighter.

\section{DISCUSSION}

Paragobiodon is currently being revised by D. F. Hoese. He records (pers. comm.) 19-20 pectoral-fin rays for $P$. echinocephalus and 21-22 for $P$. melanosomus from the
Great Barrier Reef. The Gardiner Expedition specimens from Chagos, with a mean of 21.1 pectoral rays, thus accord better with $P$. melanosomus. However, the lighter head of the Chagos material indicates $P$. echinocephalus (in $P$. melanosomus, the head and body are uniformly black). Finally, Hoese (pers. comm.) records $P$. echinocephalus as found only among the branches of the coral Stylophora pistillata and $P$. melanosomus as found only on Seriatopora caliendrum. Sheppard (1979, 1980) records $S$. pistillata from Chagos, but makes no reference to any coral with a specific name of "caliendrum". We have no explanation of our failure to collect $P$. echinocephalus in any of the 71 rotenone stations we made at Chagos.

\section{Paragobiodon lacunicolus (Kendall and Goldsborough)} Figs. 74, 75

Ruppellia lacunicola Kendall and Goldsborough, 1911:318 (Fakarava, Tuamotu Archipelago).

\section{MATERIAL}

Five lots, 6 specimens, 5.8-11.9 mm SL. Depth range 5-20 m, primarily on reef-tops (one specimen from lagoon), at Peros Banhos and Salomon.

\section{DESCRIPTION}

Based on four specimens from lots WE 79-08, 79-90, and 79-92 (9.8-11.9 mm SL). D VI + I 9-10 (9.3), fourth and fifth spines longest, reaching to base of third ray of second dorsal fin when depressed, membrane connecting dorsal fins reaching to distal tip of spine of second dorsal fin; A I 8; P 21-22 (21.6), reaching to a vertical with base of third anal-fin ray; V I 5, complete basal membrane and fraenum, reaching posteriorly to urogenital papilla. Lateral scales 23-24; transverse 8. No scales on the head, nape, pectoral base, or breast; scales ctenoid on body. Gill

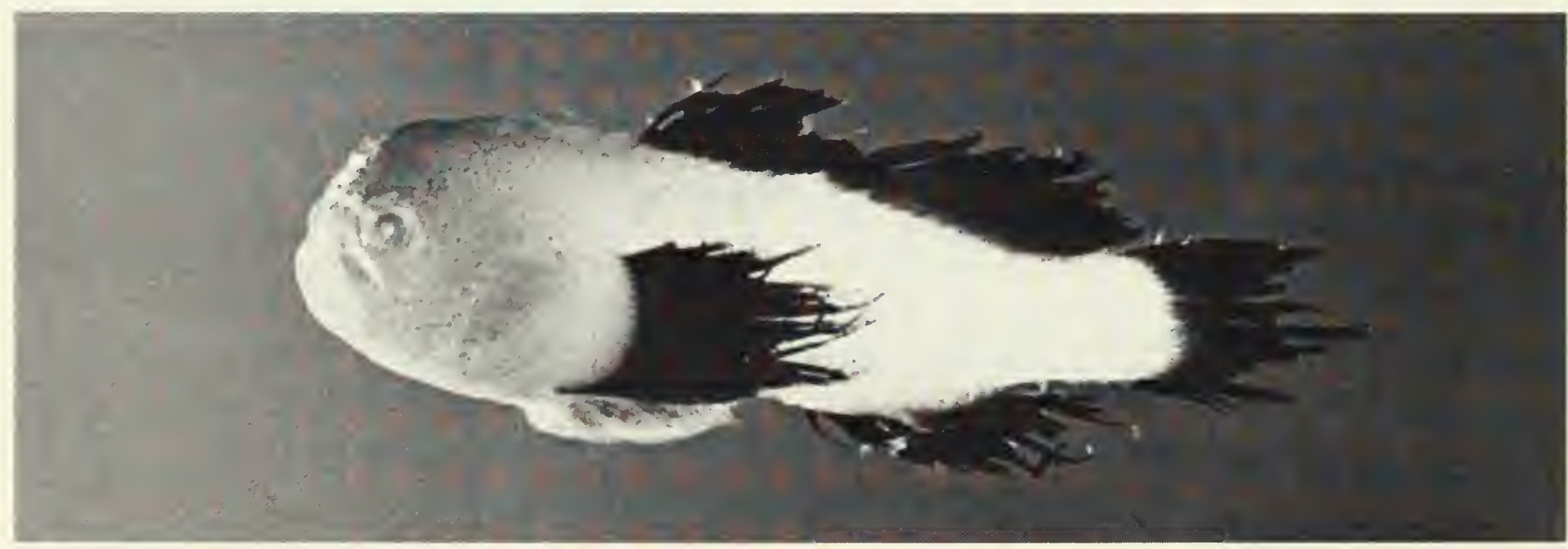

Fig. 74. Left lateral view of Paragobiodon lacunicolus, $11.8 \mathrm{~mm}$ SL. 

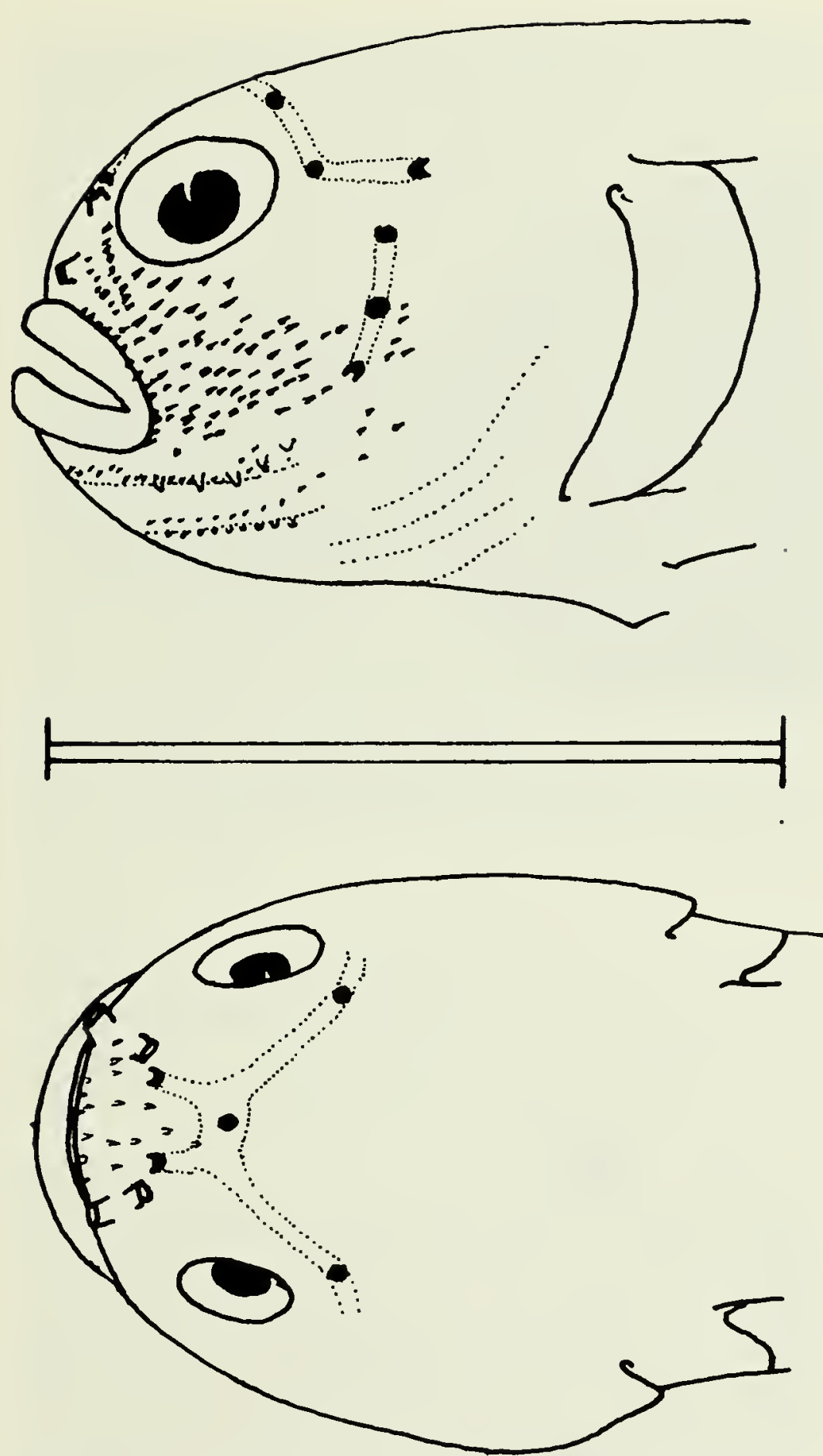

Fig. 75. Left lateral (above) and dorsal (below) views of the head of Paragobiodon lacunicolus, $11.8 \mathrm{~mm} \mathrm{SL}$, to show head pores and papillae. Scale equals $5 \mathrm{~mm}$.

opening restricted, attached ventrally to base of pectoral fin opposite last fin-ray. Mouth terminal, inclined dorsally; upper jaw with outer row of enlarged teeth and several inner rows of smaller teeth; lower jaw teeth similar, with a larger inner canine near symphysis. Both nostrils tubular. Tongue rounded. First gill slit open (not attached to suspensorium by membrane); gill rakers very short, $1+2-3$; pseudobranch with three to four lobes. Five branchiostegal rays. As percentage standard length: head length 34-37 (35.2); origin of first dorsal fin 39-42 (40.4); origin of second dorsal fin 58-60 (59.1); origin of anal fin 59-66 (62.1); caudal-peduncle length 20-23 (21.4). As percentage head length: eye diameter 25-29
(26.6); snout length 17-25 (22.6); upper-jaw length 29-35 (32.2). Caudal-peduncle depth as percentage caudal-peduncle length 65-76 (72.2). Head pores and papillae as in Fig. 75.

Colour pattern (freshly dead): head orange-brown, grading above pectoral base into yellowish white on body. All fins except pelvics jet black, pelvics dusky. Preserved: similar to above.

\section{DISCUSSION}

Koumans (1953) regarded $P$. lacunicolus as a synonym of $P$. echinocephalus, the only species in this genus that he did recognize. In this, he was followed by Smith (1959). Tyler (1971:17-18) also felt that $P$. lacunicolus was "probably" the same as $P$. echinocephalus. However, in addition to differences in colour, the latter species differs from $P$. lacunicolus in having numerous elongate flaps on top of the head vs a few short flaps (Hoese, pers. comm.).

Paragobiodon modestus (Regan)

Figs. 76, 77

Gobiopterus modestus Regan, 1908:242 (syntypes from Egmont and Salomon, Chagos).

\section{MATERIAL}

Eight lots, 21 specimens, 8.9-24.9 $\mathrm{mm} \mathrm{SL}$. Depth range 0-7 $\mathrm{m}$, primarily in lagoons (two specimens in two lots from reef-top), Eagle Island, Peros Banhos, Salomon, and Three Brothers.

\section{DESCRIPTION}

Based on 10 specimens from lots WE 79-06, 79-43, and 79-55 (11.9-24.9 mm SL), plus 2 cleared and stained specimens from WE 79-33 (11.3-18.0 mm SL). D VI + I 9 , fourth and fifth spines longest, reaching to base of first ray of second dorsal fin when depressed, membrane between dorsal fins connected basally to spine of second dorsal fin; A I 9; P 21-24 (23.0), reaching posteriorly to a vertical in line with base of anal spine or first anal-fin ray; V I 5, complete basal membrane and fraenum, reaching posteriorly to anus or base of anal spine. Lateral scales 24-25 (24.3); transverse 9. No scales on head, nape, pectoral base, breast, or midline of belly. Rest of body covered with ctenoid scales, with a few cycloid scales on belly near midline. Gill opening restricted, membrane attached ventrally to pectoral base opposite base of fourth to sixth ventralmost pectoral-fin rays. Mouth terminal, horizontal. Teeth in outer row of upper jaw enlarged, those near symphysis caniform; several inner rows somewhat enlarged, and one or two large inner canines near symphysis. Both nostrils tubular, the posterior a little shorter than the anterior. Tongue rounded. First gill slit open, no gill rakers. Five branchiostegal rays. Dorsal 


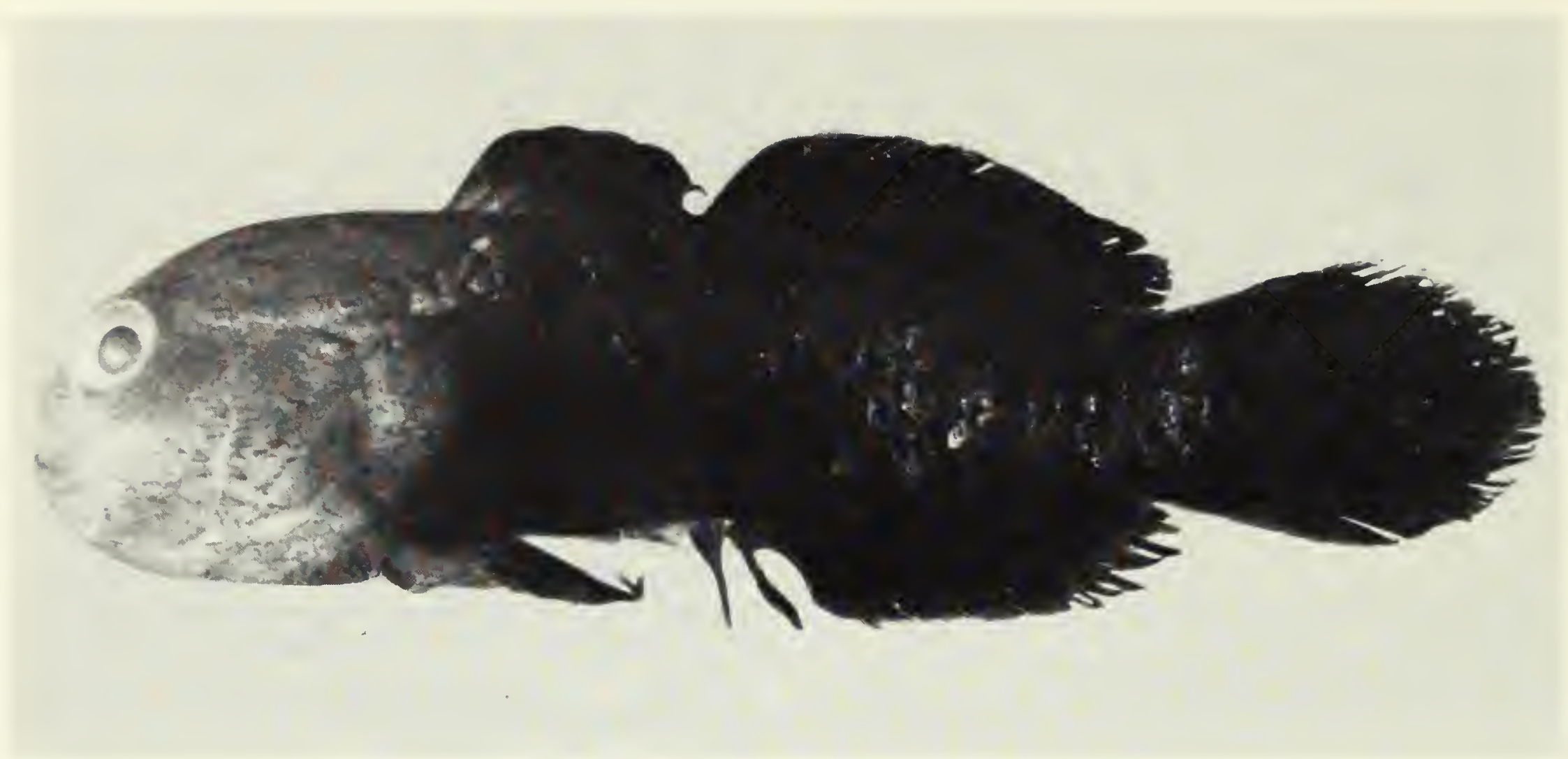

Fig. 76. Left lateral view of Paragobiodon modestus, $19.6 \mathrm{~mm} \mathrm{SL}$.
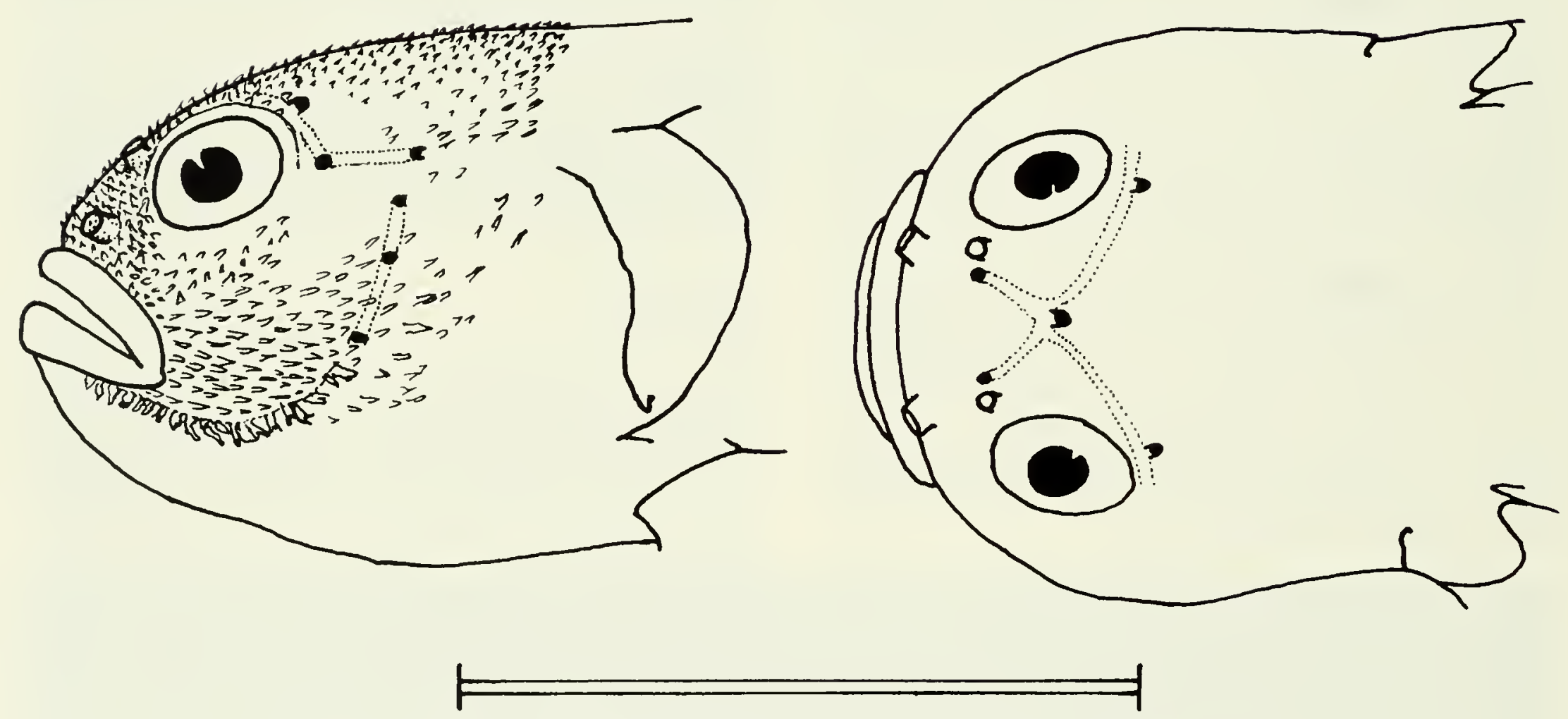

Fig. 77. Left lateral (left) and dorsal (right) views of the head of Paragobiodon modestus,

$24.8 \mathrm{~mm} \mathrm{SL}$, to show head pores and papillae. Scale equals $1 \mathrm{~cm}$.

pterygiophore formula $3(2,2,1,1,0)$; vertebrae $10+15+$ ural centrum $=26$. Nine dorsal and eight ventral branched caudal-fin rays, with four to five dorsal and ventral unbranched caudal-fin rays. As percentage standard length: head length 34-36 (34.8); origin of first dorsal fin $37-41$ (38.9); origin of second dorsal fin 56-60 (58.0); origin of anal fin 57-60 (58.0); caudal-peduncle length 19-22 (20.5). As percentage head length: eye diameter
21-29 (23.8); snout length 25-33 (28.9); upper-jaw length 33-45 (36.6). Caudal-peduncle depth as percentage caudal-peduncle length 70-84 (77.5). Head pores and papillae as in Fig. 77. Caudal skeleton as in $A$. hectori.

Gut short, contained flocculent mucoid material in $24.9 \mathrm{~mm}$ SL female.

Colour pattern (freshly dead): head orange-brown, grading into black above pectoral-fin base. Body and all 
fins black. Preserved: similar, but head of a lighter tone.

\section{DISCUSSION}

The name Paragobiodon modestus as used here is tentative. Dr D. F. Hoese (pers. comm.) informs us that one of Regan's two lots of syntypes, from Egmont, contains three species: Paragobiodon echinocephalus (3), $P$. xanthosomus (1), and a third species for which Regan's Gobiopterus modestus (4) is available. The second of Regan's syntypic lots, from Salomon, also contains three species: Gobiodon nr unicolor (see p. 42), Paragobiodon echinocephalus (3), and putative P. modestus (6). Thus, lectotype designation is necessary to stabilize the nomenclature-a task we defer to Dr Hoese in his revision of this genus.

Paragobiodon xanthosomus (Bleeker)

Fig. 78

Gobius xanthosomus Bleeker, 1852:703 (Ceram).

Gobiopterus modestus Regan, 1908:242 (partimEgmont, Chagos).

\section{MATERIAL}

Two lots, 3 specimens, $10.0-32.3 \mathrm{~mm} \mathrm{SL}$. Depth range 0-0.5 m, reef-flat, Egmont (part of the syntypic series of Paragobiodon modestus Regan, deposited in the British Museum [Natural History]), and Peros Banhos.

\section{DESCRIPTION}

Based on the single syntype of $P$. modestus belonging to this species, with fin-ray counts from the two immature specimens from Peros Banhos. D VI + I 9, third to fifth spines longest, membrane from sixth spine to spine of second dorsal fin reaching one-tenth of way up that spine; A I 9; P 18-21 (19.2); V I 5, reaching posteriorly to anus, complete fraenum and basal membrane. Lateral scales 25; transverse 8 . Nape, head, pectoral base, and breast naked; scales present on midline of belly; scales ctenoid. Gill opening restricted, equal to base of pectoral fin. Mouth terminal, oblique. Teeth in several series in both jaws, outer row enlarged. One to two enlarged canines in inner row of lower-jaw teeth near symphysis, other teeth in this row enlarged and equal in size to those of outer row. Anterior nostril a short tube, posterior with a raised rim. Head covered with numerous skinny flaps which are longest on nape and jowls, where they are pupil-diameter in length. As percentage standard length: head length 28.4; origin of first dorsal fin 31.8 ; origin of second dorsal fin 51.1; origin of anal fin 57.6; caudal-peduncle length 24.9. As percentage head length: eye diameter 26.8; snout length 28.6; upper-jaw length 39.6. Caudal-peduncle depth as percentage caudal-peduncle length 67.5. Head pores and papillae as in Fig. 78.

Colour (preserved): plain yellow-brown.
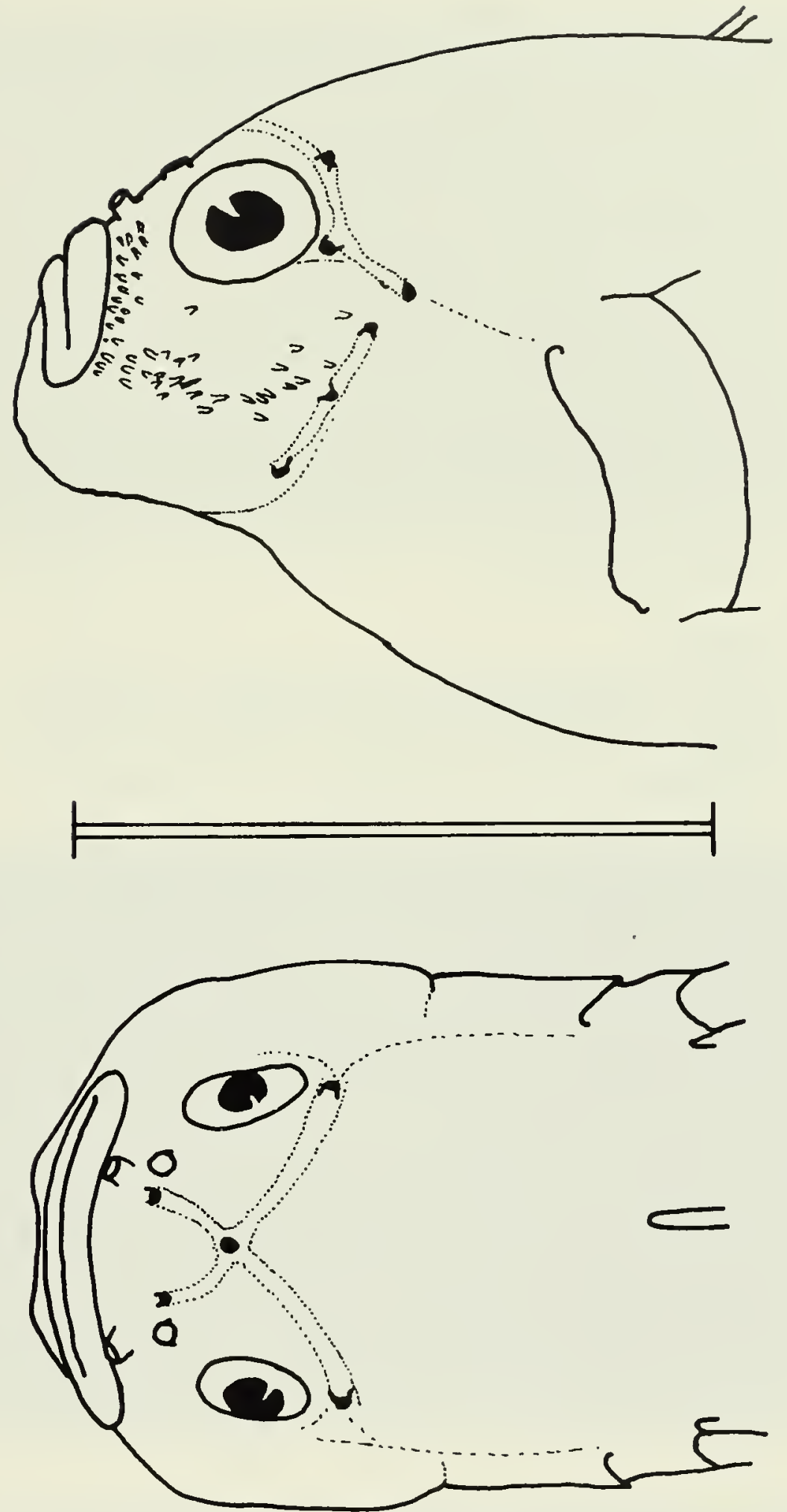

Fig. 78. Left lateral (above) and dorsal (below) views of the head of Paragobiodon xanthosomus, $32.1 \mathrm{~mm} \mathrm{SL}$, to show head pores and papillae (only those closest to eye on cheek shown). Scale equals $1 \mathrm{~cm}$.

\section{DISCUSSION}

The two small specimens $(10.0-10.8 \mathrm{~mm} \quad \mathrm{SL})$ we collected at Peros Banhos have not yet developed scales in the anterior region of the body. The only data taken from them were fin-ray counts. $P$. xanthosomus has recently been recorded from the northern Red Sea in the vicinity of Elat, the first positive record of the species from the Indian Ocean region (Goren and Voldarsky, 1980). 


\section{Genus Pleurosicya}

The genus is currently being revised by H. K. Larson, who provided the following preliminary identifications from the Chagos material. Descriptions are not offered here, pending the completion of her studies, but we do provide photographs of freshly dead specimens, where available.

\section{Pleurosicya HKL sp. 1}

Fig. 79

\section{MATERIAL}

Seven lots, 27 specimens, 7.6-14.3 mm SL. Depth range 0.5-10 m, mainly lagoons at Peros Banhos and Salomon.

\section{Pleurosicya HKL sp. 2}

Fig. 80

\section{MATERIAL}

Five lots, 5 specimens, 11.4-16.8 mm SL. Depth range 3-43 $\mathrm{m}$, lagoon and drop-off at Peros Banhos and Salomon.
Pleurosicya HKL sp. 3

\section{MATERIAL}

Thirteen lots, 71 specimens, 6.9-16.5 mm SL. Depth range $0-25 \mathrm{~m}$, primarily lagoons at Eagle Island, Peros Banhos, Salomon, and Three Brothers.

\section{Pleurosicya HKL sp. 5}

\section{MATERIAL}

Eleven lots, 47 specimens, $8.6-16.1 \mathrm{~mm} \mathrm{SL}$. Depth range 0-25 m, lagoons, intertidal, reef-tops, and drop-offs at Eagle Island, Peros Banhos, and Salomon.

\section{Pleurosicya HKL sp. 8}

\section{MATERIAL}

One lot, 2 specimens, $12.6-13.4 \mathrm{~mm}$ SL. Depth range 18-25 m, drop-off at Salomon.

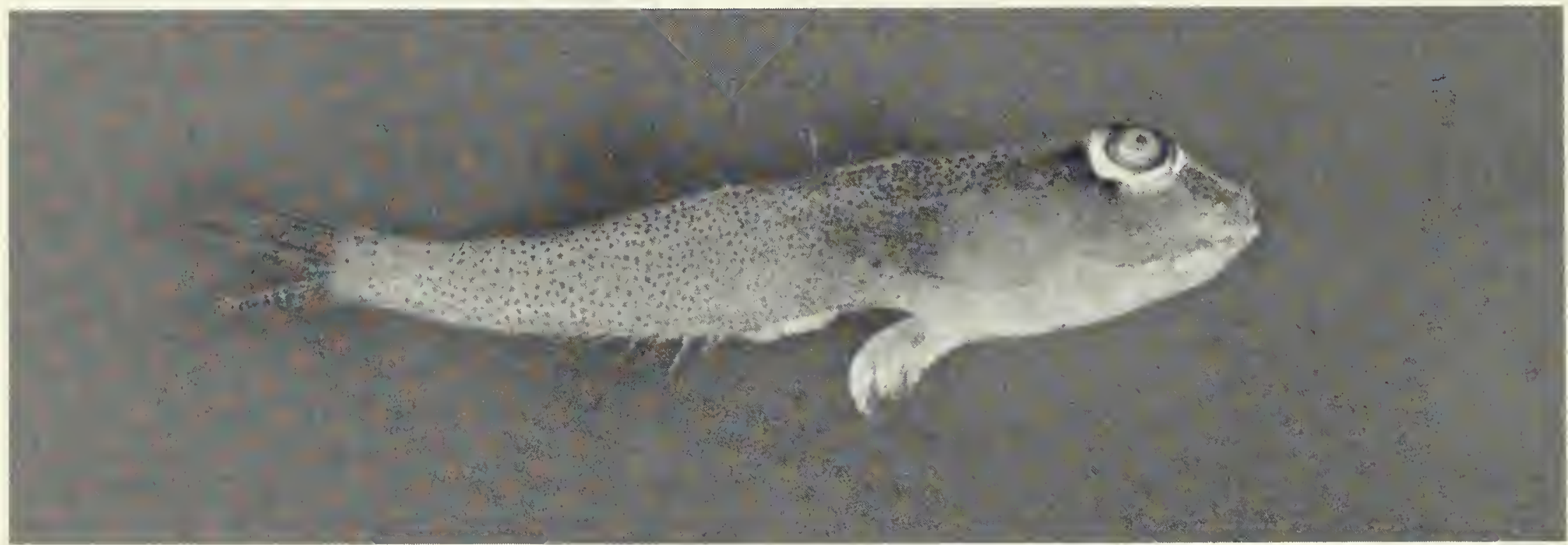

Fig. 79. Right lateral view of Pleurosicya HKL sp. 1, $13.3 \mathrm{~mm} \mathrm{SL}$.

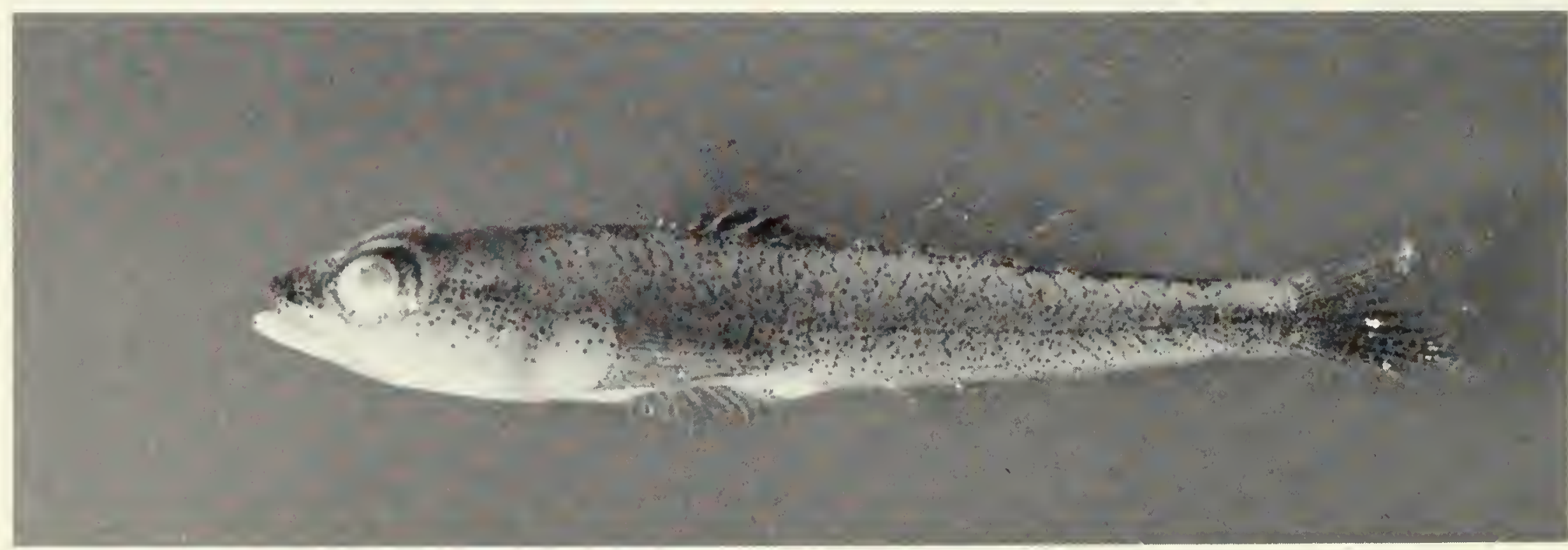

Fig. 80. Left lateral view of Pleurosicya HKL sp. 2, 16.4 mm SL. 


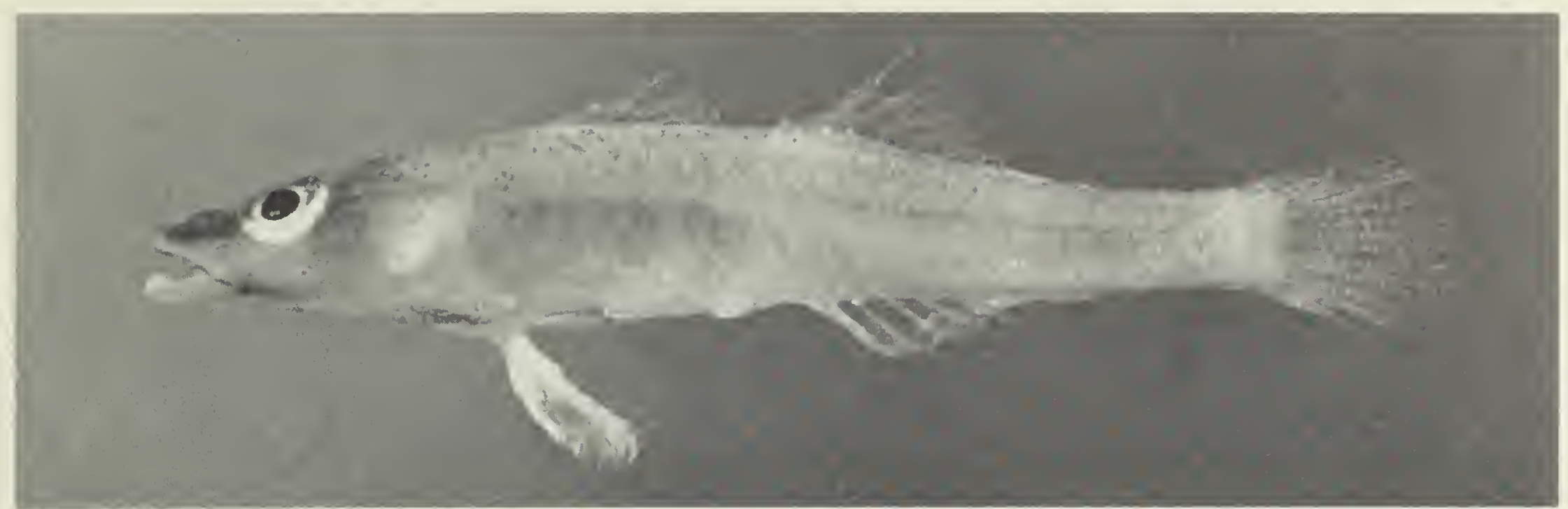

Fig. 81. Left lateral view of Pleurosicya HKL sp. 12, $20.2 \mathrm{~mm}$ SL.

Pleurosicya HKL sp. 12

Fig. 81

\section{MATERIAL}

Fourteen lots, 85 specimens, 7.9-20.2 mm SL. Depth range $0-33 \mathrm{~m}$, primarily lagoons (two lots from drop-off) at Peros Banhos, Salomon, and Three Brothers.

\section{Pleurosicya HKL sp. 15?}

\section{MATERIAL}

One lot, 1 specimen, $8.5 \mathrm{~mm} \mathrm{SL}$. Depth $36 \mathrm{~m}$, drop-off at Peros Banhos.

\section{Genus Priolepis}

\section{Priolepis sp. A}

Figs. 82,83

\section{MATERIAL}

One lot, 1 specimen, $23.5 \mathrm{~mm} \mathrm{SL}$. Depth range $0-1 \mathrm{~m}$, reef-flat at Diego Garcia.

\section{DESCRIPTION}

D VI + I 8, second and third spines longest, not quite reaching to dorsal interspace when depressed; A I 8; P 18, reaching a vertical in line with anal spine, a few of lower rays branched; V I 5, fifth ray branched and subequal to fourth, no fraenum detected, complete basal membrane, reaching posteriorly to anus. Lateral scales about 33; transverse scales about 14. Head, nape, pectoral base, and prepelvic area apparently naked; anterior extent of scalation apparently from dorsal margin of pectoral base to base of third spine of first dorsal fin. Scales small and cycloid anteriorly, becoming ctenoid and increasing in size posteriorly. Gill opening extending anteroventrally to a vertical line between posterior margin of eye and vertical limb of preopercle. Mouth large, terminal, and inclined dorsally. Teeth in both jaws in several series, with outer row enlarged. Both nostrils tubular, anterior being longer than posterior. Tongue bilobed. First gill slit open; gill rakers $3+11$. Five branchiostegal rays. Head depressed, eyes dorsolateral. As percentage standard length: head length 35.3 ; origin of first dorsal fin 42.1 ; origin of second

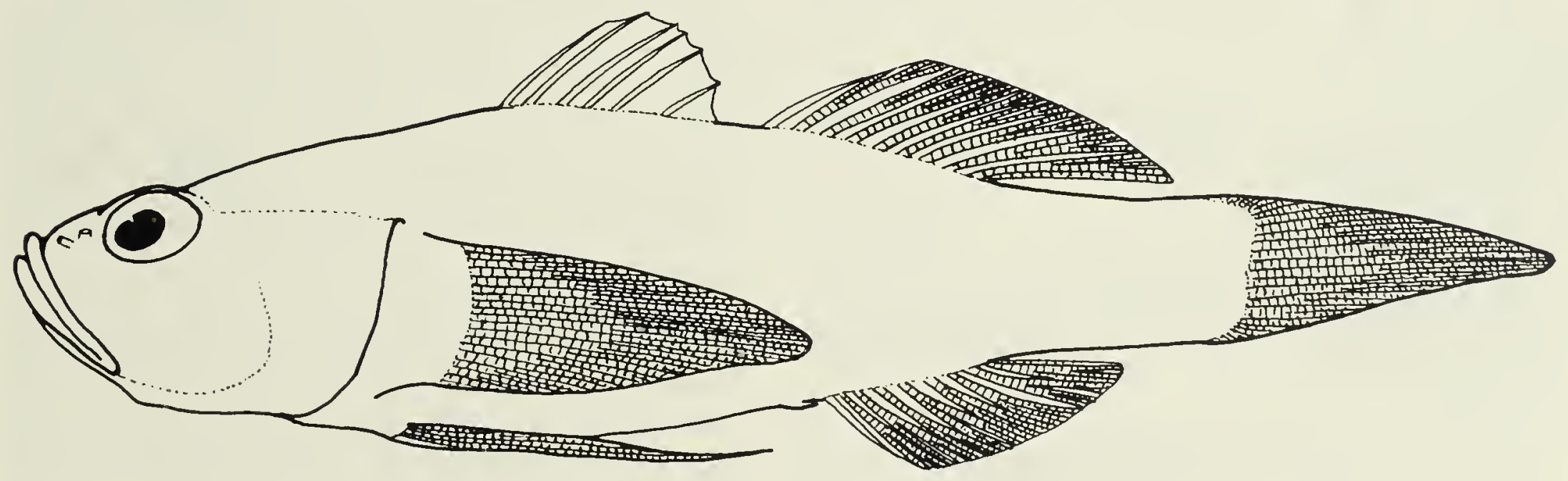

Fig. 82. Left lateral outline of Priolepis sp. A, $23.5 \mathrm{~mm} \mathrm{SL}$. Scale equals $1 \mathrm{~cm}$. 
dorsal fin 60.4; origin of anal fin 64.3; caudal-peduncle length 21.3. As percentage head length: eye diameter 22.9 ; snout length 22.9 ; upper-jaw length 39.8 . Caudalpeduncle depth as percentage caudal-peduncle length 56.0. No head pores, papillae as in Fig. 83.

Colour pattern (freshly dead): not recorded. Preserved: head and body liberally sprinkled with melanophores with no apparent pattern. All fins dusky.

\section{DISCUSSION}

The Diego Garcia specimen lacks head pores, and has a gill opening and head papillae pattern similar to the genus Priolepis. However, the somewhat depressed head, large mouth, and reduced scalation indicate that this assignment should be reassessed when more specimens become available for study.
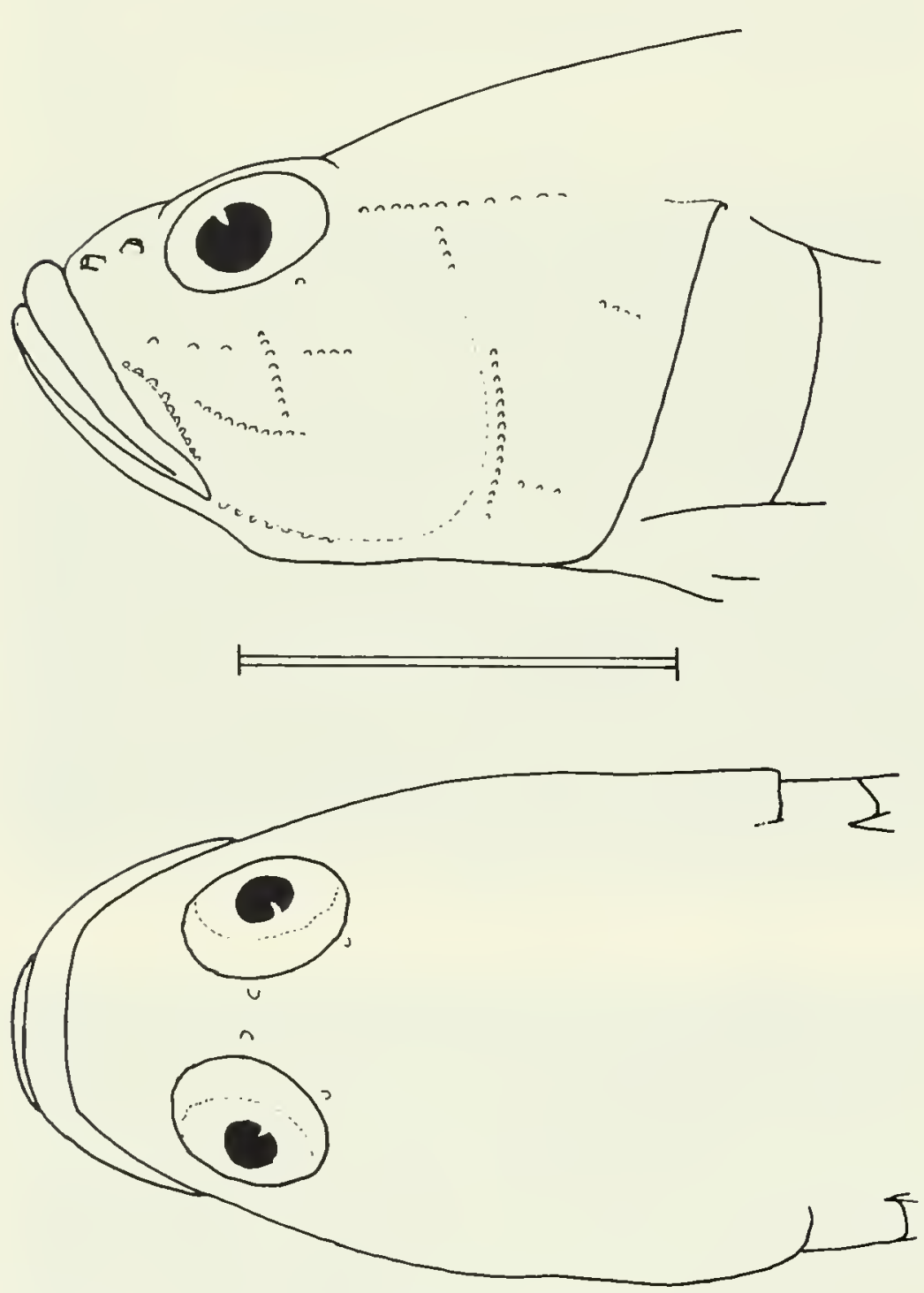

Fig. 83. Left lateral (above) and dorsal (below) views of the head of Priolepis sp. A, $23.5 \mathrm{~mm} \mathrm{SL}$, to show papillae. Scale equals $5 \mathrm{~mm}$.
Priolepis cincta (Regan)

Figs. 84,85

Gobiomorphus cinctus Regan, 1908:240 (Salomon, Chagos).

Priolepis cinctus-Allen and Steene, 1979:60 (widespread Indo-west Pacific).

\section{MATERIAL}

Twelve lots, 21 specimens, 11.0-28.3 mm SL. Depth range $0-43 \mathrm{~m}$, primarily in shallow water (four specimens from more than $7 \mathrm{~m}$ ) in lagoons and on reef-flat, reef-top, and drop-off at Peros Banhos and Salomon.

\section{DESCRIPTION}

Based on 10 specimens from lots WE 79-06, 79-12, 79-76 (15.8-28.3 mm SL), plus 2 cleared and stained specimens (ROM 5I3CS, 13.0-13.3 mm SL). D VI + I 11 (once I 10), third and fourth spines longest, reaching to base of spine of second dorsal fin when depressed, no membranous connection between dorsal fins; A I 9 (once I 8); P 16-19 (17.8), reaching posteriorly to a vertical with bases of third to fourth anal-fin rays; V 15 , no fraenum, basal membrane complete, reaching posteriorly to origin of anal fin. Lateral scales 35-36; transverse 10-13; predorsal 13-15; opercle (2-3 rows), pectoral base, and breast scaled. Scales cycloid on pectoral base and breast; others ctenoid. Gill opening somewhat restricted, attaching to isthmus below vertical limb of preopercle. Mouth terminal, inclined slightly upwards. Both jaws with an outer row of spaced, enlarged teeth (larger in lower jaw than in upper) and about two irregular rows of small conical teeth. Both nostrils tubular. Tongue truncately rounded to bilobed. First gill slit open; gill rakers $3+12$ (once $3+$ 13); pseudobranch with seven lobes. Five branchiostegal rays. Dorsal pterygiophore formula $3(2,2,1,1,0)$; vertebrae $10+15+$ ural centrum $=26$. Seven dorsal and 6 ventral branched caudal-fin rays, with 9 to 10 dorsal and ventral unbranched rays. As percentage standard length: head length $31-33$ (32.0); origin of first dorsal fin 36-40 (38.1); origin of second dorsal fin 56-60 (57.6); origin of anal fin 60-67 (61.9); caudal-peduncle length 22-25 (23.4). As percentage head length: eye diameter 28-35 (30.0); snout length 20-24 (21.7); upper-jaw length 33-39 (36.3). Caudal-peduncle depth as percentage caudal-peduncle length 42-52 (48.2). No head pores, papillae as in Fig. 85. Caudal skeleton as for A. hectori.

Gut short, peritoneum sprinkled with melanophores. Gut of $28.3 \mathrm{~mm}$ SL female contained crustacean remains.

Colour pattern (freshly dead): ground colour whitish and crossed by vertical bars, which may vary from yellow-brown to dark brown, are usually lighter on head, and frequently have edges darker than centre. First bar anterior to eye; two bars through eye; one across posterior cheek; one across posterior opercle/pectoral base; seven across body (two across base of first dorsal fin, two and a 


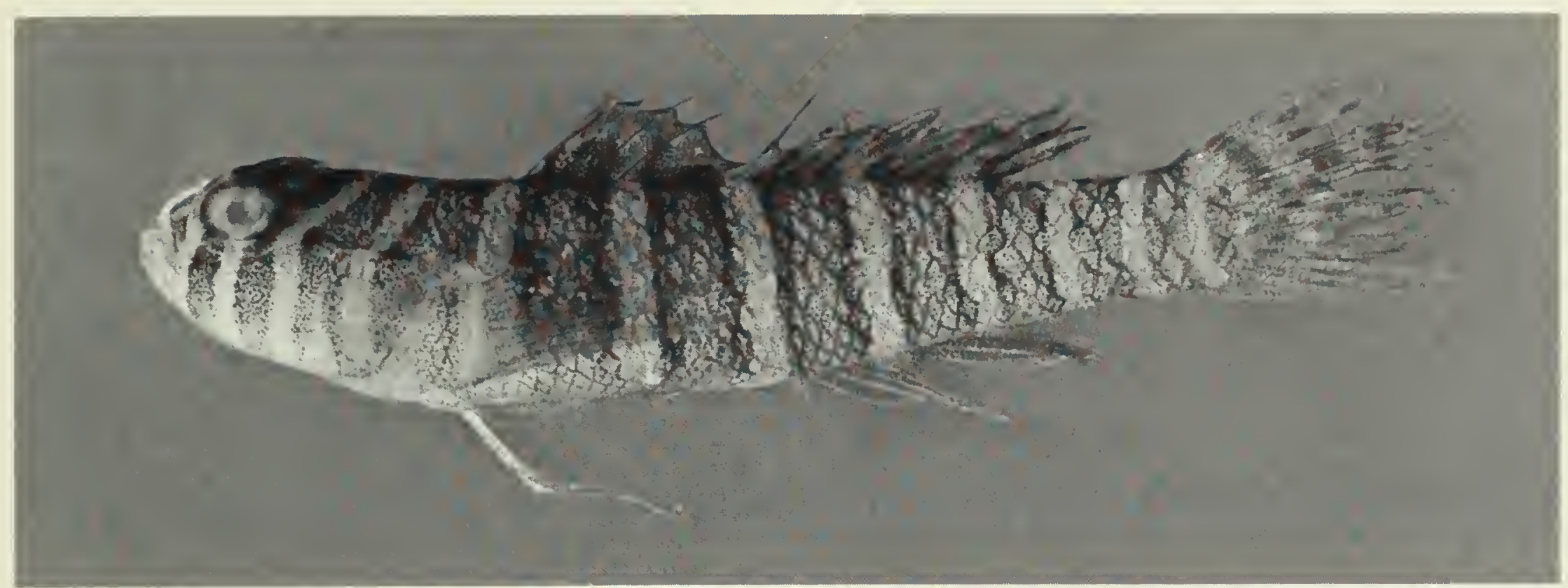

Fig. 84. Left lateral view of Priolepis cincta, $19.6 \mathrm{~mm} \mathrm{SL}$.
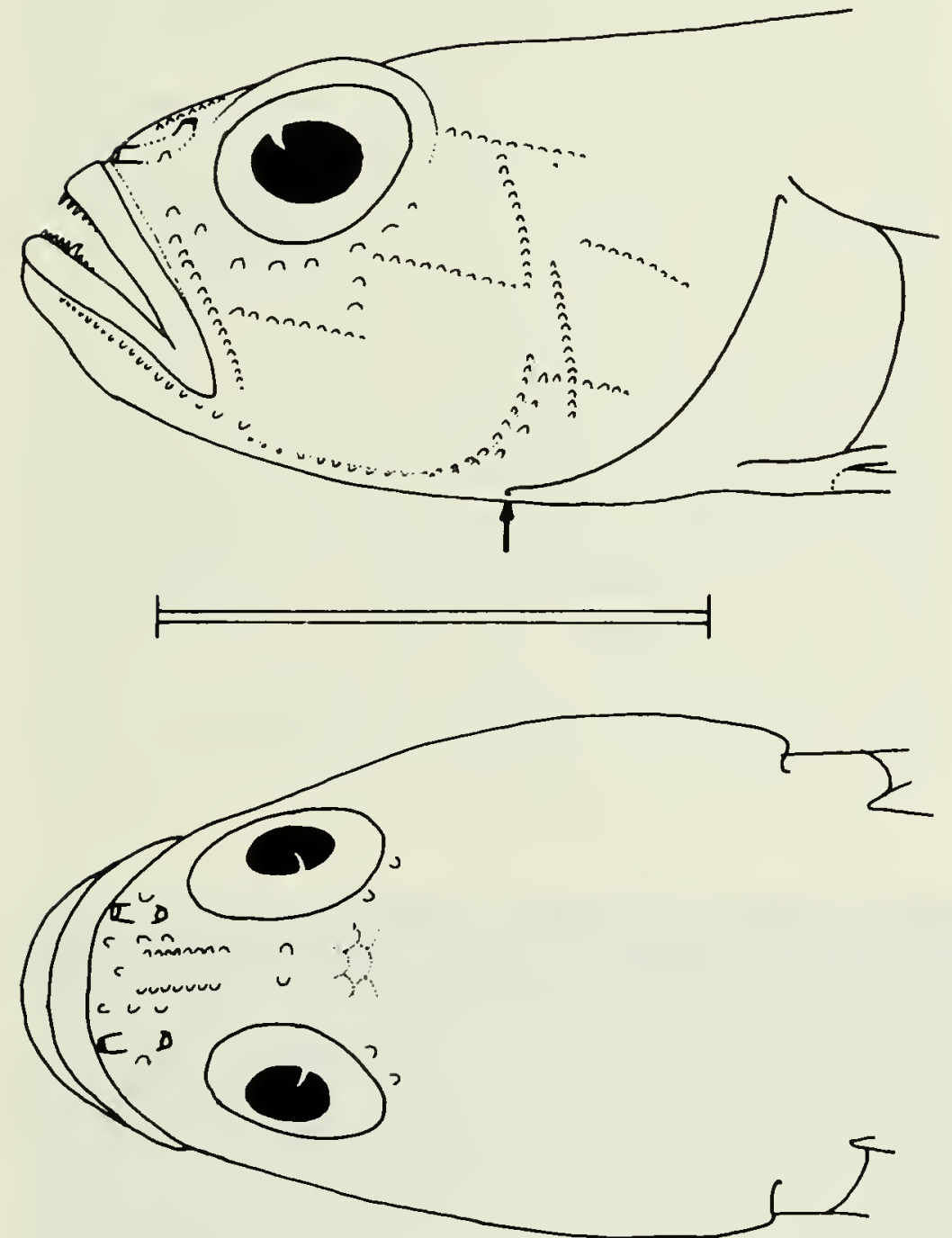

Fig. 85. Left lateral (above) and dorsal (below) views of the head of Priolepis cincta, $19.1 \mathrm{~mm} \mathrm{SL}$, to show papillae (anteroventral extent of gill opening indicated by arrow in upper figure, anterior extent of predorsal scales indicated by dotted outline in lower figure). Scale equals $5 \mathrm{~mm}$. half across base of second dorsal fin, two and a half on caudal peduncle); three vague bars formed of dark spots on caudal fin. Pelvic fins hyaline, other fins sprinkled with melanophores, chromatophores, and iridocytes. First dorsal fin usually with a dark black basal spot on membrane between first four spines. In the largest photographed specimen $(19.6 \mathrm{~mm} \mathrm{SL})$, body scales outlined by melanophores. Preserved: similar, but browns and yellow-browns duller.

\section{DISCUSSION}

Differences between the above description and that given by Goren (1979) for Red Sea specimens involve scale counts (where differences of methods may well account for the discrepancies) and gill rakers. Goren recorded $3+$ 10, whereas all Chagos specimens had at least 12 lower gill rakers. However, Smith's (1959) record of 3+10-12 indicates some degree of variation.

Priolepis compita Winterbottom

Fig. 86

Priolepis compita Winterbottom, 1985:748 (Chagos).

\section{MATERIAL}

Fourteen lots, 26 specimens, 6.3-13.4 mm SL. Depth range 3-36 m, lagoons, reef-tops, and drop-offs at Peros Banhos and Salomon.

\section{DESCRIPTION}

The description of this species is recent, detailed, and illustrated, and will not be repeated here. P. compita differs from all other congeners in having a horizontal, pale-centred line at the level of the upper pupil connecting the vertical bars across the opercle and pectoral-fin base. 


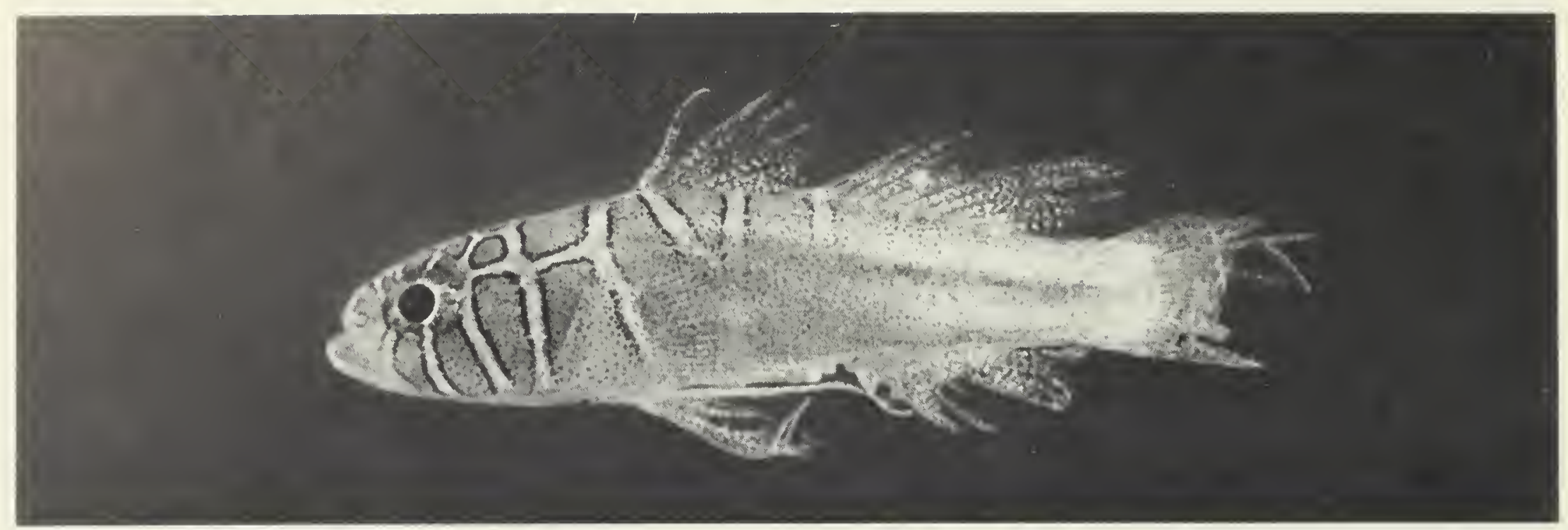

Fig. 86. Left lateral view of Priolepis compita, $11.8 \mathrm{~mm}$ SL.

Priolepis inhaca (Smith)

Figs. 87,88

Gobius inhaca Smith, 1949:103 (Inhaca, Mozambique). Quisquilius inhaca-Jones and Kumaran, 1967:8 (Inhaca; Kenya; Maldives).

\section{MATERIAL}

Two lots, 2 specimens, $8.8-18.1 \mathrm{~mm} \mathrm{SL}$. Depth range 12-26 m, lagoon and drop-off at Peros Banhos and Salomon.

\section{DESCRIPTION}

Based on a single specimen from lot WE 79-24 $(18.1 \mathrm{~mm}$ SL). D VI + I 10, fourth and fifth spines longest, reaching base of first ray of second dorsal fin when depressed, dorsal fins not connected by membrane; A I 8; P 16, reaching posteriorly to a vertical with base of second ray of anal fin; V I 5, no fraenum, basal membrane present, fifth ray branched and subequal to fourth, fin reaches posteriorly to anal-fin origin. Lateral scales 28 ; transverse 14; predorsal 15. Predorsal scales reach to posterior border of eye, pectoral base and breast scaled; these and scales near midline of body cycloid, others ctenoid; no scales on head. Gill opening somewhat restricted, reaching anteriorly to a point beneath vertical limb of preopercle. Mouth terminal, slightly inclined dorsally. Teeth in both jaws in several series, innermost and outermost rows enlarged and spaced. Anterior nostril tubular, posterior with raised rim. Tongue roundly truncate. First gill slit open; gill rakers well developed, $3+11$; pseudobranch with eight lobes. As percentage standard length: head length 32.0; origin of first dorsal fin 39.8; origin of second dorsal fin 59.1; origin of anal fin 63.0; caudal-peduncle length 23.2. As percentage head length: eye diameter 29.3; snout length 20.7; upper-jaw length 39.7 . Caudalpeduncle depth as percentage caudal-peduncle length 52.4. No head pores, papillae as in Fig. 88.

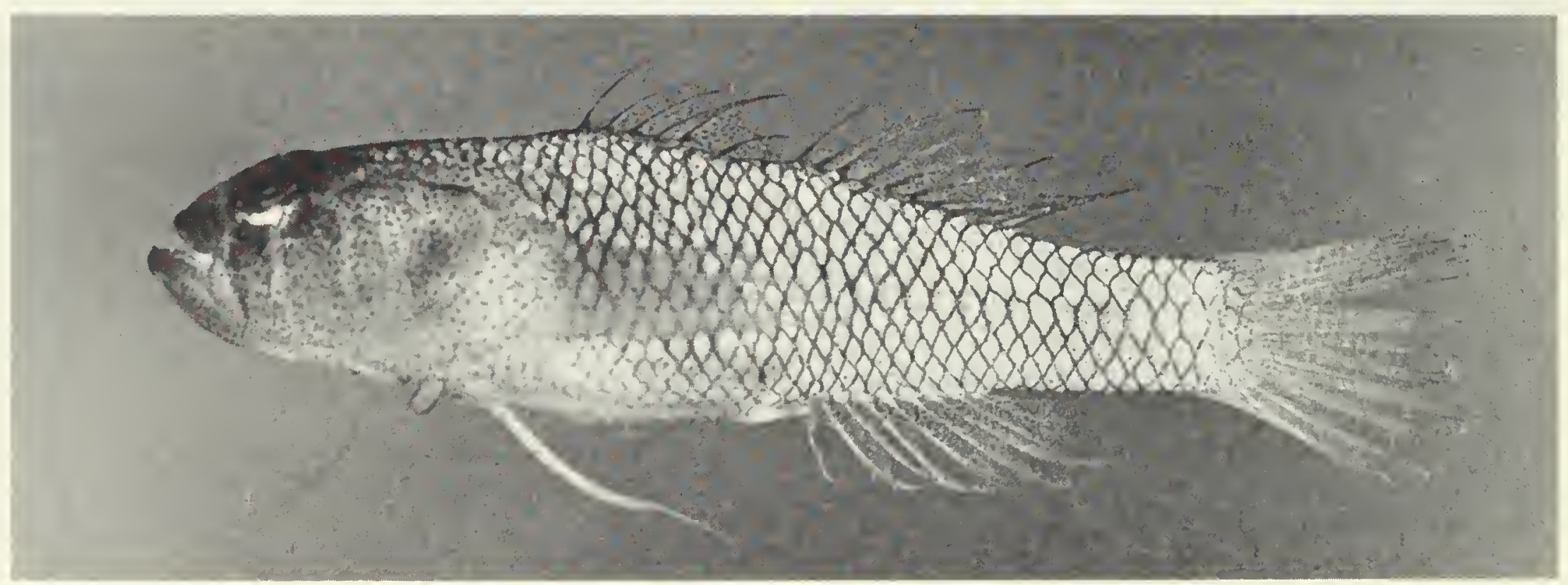

Fig. 87. Left lateral view of Priolepis inhaca, 18.1 mm SL. 

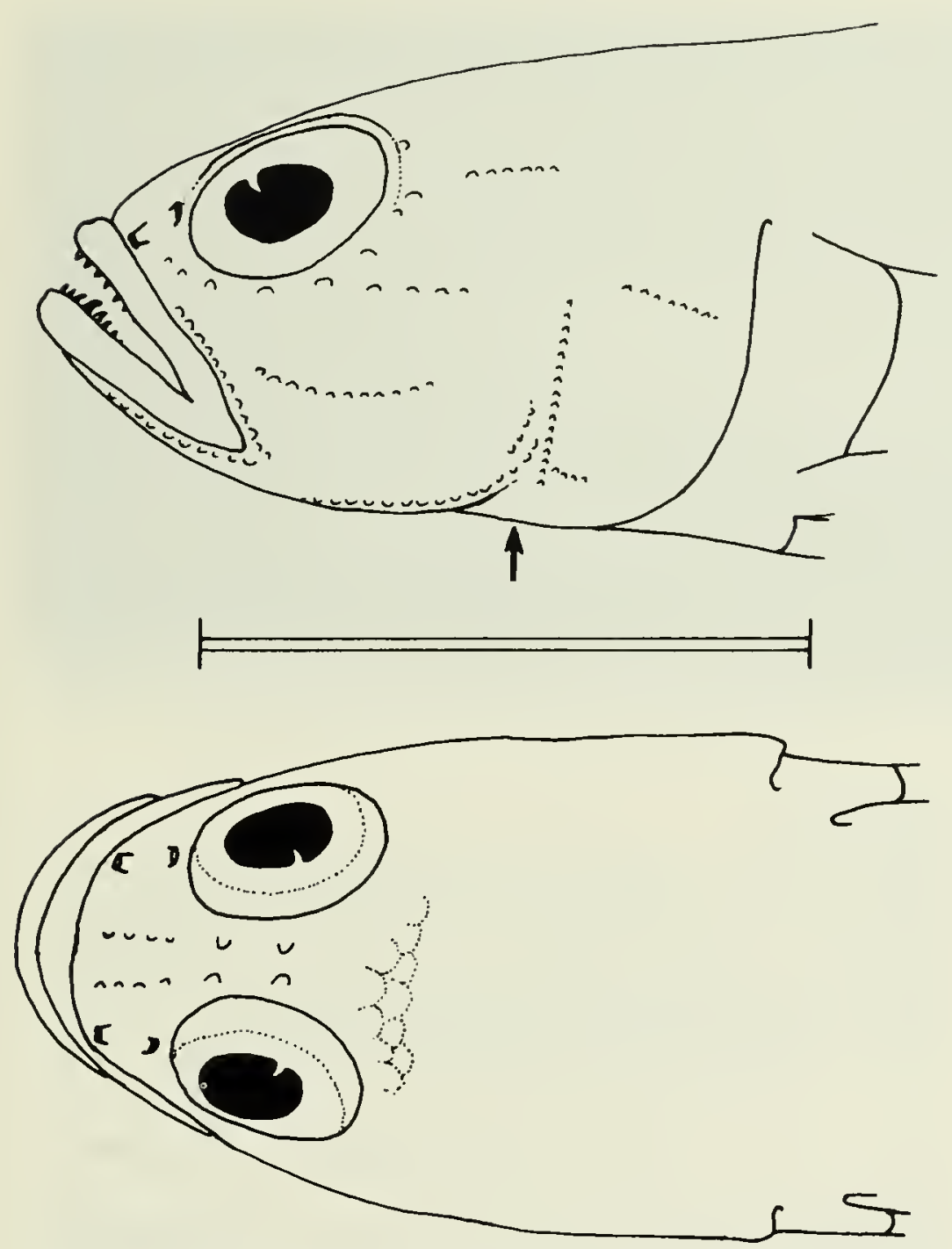

Fig. 88. Left lateral (above) and dorsal (below) views of the head of Priolepis inhaca, $18.1 \mathrm{~mm} \mathrm{SL}$, to show papillae (anteroventral extent of gill opening indicated by arrow in upper figure, anterior extent of predorsal scales indicated by dotted outline in lower figure). Scale equals $5 \mathrm{~mm}$.

Colour pattern (freshly dead): head ochre, speckled with melanophores, with three vertical light bars beneath eye (posteriormost curving posteroventrally), and a short bar curving posterodorsally from posterior margin of eye. Body pale, each scale strongly outlined with melanophores. First dorsal with many small dark spots, as in second dorsal, latter tinged with orange. Caudal, anal, and paired fins orange; anal with dark spots. Posteroventral portion of abdomen rosy (possibly due to eggs showing through translucent body). Preserved: similar, but orange and ochre dusky.

\section{DISCUSSION}

The Chagos specimen agrees well with the original description except that Smith reported " about 22 predorsal scales" (1949:103) and a brick-red background coloration. Smith (1959:210) later recorded 15-16 predorsal scales, a count which agrees with the Chagos material. The difference in background coloration would seem more likely to be due to environmental, collecting, or handling variables than to specific differences. Goren's (1978:195) Quisquilius mendelssohni, which has a similar colour pattern on the body, should be referred to the genus Trimma since the gill opening extends anteriorly to below the middle of the pupil. It further differs from Priolepis inhacae in having fewer transverse scales ( $7-8$ vs 14$)$. Of the four species Goren (1978) placed in Zonogobius (a junior synonym of Priolepis) only "Zonogobius" semidoliata appears correctly placed; the other three species (" $Z$." corallinus, "Z." avidori, and "Z." flammeus) belong in Trimma.

Three lots with four small specimens $(<12 \mathrm{~mm} \mathrm{SL})$ in poor condition may fall here. They are provisionally identified only as Priolepis sp.

\section{Genus Silhouettea}

Silhouettea insinuans Smith

Figs. 89,90

Silhouettea insinuans Smith, 1959:214 (Silhouette Island, Seychelles).

\section{MATERIAL}

One lot, 4 specimens, 13.5-19.3 mm SL. Depth $7 \mathrm{~m}$, lagoon near pass at Peros Banhos.

\section{DESCRIPTION}

Based on all four specimens from lot WE 79-06. D VI + I 11 (once I 10), second and third spines longest but not elongated; A I 13; P 16 (once 15), reaching to a vertical with base of first anal-fin ray; V I 5, basal membrane and fraenum complete, fifth ray longest, reaching to base of first ray of anal fin. Lateral scales 25-26; transverse 10; no scales on nape, head, or pectoral-fin base. Scales ctenoid, those on breast cycloid. Gill opening extending anteroventrally to a vertical just anterior to vertical limb of preopercle. Mouth inclined slightly dorsally; teeth in several series in each jaw, with a somewhat enlarged outer series in lower jaw. Anterior nostril a very short tube near lip, posterior porelike. Tongue truncate or with shallow notch. First gill slit open; first gill arch with $3+10$ short gill rakers. Five branchiostegal rays. As percentage standard length: head length 30-32 (31.1); origin of first dorsal fin 36-39 (38.0); origin of second dorsal fin 53-54 (53.6); origin of anal fin 53-55 (54.1); caudal-peduncle length 83-94 (89.3). As percentage head length: eye diameter 21-23 (21.6); snout length 16-19 (17.5); upper-jaw length $35-41$ (37.5). Caudal-peduncle depth as percentage caudal-peduncle length 83-94 (89.3). Head pores and papillae as in Fig. 90.

Colour pattern (freshly dead): not recorded. Preserved: plain white with a few scattered melanophores in first dorsal fin, these being primarily concentrated between first and second spines. 


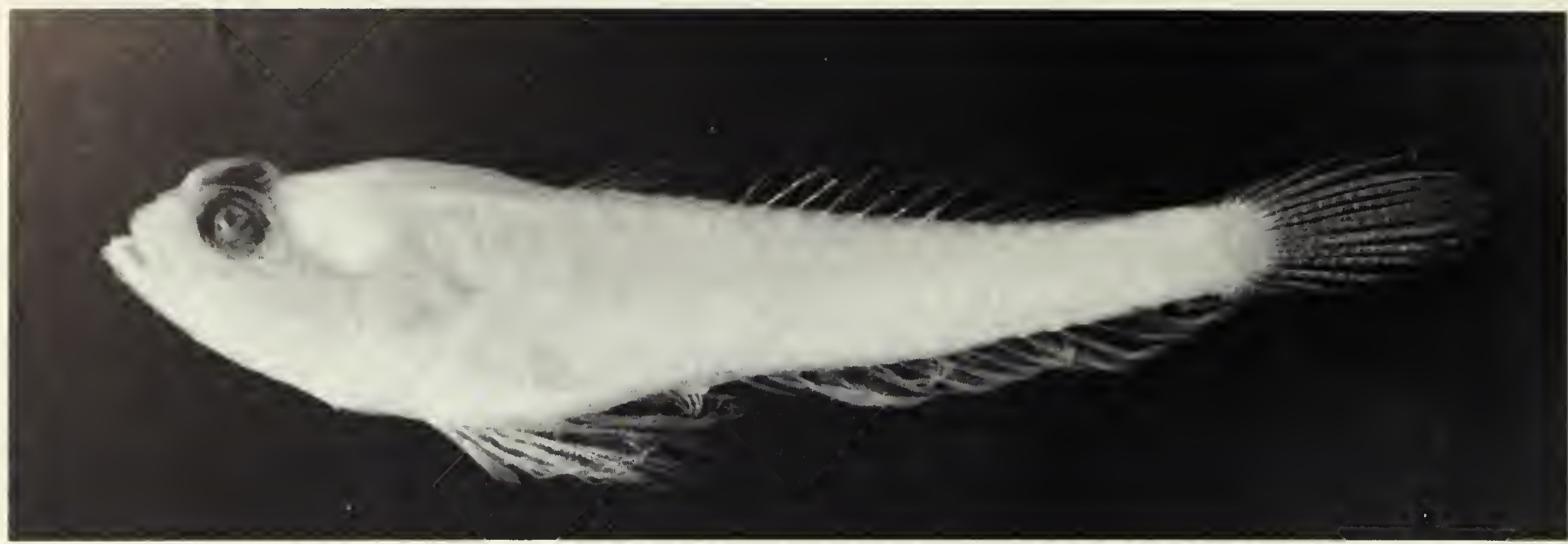

Fig. 89. Left lateral view (and slightly dorsally inclined) of Silhouettea insinuans, $19.3 \mathrm{~mm} \mathrm{SL}$ (preserved).

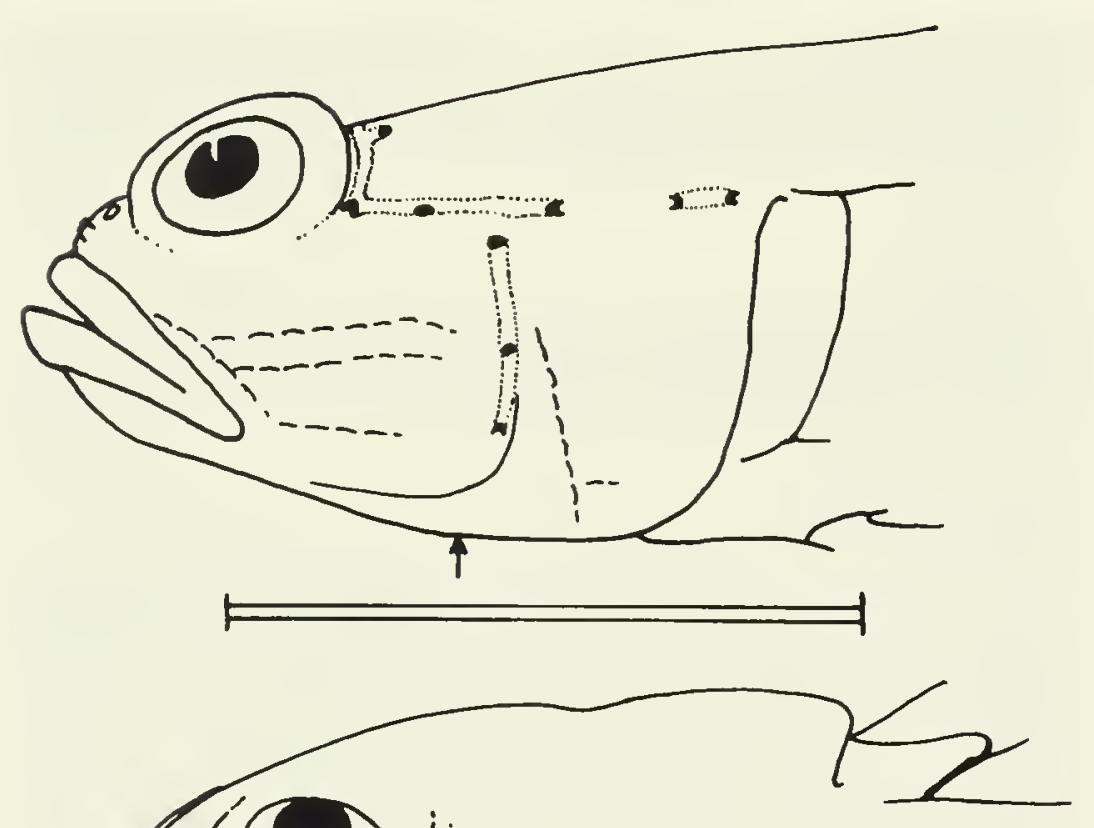

\section{DISCUSSION}

The identity of Chagos specimens was confirmed by P. J. Miller. The only difference we could find between our specimens and the description of the type was the lack of scales on the side of the head above the opercle.

\section{Genus Tenacigobius}

The genus is being revised by $\mathrm{H}$. K. Larson, to whom we have sent our material, and who provided the following preliminary identifications. No descriptions are given here, although photographs of freshly dead specimens are provided where available.

\section{Tenacigobius erythrops (Jordan and Seale)}

Chaenogobius erythrops Jordan and Seale, 1906:404 (American Samoa).

\section{MATERIAL}

Three lots, 11 specimens, 8-16 $\mathrm{mm}$ SL. Depth range 4-22 m, lagoon at Salomon. In addition, we have 3 lots, 10 specimens tentatively identified as this species.

\section{Tenacigobius HKL sp. 2}

Fig. 90. Left lateral (above) and dorsal (below) views of the head of Silhouettea insinuans, $19.3 \mathrm{~mm}$ SL, to show head pores and papillae (arrow indicates anteroventral extent of gill opening in upper figure). Scale equals $5 \mathrm{~mm}$.

\section{MATERIAL}

Seven lots, 10 specimens, 11.0-16.4 mm SL. Depth range 5-32 m, lagoons at Eagle Island, Peros Banhos, and Salomon.

Tenacigobius n. sp. A

Fig. 91

\section{MATERIAL}

Six lots, 19 specimens, 9-19 mm SL. Depth range 18-43 m, drop-offs at Peros Banhos and Salomon. 


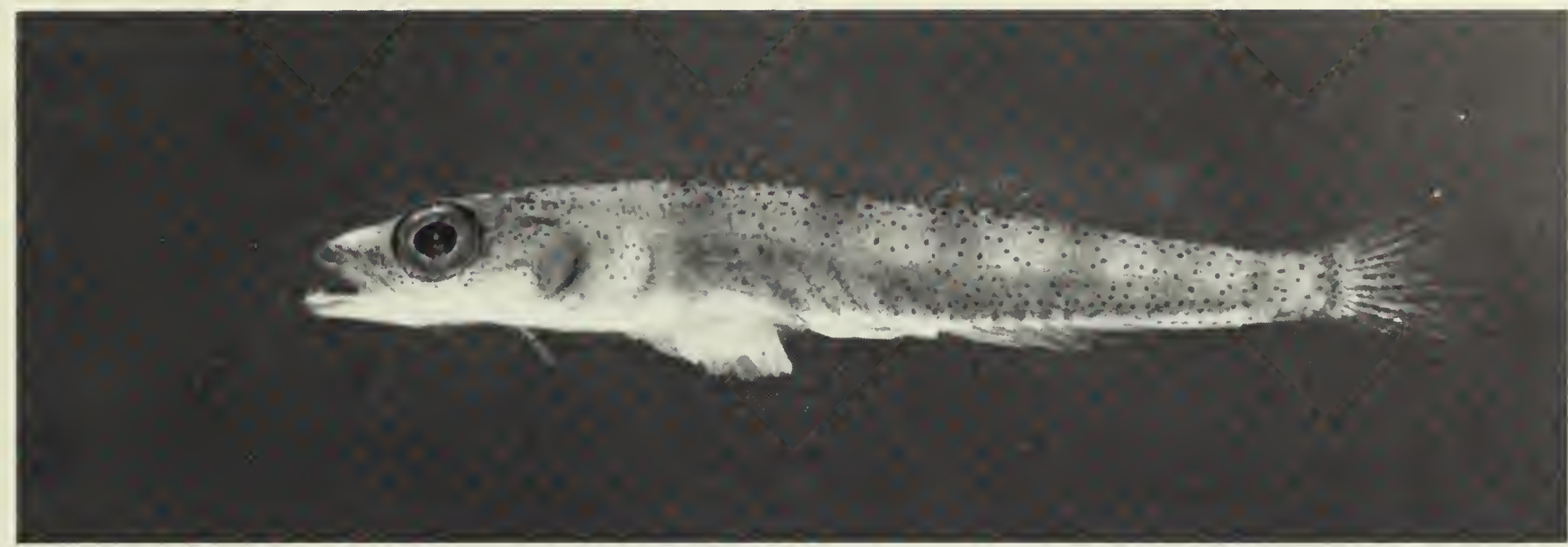

Fig. 91. Left lateral view of Tenacigobius n. sp. A, $19.0 \mathrm{~mm}$ SL.

Tenacigobius n. sp. B

\section{MATERIAL}

Five lots, 50 specimens, 11-17 mm SL. Depth range 3-25 m, lagoons at Peros Banhos and Salomon.

Tenacigobius n. sp. C

\section{MATERIAL}

One lot, 4 specimens, $15-16 \mathrm{~mm}$ SL. Depth range 20-25 m, drop-off at Salomon.

\section{Genus Trimma}

The genus has been reviewed by Winterbottom (1984), with an additional species being described later (Winterbottom, 1985-incorrectly referred to $T$. mendelssohni in
Fig. 92 the 1984 review). Descriptions and figures are not repeated here.

\section{Trimma sp. A}

\section{MATERIAL}

One lot, 1 specimen, $11.6 \mathrm{~mm} \mathrm{SL}$. Depth $7 \mathrm{~m}$, drop-off at Peros Banhos.

\section{Trimma dalerocheila Winterbottom}

Trimma dalerocheila Winterbottom, 1984:697 (Chagos Archipelago).

\section{MATERIAL}

Twenty-seven lots, 590 specimens, 9.7-19.5 mm SL. Depth range 3-38 $\mathrm{m}$, lagoon and drop-off at Peros Banhos and Salomon.

Fig. 92. Left lateral view of Tenacigobius n. sp. B, $14.7 \mathrm{~mm} \mathrm{SL}$. 
Trimma emeryi Winterbottom

Trimma emeryi Winterbottom, 1985:752 (Chagos Archipelago).

Trimma mendelssohni-Winterbottom, 1984:706 (non Goren, 1978: 195).

\section{MATERIAL}

Twenty-five lots, 363 specimens, 9.6-19.0 mm SL. Depth range 3-43 m, lagoon and drop-off at Peros Banhos and Salomon.

\section{Trimma eviotops Schultz}

Trimma eviotops Schultz, 1943:250 (Rose Island, American Samoa); Winterbottom, 1984:698 (Chagos Archipelago).

\section{MATERIAL}

Three lots, 6 specimens, 10.4-15.5 mm SL. Depth range 7-10 m, lagoons and reef-tops at Eagle Island, Three Brothers, and Peros Banhos.

\section{Trimma fraena Winterbottom}

Trimma fraena Winterbottom, 1984:699 (Chagos Archipelago).

\section{MATERIAL}

Two lots, 2 specimens, 14.9-16.8 mm SL. Depth range 9-15 m, lagoon at Salomon.

\section{Trimma griffithsi Winterbottom}

Trimma griffithsi Winterbottom, 1984:701 (Chagos Archipelago).

\section{MATERIAL}

Two lots, 110 specimens, 9.8-17.8 mm SL. Depth range 25-32 m, lagoon at Peros Banhos.

\section{Trimma haima Winterbottom}

Trimma haima Winterbottom, 1984:702 (Chagos Archipelago).

\section{MATERIAL}

Thirty-eight lots, 370 specimens, 7.7-18.8 mm SL. Depth range 0-36 m, lagoons, reef-tops, and drop-offs at Eagle Island, Peros Banhos, Salomon, and Three Brothers.

\author{
Trimma hoesei Winterbottom \\ Trimma hoesei Winterbottom, 1984:704 (Chagos Ar- \\ chipelago).
}

\section{MATERIAL}

Four lots, 128 specimens, 9.0-24.1 mm SL. Depth range 20-48 m, drop-off caves at Peros Banhos and Salomon.

\section{Trimma macrophthalma (Tomiyama)}

Eviota macrophthalma Tomiyama, 1936:47 (Hatizyozima, Japan).

\section{MATERIAL}

Three lots, 4 specimens, 8.9-17.7 mm SL. Depth range 18-26 m, drop-offs at Peros Banhos and Salomon.

\section{Trimma naudei Smith}

Trimma naudei Smith, 1956a:828 (Mahé, Seychelles).

\section{MATERIAL}

Twelve lots, 94 specimens, 8.7-26.0 mm SL. Depth range $3-40 \mathrm{~m}$, primarily lagoons at Peros Banhos and Salomon.

\section{Trimma sheppardi Winterbottom}

Trimma sheppardi Winterbottom, 1984:709 (Chagos Archipelago).

\section{MATERIAL}

Five lots, 115 specimens, $8.1-17.6 \mathrm{~mm}$ SL. Depth range 20-48 m, drop-off caves at Peros Banhos and Salomon.

\section{Trimma taylori Lobel}

Trimma taylori Lobel, 1979:2 (Oahu, Hawaii).

\section{MATERIAL}

Eight lots, 1664 specimens, 5.7-20.2 mm SL. Depth range 15-45 m, drop-offs at Peros Banhos and Salomon.

\section{Trimma winchi Winterbottom}

Trimma winchi Winterbottom, 1984:712 (Chagos Archipelago).

\section{MATERIAL}

One lot, 2 specimens, 14.2-18.8 $\mathrm{mm} \mathrm{SL}$. Depth range 33-43 m, drop-off at Salomon.

\section{Genus Trimmatom}

The two species were described and figured in detail by Winterbottom and Emery (1981), and will not be redescribed here. 
Trimmatom nanus Winterbottom and Emery

Trimmatom nanus Winterbottom and Emery, 1981:143

(Chagos Archipelago).

\section{MATERIAL}

Twenty-two lots, 94 specimens, 7.1-10.2 mm SL. Depth range 4-43 $\mathrm{m}$, drop-offs and reef-tops (one specimen from lagoon) at Eagle Island, Peros Banhos, and Salomon.

\section{Trimmatom offucius Winterbottom and Emery}

Trimmatom offucius Winterbottom and Emery, 1981:146 (Chagos Archipelago).

\section{MATERIAL}

Sixteen lots, 170 specimens, 7.6-14.6 mm SL. Depth range 15-48 m, drop-offs at Peros Banhos and Salomon.

\section{Genus Valenciennea}

\section{Valenciennea puellaris (Tomiyama)}

Figs. 93, 94

Eleotrioides puellaris Tomiyama in Tomiyama and Abe, 1956: 1136 (Japan).

Valenciennea puellaris-Russell, 1983:139 (IndoPacific).

\section{MATERIAL}

Three lots, 4 specimens, 41.1-86.6 mm SL. Depth range 10-20 m, lagoon only, at Peros Banhos.

\section{DESCRIPTION}

Based on all four specimens. D Vl + I 12, third spine may be elongate, reaching to base of second to fourth rays of second dorsal fin when depressed; A I 11-12 (11.8); P 19-20 (19.8), reaching to a vertical with anal-fin origin; $V$
I 5, no fraenum or basal membrane, fifth ray branched and three-quarters of length of fourth, reaching posteriorly almost to anus. Lateral scales 80-84 (82.5); transverse 21-26 (24.3); head, nape, and pectoral-fin base naked; prepelvic region and midline of belly with cycloid scales, others ctenoid. Gill opening restricted to pectoral-fin base. Mouth terminal; upper jaw with single row of curved, spaced canines, larger at anterior and posterior margins of jaw and smaller in midregion. Lower jaw with outer row of similar teeth, decreasing in size posteriorly; a short inner row of similar teeth near symphysis; one to two enlarged, hooked canines flaring out laterally from bend of dentary. First gill slit open; gill rakers $0+4$; pseudobranch with four lobes. As percentage standard length: head length 29-34 (31.3); origin of first dorsal fin 33-36 (34.3); origin of second dorsal fin 55-58 (56.3); origin of anal fin 59-61 (60.0); caudal-peduncle length 15-16 (15.3). As percentage head length: eye diameter $18-22$ (19.3); snout length 33-39 (36.8); upper-jaw length 39-45 (42.0). Caudal-peduncle depth as percentage caudal-peduncle length 75-82 (78.8). Head pores and papillae as in Fig. 94.

Colour pattern (freshly dead, based on two males and a female 41.1-86.6 $\mathrm{mm} \mathrm{SL}$ ): background pearly white or with pinkish tinge, with an amorphous mottling of sandy yellow, especially along midline of body. Six dark orange, pupil-width bars across dorsum, not quite reaching midlateral septum, sloping anterodorsally to posteroventrally: the first above end of opercle, second between spines 3 and 4 of first dorsal fin, third across dorsal interspace, fourth between bases of rays 5 and 6 of second dorsal fin, fifth between bases of rays 11 and 12 , and sixth just anterior to procurrent caudal-fin rays. Bars tending to be less well developed posteriorly; interspaces with light yellow spots varying from half to full pupil width in diameter. A poorly defined, yellow, pupil-width stripe

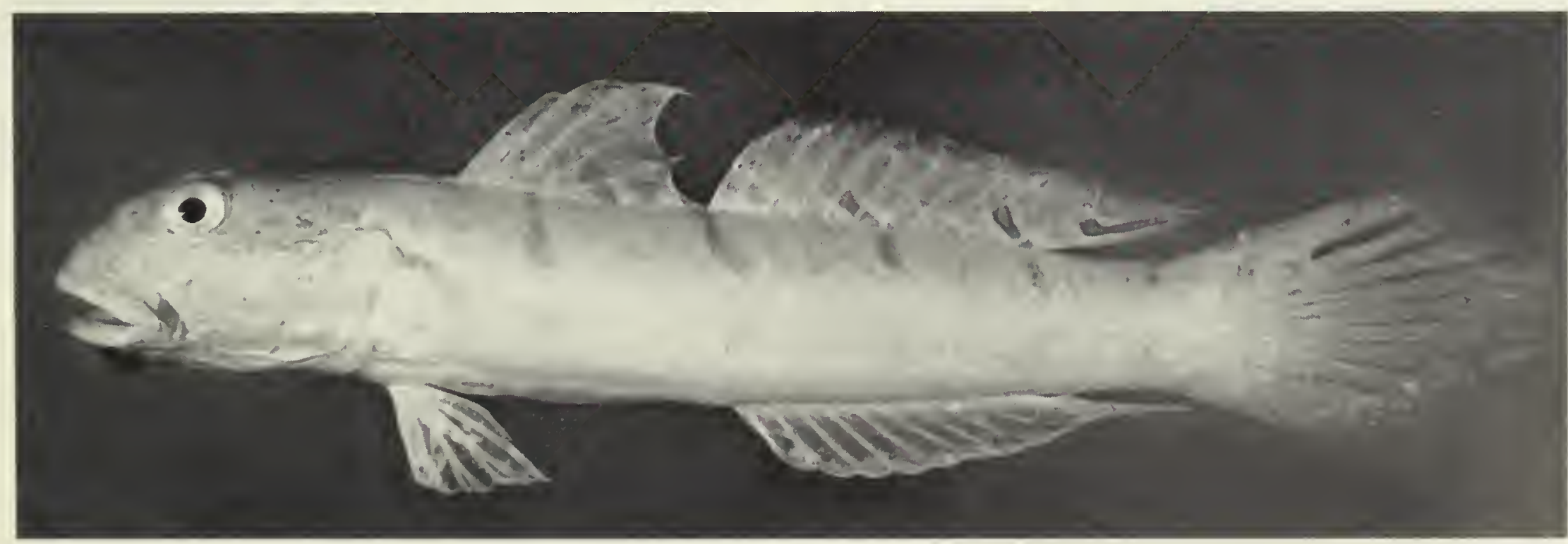

Fig. 93. Left lateral view of Valenciennea puellaris, $86.6 \mathrm{~mm}$ SL. 
from edge of subopercle to caudal peduncle just below midlateral septum, the yellow intensified to orange beneath six dorsal bars. Dorsal fins with inclined bars and mottlings of yellow; caudal fin with a thin, vertical yellow bar across posterior tips of hypurals, followed by two or three bars or rows of yellow spots; other fins hyaline. Sandy mottling dominates head, so that white background reduced to spots of pupil-to eye-diameter size. A vertical orange bar one-half of pupil diameter in width and edged with black from posterior tip of lower jaw across tissue between upper jaw and palatoquadrate. Chin black, iris yellow. Preserved: pale straw yellow, only trace of colour pattern remaining being black chin.

\section{DISCUSSION}

The specimens from Chagos differ from those from the western Pacific in details of colour pattern. Specimens from Japan (Masuda et al., 1980, pl. 90C) and our slides of a Fiji specimen indicate that the sloping bars across the dorsum are represented by eye-diameter-sized spots which do not reach the dorsal midline, that the sloping yellow bands in the second dorsal fin are represented by a horizontal yellow line (Fiji) or a row of yellow spots (Japan), and that the lateral stripe below the midlateral
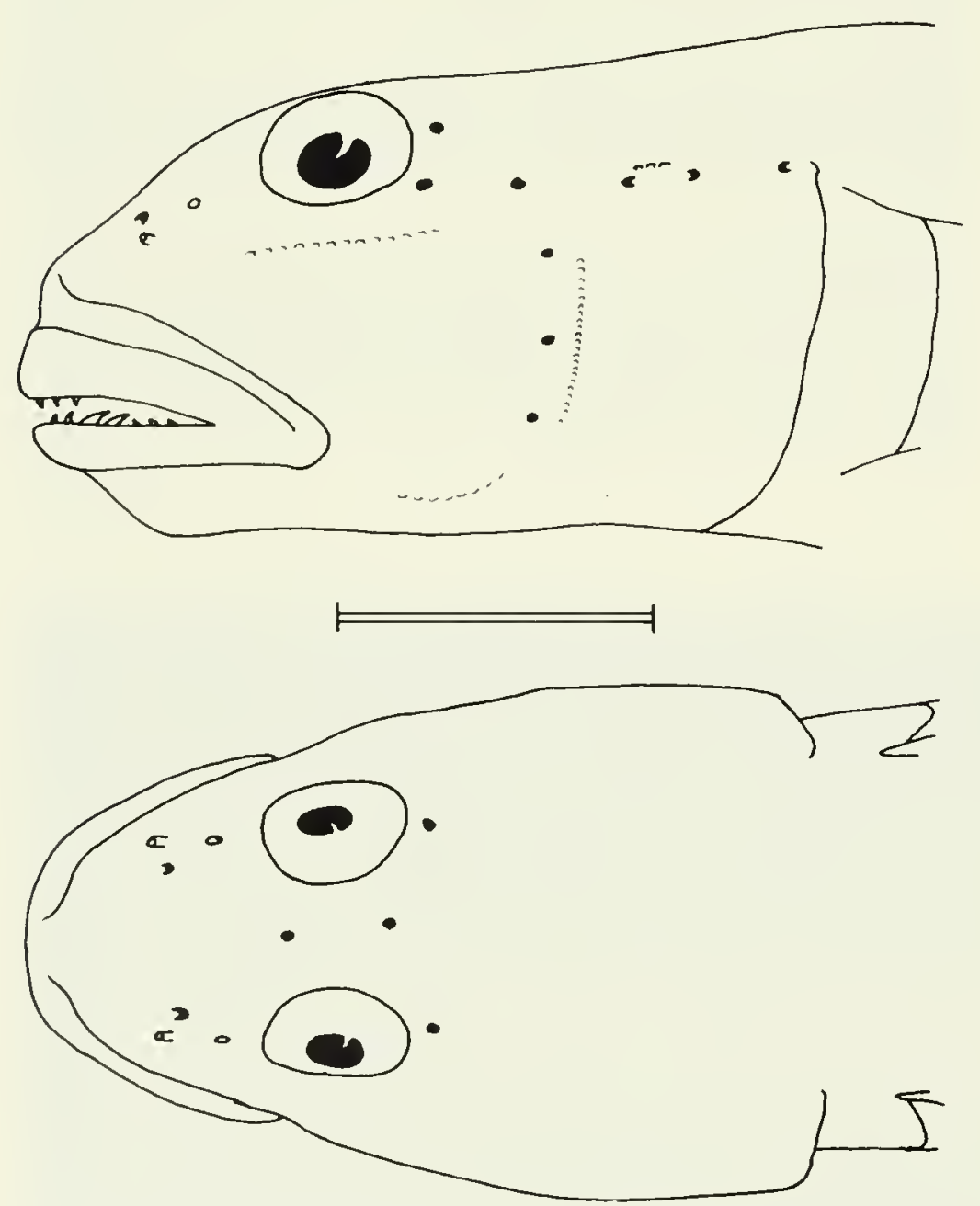

Fig. 94. Left lateral (above) and dorsal (below) views of the head of Valenciennea puellaris, $86.6 \mathrm{~mm} \mathrm{SL}$, to show head pores and papillae. Scale equals $1 \mathrm{~cm}$. septum is much more strongly pigmented. An assessment of these differences must await a revision of the genus, currently being studied by Dr D. F. Hoese.

Valenciennea sexguttata (Valenciennes) Figs. 95, 96 Eleotris sexguttatus Valenciennes in Cuvier and Valenciennes, 1837:254 (Trinquemalé, Ceylon).

Eleotris lantzi-Regan, 1908:241 (Peros Banhos, Chagos Archipelago).

Valenciennea sexguttata-Allen and Steene, 1979:61 (widespread tropical lndo-west Pacific).

\section{MATERIAL}

Ten lots, 358 specimens, 17.3-88.3 mm SL. Depth range 0-10 m, lagoons only, at Diego Garcia, Eagle Island, Peros Banhos, and Three Brothers.

\section{DESCRIPTION}

Based on 10 specimens from lot WE 79-105 (31.4-78.2 mm SL), and 10 cleared and stained specimens from lot WE 79-44. D VI + 1 12, third and fourth rays longest, reaching to base of second to fourth rays of second dorsal fin when depressed; A I 12; P 19-20 (19.6), reaching two-thirds of distance to anal-fin origin; V I 5, no fraenum or basal membrane, reaching half-way to anal origin, fifth ray branched and $80 \%$ of fourth. Lateral scales 79-89 (83.3); transverse 25-28 (27.0); midline of nape naked, scales extending anteriorly on sides of nape for a variable distance, from above gill slit almost to posterior margin of eye; pectoral base naked, prepelvic area scaled; scales small, ctenoid, increasing in size posteriorly. Gill opening restricted, extending a little beyond pectoral base anteroventrally. Anterior nostril tubular, posterior porelike. Mouth terminal, inclined slightly dorsally. Teeth in upper jaw spaced, curved, decreasing a little in size posteriorly, in single row. Lower-jaw teeth similar, but with two rows between symphysis and bend of dentary, where one to two enlarged canines present; posterior to this, teeth tending to be straighter, pointing anterodorsally. Tongue rounded to truncate. First gill slit open; $0+7-8(\bar{x}=7.2)$ gill rakers on outer limb of first arch $(2+6$ ossified rakers in cleared and stained specimen); a papillate ridge along ventral margin of first epibranchial. Five branchiostegal rays. Dorsal pterygiophore formula $3(2,2,1,1,0)$; vertebrae 10 $+15+$ ural centrum $=26$. Six to 7 dorsal and 6 ventral branched caudal-fin rays, with 12 to 14 dorsal and 12 to 13 ventral unbranched rays. As percentage standard length: head length 30-34 (31.2); origin of first dorsal fin 34-38 (36.2); origin of second dorsal fin 54-59 (56.9); origin of anal fin 59-66 (61.2); caudal-peduncle length 15-18 (16.2). As percentage head length: eye diameter 16-21 (18.7); snout length 34-40 (35.6); upper-jaw length 


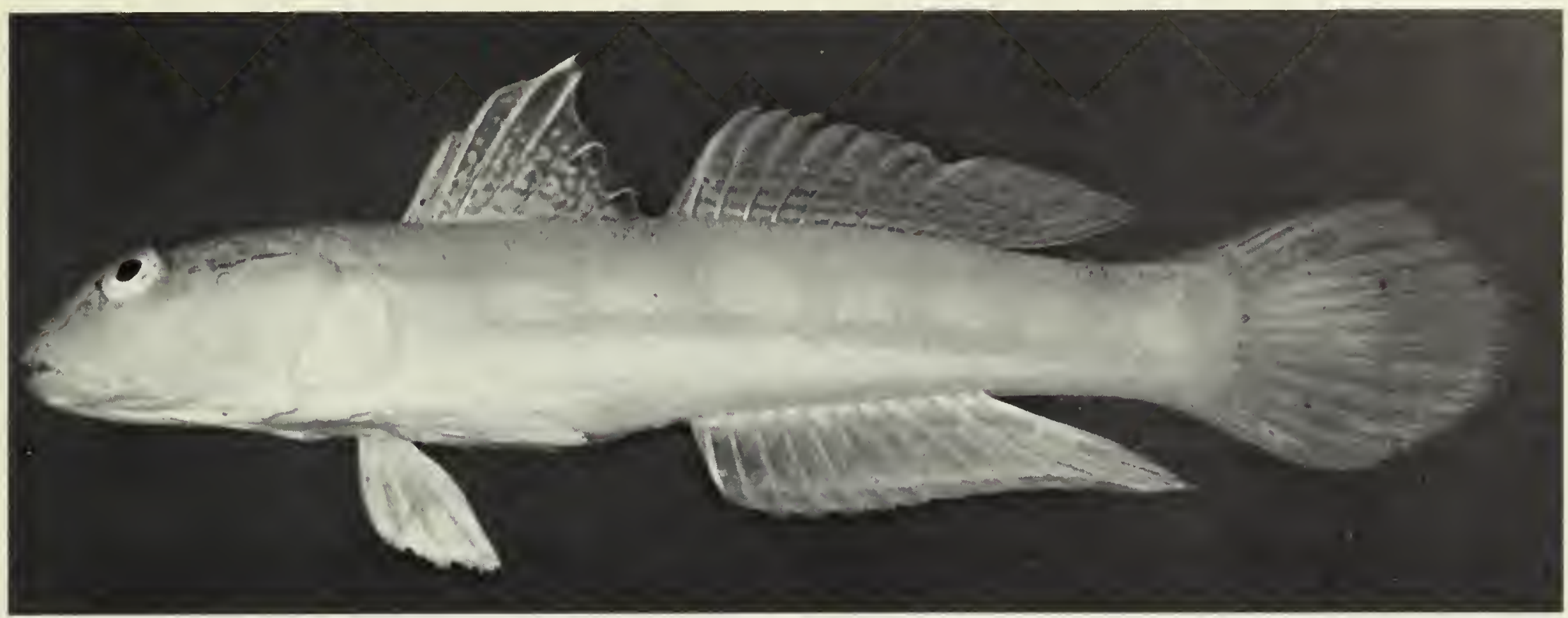

Fig. 95. Left lateral view of Valenciennea sexguttata, $66.4 \mathrm{~mm}$ SL.

35-42 (37.9). Caudal-peduncle depth as percentage caudal-peduncle length 66-84 (74.8). Head pores and papillae as in Fig. 96. Caudal skeleton as in $A$. hectori.

Gut packed with tiny harpacticoid copepods and numerous, probably parasitic, nematodes.

Colour pattern (freshly dead-based on three specimens of 29.7, 44.9, and $66.4 \mathrm{~mm} \mathrm{SL}$ ): body and fins off-white; first dorsal fin with scattering of iridocytes proximally and distally; a black, pupil-diameter-sized spot between tips of spines 3 and 4; iris yellow dorsally; two half-pupildiameter blue spots on upper opercle and a few such spots ventrally on cheek in vicinity of interopercle (two smaller specimens). Largest specimen with more numerous lavender spots extending to nape and suborbital regions; five thin, light pink lines in second dorsal fin; anal fin with pink border and pink suffusions at bases of rays; a pupil-width pink stripe along body just below lateral septum, ending half-way along caudal peduncle, with a hint of four short bars extending from it dorsally in region below second dorsal fin; a faint pink vertical bar over bases of principal caudal-fin rays. Preserved: off-white, with only black spot in first dorsal fin remaining. Many specimens also possessing an elongate dusky spot between two of uppermost branched caudal-fin rays. Spot not present in any photographed specimens.

\section{DISCUSSION}

Although our specimens were photographed as soon as possible after collection, some fading had occurred. When freshly dead, an additional pink band was present on the body above the lateral septum, and the two bands were connected by short pink crossbars. Valenciennea sexguttata seems to have fairly rigid habitat requirements. In two collections made in the same area, at the same time, about
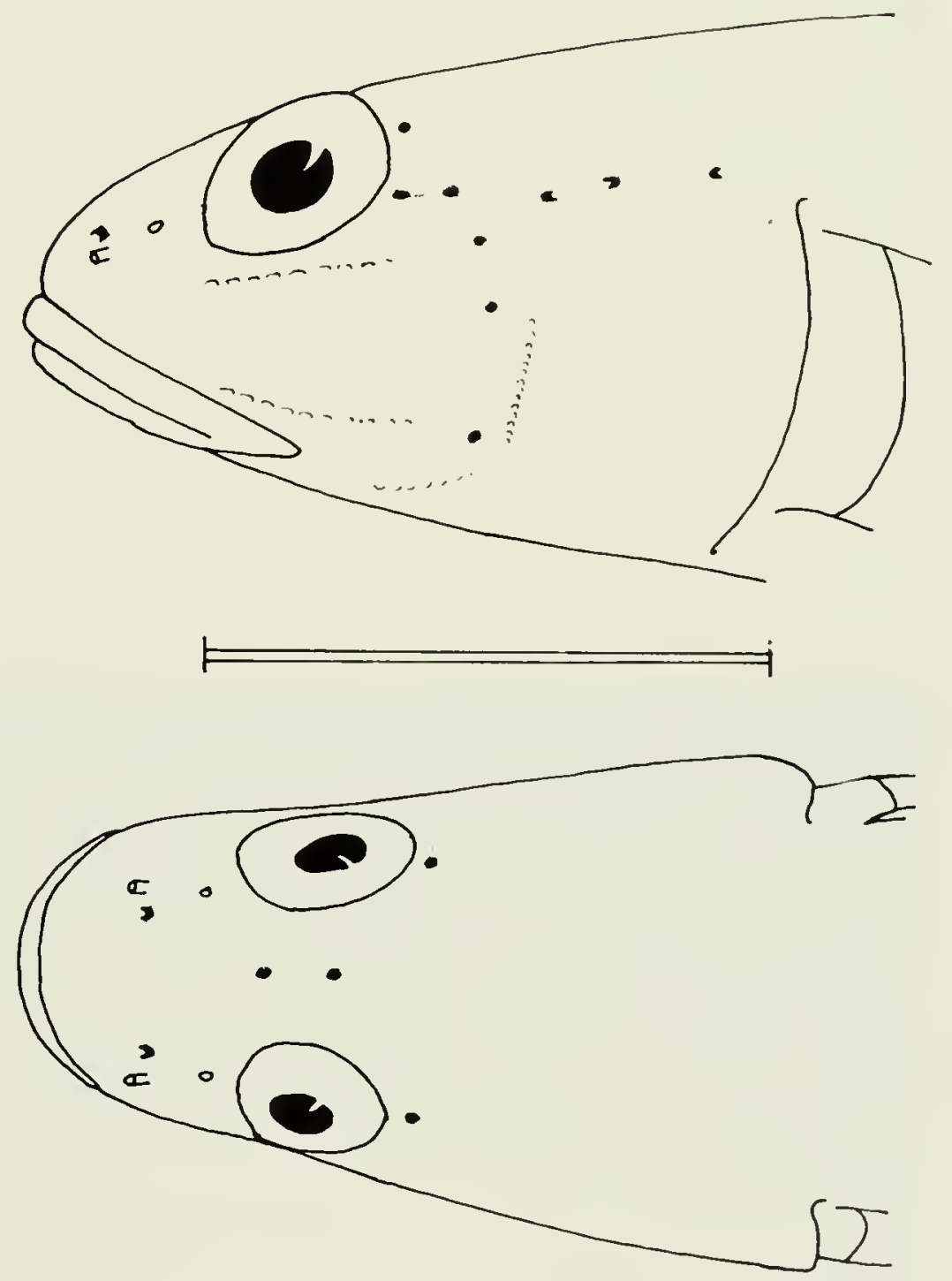

Fig. 96. Left lateral (above) and dorsal (below) views of the head of Valenciennea sexguttata, $52.5 \mathrm{~mm} \mathrm{SL}$, to show head pores and papillae. Scale equals $1 \mathrm{~cm}$. 
$200 \mathrm{~m}$ apart, in 0-0.5 $\mathrm{m}$ depth, on the lagoonal reef-flat at Peros Banhos, one yielded 323 specimens and the other none. There were no obvious discernible differences between the two stations in terms of substrate, coral cover and type, etc. No other collection contained more than 10 specimens.

\section{Valenciennea strigata (Broussonet)}

Figs. 97, 98

Gobius strigatus Broussonet, 1782:1 (Tahiti).

Valenciennea strigata-Allen and Steene, 1979:61 (widespread tropical Indo-Pacific).

\section{MATERIAL}

Two lots, 2 specimens, 28.4-82.5 mm SL. Depth range 0-15 m, lagoon only, at Peros Banhos.

\section{DESCRIPTION}

Based on both specimens. D VI + I 16-18, second and third rays elongate, reaching first or eighth to tenth dorsal-fin rays; A I 15-17; P 21-23 (21.8), reaching half-way to anus; V I 5, reaching half-way to anus, no fraenum or basal membrane, fifth ray branched and $80 \%$ as long as fourth. Lateral scales about 110; transverse about 40. Midline of nape and head naked; sides of nape, pectoral base, prepelvic base, and belly with cycloid scales; otherwise ctenoid, increasing in size posteriorly. Gill opening restricted ventrally, reaching to between pectoral base and vertical limb of preopercle. Mouth terminal, inclined dorsally; upper jaw with about 6 enlarged, curved canines near symphysis, followed by a single row of 12 to 14 similar but smaller teeth; lower jaw with two rows of small, curved teeth near symphysis, grading to single row posteriorly, and with 2 to 4 large lateral canines at bend of dentary. Anterior nostril tubular, posterior porelike. Tongue truncate. First gill slit open; 0 + 4-5 gill rakers on first arch; epibranchial with a papillated ridge ventrally. Five branchiostegal rays. As percentage standard length: head length 31-32 (31.5); origin of first dorsal fin 33-39 (36.1); origin of second dorsal fin 55-57 (56.2); origin of anal fin 62-63 (62.3); caudal-peduncle length 11-12 (11.5). As percentage head length: eye diameter 18-23 (20.5); snout length 28-40 (34.0); upper-jaw length 31-34 (32.7). Caudal-peduncle depth as percentage caudal-peduncle length 99-100 (99.5). Head pores and papillae as in Fig. 98.

Colour pattern (freshly dead, based on an $82.5 \mathrm{~mm}$ SL female): green-brown dorsally, fading to off-white ventrally. Lips, cheek, and opercle yellow; a pupil-width, black-bordered blue line from posterior margin of maxilla to upper edge of gill slit; paler blue lines along bend of preopercle; branchiostegal rays and a vertical bar on pectoral base; small blue spot just behind eye at level of pupil; three rows of two blue spots each behind pectoral-fin base. Dorsal fins with five pink stripes alternating with pale green stripes; caudal fin with pink horizontal line passing posteriorly from both dorsal and ventral procurrent rays. Preserved: pale, with the blackedged blue stripe beneath eye apparent as a grey streak, lines in second dorsal faintly visible as differing shades of grey, no other marks visible.

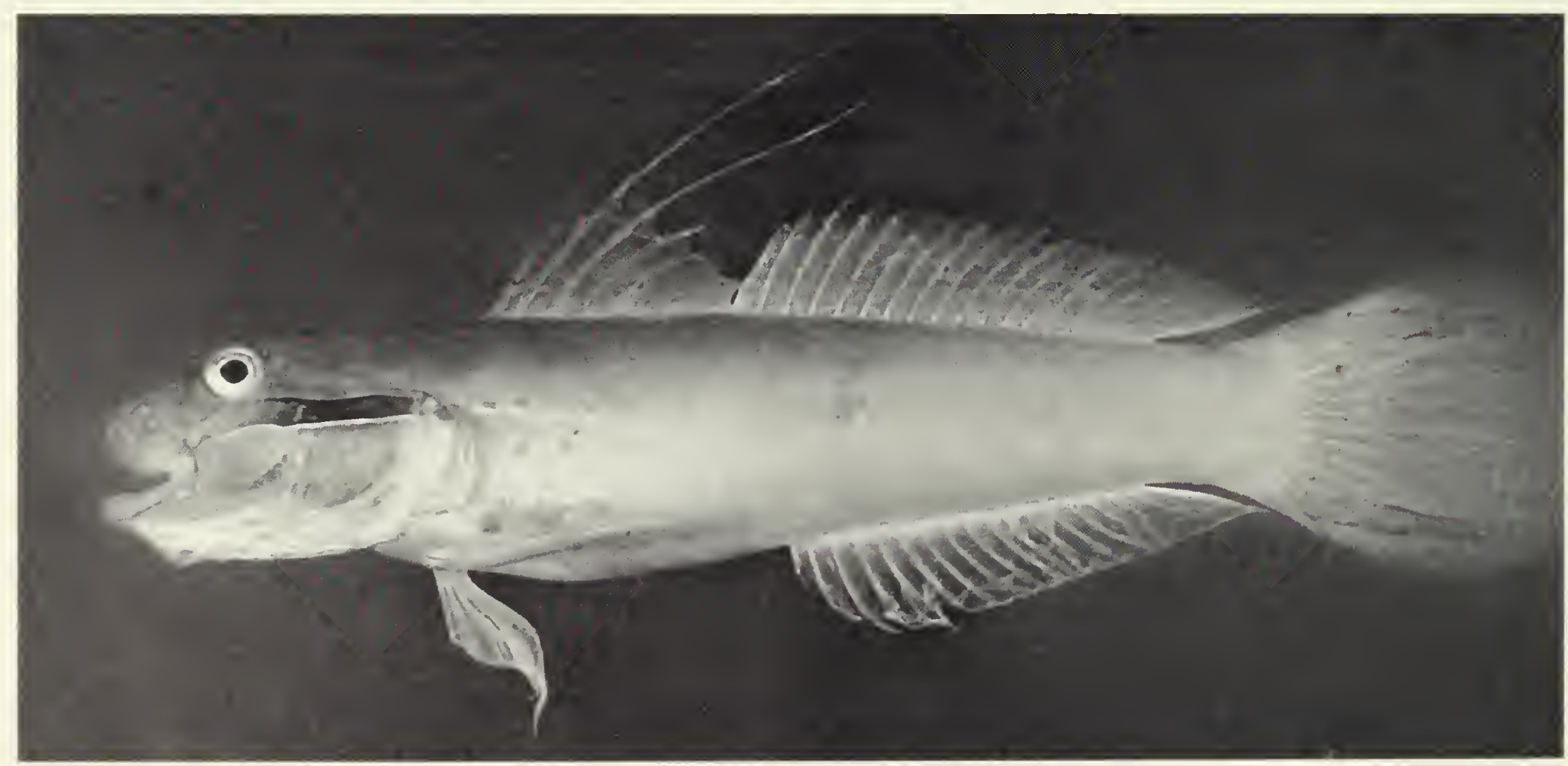

Fig. 97. Left lateral view of Valenciennea strigata, $82.5 \mathrm{~mm} \mathrm{SL}$. 

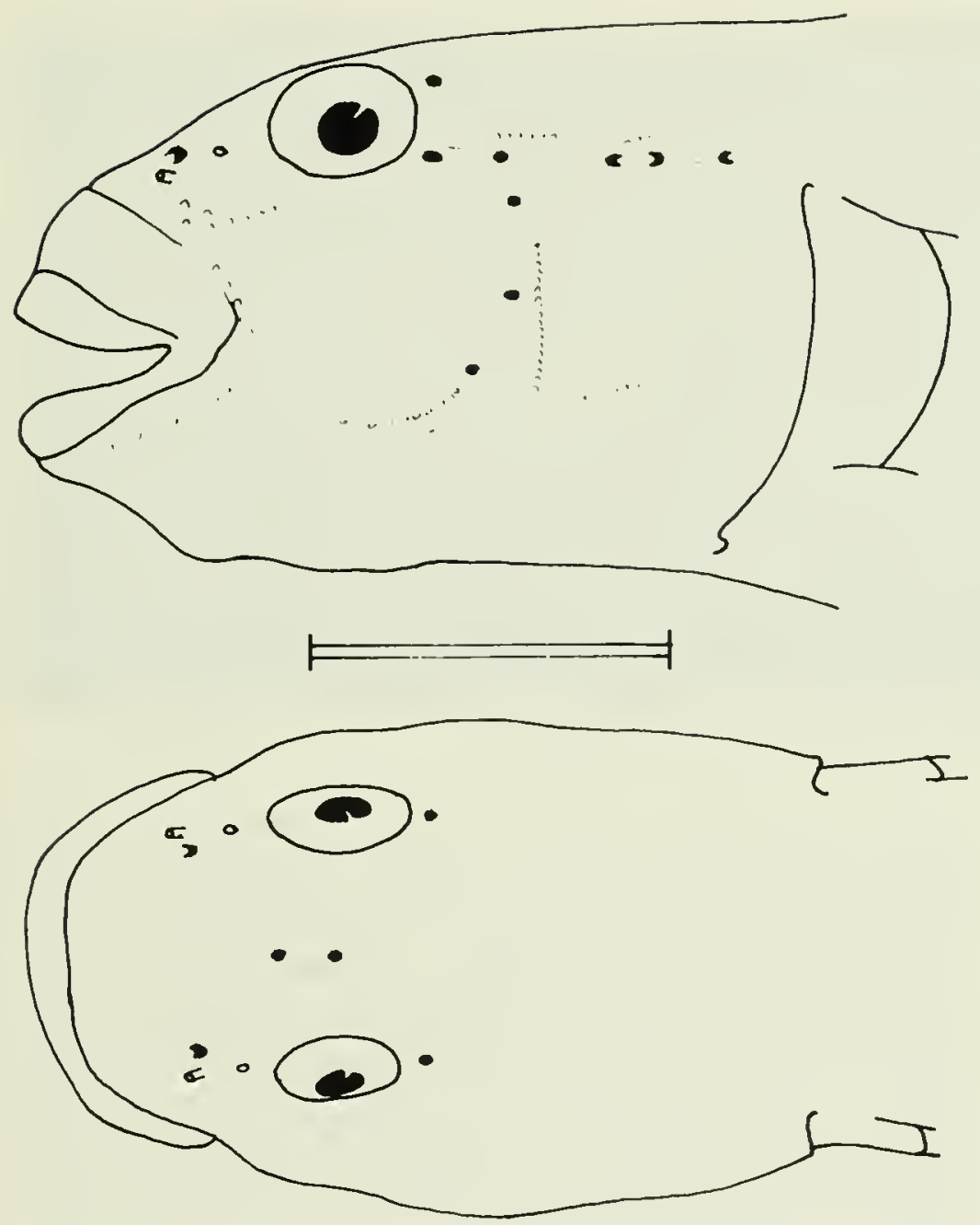

Fig. 98. Left lateral (above) and dorsal (below) views of the head of Valenciennea strigata, $82.5 \mathrm{~mm} \mathrm{SL}$, to show head pores and papillae. Scale equals $1 \mathrm{~cm}$.

\section{DISCUSSION}

The only difference we could find between Indian Ocean and Pacific Ocean specimens was the presence of three rows of blue spots on the body beneath the pectoral fin in Indian Ocean examples (Chagos specimen; Smith, 1958, pl. I D; Burgess and Axelrod, 1973:633-photograph retouched but faint blue spots still visible). These spots are absent in specimens we have photographed from the Great Barrier Reef and Fiji, and from specimens from Japan (Masuda et al., 1980, pl. 90A; Burgess and Axelrod, 1974a:476), Palau (Burgess and Axelrod, 1974a:474), the Solomons (Burgess and Axelrod, 1975:1603), and the New Hebrides (Fourmanoir and Laboute, 1976: 144). The apparent difference may be due to some other factor (e.g., sex), since Shen (1984, pl. 122 405-2a,b) and Burgess and Axelrod (1974b:1016) figure both forms from Taiwan. Further material and photographs are needed to resolve this problem.

\section{Genus Vanderhorstia}

Vanderhorstia ornatissima Smith

Figs. 99, 100

Vanderhorstia ornatissima Smith, 1959:192 (Pinda,
Mozambique; also Mahé, Seychelles); Masuda et al., 1980:277 (Japan).

\section{MATERIAL}

Four lots, 4 specimens, 20.3-45.4 mm SL. Depth range 0-7 m, lagoons only, at Peros Banhos and Salomon.

\section{DESCRIPTION}

Based on all four specimens. D VI + I 13, no rays elongate in two smaller specimens, third ray reaching to base of seventh to ninth rays of second dorsal fin in two larger specimens; A I 13; P 17-19 (18.4), reaching posteriorly to a vertical with base of third anal ray; V I 5, fraenum and full basal membrane present, fifth ray branched and a little longer than fourth, reaching to anus. Lateral scales 57-62 (59.3); transverse 14-15 (14.3); no scales on head, nape, or pectoral-fin base; cycloid scales on body, becoming larger posteriorly and weakly ctenoid on caudal peduncle. Gill opening extending anteroventrally to beneath vertical limb of preopercle. Mouth terminal, slightly inclined dorsally. Both jaws with small conical teeth in several series and with one to two enlarged curved canines at bend of jaw; outer row of teeth between these canines and symphysis somewhat enlarged. Anterior nostril tubular, posterior porelike. Tongue truncate. First gill slit open; gill rakers on first gill arch $2+7-8$. As percentage standard length: head length 24-29 (27.0); origin of first dorsal fin 28-36 (32.0); origin of second dorsal fin 50-59 (54.5); origin of anal fin 53-59 (55.5); caudal-peduncle length 11-12 (11.2). As percentage head length: eye diameter 18-26 (22.6); snout length 20-25 (23.4); upper-jaw length 29-35 (30.7). Caudal-peduncle depth as percentage caudal-peduncle length 73-79 (76.7). Head pores and papillae as in Fig. 100.

Colour pattern (freshly dead; based on two females, $19.9 \mathrm{~mm}$ and $45.4 \mathrm{~mm} \mathrm{SL}$, and on a $30.6 \mathrm{~mm}$ SL male): $45.4 \mathrm{~mm}$ SL female with an extremely complex colour pattern. Background yellowish brown, darker dorsally. Body with numerous blue spots up to one-half of pupil diameter in size, sometimes coalescing to form irregular, more or less vertical blue stripes, which are often paired and, usually anteriorly, with a yellow interspace; spots at other times coalescing to form a blue, eye-diameter-sized ring with a yellow centre, usually posteriorly. Head with short parallel stripes of blue with yellow centres, or with yellow-centred blue rings. Head and body with diffuse brown blotches ranging from pupil diameter to eye diameter in size. First dorsal with small brown flecks; second dorsal with light brown interradial membranes on distal two-thirds; caudal with yellow-brown streaks and spots; anal dusky; pelvics yellow with blue spots; pectoral hyaline. Iris dark brown around rim, becoming lighter towards centre. A $30.6 \mathrm{~mm}$ SL male with pale strawcoloured background, scattered yellow spots and blotches, 


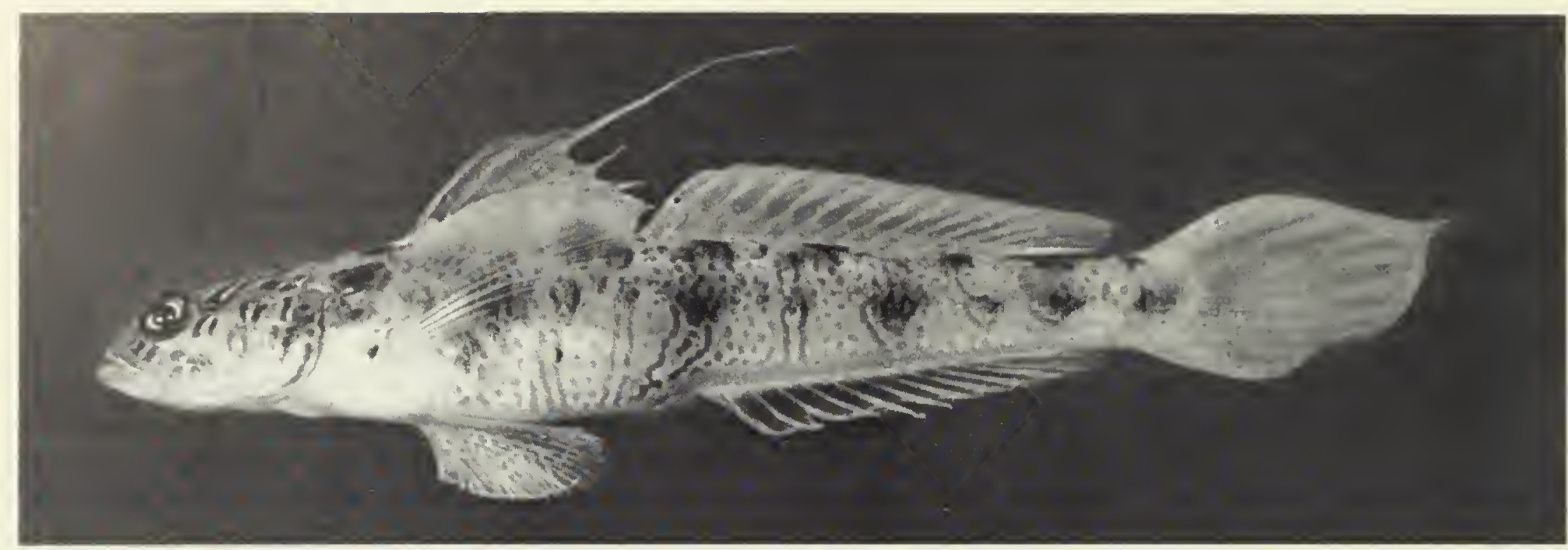

Fig. 99. Left lateral view of Vanderhorstia ornatissima, $45.4 \mathrm{~mm} \mathrm{SL}$.
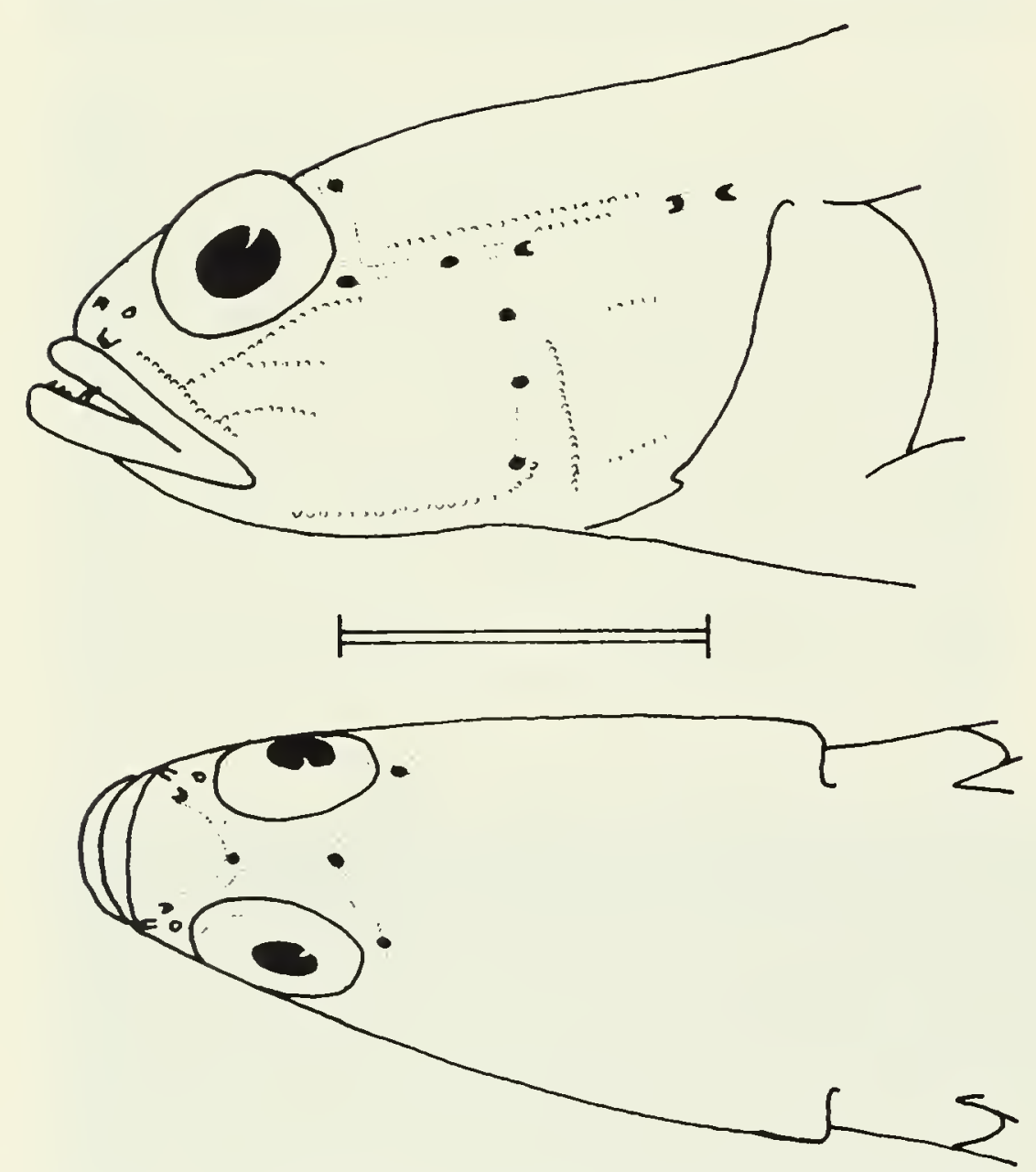

Fig. 100. Left lateral (above) and dorsal (below) views of the head of Vanderhorstia ornatissima, $45.4 \mathrm{~mm} \mathrm{SL}$, to show head pores and papillae. Scale equals $5 \mathrm{~mm}$. and a few diffuse brown spots. Median fins with melanophores and iridocytes (the latter especially evident basally). A $19.9 \mathrm{~mm}$ SL female basically similar to male, but with well-developed, pupil-width band of iridocytes along bases of dorsal and anal fins. Preserved: pale straw-yellow, with brown and blue areas represented by brownish chromatophores, yellow areas faded into background coloration.

\section{DISCUSSION}

Chagos specimens agree well with a specimen photographed in Fiji, except that the latter had more yellowcentred blue rings and fewer yellow-centred blue stripes on the body. The type specimen figured by Smith (1959, pl. 10C, from Pinda) had brown spots on the body (rather than blue), and the blue stripes and rings had red, rather than yellow, centres. A specimen from Japan figured by Masuda et al. (1980, pl. 92D) showed the stripes and rings poorly outlined with very pale blue and with red centres; this specimen apparently had fewer lateral scales (52-54). A specimen from Moorea illustrated by Burgess and Axelrod (1974a:475) was similar to the Japanese specimen in coloration. Further specimens and photographs are needed to resolve whether these minor differences have any taxonomic significance. 


\section{Family Eleotrididae}

\section{Genus Calumia}

\section{Calumia godeffroyi (Günther)}

Figs. 101, 102

Eleotris godeffroyi Günther, 1877:188 (Raiatea, Society Islands).

Calumia biocellata Smith, 1958:148 (Zanzibar; ranges from Bazaruto to Shimoni).

\section{MATERIAL}

Two lots, 3 specimens, $8.4-26.5 \mathrm{~mm}$ SL. Depth range 5-25 m, lagoon and drop-off at Peros Banhos and Salomon.

\section{DESCRIPTION}

Based on $26.5 \mathrm{~mm}$ SL specimen only; all specimens in poor condition. D VI +17 , second to fourth spines longest, reaching to base of third dorsal ray; A I 7; P 14 on left side and 17 on right, all rays simple, reaching to a vertical with third anal ray; V I 5 , bases well separated, no fraenum or basal membrane, reaching to base of second anal ray, fifth ray simple and two-thirds of length of fourth ray. Lateral scales 24; transverse 7 ; predorsal 7 . Scales on prepelvic and pectoral bases, cheeks, and opercles. Scales on nape, belly, and prepelvic and pectoral bases cycloid; rest of body with ctenoid scales. Gill opening extends ventrally to a point between verticals of posterior margin of eye and of vertical limb of preopercle. Mouth terminal, slightly inclined dorsally; jaws with an outer row of enlarged, curved teeth and irregular inner rows of small conical teeth. Anterior nostril a long, darkly pigmented tube; posterior nostril porelike. Tongue rounded. First gill slit open; $1+6$ gill rakers; pseudobranch with three lobes. Six branchiostegal rays. As percentage standard length: head length 33.2 ; origin of first dorsal fin 37.7 ; origin of second dorsal fin 58.9; origin of anal fin 61.1; caudalpeduncle depth 29.4. As percentage head length: eye diameter 25.0; snout length 21.6; upper-jaw length 29.5 . Caudal-peduncle depth as percentage caudal-peduncle length 51.3. No head pores visible, papillae on cheek not discernible owing to specimen condition. A longitudinal row on either side of snout medial to nostrils (Fig. 102).

Colour pattern (freshly dead): background light with sprinkling of melanophores; scales outlined with orangebrown; body with five dark bands, end of caudal peduncle dark; median fins dusky, distal half of second dorsal orange-brown; an intense, black, pupil-sized spot on the posterior dorsal and ventral procurrent caudal-fin rays; pectoral- and pelvic-fin rays dusky, membrane clear. Iris red-brown. Preserved: similar to above, but orange-brown areas dark.

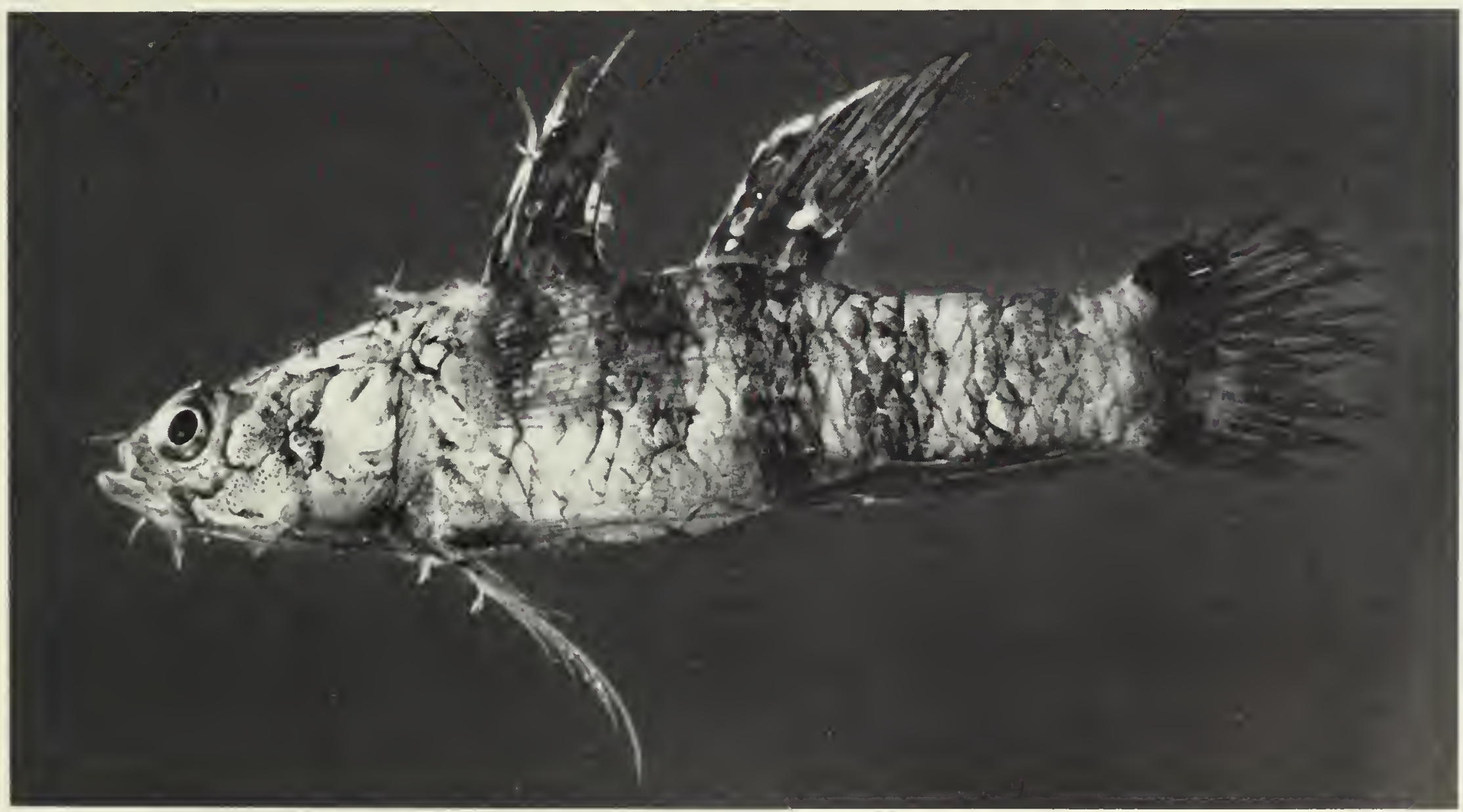

Fig. 101. Left lateral view of Calumia godeffroyi, $26.5 \mathrm{~mm} \mathrm{SL}$. 

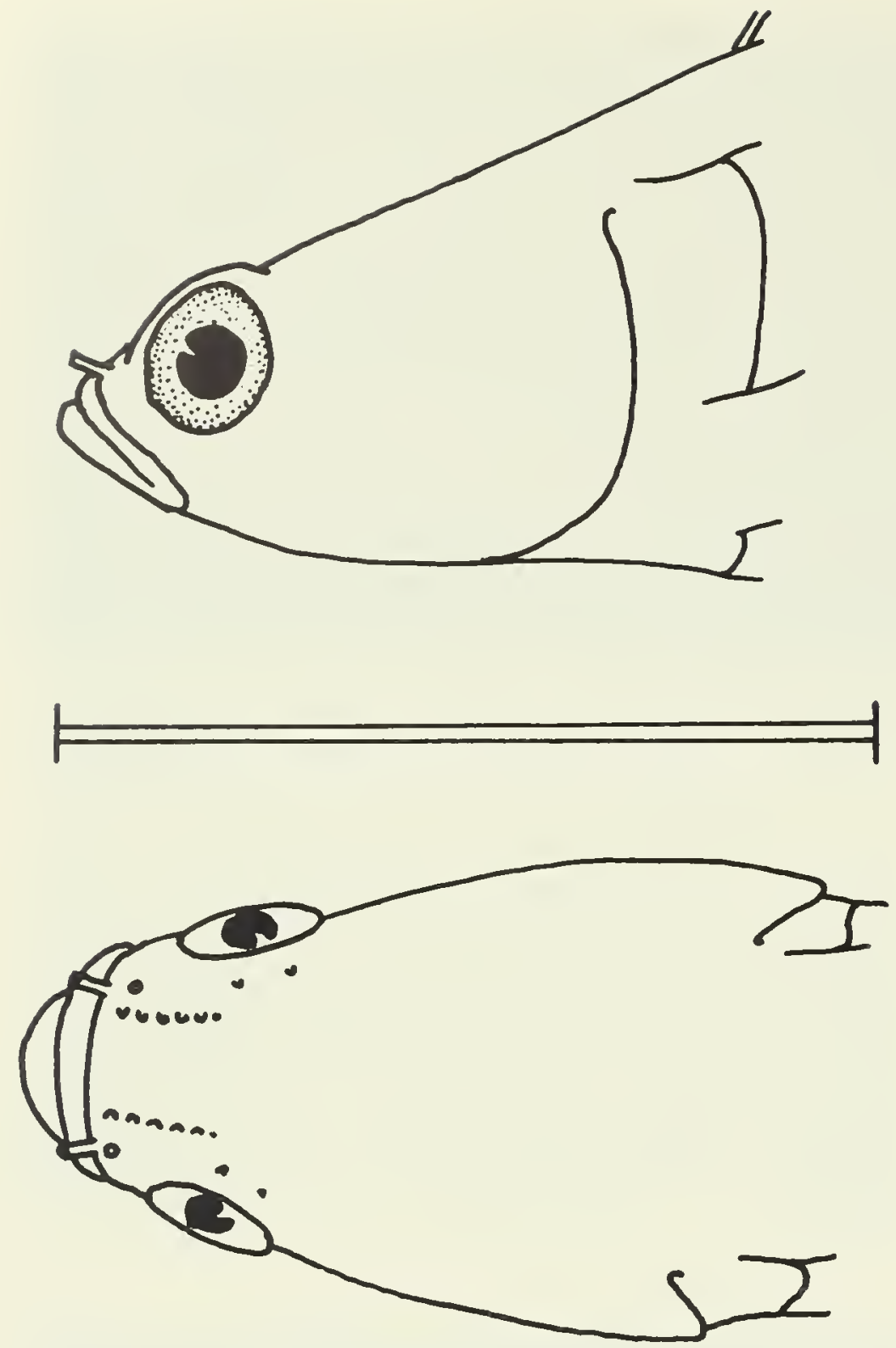

Fig. 102. Left lateral (above) and dorsal (below) views of the head of Calumia godeffroyi, $26.5 \mathrm{~mm} \mathrm{SL}$, to show outline and nasal papillae. Scale equals $1 \mathrm{~cm}$.

\section{DISCUSSION}

Calumia godeffroyi differs from the only other species in the genus, $C$. profunda, in pectoral-fin ray and gill raker counts, tongue shape, mouth, and gill opening extent, and in having black spots on the caudal-fin base (Larson and Hoese, 1980).

\section{Genus Xenisthmus}

This genus is currently being revised by Dr D. F. Hoese, to whom we have sent our material. Preliminary identifications using Smith (1958) indicate the following two species at Chagos, for one of which we provide a figure of a freshly dead specimen.

\section{Xenisthmus africanus Smith}

Xenisthmus africanus Smith, 1958:153 (Pinda, Mozambique; also Kenya and Aldabra).

\section{MATERIAL}

Three lots, 8 specimens, 13.1-18.1 mm SL. Depth range 0-1 m, lagoons at Eagle Island and Peros Banhos.

Xenisthmus polyzonatus (Klunzinger)

Fig. 103

Eleotris polyzonatus Klunzinger, 1871:482 (Red Sea).

Xenisthmus polyzonatus-Clark, 1962:7 (Al Ghardaqah, Red Sea).

\section{MATERIAL}

Three lots, 3 specimens, 16.1-19.8 mm SL. Depth range 5-7 m, lagoon and reef-top at Peros Banhos, Salomon, and Three Brothers.

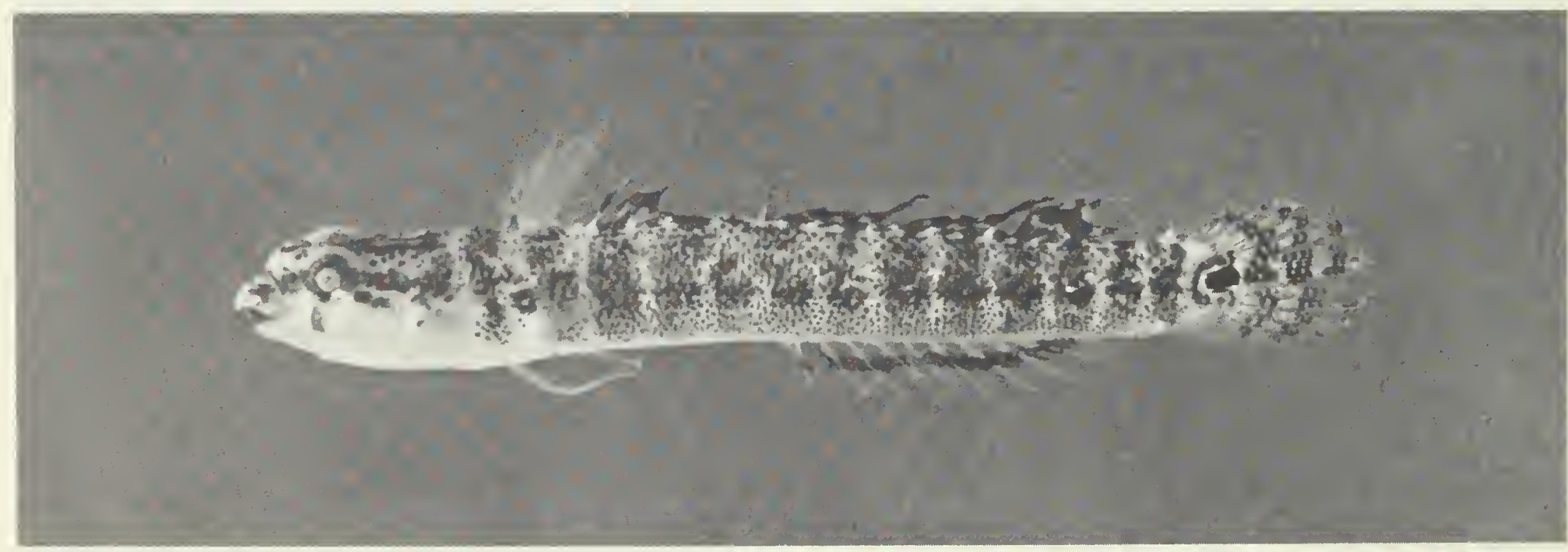

Fig. 103. Left lateral view of Xenisthmus polyzonatus, $17.0 \mathrm{~mm}$ SL. 


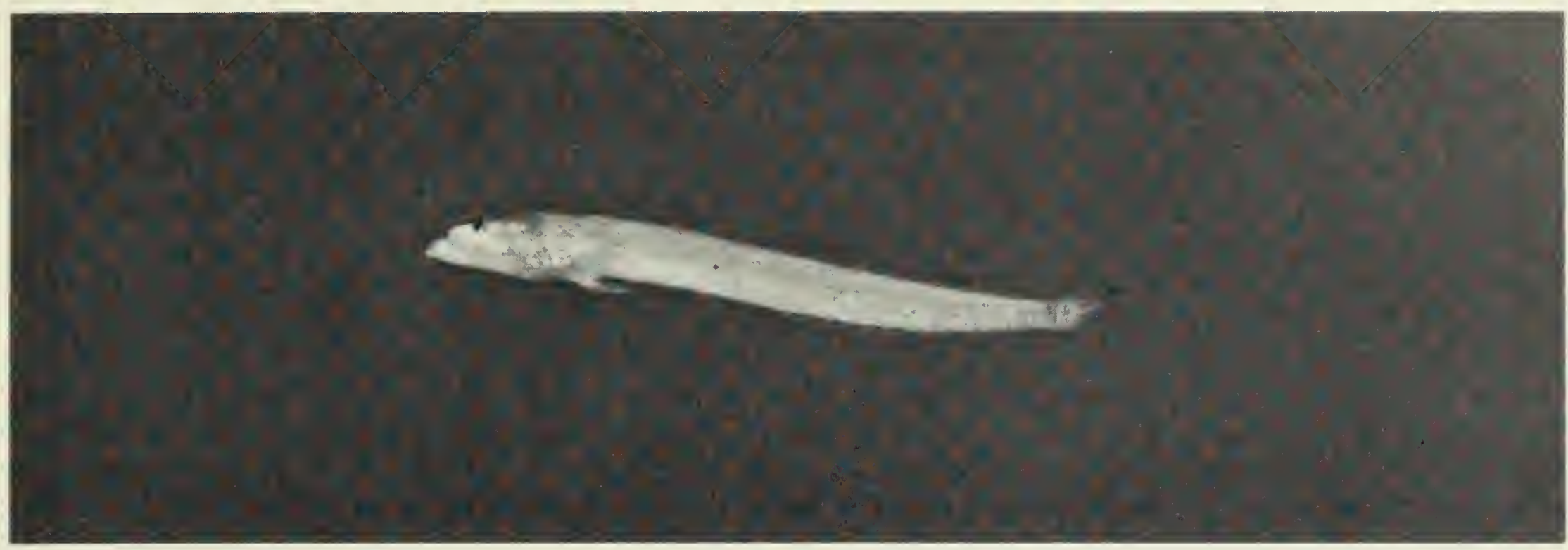

Fig. 104. Left lateral view of Kraemeria samoensis, $23.6 \mathrm{~mm}$ SL.

\section{Family Kraemeriidae}

\section{Genus Kraemeria}

\section{Kraemeria samoensis Steindachner}

Figs. 104, 105

Kraemeria samoensis Steindachner, 1906:41 (Samoa); Winterbottom, 1976:67 (widespread in Indo-Pacific).

\section{MATERIAL}

Three lots, 20 specimens, 17.9-23.6 mm SL. Depth range 0-7 m, lagoon only, at Peros Banhos.

\section{DESCRIPTION}

Based on 10 specimens from lot WE 79-109 (20.2-23.6 mm SL), and 3 cleared and stained specimens from the same lot. D V + I 4 (once with a small additional spine anterior to the first dorsal spine and borne on same pterygiophore; once I 5 rays in second dorsal fin), fourth to fifth spines longest, latter reaching base of first ray of second dorsal fin when depressed; A I 13 (once I 14); P 8, reaching posteriorly to a vertical with base of second spine of first dorsal fin; V I 5, no fraenum or basal membrane, reaching posteriorly one-third of distance from its origin to anus. No scales. Gill opening extending anteroventrally to a vertical half-way between eye and end of opercle. Mouth inclined obliquely upwards, a prominent rounded knob of connective tissue at tip of lower jaw. Teeth in outer row of upper jaw strongly curved or hooked, decreasing in size posteriorly, with short inner row of about three teeth near symphysis. Lower jaw with two rows of similar teeth, outer row a little enlarged. Anterior nostril tubular, posterior porelike. Tongue deeply forked. First gill slit open; gill rakers short, $0+10-11(10.3)$, all ossified. Five branchiostegal rays. Dorsal pterygiophore formula $3(2,2,1,1,0)$; vertebrae $10+15+$ ural centrum $=26$. Six dorsal and five ventral branched caudal-fin rays, with seven dorsal and seven ventral unbranched caudal-fin
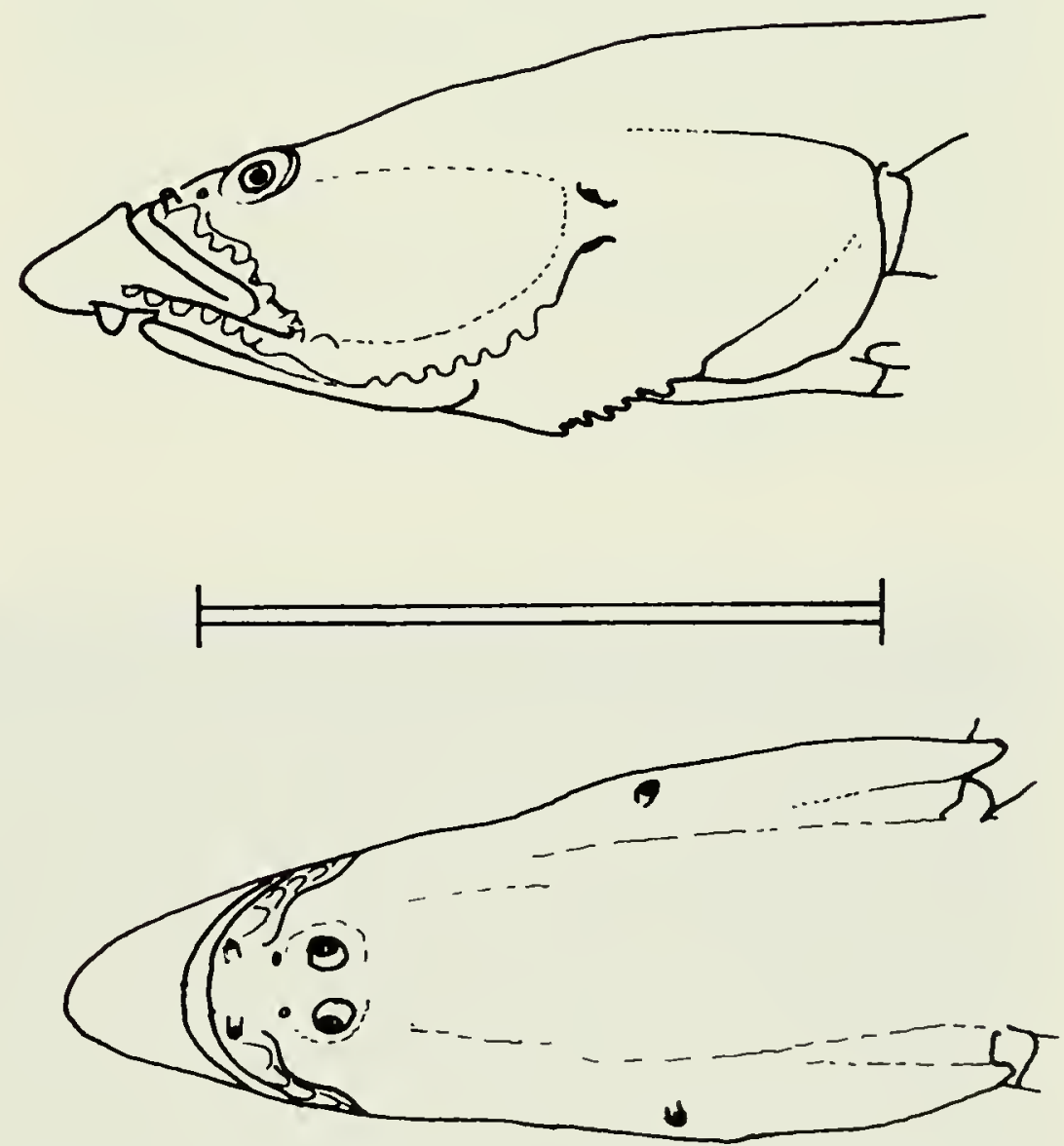

Fig. 105. Left lateral (above) and dorsal (below) views of the head of Kraemeria samoensis, $23.6 \mathrm{~mm} \mathrm{SL}$, to show head pores. Scale equals $5 \mathrm{~mm}$.

rays. As percentage standard length: head length $25-26$ (25.7); origin of first dorsal fin 31-33 (32.2); origin of second dorsal fin 48-51 (49.6); origin of anal fin 51-55 (52.9); caudal-peduncle length 9-12 (10.4). As percentage head length: eye diameter 5-6 (5.5); snout length 14-16 (14.9); upper-jaw length 25-30 (27.6). Caudalpeduncle depth as percentage caudal-peduncle length 
44-58 (51.2). Head pores absent except for preopercular series, where pores 2 and 3 remain; head papillae as in Fig. 105. Caudal skeleton with haemal spine of pu 2 well developed, normal or bifid; parhypural rodlike, separated from ural centrum by a distance equal to one-third of its length; ural centrum fused to hypurals 1 and 2 and to hypurals 3 and 4; hypural 5 represented by cartilage in one specimen, a minute nubbin of bone in second specimen, and a small splint of bone in a third specimen; epural broad; neural spine of pu 2 with up to seven projections.

Intestine coiled; guts in cleared and stained specimens contained harpacticoid copepods.

Colour pattern (freshly dead): whole animal translucent white, with a small suffusion of light orange-yellow on nape above pectoral base. Preserved: white, interradial fin membranes hyaline.

\section{DISCUSSION}

This widespread species was most common in the seepage rivulets on sandy beaches, as reported by Smith (1959:222), associated with small specimens of Bathygobius cocosensis.

\section{Family Microdesmidae}

\section{Genus Nemateleotris}

\section{Nemateleotris magnifica Fowler}

Figs. 106, 107

Nemateleotris magnifica Fowler, 1938:131 (Buka-Buka Island, Sulawesi); Randall and Allen, 1973:350 (tropical Indo-Pacific; Mauritius to Pitcairn).

\section{MATERIAL}

Thirteen lots, 21 specimens, 17.1-44.7 mm SL. Depth range 5-43 $\mathrm{m}$, primarily reef-top and drop-off (three specimens, two lots from lagoons, near passes), Peros Banhos and Salomon.

\section{DESCRIPTION}

Based on 10 specimens from lots WE 79-26, 79-76, 79-94, and 79-106 (27.1-44.2 mm SL), plus 2 cleared and stained specimens (ROM 510CS, 27.9-37.9 mm SL). D VI + I 29-30 (29.3), first spine longest, reaching posteriorly from middle of base of second dorsal fin to caudal fin; A I 26-28 (27.1); P 19-20 (19.5), reaching posteriorly to below origin of second dorsal fin; V I 5, no fraenum, no basal membrane, fourth and fifth rays unbranched, reaching posteriorly to anus or to a point between anus and three-quarters of distance towards it. Lateral scales 110-130; head and midline of nape naked;

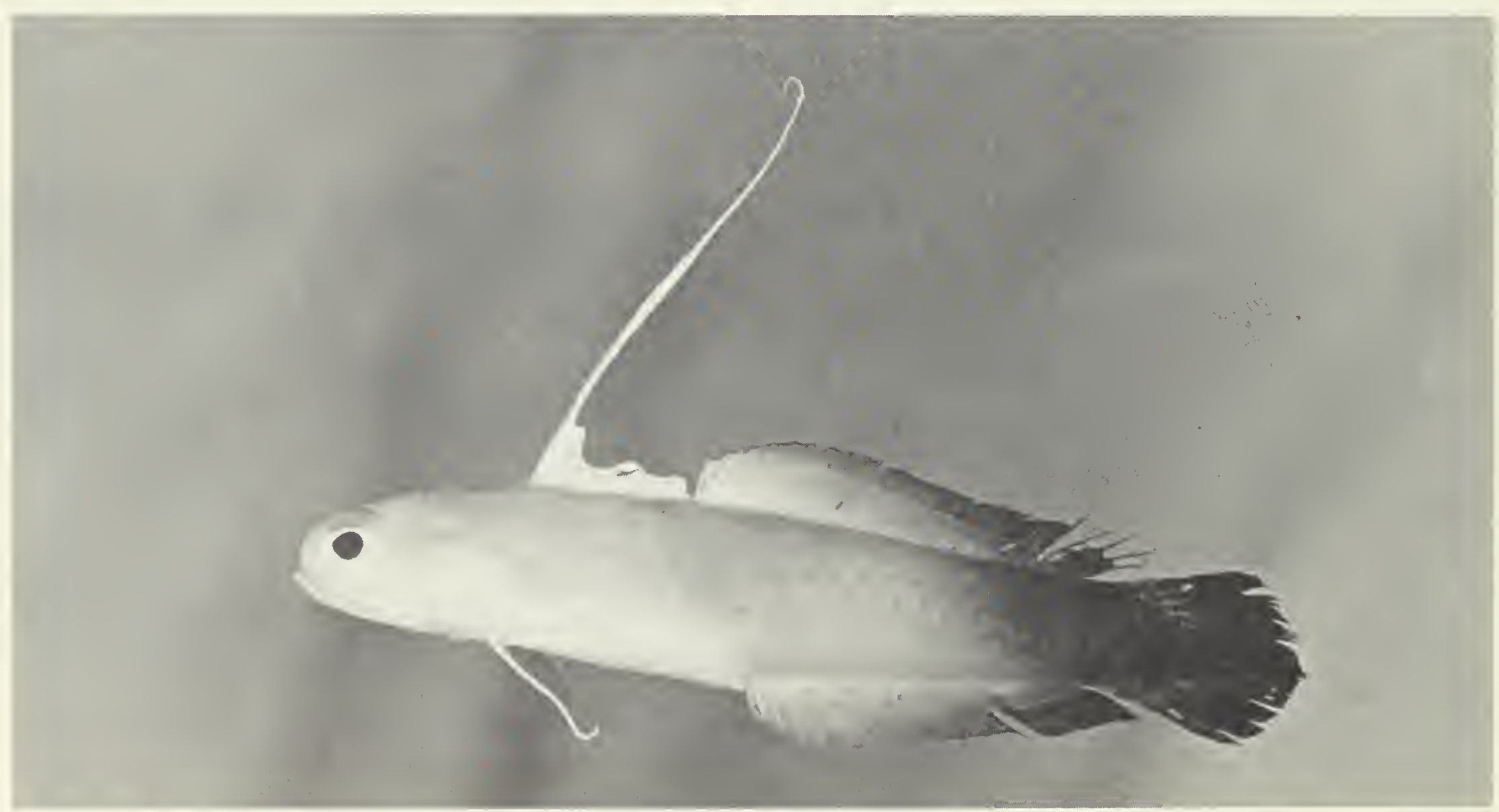

Fig. 106. Left lateral view of Nemateleotris magnifica, $39.4 \mathrm{~mm} \mathrm{SL}$. 

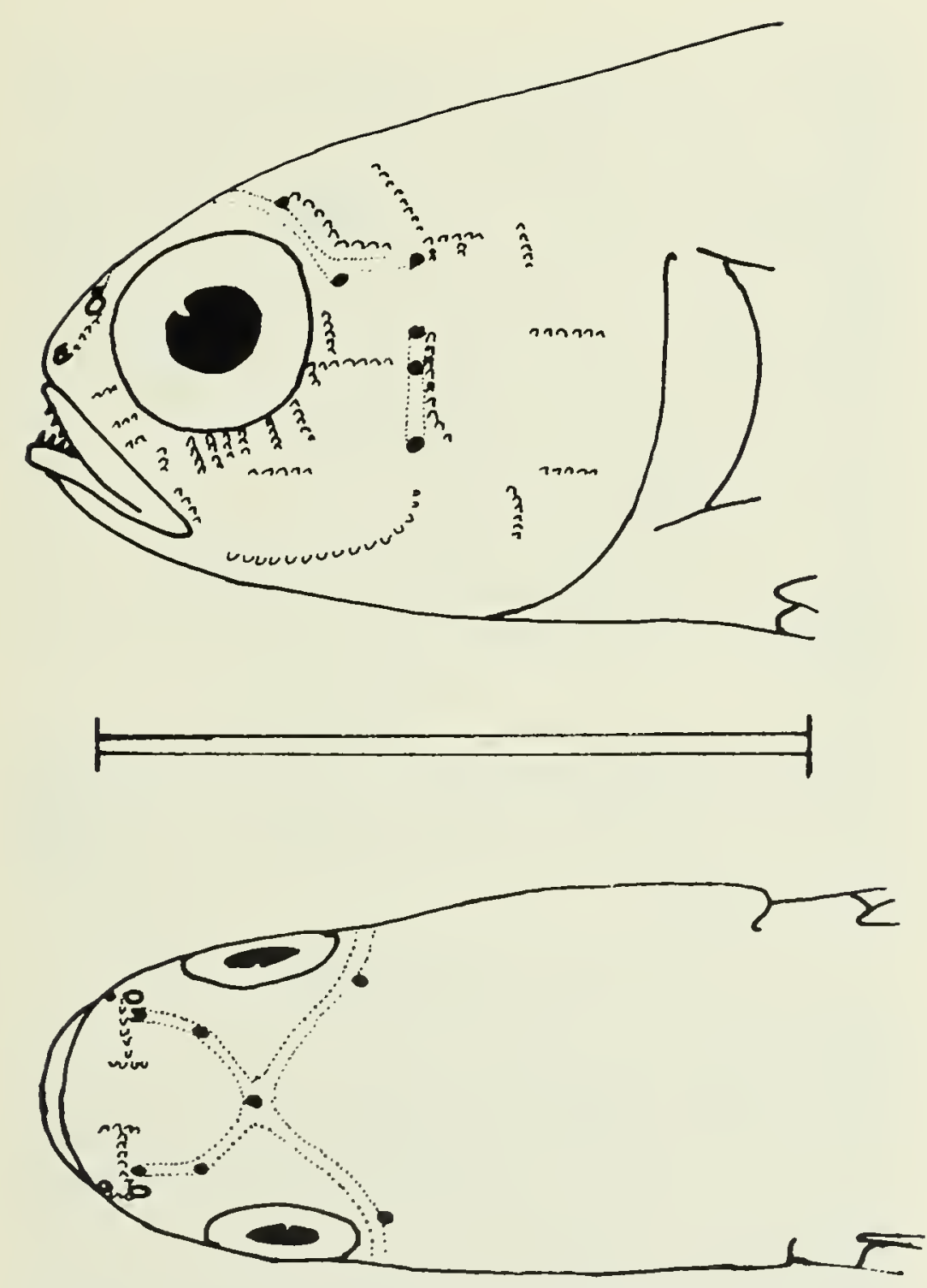

Fig. 107. Left lateral (above) and dorsal (below) views of the head of Nemateleotris magnifica, $39.0 \mathrm{~mm} \mathrm{SL}$, to show head pores and papillae. Scale equals $1 \mathrm{~cm}$.

pectoral- and pelvic-fin bases scaled. Scales small, cycloid anteriorly, becoming larger and ctenoid posteriorly. Gill opening extending anteroventrally to below vertical limb of preopercle. Mouth terminal, slightly inclined upwards. Upper jaw with about four spaced, enlarged, curved conical canines and single inner row of small conical teeth. Lower jaw with two to three enlarged outer canines similar to those of upper jaw, followed by an irregular row of small conical teeth, and finally one to two enlarged, curved inner canines. Both nostrils porelike, anterior with raised rim. Tongue truncate. First gill slit open; gill rakers lamellar, 4-6 + 15-17 $(5.0+16.1)$. Five branchiostegal rays. Dorsal pterygiophore formula $3(2,2,1,1,0)$; vertebrae $10+15+$ ural centrum $=26$. Six dorsal and 5 ventral branched caudal-fin rays, with 14 to 15 dorsal and 13 to 15 ventral procurrent fin rays. As percentage standard length: head length 23-25 (24.2); origin of first dorsal fin 29-33 (31.1); origin of second dorsal fin 49-52 (50.4); origin of anal fin 55-59 (57.0); caudal-peduncle length 9-10 (9.3). As percentage head length: eye diameter 30-37 (33.0); snout length 19-21 (19.9); upper-jaw length 29-33
(31.1). Caudal-peduncle depth as percentage caudalpeduncle length 129-155 (140.1). Head pores and papillae as in Fig. 107. Caudal skeleton as for $A$. hectori.

Intestine S-shaped, full of small copepods in cleared and stained specimens.

Colour pattern (freshly dead): as in Randall and Allen (1973, fig. 1). Preserved: as described by the above authors (1973:351).

\section{DISCUSSION}

Chagos specimens accord well with description and figures of this species given by Randall and Allen (1973:350-355). Minor differences, which may be due to methods, include one fewer anal rays (26-28 vs $27-30$ ) and two fewer lower gill rakers (15-17 vs 17-19) in some Chagos specimens. Our specimens, when freshly dead, had lavender markings only dorsally and ventrally on the iris and a single lavender spot behind the eye (with none on the nape). Further, the dark lines in the dorsal fin and posterior part of the anal fin are more distal in position than those in a Society Islands specimen (Randall and Allen, 1973, fig. 1). The dark line in the dorsal fin in Chagos specimens is at the distal two-thirds point on the fin (versus half-way) and that of the anal fin is at the half-way point (versus proximal one-third).

\section{Genus Paragunnellichthys}

\section{Paragunnellichthys fehlmanni Dawson \\ Paragunnellichthys fehlmanni Dawson, 1969:373 (Diego Garcia).}

\section{MATERIAL}

Known only from the 5 specimens collected by Fehlman in 0-2.5 $\mathrm{m}$ depth range, in the lagoon near Main Pass, Diego Garcia, in 1967.

\section{Genus Ptereleotris}

Ptereleotris evides (Jordan and Hubbs) Figs. 108, 109 Encaeura evides Jordan and Hubbs, 1925:303 (Japan). Ptereleotris tricolor Smith, 1956b: 817 (Aldabra); Smith, 1958: 155 (western Indian Ocean northwards from $14^{\circ} \mathrm{S}$ ).

\section{MATERIAL}

Three lots, 10 specimens, $13.3-92.0 \mathrm{~mm}$ SL. Depth range $0.5-22 \mathrm{~m}$, collected from lagoon and deep reef, but seen on edge of drop-off as well, at Peros Banhos and Salomon.

\section{DESCRIPTION}

Based on three specimens from lots WE 79-24 and WE 
79-72 (68.5-92.0 mm SL), plus two cleared and stained specimens from lot WE 79-33 (16.8-19.6 mm SL). D VI + I 25-26, first dorsal broadly rounded, fourth spine longest but not elongate; A I 25; P $21-23$ (22), reaching a vertical with base of fifth dorsal spine; V I 5, fifth ray hidden beneath skin, appearing to be I 4 on external examination, reaching about two-thirds of distance to anal origin. Scales cycloid, small, embedded, not uniformly distributed on body; each scale with an elongate projection extending from its posterior end. Lateral scales approximately 140 (135-148); transverse scales approximately 40 (39-42); predorsal scales highly variable, but stopping abruptly just posterior to skull. Prepelvic- and pectoral-fin bases scaled, head naked. Gill opening not restricted, reaching well up into isthmus. A median flap of tissue on lower surface of jaw and isthmus (possibly a remnant or precursor of the barbel found in other members of the genus Ptereleotris, in the subgenus Vireosa). Mouth with lower jaw projecting, jaws at a sharply oblique angle inclined dorsally; upper jaw with several rows of caniform teeth, outer enlarged particularly near front of jaw; lower jaw with three to five enlarged canines on each side of jaw. Anterior nostril tubular, posterior a large pore. Tongue elongate, pointed, with several brown chromatophores on dorsal surface. First gill slit open; gill rakers long, bony, relatively numerous, $6+21-22$; pseudobranch with 9 to 11 lobes. Five branchiostegal rays, first very weak, last broadly thickened. Dorsal pterygiophore formula $3(3,2,0,1,0)$; vertebrae $10+15+$ ural centrum $=26$. Six dorsal and five ventral branched caudal-fin rays in specimen $20.7 \mathrm{~mm} \mathrm{SL}$, seven dorsal and six ventral branched caudal-fin rays in adult specimens. Sixteen or 17 unbranched caudal-fin rays dorsally, 15-16 ventrally. As percentage standard length: head length 20-24 (21.7); origin of first dorsal fin 27-30 (28.2); origin of second dorsal fin 48-50 (48.8); origin of anal fin 52-57 (53.9); caudal-peduncle length 9-10 (9.8). As percentage head length: eye diameter 26-29 (26.8); snout length 24-27 (25.6); upper-jaw length 30-33 (31.5). Caudal-peduncle depth as a percentage of caudal-peduncle length 100-119 (110.8). Head pores and papillae as in Fig. 109. Caudal skeleton with haemal spine of pu 2 broad, with a rodlike posterior margin and a large basal foramen, appearing as if spine attached to centrum by anterior and posterior struts. Neural spine of pu 2 triangular, with large foramen at base (similar to haemal spine of pu 2). Otherwise, caudal skeleton similar to $A$. hectori.

Intestine short, with simple loop, peritoneum speckled with brown. Of two specimens, one gut empty and other gut almost empty with a few remains of calanoid copepods and a larval mantid. One specimen with a long nematode parasite on liver.

Colour pattern (freshly dead adult): body colour a countershaded blue-grey, increasing in intensity posteriorly until posterior third of body quite dark. No stripes or bars on body in adult. Snout slightly darker, more grey than rest of head. Area below and posterior to eye washed with yellow, grading to bright yellow on throat and lower opercular area. Large blue dots posterior to eye and on opercles, coalescing into abbreviated wavy lines, contrasting sharply with yellow colour. Pectoral-fin base with series of curved wide vertical bars, beginning with a magenta bar marking origin of rays. Anterior to that bar, a wide blue, then yellow, then blue, then yellow-pink, finally diffuse magenta bar against edge of opercle. First

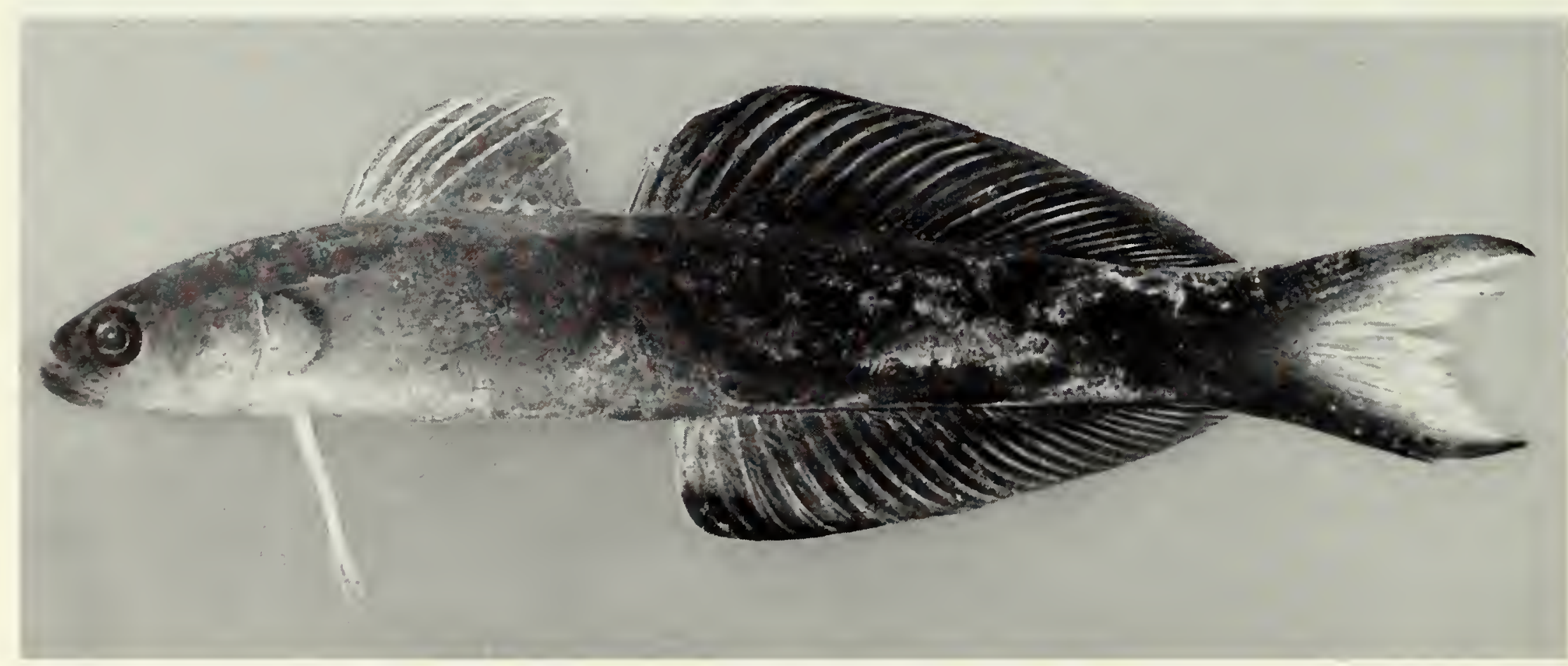

Fig. 108. Left lateral view of Ptereleotris evides, $91.8 \mathrm{~mm}$ SL. 


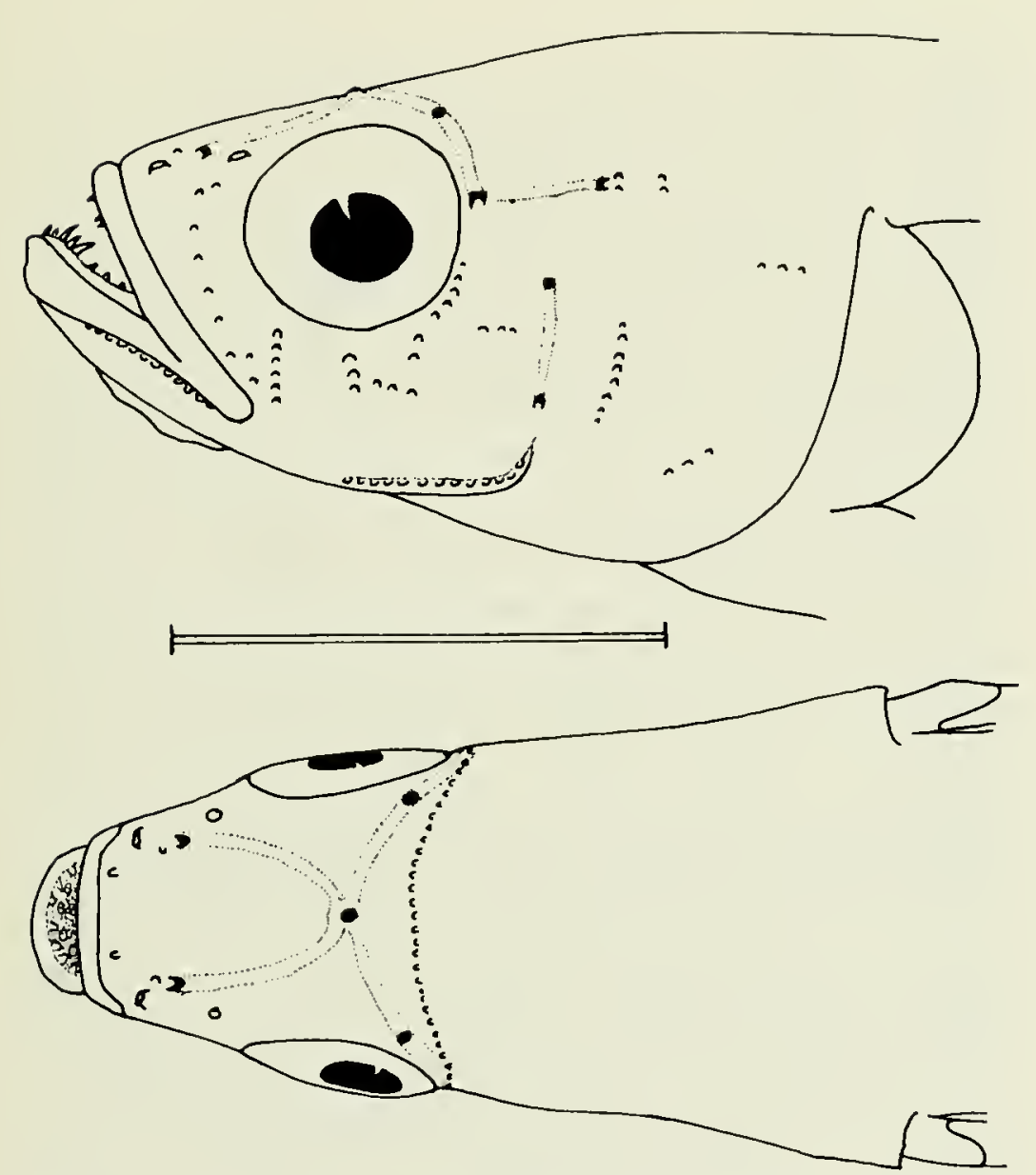

Fig. 109. Left lateral (above) and dorsal (below) views of the head of Ptereleotris evides, $72.9 \mathrm{~mm} \mathrm{SL}$, to show head pores and papillae. Scale equals $1 \mathrm{~cm}$.

dorsal fin a pink-grey ground colour; base bright blue, with blue spots scattered on membranes and spines, most abundant posterior to fifth spine; distal margin with wide band of bright yellow. Second dorsal fin dark blue-grey overall; anterior portion tinged with pink; outer margin anteriorly marked with bright blue and black elongate spots; posterior margin edged with yellow; whole fin with bright blue spots. Anal fin similarly marked; extent of blue and black elongate spots less and yellow margin greater. Outer margins of upper and lower caudal peduncles continue dark blue body colour to tips. Inner portion grading to pink; central portion of caudal fin yellow, covering inner six or seven branched caudal-fin rays. Juvenile colour pattern pale blue-grey with dark pigment along bases and margins of dorsal and anal fins. Caudal lobes with dark margins. Most prominent mark a large black spot located on lower half of caudal base and out onto caudal rays, spot covering hypurals and rays equally.

\section{DISCUSSION}

Ptereleotris evides appears to be a widespread species, having been recorded from many areas in the Indo-west Pacific, including Japan, Vanuatu, Great Barrier Reef, Aldabra, and the east coast of Africa, as well as from the Chagos Archipelago. Within this wide distribution some variation may be expected. We consider the minor differences between the western Indian Ocean and Pacific populations to be insufficient to warrant a separate specific designation. We therefore regard $P$. tricolor Smith as a junior synonym of $P$. evides (Jordan and Hubbs). The number of scales in longitudinal rows is variously reported between 125 and 150 (Chagos specimens range from 135 to 148). The dorsal and anal fins appear to become more convex on their outer border with increasing size of the fish. All published descriptions indicate the teeth are uniserial; Chagos specimens have multiple rows as adults, but single rows as juveniles.

Ptereleotris heteroptera (Bleeker)

Fig. 110

Eleotris heteropterus Bleeker, 1855:422 (Borneo).

Ptereleotris heteropterus-Davis, Randall, and French, 1977:263-266 (widespread Indo-Pacific).

\section{MATERIAL}

One lot, 1 specimen, $26.7 \mathrm{~mm}$ SL. Depth range 10-20 m, lagoon at Peros Banhos.

\section{DESCRIPTION}

Based on one specimen, which was X-rayed. D VI + 127 , fourth dorsal spine longest but not elongate; A I 24; P 26, reaching to a vertical with fourth dorsal spine base; V I 4, no basal membrane or fraenum present, reaches posteriorly to about three-quarters of length of pectoral fin. Scalation not developed. Gill opening partly restricted, reaching just forward of angle of preopercle. Mouth with
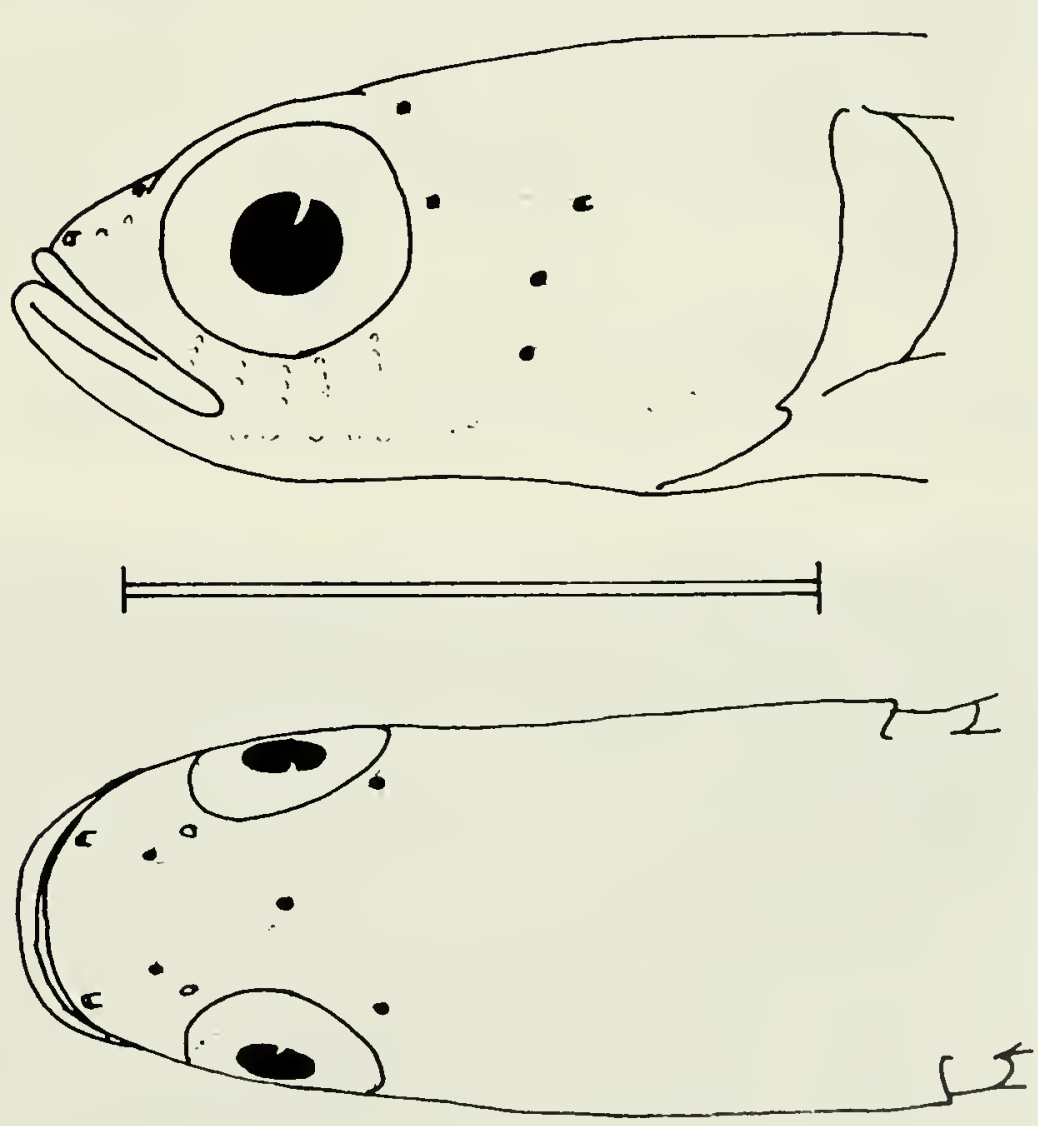

Fig. 110. Left lateral (above) and dorsal (below) views of the head of Ptereleotris heteroptera, $26.6 \mathrm{~mm} \mathrm{SL}$, to show head pores and papillae. Scale equals $5 \mathrm{~mm}$. 
lower jaw projecting, jaws inclined at an oblique angle dorsally; both jaws with caniform teeth in irregular rows (almost uniserial); several teeth enlarged near midline of both jaws. Anterior nostril with very small tube which is scarcely visible; posterior nostril a pore. Tongue pointed. First gill slit open; gill rakers long, bony, $0+17$; pseudobranch with 10 lobes. Five branchiostegal rays. Dorsal pterygiophore formula $3(3,2,0,1,0)$; vertebrae 10 $+15+$ ural centrum $=26$. Caudal fin with 7 dorsal and 6 ventral branched rays, 17 dorsal and 15 ventral unbranched rays. As percentage standard length: head length 24.3; origin of first dorsal fin 33.0; origin of second dorsal fin 53.6; origin of anal fin 55.8; caudal-peduncle length 5.6. As percentage head length: eye diameter 36.9 ; snout length 20.0; upper-jaw length 26.2. Caudal-peduncle depth as a percentage of caudal-peduncle length 133.3. Head pores and papillae as in Fig. 110. Caudal skeleton as for $P$. evides.

Colour pattern (freshly dead; from field notes only, no colour photograph taken): background pale brown, countershaded. Dark vertical bar below eye, about width of pupil, crossing posterior edge of jaw. Dark blotch located centrally on anterior half of caudal rays. Preserved: body pale yellow-brown, trace of caudal blotch, and line of separated melanophores at base of second dorsal fin.

\section{DISC USSION}

The only specimen captured was a small juvenile, caught accidentally. In life it agreed fairly well in colour pattern with Laccoeleotris lineopinnis Fowler, as figured by Smith (1958).

Ptereleotris n. sp.

Figs. 111,112

\section{MATERIAL}

One lot, 2 specimens, 78.1-80.1 mm SL. Depth range 12-15 m, collected near a small, isolated patch-reef in lagoon, about 3-4 $\mathrm{m}$ from edge of coral, over sand and in burrows, at Peros Banhos.

\section{DESCRIPTION}

Based on the two specimens, both from WE 79-24, and both of which were X-rayed. D VI + 1 35-37, third, fourth, and fifth dorsal spines longest and of approximately same length, spinous and soft dorsal fins joined by a membrane not appreciably notched (giving appearance of a single dorsal fin), spinous portion low, approximately same height as soft, rayed portion of the fin; A I 33-35; P 23-24, reaching a vertical with interspace between fifth and sixth dorsal spines; V 14 , vestige of a basal membrane, no fraenum in evidence, reaching to end of pectoral fin. Lateral scales approximately 105; transverse scale "rows"' not apparent. Prepelvic, predorsal, and pectoral-base areas naked. All scales tiny, cycloid, embedded in pits in skin. Scales lacking a single, posteriorly directed spine at posterior margins. Gill opening partly restricted, reaching a point approximately half-way between pectoral base and vertical limb of preopercle. Lower jaw projecting, jaw inclined at an oblique angle dorsally; upper jaw with four enlarged recurved canines on each side; rest of teeth smaller but caniform. Anterior nostril a flattened tube, posterior a large pore. Tongue pointed, with scattered small melanophores. Throat with loose fold of tissue extending from lower jaw to about preopercle or a little further, marked with darkened ventral edge. First gill slit open; gill rakers elongate, bony, 6-7 + 18-20; pseudobranch with 10 fleshy lobes. Five branchiostegal rays. Dorsal pterygiophore formula $3(3,2,0,1,0)$; vertebrae $10+15+$ ural centrum $=26$. Seven dorsal and 6 ventral branched caudal-fin rays, with 12 dorsal and 13 ventral unbranched rays. Caudal-fin rays on upper and lower lobes elongated into filaments. As percentage standard length: head length 18-19 (18.8); origin of first dorsal fin 24-25 (24.6); origin of second dorsal fin 43-44 (43.8); origin of anal fin 51-52 (51.4); caudal-peduncle length 5 (5.2). As percentage head length: eye diameter 24 (24.0); snout length 19-20 (19.2); upper-jaw length 34-35 (34.4). Caudalpeduncle depth as percentage of caudal-peduncle length

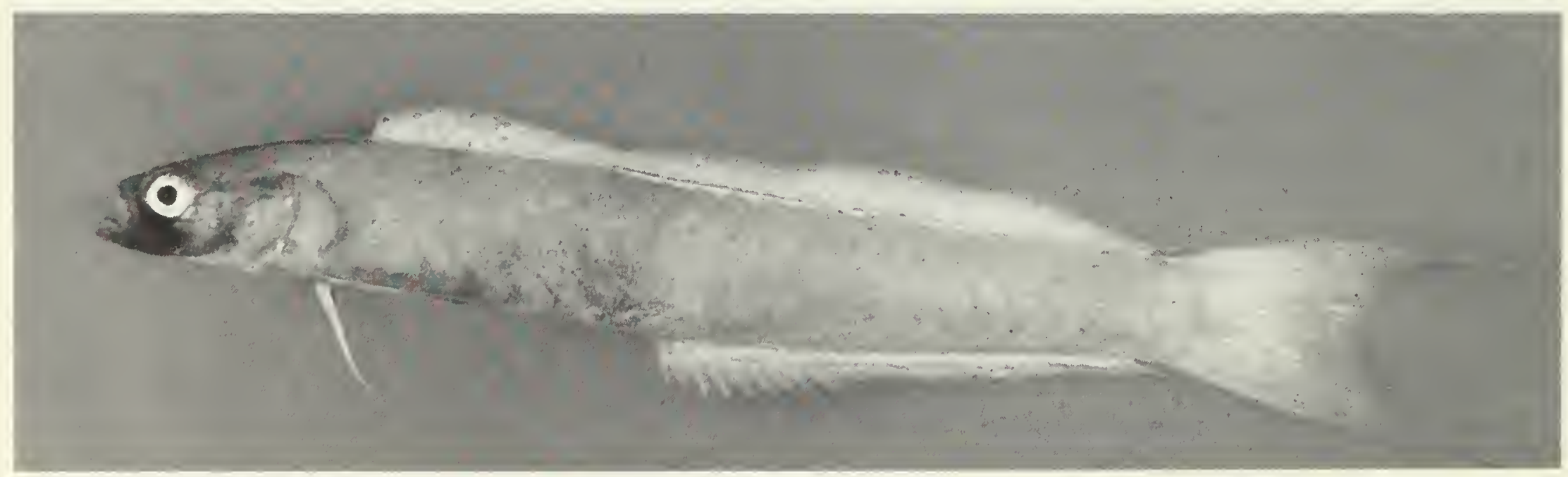

Fig. 111. Left lateral view of Ptereleotris n. sp., $79.4 \mathrm{~mm} \mathrm{SL.}$ 

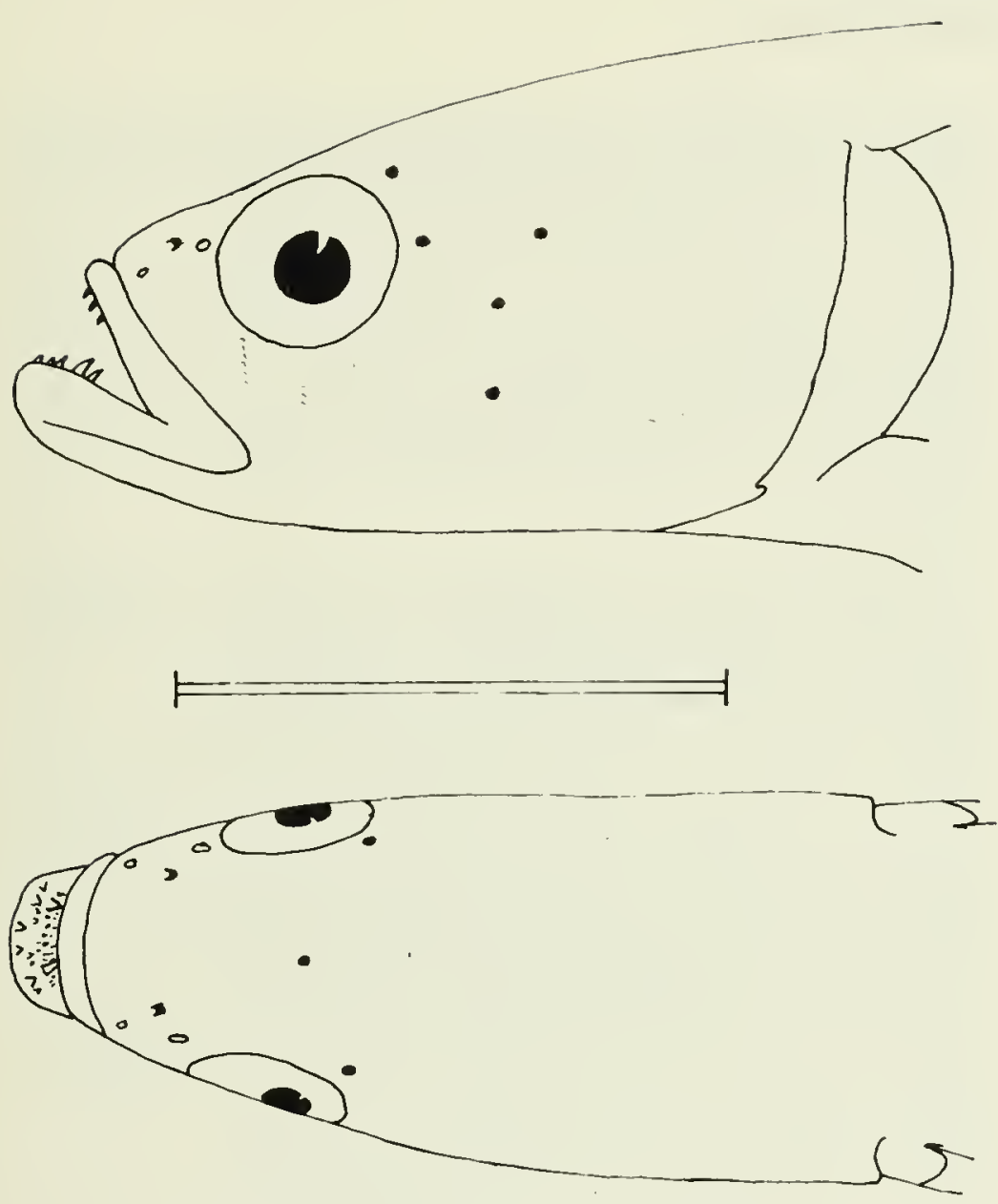

Fig. 112. Left lateral (above) and dorsal (below) views of the head of Ptereleotris n. sp., $79.4 \mathrm{~mm} \mathrm{SL}$, to show head pores and papillae. Scale equals $1 \mathrm{~cm}$.

181-192 (186.9). Head pores and papillae as in Fig. 112. Caudal skeleton as for $P$. evides, but haemal spine of pu 2 less broad, and hypurals 1 and 2 apparently fused to, rather than articulating with, urostyle.

Colour pattern (freshly dead): background colour a pale purple or purple-magenta, shading to purple-yellow dorsally and ventrally. Area of body cavity infused with dark blue. Pectoral-fin base brighter purple than body and with pink line defining base of rays. Head coloration complex: jaws a dusky yellow at tips; a black/blue smudge beginning below eye, covering posterior half of both jaws and extending posteriorly onto cheek; snout dark dorsally. A blue line beginning at upper jaw near nostrils and extending posteriorly to orbit, splitting to surround orbit. Blue lines running from posterior of orbit, dorsal line to opercle and ventral line to preopercle. Posteroventral margin of opercle with a blue line joining dorsal line from orbit at posterodorsal margin of opercle to form a broad triangle. Triangle contains smudges of bright pink. Dorsal fins pale yellow except for margin; margin with double band of colour, blue ventrally, bright yellow dorsally, extending entire length of fin. Anal fin with a broad blue band along its base, sharply separated from a yellow band that shades to red both ventrally and posteriorly. Fin edged with a narrow, bright blue line. Caudal fin yellow, centre with a pink wash, a narrow, bright blue streak just inside edge of both upper and lower lobes, filamentous extensions bright yellow. Preserved: all colours and stripes disappearing, fish pale with a heavy black smudge forming a ventral saddle from eye to eye. Dark line of melanophores on chin fold also retained.

\section{DISCUSSION}

This species is being described by Hoese and Randall, based on specimens from the Indo-west Pacific (Randall, pers. comm.). It is unusual among gobies in having the first and second dorsal fins completely joined. It differs from other Ptereleotris we have examined in that the scales, while small, lack the small spine extending from the posterior margin. Furthermore, the scales are scattered, do not overlap as in other Ptereleotris, and are buried in small pits. 


\section{Geographic Distribution}

Zoogeographic regions in the Indo-Pacific have recently undergone considerable modification (e.g., Springer, 1982). For the purposes of this analysis, we regard the western Indian Ocean as that region west of latitude $76^{\circ} \mathrm{E}$, the Indian Ocean to include Christmas Island and Cocos-Keeling, the western Pacific to extend from the western margins of Indonesia and Australia to the Andesite line in the east, and the Pacific to extend east of the Andesite line. Marine fish distributions appear to be complicated by the dispersal of the western Pacific fauna onto the Pacific plate via the Caroline conduit (Springer, 1982). This is included as a separate category (Indo-west Pacific and marginally on the Pacific plate) and comprises fishes which have been recorded from one or more of the following localities: Carolines, Marshalls, Marianas, Gilberts, and Samoa.

In most cases, geographic distributions of gobioid fishes are not well known, at least in part because of the possibilities of mistaken identities, but also because few faunal works pay them more than cursory attention. As a result, $57 \%$ of the 100 species here recorded from Chagos were not included in the analysis of geographic distribution. Of the remaining 43 species, $51 \%$ had an IndoPacific distribution, and $30 \%$ have been recorded from the Indo-west Pacific. Other areas each accounted for less than $10 \%$ of the analyzed fauna: Indo-west Pacific and marginally on the Pacific plate $7 \%$, Indian Ocean $5 \%$, western Indian Ocean 5\%, and $2 \%$ endemic to the archipelago.

It would serve no purpose to compare the faunal breakdown of Chagos gobioids to those given in recent checklists from other areas (e.g., Allen and Steene, 1979; Russell, 1983), since the zoogeographic regions used by those authors are not always comparable to those used here. For example, the "Indo-west Pacific" region as used by the above authors may include distributions that extend well out onto the Pacific plate to the Society, Tuamotu, and Hawaiian islands, instead of being restricted to west of the Andesite line, as we have done.

\section{Acknowledgements}

Our participation in the 1978-79 Joint Services Chagos Research Expedition was due in part to the generous transportion facilities offered by the Canadian and British Armed Forces. Special thanks to our companions who assisted us in everything from collecting and documenting specimens to warding off inquisitive sharks: $H$. Arnold, $R$. Crawford, S. Crellin, J. Cook, R. Crosby, J. Griffiths, L. Griffiths, J. Liptrot, P. Ormerod, R. Perry, A. Ryan, B. Simm, J. Smith, and S. Syson. Our deep gratitude to Major John Griffiths and Dr Charles Sheppard, who, as military and scientific leaders, respectively, strove to supply us with every conceivable kind of assistance and equipment, and to Captain Peter Winch, whose ketch made the expedition possible. The generous assistance of
Benjamin Film Laboratories Ltd and the University of Toronto is gratefully acknowledged. A number of our colleagues have assisted us with identifications, literature, and specimens for comparative purposes: W. N. Eschmeyer, P. C. Heemstra, S. L. Jewett, H. K. Larson, E. A. Lachner, E. O. Murdy (who also kindly reviewed the manuscript), P. J. Miller, J. E. Randall, W. F. Smith-Vaniz, and A. Wheeler. A special note of gratitude to Douglass F. Hoese, who has been of tremendous assistance to us in this work, and who, while not responsible for the errors that undoubtedly remain, can take much of the credit for such usefulness and accuracy as may be found in this paper. 


\section{Literature Cited}

AKIHITO, Prince and K. MEGURO

1981 A gobiid fish belonging to the genus Hetereleotris collected in Japan. Japanese Journal of Ichthyology 28:329-339.

ALLEN, G. R. and R. C. STEENE

1979 The fishes of Christmas Island, Indian Ocean. Australian National Parks and Wildlife Service, Special Publication 2:1-81.

BENNETT, E. T.

1833 Characters of new species of fishes from the Mauritius, presented by C. Telfair, Esq. Proceedings of the Zoological Society of London $1: 32$

BIRDSONG, R. S

1975 The osteology of Microgobius signatus Poey (Pisces: Gobiidae), with comments on other gobioid fishes. Bulletin of the Florida State Museum, Biological Sciences 19:135-187.

BLEEKER, $P$.

1850 Over eenige nieuwe soorten van Blennioiden en Gobioiden van der Indischen Archipel. Natuurkundig Tijdschrift voor Nederlandsch Indië $1: 236-258$.

1852 Nieuwe bijdrage tot de kennis der ichthyologische fauna van Ceram. Natuurkundig Tijdschrift voor Nederlandsch Indië 3:689-714.

1853 Diagnostiche beschrijvingen van nieuwe of wenig bekende vischoorten van Sumatra. Tiental V-X. Natuurkundig Tijdschrift voor Nederlandsch Indië 4:243-302.

1854 Bijdrage tot de kennis der ichthyologische fauna van de Kokos-eilanden. Natuurkundig Tijdschrift voor Nederlandsch Indië 7:37-48.

1855 Negende bijdrage tot de kennis der ichthyologische fauna van Borneo. Zoetwatervisschen van Pontianak en Bandjermasin. Natuurkundig Tijdschrift voor Nederlandsch Indië 9:415-430.

1874a Notice sur les genres Amblyeleotris, Valenciennesia et Brachyeleotris. Verslagen en Mededeelingen der Koninlijke Akademie van Wetenschappen, ser. 2, 8:372-376.

1874b Esquisse d'un système naturel des Gobioides. Archives Néerlandaises des sciences exactes et naturelles 9:289-331.

BROUSSONET, P. M. A.

1782 lchthyologia, sistens piscium descriptiones et icones. Ichthyologiae. Decas I. London. 41 pp.

BURGESS, W. and H. R. AXELROD

1973 Pacific marine fishes. Book 3. Fishes of Sri Lanka (Ceylon), the Maldive Islands and Mombasa. Neptune City, TFH Publications, pp. 561-839.

1974a Pacific marine fishes. Book 2. Fishes of southern
Japan and the western Pacific. 2nd ed. Neptune City, TFH Publications, pp. 281-560

1974b Pacific marine fishes. Book 4. Fishes of Taiwan and adjacent waters. Neptune City, TFH Publications, pp. 841-1110

1975 Pacific marine fishes. Book 6. Fishes of Melanesia (from New Guinea and the Solomons to Fiji). Neptune City, TFH Publications, pp. 1383-1654.

CASTELnAU, $\mathrm{F}$.

1873 Contribution to the ichthyology of Australia. No. V. Notes on fishes from north Australia. Proceedings of the Zoological and Acclimatisation Society of Victoria 2:87-97.

CLARK, E

1962 Eleotrid gobies collected during the Israel South Red Sea expedition (1962), with a key to Red Sea species. Sea Fisheries Research Station, Haifa, Bulletin 49:3-7.

CUVIER, G. and A. VALENCIENNES

1837 Histoire naturelle des poissons. Vol. 12. Paris, F. G. Levrault. 559 pp.

DAVIS, W. P., J. E. RANDALL, and D. O. FRENCH

1977 The systematics, biology and zoogeography of Ptereleotris heteropterus (Pisces: Gobiidae). Proceedings of the Third International Coral Reef Symposium, Miami 1:261-266.

DAWSON, C. E.

1969 Paragunnellichthys fehlmanni, a new gobioid fish (Microdesmidae) from the Indian Ocean. Proceedings of the Biological Society of Washington $82: 373-380$.

FOURMANOIR, P. and P. LABOUTE

1976 Poissons de Nouvelle Calédonie et des Nouvelles Hébrides. Papeetee, Les Éditions du Pacifique. $376 \mathrm{pp}$.

FOWLER, H. W.

1918 New and little-known fishes from the Philippine Islands. Proceedings of the Academy of Natural Sciences of Philadelphia 70:2-71.

1927 Fishes of the tropical central Pacific. Bernice P. Bishop Museum, Bulletin 38:1-32.

1938 Descriptions of new fishes obtained by the United States Bureau of Fisheries steamer "Albatross", chiefly in Philippine seas and adjacent waters. Proceedings of the United States National Museum 85:31-135.

1946 A collection of fishes obtained in the Riu Kiu Islands by Captain Ernest R. Tinkham, A.U.S. Proceedings of the Academy of Natural Sciences of Philadelphia 98:123-218. 
GOREN, M

1978 A new gobiid fish genus and seven new species from Sinai coasts (Pisces: Gobiidae). Senckenbergiana Biologia 59:191-203.

1979 The Gobiinae of the Red Sea (Pisces: Gobiidae). Senckenbergiana Biologia 60:13-64.

GOREN, M. and Z. VOLDARSKY

1980 Paragobiodon xanthosoma (Bleeker) new for the Red Sea (Pisces: Gobiidae). Israel Journal of Zoology 29: 150-152.

GOSLINE, W. A.

1971 The zoogeographic relationships of Fanning 1sland inshore fishes. Pacific Science 25:282-289.

GÜNTHER, A.

1861 Catalogue of the Acanthopterygian fishes in the collection of the British Museum. Vol. 3. London, British Museum. 586 pp.

1877 Andrew Garrett's Fische der Südsee. Band II, Heft VI. Journal des Museum Godeffroy 4:169-216 [reprint 1966, Lehre, J. Cramer].

HERRE, A. W. C. T.

1927 Gobies of the Philippines and the China Sea. Monographs of the Bureau of Science, Manila 23:1-352.

1935 New fishes obtained by the Crane Pacific Expedition. Publications of the Field Museum of Natural History, Zoological Series 18:383-438.

1945 Two new genera and four new gobies from the Philippines and India. Copeia 1945:1-6.

HOESE, D. F.

1975 A revision of the gobiid fish genus Kelloggella.

Records of the Australian Museum 29:473-484.

1983 Sensory papilla patterns of the cheek lateralis system in the gobiid fishes Acentrogobius and Glossogobius, and their significance for the classification of gobioid fishes. Records of the Australian Museum 35:223-229.

HOESE, D. F. and P. FOURMANOIR

1978 Discordipinna griessingeri, a new genus and species of gobiid fish from the tropical Indo-west Pacific. Japanese Journal of Ichthyology 25:19-24.

HOESE, D. F. and S. READER

1985 A new gobiid fish, Fusigobius duospilus, from the tropical Indo-Pacific. Smith Institute, Special Publication 36:1-9.

HOESE, D. F. and R. WINTERBOTTOM

1979 A new species of Lioteres (Pisces, Gobiidae) from Kwazulu, with a revised checklist of South African gobies and comments on the generic relationships and endemism of western Indian Ocean gobioids. Royal Ontario Museum, Life Sciences Occasional Paper 31:1-13.

JEWETT, S. L. and E. A. LACHNER

1983 Seven new species of the Indo-Pacific genus
Eviota (Pisces: Gobiidae). Proceedings of the Biological Society of Washington 96:780-806.

JONES, $S$. and M. KUMARAN

1967 New records of fishes from the seas around India.

Part V. Journal of the Marine Biological Association of India 9:1-12.

JORDAN, D. S. and C. L. HUBBS

1925 Record of fishes obtained by David Starr Jordan in Japan, 1922. Memoirs of the Carnegie Museum 10:93-346.

JORDAN, D. S. and A. SEALE

1906 The fishes of Samoa; description of the species found in the archipelago, with a provisional check-list of the fishes of Oceania. Bulletin of the United States Bureau of Fisheries 25:173-455.

KENDALL, W. C. and E. L. GOLDSBOROUGH

1911 Reports on the scientific results of the expedition to the tropical Pacific, in charge of Alexander Agassiz, by the U.S. Fish Commission steamer "Albatross" from August, 1899, to March, 1900, Commander Jefferson F. Moser, U.S.N., commanding. XIII. The shore fishes. Memoirs of the Museum of Comparative Zoology 26:239-343.

KLAUSEWITZ, $w$.

1974 Fische aus dem Roten Meer. XIII. Cryptocentrus steinitzi n. sp., ein neuer "Symbiose-Gobiidae" (Pisces: Gobiidae). Senckenbergiana Biologia $55: 69-76$.

KLUNZINGER, C. B.

1871 Synopsis der Fische des Roten Meeres. II Theil. Verhandlungen Zoologisch-Botanischen Gesellschaft in Wien 21:441-688.

KOUMANS, F. P.

1953 Gobiodea. In Weber, M. and L. F. de Beaufort. The fishes of the Indo-Australian Archipelago. Vol. X. Leiden, E. J. Brill. 423 pp.

KYUSHIN, K., K. AMAOKA, K. NAKAYA, and H. IDA

1977 Fishes of the Indian Ocean. Tokyo, Japan Marine Fishery Resource Center. 392 pp.

LACHNER, E. A. and M. F. GOMON

1974 Species of the Amblygobius albimaculatus complex with an analysis of sexual dichromatism within the group. In Abstracts of the Fifty-fourth Meeting of the American Society of Ichthyologists and Herpetologists, Ottawa, pp. 18-19 [Abstract].

LACHNER, E. A. and S. J. KARNELLA

1978 Fishes of the genus Eviota of the Red Sea with descriptions of three new species (Teleostei: Gobiidae). Smithsonian Contributions to Zoology 286: 1-23.

1980 Fishes of the Indo-Pacific genus Eviota with descriptions of eight new species (Teleostei: Gobiidae). Smithsonian Contributions to Zoology 315:1-127. 
LACHNER, E. A and J. F. MCKINNEY

1974 Barbuligobius boehlkei, a new Indo-Pacific genus and species of Gobiidae (Pisces) with notes on the genera Callogobius and Pipidonia. Copeia 1974:869-879.

LARSON, H. K. and D. F. HOESE

1980 The species of the Indo-west Pacific genus Calumia (Pisces: Eleotridae). Proceedings of the Linnean Society of New South Wales 104:17-22.

LOBEL, P. S

1979 Description of a new Hawaiian gobiid fish of the genus Trimma. Breviora 456:1-15.

LUBBOCK, R. and N. V. C. POLUNIN

1977 Notes on the Indo-west Pacific genus Ctenogobiops (Teleostei: Gobiidae), with descriptions of three new species. Revue suisse de Zoologie $84: 505-514$.

MASUDA, H., C. ARAGA, and T. YOSHINO

1980 Coastal fishes of southern Japan. Rev. ed. Tokyo, Tokai University Press. 379 pp.

POLUNIN, N. V. C. and R. LUBBOCK

1977 Prawn-associated gobies (Teleostei: Gobiidac) from the Seychelles, western Indian Ocean: systematics and ecology. Journal of Zoology 183:63-101.

RANDALL, J. E. and G. R. ALLEN

1973 A revision of the gobiid fish genus Nemateleotris, with descriptions of two new species. Quarterly Journal of the Taiwan Museum 26:347-367.

REGAN, C. T.

1908 Report on the marine fishes collected by Mr. J. Stanley Gardiner in the Indian Ocean. Transactions of the Linnean Society of London, ser. 2 (Zool.) 12:217-255.

ROSEN, D. E.

1973 Interrelationships of higher euteleostean fishes. In Greenwood, P. H., R. S. Miles, and C. Patterson, eds., Interrelationships of fishes. Supplement No. 1 of the Zoological Journal of the Linnean Society of London 53:397-513.

RÜPPELL, E.

1830 Fische des rothen Meers. In Atlas zu der Reise im nördlichen Africa. Frankfurt, Bronner, pp. 119141 .

RUSSELL, B. C.

1983 Annotated checklist of the coral reef fishes in the Capricorn-Bunker group Great Barrier Reef Australia. Townesville, Qucensland, Great Barrier Reef Marine Park Authority. 184 pp.

SAWADA, Y.

1977 First record of the gobiid fish, Kelloggella centralis, from Japan. Bulletin of the National Science Museum, Tokyo, ser. A (Zool.) 3:193-197.

SAWADA, Y. and R. ARAI

1973 Three species of coral gobies (the genus Gobiodon) from the Ryukyu Islands, Japan. Bulletin of the National Science Museum, Tokyo $16: 585-603$.

SCHULTZ, L. P.

1943 Fishes of the Phoenix and Samoan islands collected in 1939 during the expedition of the U.S.S. "Bushnell', Bulletin of the United States National Museum 180:1-316.

SHEN, S.-C.

1984 Coastal fishes of Taiwan. Taipai, Shen. 190 pp. SHEPPARD, C. R. C.

1979 Interspecific aggression between reef corals with reference to their distribution. Marine Ecology, Progress Series 1:237-247.

1980 Coral fauna of Diego Garcia lagoon, following harbour construction. Marine Pollution Bulletin $11: 227-230$.

SMITH, J. L. B.

1949 Forty-two fishes new to South Africa, with notes on others. Annals and Magazine of Natural History, ser. 12, 2:97-111.

1956a The fishes of Aldabra. Part V. Annals and Magazine of Natural History, ser. 12 , 9:721-729.

1956b The fishes of Aldabra. Part V1. Annals and Magazine of Natural History, ser. 12, 9:817-819.

1958 The fishes of the family Eleotridae in the western Indian Ocean. Rhodes University, lchthyological Bulletin 11:137-163.

1959 Gobioid fishes of the families Gobiidae, Periophthalmidae, Trypauchenidae, Taenioididae and Kraemeriidae of the western Indian Ocean. Rhodes University, lchthyological Bulletin 13:185-225.

SPRINGER, V. G.

1982 Pacific plate biogeography, with special reference to shorefishes. Smithsonian Contributions to Zoology 367:1-182.

1983 Tyson belos, new genus and species of western Pacific fish (Gobiidae, Xenisthminae), with discussions of gobioid osteology and classification. Smithsonian Contributions to Zoology 390: 1-40.

STEINDACHNER, F

1880 lchthyologische Beiträge (VIII). Sitzungsberichte der Mathematisch-Naturwissenschaftlichen Klasse der Kaiserlichen Akademie der Wissenschaften 80:119-191.

1906 Zur Fischfauna der Samoa-Inseln. Sitzungs berichte der Mathematisch-Naturwissenschaftlichen Klasse der Kaiserlichen Akademie der Wissenschalten 115:1369-1425. 
TOMIYAMA, 1 .

1936 Gobiidae of Japan. Japanese Journal of Zoology $7: 37-112$.

TOMIYAMA, I. and T. ABE

1956 Figures and descriptions of the fishes of Japan. Tokyo, Kazama Shobô 55:1114-1140.

TYLER, J. C.

1971 Habitat preferences of the fishes that dwell in shrub corals on the Great Barrier Reef. Proceedings of the Academy of Natural Sciences of Philadelphia 123:1-26.

WEBER, M.

1909 Diagnosen neuer Fische der Siboga-Expedition. Notes from the Leyden Museum 31:143-169.
WINTERBOTTOM, R.

1976 Additions to, and range extensions of, the South African marine ichthyofauna. Zoologica Africana $11: 59-73$.

1984 A review of the gobiid fish genus Trimma from the Chagos Archipelago, central Indian Ocean, with descriptions of seven new species. Canadian Journal of Zoology 62:695-715.

1985 Two new gobiid fish species (in Priolepis and Trimma) from the Chagos Archipelago, central Indian Ocean. Canadian Journal of Zoology $63: 748-754$.

WINTERBOTTOM, R. and A. R. EMERY

1981 A new genus and two new species of gobiid fishes (Perciformes) from the Chagos Archipelago, central Indian Ocean. Environmental Biology of Fishes 6:139-149. 



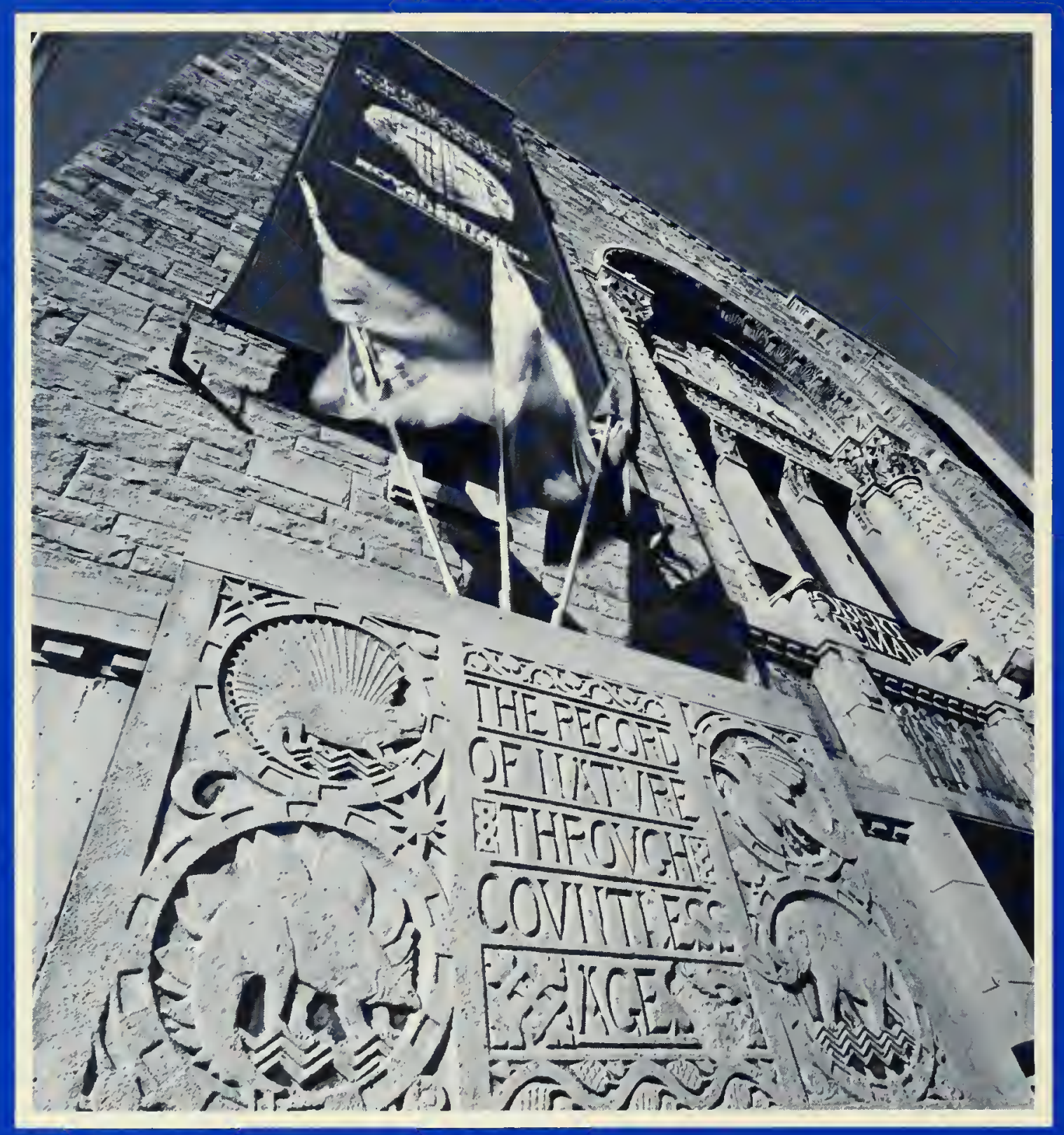

ISBN 0-88854-320-4

ISSN 0384-8159 